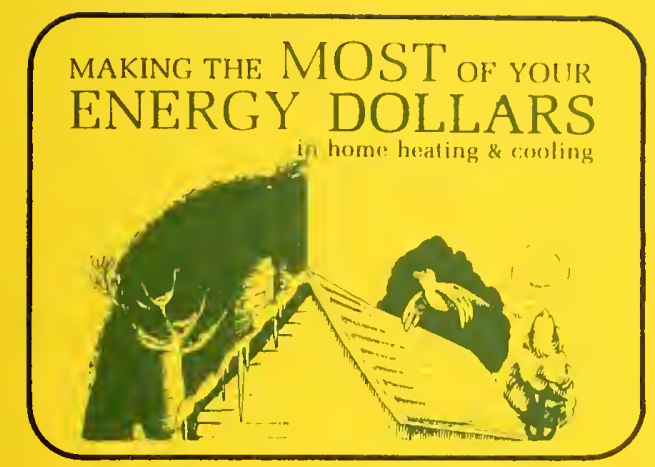

The CENTER for BUILDING TECHNOLOGY INSTITUTE for APPLIED TECHNOLOGY NATIONAL BUREAU of STANDARDS DEPARTMENT of COMMERCE

\title{
building technology publications 1965-1975
}
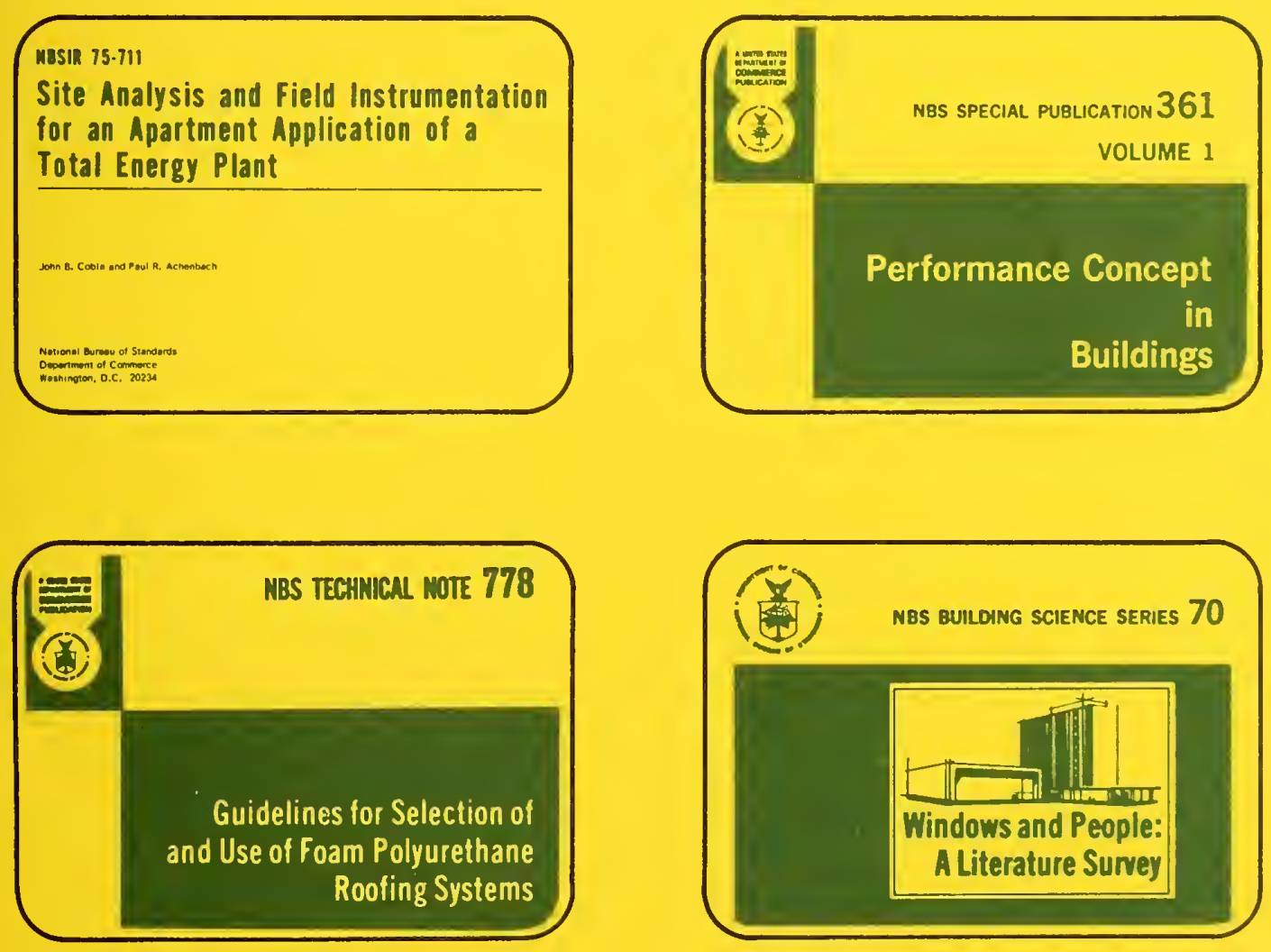



\title{
Introduction
}

7 his report presents the National Bureau of Standard's (NBS), Center for Building Technology (CBT) publications of the past decade. It links with two companion documents, NBS Special Publication 439, The Center for Building Technology: A Perspective (which discusses CBT's laboratories and special facilities), and NBS Special Publication 446, Building Technology Project Summaries (which reviews CBT's 1975 research projects by subject matter categories). These three publications provide a means of communicating the results of CBT's research, criteria and service activities to the building community and the general public.

Publications constitute a major end product of CBT's efforts. They appear in several publication series (Building Science Series, Technical Note, NBS Report, NBS Interagency Report, Handbook, Special Publication, the Journal of Research, and the Consumer Information Series).

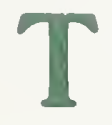

his document, addressing only NBS published reports, is divided into two sections. The first, Titles and Abstracts, provides report titles, author(s), date of publication, selected key words and abstracts of the technical reports. The Key Word Index, starting on page 49, can help you locate specific technical subjects. To use the index, first select a one-word summary of the building research subject you want to locate. The publication title and number for the subject in question is at the end of each key word list. Now, with the publication designation turn to the Titles and Abstracts section of the report under the appropriate publication series. NBS publication abbreviations are:

\author{
BSS - Building Science Series \\ TN - Technical Note \\ SP - Special Publication \\ $H$ - Handbook \\ NBSIR - National Bureau of Standards Interagency Report \\ NBSR - National Bureau of Standards Report \\ CIS - Consumer Information Series \\ J.Res. - Journal of Research
}

CBT is part of the Institute for Applied Technology, National Bureau of Standards. NBS undertakes basic and applied research in many disciplines other than building technology. Interested readers will find other NBS research publications listed in the NBS Special Publication 305, Publications of the National Bureau of Standards and its supplements, from which portions of this report have been taken. 


\section{Obtaining Publications}

Most current CBT publications (excluding NBS Interagency Reports and NBS Reports) are available from the Superintendent of Documents, U.S. Government Printing Office, Washington, D.C. 20402. Microfiche and paper copies of most CBT publications may be ordered through the National Technical Information Service, U.S. Department of Commerce, Springfield, VA 22161. Two other sources are the Department of Commerce field offices and libraries designated to receive government publications. The current price list and availability of publications listed in this report are given in Appendix C.

Department of Commerce field offices are maintained in the cities listed in Appendix A.. Their purpose is to provide ready access at the local level, to publications, statistical statements, and surveys. Each field Office serves as an official sales agent of the Superintendent of Documents, U.S. Government Printing Office. These offices make available for local purchase a wide range of Government publications. The reference library maintained by each Field Office contains many Government and private publications, periodicals, directories, reports, and other reference materials.

The libraries listed in Appendix B are designated depositories for Government publications and are now receiving selected publication series of the National Bureau of Standards for general reference use. While every Government publication cannot be consulted at all depository libraries, certain designated Regional libraries are required to receive and retain one copy of all Government publications made available either in printed or microfiche form. To obtain information on which publications are available, please contact the depository library in your area.

The Photoduplication Service, Library of Congress, Washington, D.C. 20540, makes photoduplicates of material in its collections for research use. National Bureau of Standards publications are on file at the library, so that copies of any Bureau document that is out of print usually can be obtained. Full information concerning this service may be secured by writing to the Library of Congress at the address noted above. In making such inquiry, it is important to give an accurate and complete identification whenever possible (author, title, place of publication, name of series and number, if known) of the document desired. 


\section{Contents}

TITLES AND ABSTRACTS 1

3 Building Science Series

19 Technical Notes

26 Special Publications

29 Handbooks

30 NBS Interagency Reports

45 NBS Reports

46 Consumer Information Series

46 Journal of Research

KEY WORD INDEX

49

APPENDIX A.

89

List of Field Offices of the U.S. Department of Commerce

APPENDIX B.

91

List of Depository Libraries in the United States.

APPENDIX C.

105

CBT Publication Order Numbers and Price List 



\section{Titles \\ and \\ Abstracts}

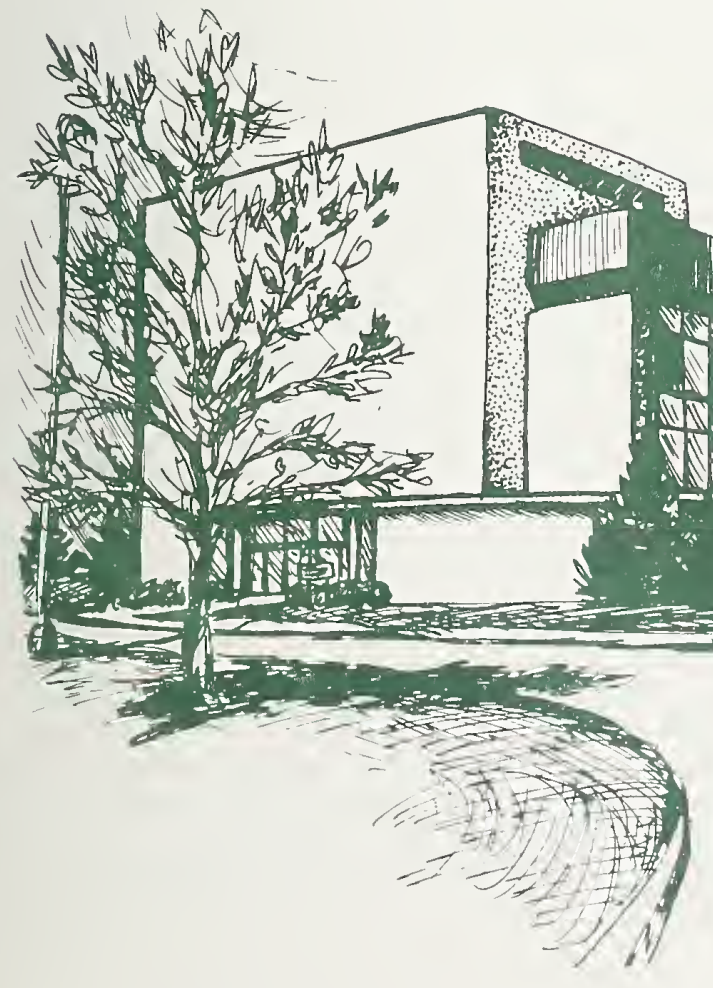

The Center for Building Technology is part of the NBS campus at Gaithersburg, Maryland. Its $6,500 \mathrm{~m}^{2}\left(69,500 \mathrm{fl}^{2}\right)$ includes office space as well as the Center's unique and specialized laboratories. 



\section{BUILDING SCIENCE SERIES}

Building Science Series reports disseminate technical information developed at the Center on building materials, components, systems, and whole structures. The series presents research results, test methods, and performance criteria related to the structural and environmental functions and the durability and safety characteristics of building elements and systems.

BSS0. Building research at the National Bureau of Standards, $P$ R. Achenbach, Nat. Bur. Stand. (U.S.), Bldg. Sci. Ser. 0, 59 pages (Oct. 1970)

Key words: Building materials; building performance: building research; building systems; building technology; history.

The history of building research and technology at the $\mathrm{Na}$ tional Bureau of Standards is as long as the history of the institution itself. The participation of the Bureau in the application of science and engineering to building materials and components played an early and important role in the development of steel and reinforced concrete as structural materials; in the understanding of physics and chemistry of cement, lime and gypsum; in the evaluation of the fire properties of building components; in safe plumbing practices; in laboratory evaluation of the effects of weather on deterioration of building materials; and in measurement of the heat and sound transmission properties of building materials and constructions. The central and continuing objectives of the building research program are shown to be the development of new technical information and new measurement methods for building materials, components, and systems, and the application of this knowledge to the specifications for Federal procurement, to the national standards of the building industry, and to the building code structure of the nation. The Bureau has served as a major technical resource in three large-scale national efforts to accelerate the construction of economical and effective buildings for housing and commercial purposes. One of these efforts is currently in progress and is characterized by an emphasis on the design of buildings to meet the performance requirements of the user rather than through the specification of the properties of the materials used.

BSS1. Performance of buildings - concept and measurement. Proceedings of the 1 st conference in a series of Conferences on Man and His Shelter held at the National Bureau of Standards, Gaithersburg, Md., September 23-25, 1968. W. W. Walton and B. C. Cadoff, Editors, Nat. Bur. Stand. (U.S.), Bldg. Sci. Ser. 1, 132 pages (Jan. 1970).

Key words: Building systems; performance of buildings: standards; test methods; urban planning; user needs.

The Conference entitled "Performance of Buildings - Concept and Measurement" was held at the National Bureau of Standards, Gaithersburg, Md. on September 23-25, 1968. This was the first in a planned series of conferences on "Man and His Shelter." The purpose of these conferences is to bring together those people from various disciplines who may contribute to improving the quality of man's shelter. At the present conference, papers were presented by nineteen authors representing government and industry in such diverse disciplines as architecture, engineering, science, urban planning, and standards. These papers emphasize the prime importance of considering user needs in the development of performance criteria, the necessity of test methods to determine whether the desired performance has been achieved, and the development of performance specifications and standards. Application of these ideas to building systems, and to the planning and design of entire communities, is also discussed.
BSS2. Interrelations between cement and concrete properties. Part 1. Materials and techniques, water requirements and trace elements. R. L. Blaine, H. T. Arni, B. E. Foster, R. A. Clevenger, L. Bean, and E. K. Hubbard, Nat. Bur. Stand. (U.S.) Bldg. ScI. Ser, 2, 36 pages (Aug. 1965).

Key words: Cement; concrete; material properties; physıcal properties; trace elements; portland cement; spectrographic analyses.

Section 1. Materials and techniques

The studies of the interrelations between cement and concrete properties are presented in a series of rclated articles. This first section presents the type classification of the cements and the areas from which they were procured together with the tests performed on the cements and concretes. Also presented are the methods employed in the statistical treatment of the data and a discussion of the significance of the various statistical techniques employed in the following sections dealing with specific aspects of the interrelations between cement and concrete properties.

Section 2. Water requirements of portland cement

The relationship between cement characteristics and the water requirements of near cement pastes, mortars, and concretes made with 199 portland cements of different types and from various areas were studied by fitting multivariable regression equations with the aid of a digital computer. The principal variables which appeared to have the greatest effect on water requirements were as follows: (1) For neat cement pastes of normal consistency-fineness; (2) for the $1: 4$ and 1:2.75 mortars of standard consistency-the air content, $\mathrm{Al}_{2} \mathrm{O}_{3}$, and silica modulus; (3) for concretes-the air content, $\mathrm{Al}_{2} \mathrm{O}_{3}$, and $\mathrm{Fe}_{2} \mathrm{O}_{3}$. The use of $\mathrm{A} / \mathrm{F}$ ratios or the potential $\mathrm{C}_{3} \mathrm{~A}$ values in place of the $\mathrm{Al}_{2} \mathrm{O}_{3}$ values in the computations resulted in concordant equations. Other commonly determined variables as well as a number of the minor con. stituents and trace elements also appeared to be associated with the water requirements to a lesser degree. Section 3. Occurrence of minor and trace elements in portland cement

Minor and trace elements in 186 portland cements were determined by spectrographic analyses. The semiquantitative values obtained ranged up to 1 percent for $\mathrm{Ti}$ and $\mathrm{Mn}$, to 0.5 percent for $\mathrm{P}$, and $\mathrm{Zr}$, to 0.2 percent for $\mathrm{Ba}$ and $\mathrm{Zn}$, to 0.1 percent for $\mathrm{V}$, to 0.05 percent for $\mathrm{Cu}$, $\mathrm{Mo}$, and $\mathrm{Pb}$. Other elements such as $\mathrm{Cr}, \mathrm{Li}, \mathrm{Ni}, \mathrm{Co}$, $\mathrm{Rb}, \mathrm{Ag}_{\mathbf{g}}, \mathrm{B}$, and $\mathrm{Sn}$ were found in lesser amounts in some of the cements. The quantities of $\mathrm{Na}_{2} \mathrm{O}, \mathrm{K}_{2} \mathrm{O}$, and $\mathrm{SrO}$ as determined by flame photometric methods were determined in 199 portland cements. The frequency distributions are presented and the effect of these minor and trace elements on the oxide values and the calculated compound composition values are discussed.

BSS3. Doors as barriers to fire and smoke. H. Shoub and D. Gross, Nat. Bur. Stand. (U.S.), Bldg. Sci. Ser. 3, 10 pages (Mar. 1966).

Key words: Doors; barriers; combustibility; fire; smoke; radiation flux measurements. 
A study was made of means for improving dwelling unit entrance doors as fire and smoke barriers. Existing combustible doors and frames could be modified to enhance their fire resistance, but it did not appear practical to raise them to the level of rated commercial fire door assemblies. Fire retardant paints, except those consisting of heavy, reinforced, intumescent-type coatings, provided little or no increase in fire resistance.

Several modifications of existing doors were not effective in preventing the transmission of smoke. However, controlling the pressure levels on both sides of a door, as by suitable venting, appeared to offer a means of reducing smoke penetration into an area.

It is recommended that current methods of fire tests of doors, and criteria relating to their fire and smoke transmission be improved.

BSS4. Weather resistance of porcelain enamels. Effect of exposure site and other variables after seven years, M. A. Rushmer and M. D. Burdick, Nat. Bur. Stand. (U.S.) Bldg. Sci. Ser. 4, 16 pages (May 1966).

Key words: Acid resistance; color; gloss; $\mathrm{pH}$; porcelain enamel; relative humidity; weather resistance.

An exposure test of porcelain enamels at seven representative sites in the continental United States was initiated by the National Bureau of Standards and the Porcelain Enamel Institute in 1956. After seven years all specimens were retumed to the Bureau and thechanges in gloss and color determined. These changes were found to be different at all exposure sites except Pittsburgh and New Orleans. The most severe changes occurred for specimens exposed at Kure Beach, 80 feet from the ocean, while the least change occurred for specimens exposed at Los Angeles. The differences in behavior of the specimens correlated with both the relative humidity and the $\mathrm{pH}$ of the suspended particulate matter at the different sites.

A direct relation existed between the acid resistance of the enamels and weather resistance. However, en amels of different types, such as enamels on aluminum and steel, having the same acid resistance did not necessarily show the same weather resistance.

Comparison with enamel specimens exposed for seven years in an earlier test showed that porcelain enamels produced after the end of World War II were equally resistant to changes in gloss at the Washington, D.C., site as those produced before the war.

As a group, the regular glossy acid-resistant en amels on steel showed the best weather resistance of the various types tested. No corrosion of the base metal was noted for any specimen on which the initial coverage was complete.

BSS5. Interrelations between cement and concrete properties. Part 2 , Sulfate expansion, heat of hydration, and autoclave expansion, R. L. Blaine, H. T. Arni, and D. A. Evans, Nat. Bur. Stand. (U.S.), Bldg. Sci. Ser. 5, 44 pages. (July 1966).

Key words: Autoclave expansion; cement; concrete; heat of hydration; portland cement; sulfate expansion.

Section 4. Variables associated with expansion in the potential sulfate expansion test

The relationships between the chemical characteristics of 183 portland cements and the expansion of mortar bars made of one part cement with 7.0 percent $\mathrm{SO}_{3}$ and 2.75 parts graded Ottawa sand were studied by computing multivariable regression equations with the aid of a digital computer and determining which of the independent variables had a significant effect on the expansion values. For cements containing 0 to 9 percent $C_{3} A$, a linear relationship appeared adequate whereas a higher power of the $C_{3} A$ content was required with cements having 7 to 15 percent $\mathrm{C}_{3} \mathrm{~A}$. The principal variables other than the potential $\mathrm{C}_{3} \mathrm{~A}$ content associated with the expansion were the $\mathrm{Fe}_{2} \mathrm{O}_{3}$ content and $\mathrm{CaO} / \mathrm{SiO}_{2}$ ratio. Of the other commonly determined variables, the loss on ignition, insoluble residue and $\mathrm{K}_{2} \mathrm{O}$ content were associated with high expansion values of the low $\mathrm{C}_{2} \mathrm{~A}$ cements. Certain minor constituents or trace elements such as $\mathrm{SrO}, \mathrm{Cu}, \mathrm{Cr}_{\mathbf{r}}, \mathrm{Ni}, \mathrm{P}, \mathrm{V}$, and $\mathrm{Z}_{\mathrm{n}}$ also appeared to be associated with the expansion values of the cements. The use of the potential $\mathrm{C}_{3} \mathrm{~S}$ content or the compressive strength of mortar cubes as variables indicated that high $\mathrm{C}_{3} \mathrm{~S}$ was associated with cements having low expansion values as determined by this test.

Section 5. Heat of hydration of portland cements

The relationships between the chemical characteristics of portland cements and the heat of hydration at 7 and 28 days and at $l$ year were studied by computing multivariable regression equations with the aid of a digital computer and determining which of the independent variables appeared to have a significant relationship to the heat of hydration values. The computed equations verified to a reasonable degree effects usually attributed to the major potential compounds. Other commonly determined variables, such as fineness and loss on ignition, were associated with the heat of hydration at ail ages: $\mathrm{K}_{2} \mathrm{O}$ and $\mathrm{SO}_{3}$ with the 7 day; and $\mathrm{Na}_{2} \mathrm{O}$ with the l-year heat of hydration. Of the other minor constituents $\mathrm{Cu}$ and $\mathrm{P}$ appeared to be associated with the heat of hydration at all ages. In addition, $\mathrm{Cr}$ and $\mathrm{Zr}$ were associated with heat of hydration at 7 days; $\mathrm{Co}, \mathrm{Z}_{\mathrm{r}}$, and $\mathrm{SrO}$ at 28 days; and $V$ and $B a$ at $l$ year.

Section 6. Variables associated with small autoclave expansion values of portland cements

The autoclave expansion values of the cements in this investigation ranged from minus 0.05 to plus 0.50 percent. Statistical analyses used to determine the variables associated with the expansion confirmed that $\mathrm{MgO}$ and $\mathrm{C}_{3} \mathrm{~A}$ were most significant. Increased values of the alkalies, $\mathrm{SrO}, \mathrm{V}$, and loss on ignition were also associated with higher autoclave expansion, whereas increases in $\mathrm{SO}_{3}$ and $\mathrm{Cr}$ were associated with a decrease in the expansion values.

BSS6. Some properties of the calcium aluminoferrite hydrates, E.

T. Carlson, Nat. Bur. Stand. (U.S.), Bldg. Sci. Ser. 6, 11 pages (June 1966).

Key words: Calcium aluminoferrite hydrates; calcium sulfate reaction with calcium aluminoferrite hydrates; DTA of calcium aluminoferrite hydrates; x-ray patterns of calcium aluminoferrite hydrates.

Calcium aluminoferrite hydrates in two series, $4 \mathrm{CaO}$. $\left(\mathrm{Al}_{2} \mathrm{O}_{3}, \mathrm{Fe}_{2} \mathrm{O}_{3}\right.$ ). $n \mathrm{H}_{2} \mathrm{O}$ (hexagonal plates) and $3 \mathrm{CaO}$. $\left(\mathrm{Al}_{2} \mathrm{O}_{3}, \mathrm{Fe}_{2} \mathrm{O}_{3}\right) \cdot 6 \mathrm{H}_{2} \mathrm{O}$ (isometric), were prepared from the anhydrous aluminoferrites by hydration in the presence of $\mathrm{Ca}(\mathrm{OH})_{2}$. The hexagonal phase was stable below $15^{\circ} \mathrm{C}$, the isometric above $35^{\circ} \mathrm{C}$, in contact with solution. The end member, $2 \mathrm{CaO} \cdot \mathrm{Fe}_{2} \mathrm{O}_{3}$, did not produce an isometric hydrate, however, X-ray diffraction patterns of the hexagonal series in the $19 \mathrm{H}_{2} \mathrm{O}$ stage of hydration were indistinguishable from patterns of $4 \mathrm{CaO} \cdot \mathrm{Al}_{2} \mathrm{O}_{3} \cdot 19 \mathrm{H}_{2} \mathrm{O}$. After 
drying to the 13-hydrate stage, slight differences in the patterns were observed. The isometric series shows a definite shift in $x$-ray pattern with change in $\mathrm{Fe}_{2} \mathrm{O}_{3} / \mathrm{Al}_{2} \mathrm{O}_{3}$ ratio, the unit-cell edge increasing from 12.573 for $3 \mathrm{CaO}$. $\mathrm{Al}_{2} \mathrm{O}_{3} \cdot 6 \mathrm{H}_{2} \mathrm{O}$ to 12.716 for the member having $\mathrm{Fe}_{2} \mathrm{O}_{3} / \mathrm{Al}_{2} \mathrm{O}_{3}$ close to 5. DTA traces show endotherms near 100 and $200^{\circ} \mathrm{C}$ corresponding to dehydration stages of the hexagonal series and one near $300^{\circ} \mathrm{C}$ representing the first dehydration stage of the isometric phase. The hexagonal hydrates are converted to the isometric during the course of the DTA run. The peak attributed to the isometric phase shifts from 323 to $290^{\circ} \mathrm{C}$ going from the pure aluminate to the member richest in $\mathrm{Fe}_{2} \mathrm{O}_{3}$. All the aluminoferrite hydrates, both hexagonal and isometric, reacted with $\mathrm{CaSO}_{4}$ solution to give products of the monosulfate and trisulfate (ettringite) types, the latter predominating at later $\mathrm{stages}$. The rate of reaction decreased with increasing $\mathrm{Fe}_{2} \mathrm{O}_{3}$ content.

BSS7. Organic coatings. Properties, selection, and use, A. G. Roberts, Nat. Bur. Stand. (U.S.), Bldg. Sci. Series 7, 202 pages (Feb. 1968).

Key words: Application; coatings; coating systems; corrosion-inhibiting; Federal specifications; fire-retardant; lacquer; latex; multicolor; organic coatings; paint; pigments; polymers; properties; resins; selection; substrates; surface preparation; varnish; water-thinned.

This publication was prepared to fill the need for a comprehensive, unifying treatise in the field of organic coatings. Besides presenting practical information on the properties, selection, and use of organic coatings (and certain inorganic coatings), it provides basic principles in a number of important areas such as polymer structure, coatings formulation, pigment function, use of thinners, coating system compatibility, and theory of corrosion. Each chapter deals with a major area of the coatings field, including types of coatings, properties of synthetic resins, selection of coating systems, storage and safety, application methods, and surface preparation and pretreatment. There is also a consolidating chapter with illustrative examples of solutions to typical coatings problems. Interrelationships among the various areas of information are indicated through appropriate crossreferencing in the text. Specific references to Federal, Military, and other specifications are given where pertinent, and an entire chapter is devoted to a quick guide and summary of Federal specifications for organic coating materials. Finally, a selected bibliography and a comprehensive index are provided. While written primarily to meet the informational needs of the engineer, architect, maintenance superintendent, and responsible coatings procurement officer, the treatise is sufficiently broad in scope to serve as a general manual, a concise text, or a convenient reference source in the field of organic coatings.

BSS8. Interrelations between cement and concrete properties, Part 3. Compressive strengths of portland cement test mortars and steam-cured mortars, (Contains section 7 and section 8. ) R. L. Blaine, H. T. Arni, and M. R. DeFore, Nat. Bur. Stand. (U.S.), Bldg. Sci. Series 8, Part 3, 101 pages (Apr. 1968).

Key words: Accelerated curing of cements; autoclave curing of portland cement mortars; chemical composition; compressive strength of portland cement; compressive strength of steampcured cements; fineness; heat of hydration; steam curing of portland cement mortars; strength gain of portland cements; trace elements.

Section 7. Compressive sirength of test mortars.

The relationships between cement characteristics and compressive strength of 1:2.75 (cement to graded Ottawa sand) mortars of standard consistency at ages of 24 hours to 10 years, and made with 199 cements of different types, were studied by fitting multivariable regression equations with the aid of a digital com- puter. The dominant variables associated with the differences of compressive strength, strength gain, and strength rallos were dif ferent at the various test ages. and after different curing conditions. The additional use of certain trace elements with commonly determined independent variables resulted in a signifi. cantly better fit between the equations and the observed data. Interactions between the fineness values and other independent variables were noted. ( ertain parallelisms and differences were noted with respect to variables associated with compressive strength differences at various ages and the heat of hydration of the cements at these ages.

Section 8. Compressive strength of steam-cured portland cement mortars.

The relationships between the chemical and physical characteristics of 161 portland cements and the compressive strength of 2-inch mortar cubes made from those cements after both lowand high-pressure steam, as well as moist-air curing, wcre studied by computing multivariable regression equations with the aid of a digital computer, and determining which of the independent variables appeared to have a significant relationship to the compressive-strength values. An increase in $\mathrm{C}_{3} \mathrm{~A}, \mathrm{SO}_{3}$, and $\mathrm{K}_{2} \mathrm{O}$ each appeared associated with higher compressive strengths with the low-pressure-stcam-cured specimens but not with 28 . day strengths of the $23{ }^{\circ} \mathrm{C}$ moist-air-cured specimens. Increases of $\mathrm{C}_{3} \mathrm{~A}, \mathrm{C}_{3} \mathrm{~S}, \mathrm{C}_{2} \mathrm{~S}, \mathrm{SO}_{3}$ and fineness were all associated with higher strength values when autoclave curing was started after 5 hours, but when started after 24 hours, variations of neither $C_{3} A$ nor $\mathrm{C}_{3} \mathrm{~S}$ appear to have any effect. The use of certain of the trace elements in the equations together with commonly determined variables resulted in a reduction in variance although the coefficients of the individual trace elements were, in most instances, not highly significant.

BSS9. Thermal-shock resistance for built-up nembranes, W. C Cullen and T. H. Boone, NBS Bldg. Sci. Series 9 (Aug. 21 1967).

Key words: Bituminous built-up roofing; built-up roofing membranes; roofing membranes; thermally induced forces; thermal-shock resistance factor.

Section 1. Progress in the development of a thermal-shock resistance factor for bituminous built-up roofing membranes.

The resistance of bituminous tuilt-up roofing memtranes to thermally induced forces is considered in terms of their strength properties such as breaking load in tension, modulus of elongation and apparent linear thermal expansion coefficient. The development of a Thermal-Shock Resistance Factor is described and values are given for three bituminous built-up membranes at temperatures of $-30{ }^{\circ} \mathrm{F}\left(-34.4{ }^{\circ} \mathrm{C}\right), 0{ }^{\circ} \mathrm{F}\left(-17.8{ }^{\circ} \mathrm{C}\right)$, $30{ }^{\circ} \mathrm{F}\left(-1.1^{\circ} \mathrm{C}\right)$ and $73{ }^{\circ} \mathrm{F}\left(22.8{ }^{\circ} \mathrm{C}\right)$. The apparent relation between the values obtained in the laboratory and the observed performance of rocfing membranes in service is considered. The utilization of the Thermal-Shock Resistance Factor in the reduction of potential failures of bituminous built-up roofing membranes in service from thermally induced forces is also discussed.

Section 2. Thernal-shock resistance for bituminous built-up roofing membranes--1ts relation to servicc life.

The assignment of a service life to a bituminous built-up roofing system is frequently difficult because of the many variables involved. A knowledge of these variables, and of their effect on the performance of the total building system. will greatly assist in the selection of a roofing assembly and the assignment of a service life to such an assembly.

Some of the factors such as breaking load in tension. modulus of elongation, and apparent linear thernial expansion coefficient of roofing membranes of different comoosition are given for both laboratory-prepared and field-obtained samples. Membranes of 2, 3, and 4-plies of felt are included. The relations of some engineering properties of a roofing membrane to perfor mance in sevice as expressed by a Thermal-Shock Resistance Factor are 
also given. Ways and means to reduce potential failures of bituminous built-up roofing membranes resulting from thermally induced forces are discussed.

BSS 10. Field burnout tests of apartment dwelling units, D. Gross, NBS Bldg. Sci. Series 10 (Sept. 29, 1967 ).

Key words: Apartment dwelling; burnout test; fire load; fire performance; flame penetration; potential heat; structural load.

Results are reported of three burnout tests in an experimental test building, using a wood crib fuel load of $6 \mathrm{lb} / \mathrm{ft}^{2}$, representing combustible contents, and a structural design load of $40 \mathrm{lb} / \mathrm{ft}^{2}$ applied to the floor or roof above the test rooin. Measurements were made of temperature, radiation, smoke, gas composition, and structural deflection. A discussion of the fire performance of materials and methods of construction, and conclusions with regard to specific fire protective objectives are presented.

BSSII. Fire resistance of steel deck floor assemblies, H. Shoub andS. H. Ingberg, NBS Bldg. Sci. Series 12 (Dec. 1967).

Key words: Burnout tests; fire endurance; fire severity; floor tesis; steel plate floors.

Tests were conducted to determine the resistance to fire of welded steel plate and beam floor assemblies with various conditions of floor covering on the plates. and ceiling protections beneath the beams. The trials included fire exposures from the burnout of combustible materials ranging from 10 to $40 \mathrm{lb} / \mathrm{ft}^{2}$ on the floor surface as well as standard fire endurance tests in which the ceiling of the structure was exposed to fire.

The results of the tests indicated that the use of steel floor structures was practical from considerations of fire safety. For the test conditions established, fire exposure on top of the floor did not heat the structural steel supporting members sufficiently to cause load failure or collapse, and did not produce untenable conditions in the room below. In tests involving fire exposure to the underside of floors, the fire endurance times, based solely on heat transmission criteria, ranged from I hr 24 min to over $4 \mathrm{hr}$. Temperature levels attained by the structural members and deflection of the floor assemblies are also reported.

BSS12. Performance of square-edged orifices and or:fice-target combinations as air mixers, T. K. Faison, Jr..J. C. Davis, and P. R. Achenbach. NBS Bldg. Sci. Series 12 (Nov. 24, 1967).

Key words: Diameter ratio; mixing effectiveness: squareedged orifice: temperature measurement; temperature pattern.

A study was made at the National Bureau of Standards to determine the efiectiveness of the square-edged orifice. or the orifice in combination with a target (circular baffle), for mixing an air stream which was initially nonuniform with respect to temperature. By achieving uniformity of temperature at all points within the cross section of an air stream. instrumentation for measurement might be simplified and a more representative temperature value obtained. Orifices having throat diameters of 8,12 , and 16 in were evaluated in a 24-in circular test duct to determine mixing effectiveness under selected test conditions of temperature distribution and flow rate. Targets of 8,12 . and 16 in in diameter in combination with a 12-in orifice were also investigated under similar conditions.

Graphic maierial is presented which illustrates how the orifice and orifice-target combinations perform as mixing devices under selected conditions. Results indicate that the 8 -in $(0.33$ diam ratio) orifice effectively diminished the nonuniformity of temperature but only at a high pressure drop across the orifice and that a distance of 4.5 duct diameters was required for mixing.

BSSI 3. Shrinkage and creep in prestressed concrete, P. H. Petersen and D. Watstein, Nat. Bur. Stand. (U.S.), Bldg. Sci. Series 13 (Mar. 22, 1968)
Key words: Creep; loss of prestress; prestressed concrete; relaxation; shrinkage; variable prestress.

The loss of prestress resulting from creep and shrinkage in concrete was investigated for concrete specimens made with Type I portland cement and with Type III portland cement. The primary variables in this study were: (1) Relative humidity at which the concrete was maintained while under observation. (2) Age of the concrete at the time it was prestressed. (3) Ratio of prestress to strength; variation of this parameter required that the ratio of reinforcement be a variable. (4) Mass ratio factor defined as the ratio of the cross-section area of concrete specimen to its surface area per unit length.

Forty-nine sets of specimens were fabricated and tested; each set consisted of a prestressed specimen and an otherwise identical companion specimen without reinforcement.

The length changes with time were observed at intervals up to an age of 500 days. These observations were made for concretes subjected to different levels of prestress, and for concretes prestressed at different ages. Length changes in nonreinforced companion specimens were also obtained. Thus this study is concerned with elastic deformation occurring at time of stress transfer, shrinkage or swelling, and creep.

BSS 14. Experimental determination of eccentricity of floor loads applied to a bearing wall, D. Watstein and P. V. Johnson, Nat. Bur. Stand. (U.S.), BIdg. Sci. Series 14 (June 1968).

Key words: Bearing pads; bearing walls; brick masonry; design of bearing walls; eccentricity of applied loads.

The eccentricity of the loads applied to a specially calibrated compressive strut simulating a brick bearing wall was experimentally determined for a variety of bearing materials and conditions of contact. In one series of tests, an I-beam was bedded in high strength gypsum plaster, bonded and unbonded. For the unbonded plaster bed the eccentricity ratio increased with the applied load to a maximum value of about 0.42 , while for the bonded plaster bearing this ratio decreased to an average value of about 0.24 at the maximum load.

In the second series of tests the eccentricity was observed for an I-beam supported on neoprene rubber pads, capped and uncapped, of different thicknesses, and of different bearing length. In general the eccentricity ratio increased slightly with the applied load. Lack of intimate contact between the 1-beam and the rubber pad $1 / 8$ in thick resulted in an eccentricity ratio of about 0.40 , or nearly the same as for unbonded plaster bearing. Intimacy of contact produced by plaster capping resulted in a marked reduction in the eccentricity ratio to about 0.29 ; the confinement of the bearing length of the rubber pad to one-half of that used in previous tests and placing it at the extreme end of the beam, further reduced the eccentricity ratio to about 0.18 , and to 0.13 for a rubber pad 0.25 in thick.

BSS15. Interrelations between cement and concrete properties, Part 4. Shrinkage of neat portland cement pastes and concretes, (Contains section 9 and section 10.) R. L. Blaine, H. T. Arni, and D. N. Evans, Nat. Bur. Stand. (U.S.), Bldg. Sci. Series 15 , Part 4, 79 pages (Mar. 1969).

Key words: Cement composition; chemical composition of portland cements; cracking of portland cements; cracking resistance of cements; expansion-shrinkage ratios; portland cement; portland cement concrete; shrinkage of concrete; shrinkage of portland cements; trace elements.

Section 9. Shrinkage of hardened portland cement pastes.

The relationship between cement properties and drying shrinkage of partially hydrated neat cement pastes of normal consistency made of a large number of portland cements of different types and composition were studied by fitting multivariable regression equations with the aid of a digital computer. The time of cracking of annular specimens restrained from shrinking 
by a steel core varied from 0.1 to more than 40 hours. The principal variables which appeared to have the greatest effect were the fineness and $\mathrm{K}_{2} \mathrm{O}$ and $\mathrm{C}_{4} \mathrm{AF}$ contents of the cements. The fineness and $\mathrm{K}_{2} \mathrm{O}$ contents of the cements appeared to have the greatest effect on the nonrestrained shrinkage of prisms at the time of cracking of the annular specimens. The shrinkage of neat cement bars after 1, 6, 27 days, and 6 months in laboratory air differed greatly with different cements. The principal variables appeared to be the $\mathrm{C}_{3} \mathrm{~A}, \mathrm{SO}_{3}$, and $\mathrm{C}_{3} \mathrm{~A} / \mathrm{SO}_{3}$ ratios. Other commonly determined variables were associated with each of the above test values. The trace elements, other than $\mathrm{Na}_{2} \mathrm{O}$ and $\mathrm{K}_{2} \mathrm{O}$, were not generally associated with the shrinkage or cracking characteristics.

Section 10. Shrinkage and expansion of concrete.

The relationship between the cement characteristics and the drying shrinkages of concretes made of a large number of cements of different types and compositions, as well as the subsequent expansions when the concretes were rewetted, were studied by fitting multivariable regression equations with the aid of a digital computer. Specimens $6 \times 8 \times 16$ inches, were made using 5.5 bags of cement (nominal) per cubic yard with a water/cement ratio of 0.635 , as well as with a slump of $5 \pm 1$ inches. Increases in $\mathrm{C}_{3} \mathrm{~A}, \mathrm{C}_{4} \mathrm{AF}$, fineness of the cement, and air content of the concrete were associated with increases in both shrinkage on drying and expansion on rewetting of the concretes. Increases in $\mathrm{Na}_{2} \mathrm{O}, \mathrm{SO}_{3}$, and ignition loss of the cements were as sociated with decreases in the shrinkage values of the concretes. None of the individual trace elements, except possibly $\mathrm{Rb}$ and $\mathrm{SrO}$, were associated to a highly significant degree with shrinkage or expansion characteristics of the concretes. The use of trace elements in equations with other more commonly determined variables resulted in a significant reduction in variance. There was no relationship between the shrinkage of concrete specimens moist cured 14 days and then dried in laboratory air for eight weeks, and the shrinkage of neat cements, moist cured only 24 hours and then dried in laboratory air. Higher values for dynamic Young's modulus of elasticity of the concretes were associated with lower shrinkage and expansion values.

BSS16. Techniques for the survey and evaluation of live floor loads and fire loads in modern office buildings, J. O. Bryson and D. Gross, Nat. Bur. Stand. (U.S.), Bldg. Sci. Series 16, 32 pages (Dec. 1968).

Key words: Fire loads; live floor loads; loads survey techniques; occupancy loads.

The procedures and techniques developed for measuring and evaluating the live floor loads and fire loads in modern office buildings are summarized. The main features of a computer program for analyzing the data are outlined. This program provides a tabulation of the data, some statistical properties, and selected graphical relationships between the measured loads and the characteristics and usage of the structure. A rationale is developed which is intended to achieve the ultimate goal-easier and less expensive means of surveying live loads in buildings and their combustible content.

Two office buildings have been surveyed in a pilot evaluation of the survey techniques - the National Bureau of Standards Administration Building in Gaithersburg, Maryland, and the U.S. Civil Service Commission in downtown Washington, D.C. Typical results are presented to illustrate the computer output.

BSS17. Causes of variation in chemical analyses and physical tests of portland cement, B. L. Bean and J. R. Dise, Nat. Bur. Stand. (U.S.), Bldg. Sci. Series 17, 34 pages (Mar. 1969).

Key words: Chemical analyses; physical tests; portland cement.

Variations in testing that could lead to the rejection of a material fully conforming to specification requirements, or the acceptance of a material with undesirable chemical or physical properties, are apparent in the results reported by latoratories participating in comparative tests of portland cements. Many of the causes for variation in ehemical analyses and physical test results are listed in this discussion. and remedies lor some of the more frequently encountered deficiencies in apparatus and methods are suggested. Particular consideration is given to problems which do not seem to have been covered in suflicient detail in previous discussions of cement testing procedures. Literature references are given for additional informatıon. (Supersedes NBS Monograph 28.)

BSS 18. Smoke and gases produced by burning aircraft interior materials, D. Gross, J. J. Loftus, T. G. Lee, and V. F. Gray Nat. Bur. Stand. (U.S.), Bldg. Sci. Series 18, 29 pages (t eh. 1969).

Key words: Aircraft materials; combustion products: fire tests; interior finish: smoke; toxic gases.

Measurements are reported of the smoke produced during both flaming and smoldering exposures on 141 a arcraft interior materials. Smoke is reported in terms of specific opucal density. a dimensionless attenuation coefficent which defines the photometric obscuration produced by a quantity of smoke accu. mulated from a specimen of given thickness and unit surface area within a chamber of unit volume. A very wide range in the max imum specific optical density was observed. For the majority of materials, more smoke was produced during the flaming exposure test. However, certain materials produced significantly more smoke in the absence of open flaming.

During the smoke chamber tests. indications of the maximum concentrations of $\mathrm{CO}, \mathrm{HCl}, \mathrm{HCN}$, and other selected potentially toxic combustion products were obtained using commercial colorimetric detector tubes. A study was made of the operation. accuracy, and limitations of the detector tubes used. Measurements of the concentrations of $\mathrm{HCl}$ were also made using specific ion electrode techniques.

Qualitative identification of the major components of the original test materials was accomplished primarily by infrared absorption spectrophotometry.

BSS19. A study of the variables involved in the saturating of roofing felts, S. H. Greenfeld. Nat. Bur. Stand. (U.S.). Bldg. Sci. Series 19, 18 pages (June 1969).

Key words: Absorption; asphalts; felts; moisture: roofing: saturation.

The degree of saturation of a No. 27 felt with a typical roll saturant and a No. 55 felt with roll, mixed, and shingle saturants varied with saturation time and pressure, saturant temperature and viscosity, felt conditions, and press roll pressure and clearance. Optimum temperature and viscosity ranges were determined for each asphalt-felt combination. Both pressure and vacuum increased the completeness of saturation under optimum conditions, but frequently shortened the working temperature range in which optimum saturation could be produced.

Rate and degree of moisture and liquid water absorption decreased with increasing saturation. Air permeability decreased with increasing saturation. The consequences of some of these findings are discussed.

BSS20. Durability of insulating glass. Proceedings of a seminar held at the National Bureau of Standards, Gaithersburg. Md. November 14-15, 1968, H. E. Robinson. Editor, Nat. Bur. Stand. (U.S.), Bldg. Sci. Ser. 20, 84 pages (Feb. 1970).

Key words: Accelerated laboratory tests: double-glazed window units: factory-sealed insulating glass units: field performance tests, correlation with laboratory tests; sealant performance; standardized testing: test methods.

A two-day seminar on the Durability of Insulating Glass was attended by some 130 persons on November 14 and 15.1968. 
The seminar was held at the Gaithersburg, Maryland, facilities of the National Bureau of Standards and featured fourteen speakers who participated in panel discussions or delivered individual papers. Numerous agencies interested in design, manufacture, specification, purchase, installation or maintenance of windows were represented at the seminar.

Among the topics considered in the panel discussions were: (1) the need for reliability and durability of insulating glass; (2) manufacturers' test methods; (3) proposals for future action. The Canadian experience with an accelerated test method and acceptance program was presented and discussed, as were the Norwegian accelerated test methods and their correlation with field experience. A review of current practices leading to new test methods and standards was also presented, and a "round robin" program that would compare various test methods now employed in the industry was proposed. Affirmative interest in participating in the proposed round robin was expressed by about a score of manufacturers present at the seminar

BSS2 1. Algorithms for psychrometric calculations (skeleton tables for the thermodynamic properties of moist air), T. Kusuda, Nat. Bur. Stand. (U.S.), Bldg. Sci. Ser. 21, 53 pages (Jan. 1970).

Key words: Computer algorithm; psychrometrics; saturated and unsaturated moist air; thermodynamic properties.

Computer algorithms to obtain thermodynamic properties of saturated and unsaturated moist air are presented in this paper. The saturated moist air properties are calculated by the methodology developed by J. A. Goff and S. Gratch for their ASHRAE tables (1967 Book of Fundamentals, The American Society of Heating, Refrigerating and Air Conditioning Engineers). Sample calculations were performed using a computer program based upon the algorithms presented herein and the results are attached.

BSS22. Investigation of performance characteristics for sanitary plumbing fixtures, P. R. Achenbach, Project Director Coordinator, Nat. Bur. Stand. (U.S.), Bldg. Sci. Series 22, 72 pages (Jan. 1970).

Key Words: Abrasion resistance; chemical resistance: cigarette-burn resistance: cleanability and soilability; concentrated static-load capacity; performance characteristics: performance level; sanitary plumbing fixtures; scratch resistance; stain resistance; surface-impact resistance; test methods.

This report gives findings and recommendations developed during an investigation of performance characteristics for sanitary plumbing fixtures, conducted at the request of the Building Research Advisory Board of the National Academy of Sciences - National Research Council. The report describes the test methods that are recommended for the evaluation of 16 performance characteristics, and the nature of further work required to complete the development of four or five additional test procedures.

The suitability of various existing test methods for evaluating the functional and performance characteristics of sanitary plumbing fixtures was investigated in the laboratory. In addition, new or modified tests for certain characteristics were developed. The laboratory work was performed only on bathtubs and flat specimens provided by industry through appropriate arrangements with the Building Research Advisory Board. Field inspection trips were made to provide the NBS project staff with up-todate information on certain manufacturing processes and on installation and use problems. The complexities involved in the selection of valid performance levels are discussed, as well as the elements of judgment involved. A format that might be used in specifying performance is suggested for each test procedure, and the rationale underlying each suggested format is given.

BSS23. Hail resistance of roofing products, S. H. Greenfeld, Nat. Bur. Stand. (U.S.), Bldg. Sci. Series 23, Il pages (Aug. 1969).
Key words: Asphalt shingles; built-up roofing; hail; roofing; shingles; storm damage.

A test was developed for evaluating the hail resistance of roofings, in which synthetic hailstones (ice spheres) of various sizes were shot at roof assemblies at their free-fall terminal velocities. Indentations, granule loss and roofing fracture were observed. The following conclusions have been made from these results: (a) All roofing materials have some resistance to hail damage, but as the size of the hail increases, a level of impact energy is reached at which damage occurs. This level lies in the range of $11 / 2$ to 2 inch $(3.8-5.1 \mathrm{~cm})$ hailstones for most prepared roofings. (b) Because of the ways in which prepared roofings are applied, most products have areas of different vulnerability. (c) The solidly supported areas of roofing tend to be the most resistant to hail damage. (d) Heavier shingles tend to be more hail-resistant than Type 235 shingles. (e) Weathering tends to lower the hail resistance of asphalt shingles. (f) Built-up roofs on dense substrates tend to resist hail better than those on soft substrates. (g) Built-up roofs made with inorganic felts tend to be more hail resistant than those made with organic felts. (h) Coarse aggregrate surfacing tends to increase the hail resistance of roofing.

BSS24. Natural weathering of mineral stabilized asphalt coatings on organic felt, S. H. Greenfeld, Nat. Bur. Stand. (U.S.), Bldg. Sci. Series 24, 17 pages (Oct. 1969).

Key words: Additive; aspkalt; durability; felt; stabilizer; weathering.

Sixteen years of outdoor weathering of laboratory-prepared smooth-surface and mineral-surfaced, felt-base roofing specimens has provided information on the effects of mineral additives on the durability of coating-grade roofing asphalts. Six finely divided mineral additives (blue black slate, clay. dolomite, fly ash, mica and silica) were evaluated at concentrations up to 60 percent in California, Mid-Continent and Venezuela asphalts. The mineral-surfaced specimens are all performing satisfactorily, and show only minor degrees of degradation. Of the smooth-surfaced specimens, the Mid-Continent asphalt performed the best and the California asphalt the poorest. The mica and blue black slate increased the durabilities of all three asphalts at all concentrations and two coating thicknesses. Fly ash. clay, dolomite and silica were beneficial in some combinations, but had little effect in others. In general, these early results from outdoor exposure tend to corroborate the results obtained on these coatings exposed in weatherometers.

BSS25. Structural performance evaluation of a building system, E. O. Pfrang and F. Y. Yokel. Nat. Bur. Stand. (U.S.), Bldg. Sci. Series 25, 127 pages (Nov. 1969).

Key words: Building systems; low-income housing; performance criteria; performance testing.

A full-scale, first-story portion of a building system was tested in the laboratory in such a manner as to simulate the structural behavior of a three-story building under both service and potential ultimate loading conditions. Additional tests were performed on the system components to provide behavioral data needed for the evaluation of the system.

Performance criteria for the evaluation of the structural safety and adequacy of certain building systems were developed. This report presents the results of the physical tests performed in the evaluation of the safety and structural adequacy of one such system, and discusses their significance. The report also presents data concerning the complex interaction between components which takes place in the building system.

The primary conclusions reached were: (1) The system, as erected in the laboratory, satisfied the performance criteria which were set for its evaluation with a substantial margin. As a system, it exhibited strength and stiffness in excess of service and ultimate load requirements. (2) The walls of the system behaved as an integral part of the structure. They provided most 
of the stiffness of the system with respect to lateral loads, and provided a significant portion of the stiffness against vertical loads.

BSS26. Radiation errors in air ducts under nonisothermal conditions using thermocouples, thermistors, and a resistance thermometer, J. C. Davis, Nat. Bur. Stand. (U.S.), Bldg. Sci. Ser. 26, 14 pages (Nov. 1969).

Key words: Conduction error; radiation error; resistance thermometer; temperature measurement; thermistor; thermocouple.

Studies were made to determine the radiation error in temperature measurements made with thermocouples, thermistors, and a resistance thermometer in moving air at velocities ranging from 300 to $1300 \mathrm{fpm}$ when the temperature of the duct wall surrounding the air stream was from 0 to $50^{\circ} \mathrm{F}$ higher than that of the air in the center of the duct. To eliminate all but the variable under study, conduction errors were minimized to a point where they were almost nonexistent by using Chromel P-constantan thermocouple wire and by employing other techniques. Radiation effects were studied when the probe housing the three types of temperature sensors was unshielded and again when it was shielded. The studies showed that "when the sensors were unshielded and the temperature difference between the duct wall and the air was $50^{\circ} \mathrm{F}$ ( $28 \mathrm{~K}$, approximately), the error in the sensors was about $3.8^{\circ} \mathrm{F}(2.1 \mathrm{~K})$ for an air velocity of $300 \mathrm{fpm}(1.5$ $\mathrm{m} / \mathrm{s})$ and $1.0^{\circ} \mathrm{F}(0.6 \mathrm{~K})$ for an air velocity of $1300 \mathrm{fpm}(6.6 \mathrm{~m} / \mathrm{s})$. When the sensors were shielded, the error was about $0.2{ }^{\circ} \mathrm{F}(0.1$ K) for 300 and $500 \mathrm{fpm}$ velocities and the same duct wall airtemperature difference. Tests were not performed at $1300 \mathrm{fpm}$ with the sensors shielded because theory indicated that radiation error would be negligible at this velocity. Under the test conditions that prevail in the testing of air conditioners and heat pumps in laboratories, it should be possible to reduce the error in temperature measurement of the moving air to about $0.2^{\circ} \mathrm{F}(0.1$ $\mathrm{K})$ by a suitable combination of air mixers, duct insulation, radiation shields, and calibration techniques.

BSS27. Performance of louvered devices as air mixers, T. K Faison, Jr., J. C. Dayis, and P. R. Achenbach, Nat. Bur. Stand. (U.S.), Bldg. Sci. Ser. 27, 22 pages (Mar. 1970).

Key words: Effectiveness; forced mixing; mixing device; pressure drop; temperature; uniformity.

As part of a study of evaluating methods for reducing thermal gradients within the cross section of an air stream, three louvered mixing devices were investigated. Each of these devices was found to be capable of reducing the cross-sectional nonuniformity of air temperature to a few percent of the entering value. The three devices covered in this report contain combinations of louvers (directing vanes) and baffles as mixing elements. Two of the devices were designed at the National Bureau of Standards; the third was a modification of a previous design. The three mixers (the louvered strip, the concentric louvers, and the louvered-baffle) required $4.75,3.8$, and 3.0 duct diameters, respectively, to reach a mixing effectiveness level of 97 percent. The mixing effectiveness of the louvered strip and concentric louver models was independent of the approach velocity, whereas the effectiveness of the louver-baffle model was somewhat dependent on the approach velocity. The pressure drops accompanying air flow through the mixers, expressed as multiples of the velocity head of the entering air, were approximately 7,5 , and 38 for the louvered strip, concentric louver, and louver-baffle mixers, respectively.

BSS28. Exploratory studies of early strength development in portland cement pastes and mortars, R. L. Blaine and L. A. Tomes, Nat. Bur. Stand. (U.S.), Bldg. Sci. Ser, 28, 14 pages (July 1970).

Key words: Cement; cement mortar; cement paste: early strength; false set; hardening of cement; hydration; shear re- sistance; theory of cement hardening. tıme of set; vane shear apparatus.

A modified vane-shear apparatus was used to measure the shear resistance of neal cement pastes of normal consistency and 1:2.75 (cement to sand) mortars of standard consistency, and to measure the increase in shear resistance with tume as the cements hardened. The hardening process appeared to oceur in three stages. The rate of increase of shear resistance as well as the duration of the different phases differed with the different cements. The results were analyzed in terms of the various theories proposed to explain the hardening of cements.

BSS29. 1964 exposure test of porcelain tnamels on aluminum three year inspection, M. A. Baker, Nat Bur. Stand. (L S.), Bldg. Sci. Ser, 29, 13 pages (A pril 197(1).

Key words: Color; gloss; porcelain enamel on aluminum: weather resistance.

An exposure test of porcelain enamels on aluminum was initiated by the National Bureau of Standards and the Porcelain Enamel Institute in 1964. The enamels were returned from the exposure sites to the laboratory at NBS 10 be measured for changes in gloss and color after exposures of six months, one year, and three years. Changes were found to be greatest at Kure Beach and least at Montreal and Los Angeles, with moderate changes occurring at Washington and New York.

Although the boiling citric acid test is used as an acceptance test for these enamels, the correlation with color change, particularly at Kure Beach, was not as good as expected. A cupric chloride test was developed which shows an improvement in this correlation.

BSS30. Wind loads on buildings and structures. Proceedings of a Technical Meeting held at the National Bureau of Standards, Gaithersburg, Maryland, January 27-28, 1969, R. D. Marshall, Editor, Nat. Bur. Stand. (U.S.), Bldg. Sci. Ser. 30, 169 pages (Nov. 1970).

Key words: Aerodynamic forces; atmospheric boundary layer; disaster mitigation; structural design; turbulence; wind effects; wind loads.

A technical meeting concerning wind loads on buildings and structures was held at the Gaithersburg Facility of the National Bureau of Standards on January 27 and 28, i969. The meeting, jointly sponsored by the Building Research Division of the National Bureau of Standards and the Environmental Data Service of the Environmental Science Services Administration, was intended to promote the exchange of information between research workers and practicing engineers engaged in this important area of technology.

Thirteen papers covering four themes were presented. These themes were as follows: engineering problems in the design of structures to resist wind loads; atmospheric considerations; experimental and theoretical determination of aerodynamic forces; and recent advances in design procedures and current deficiencies. Presentations were followed by a panel discussion which in. cluded a summary of each theme. The last session of the meeting was devoted to open discussion.

Design and construction for what wind loads and why, L. C Maugh, BSS30, pp. 5-8 (Nov. 1970).

Design wind loads for building wall elements, W. F. Koppes. BSS30, pp. 9-18 (Nov. 1970).

Guidelines in selecting wind measuring instruments and their locations for wind loading studies, G. C. Gill. BSS30. p. 21 (Nov. 1970).

The adequacy of existing meteorological data for evaluating structural problems, 1. A. Singer and M. E. Smith. BSS 30, pp. 23-25 (Nov. 1970). 
The characteristics of atmospheric turbulence as related to wind loads on tall structures, G. H. Fichtl, J. W. Kaufman, and W. W. Vaughan, BSS30, pp. 27-41 (Nov. 1970).

Fluctuating moments on tall buildings produced by wind loading, J. E. Cermak, W. Z. Sadeh, and G. Hsi, BSS30, pp. 45-59 (Nov. 1970).

Experience with wind pressure measurements on a full-scale building, W. A. Dalgliesh, BSS30, pp. 61-71 (Nov. 1970).

Influence of architectural features on the static wind loading of buildings, H. J. Leutheusser, BSS30, pp. 73-86 (Nov. 1970).

The unsteady surface pressure around circular cylinders in two-dimensional flow, W. E. Simon, BSS30, pp. 87-91 (Nov. 1970)

On the reliability of gust loading factors, B. J. Vickery, BSS30, pp. 93-104 (Nov. 1970).

The treatment of wind in the design of very tall buildings, $\mathrm{L}$. E. Robertson and P. W. Chen, BSS30, pp. 107-114 (Nov 1970)

Dynamic response of tall flexible structures to wind loading, J. Vellozzi and E. Cohen, BSS30, pp. 115-128 (Nov. 1970).

Some deficiencies in current methods of analysis, R. W Clough, Chairman, BSS30, pp. 129-131 (Nov. 1970).

Combining a wind tunnel analysis with a three-dimensional analytic building analysis, G. C. Hart, BSS30, pp. 145-149 (Nov. 1970).

The engineering interpretation of Weather Bureau records for wind loading on structures, S. C. Hollister, BSS30, pp. 151-164 (Nov. 1970).

BSS31. Flexural behavior of prestressed concrete composite Teebeams, J. O. Bryson and E. F. Carpenter, Nat. Bur. Stand. (U.S.), Bldg. Sci. Ser. 31, 14 pages (July 1970).

Key words: Composite concrete construction; prestressed concrete beams; Tee-beams

Prestressed Tee-beams constructed by the split-beam method were tested to failure in flexure to study the behavior and ultimate strength of these beams and to "compare their flexural characteristics with those of prestressed beams of conventional construction. The compressive portion of the cross section of the split-beam is cast after the web of the beam has been formed and prestressed. The variables in the study included the precentage of prestressing steel, strength of concrete in the compressive element of the composite split-beams, manner of prestressing and web reinforcement.

Results showed that the composite split-beams behaved similarly to the monolithically constructed beams on the basis of flexural response and ultimate load. The strength of the concrete for the compressive element can be reduced within limits from that required for the prestressed element without sacrificing ultimate load capacity. The required percentage of reinforcing steel is less for the split-beam compared with conventional beams.

BSS32. Precoordination-basis for industrialized building Proceedings of a conference held at Gaithersburg, Md., September 24-26, $1969, \bar{R}$. W. Smith, Jr., Editor, Nat. Bur. Stand. (U.S.), Bldg. Sci. Ser. 32, 136 pages (Jan. 1971).

Key words: Building; components; precoordination; standards.

The Conference entitled "Precoordination-Basis for Industrialized Building" was held at the National Bureau of Standards, Gaithersburg, Md., on September 24-26, 1969. The Conference was sponsored by the American National Standards Institute's Committee A62. Precoordination of Building Components and Systems, to explore the standards required to establish a basis for an industrywide system of building using interchangeable components. Coordinated components, conforming to these standards, will be compatible and interchangeable in both dimension and function and thereby offer unlimited opportunities for product and material selection as well as design flexibility.
BSS33. Compressive strength of slender concrete masonry walls, F. Y. Yokel, R. G. Mathey, and R. D. Dikkers, Nat. Bur. Stand. (U.S.), BIdg. Sci. Ser. 33, 32 pages (Dec. 1970).

Key words: Buckling; compressive strength; concrete block walls; elastic stability; flexural strength; masonry walls; reinforced concrete masonry walls; slenderness effect; structural stability.

Sixty reinforced and unreinforced concrete masonry walls of different slenderness ratios were tested to failure under vertical loads applied axially and at various eccentricities. Prism specimens, made of similar masonry units and mortars, were also tested under the same loading conditions. Analysis of test results indicates that wall strength can be conservatively predicted by evaluating cross-sectional wall capacity on the basis of prism strength and reducing the capacity for slenderness effects by evaluating the added moments attributable to wall deflection. Test results were also compared with allowable loads computed in accordance with the current NCMA standard.

BSS34. Strength of masonry walls under compressive and transverse loads, F. Y. Yokel, R. G. Mathey, and R. D. Dikkers, Nat. Bur. Stand. (U.S.), Bldg. Sci. Ser. 34, 74 pages (Mar. 1971).

Key words: Brick; cavity walls; composite walls; compressive strength; concrete block; flexural strength; masonry; mortar; slenderness effects; standards; structural stability; walls.

Ninety walls of 10 different types of masonry construction were tested under various combinations of vertical and transverse load. It is shown that the effect of vertical load and wall slenderness on transverse strength can be predicted by rational analysis. The analysis is based on established theory which has been extended to account for the properties of masonry. Similar methods of rational analysis have been adopted for the design of steel structures and are presently being considered for reinforced concrete structures.

BSS35. Interrelations between cement and concrete properties, Part 5. Freezing-and-thawing durability, saturation, water lose and absorption, dynamic modulus, R. L. Blaine and H. T. Arni, Nat. Bur. Stand. (U.S.), Bldg. Sci. Ser. 35, 129 pages (Nov. 1971).

Key words: Absorption; autogenous healing; durability factor; dynamic modulus of elasticity; saturation coefficient.

The concretes described in earlier parts of this series were subjected to laboratory freezing and thawing tests, and measurements were made of the weight loss, dynamic modulus, durability factor, and number of cycles required to reach 40 percent reduction in dynamic modulus. Companion specimens were subjected to drying and subsequent soaking in the laboratory and to dynamic modulus tests at various ages and moisture conditions. The effect on these properties of a large number of variables connected with chemical and physical properties of the cements and with properties of the concretes was studied by multivariable regression techniques. Air content of the concretes and degree of saturation generally had the greatest effect on the measurements. In general, minor constituents and trace elements did not show significant relationships with the measured properties, but there was evidence that some of the variables, such as alkali content, water cement ratio, slump, and possibly setting time might have influenced durability through an effect on the air-void system. Specimens stored in the fog room after the freezing-andthawing tests generally regained most or all of their original dynamic modulus. There were significant differences between cements with respect to regain of dynamic modulus (autogenous healing), with the non-air-entrained cements gaining more than the air-entraining cements, on the average. 
BSS36. Interrelations between cement and concrete properties, Part 6. Compilation of data from laboratory studies, J. R. Clifton and R. G. Mathey, Nat. Bur. Stand. (U.S.), Bldg. Sci. Ser. 36, 118 pages (Aug. 1971).

Key words: Cement; chemical composition; concrete; durability; material properties; physical properties.

Data are presented on the properties of Portland cements, mortars and concretes from a long term study reported principally by Blaine and Arni.

These data are from laboratory studies and cover a wide range of cements and concretes. A total of 199 different cements were included in the study.

BSS37. The effect of moisture on the heat transfer performance of insulated flat-roof constructions, F. J. Powell and H. E. Robinson, Nat. Bur. Stand. (U.S.), Bldg. Sci. Ser. 37, 81 pages (Oct. 1971).

Key words: Flat roofs; heat transfer; moisture transfer; thermal insulation.

A solution to the problem of unwanted moisture in the thermal insulation of flat roofs was found during a recently completed laboratory investigation of the effects of moisture on heat transfer through these constructions. The objective of the research was to ascertain how much the insulating performance of conventional constructions, having insulation over concrete decks, was affected by moisture. This is presented as Part I. Also, the objective was to investigate properties of materials, their arrangement and dimensions which would yield a construction having an adequate degree of self-drying ability, combined with low winter moisture regain rate. This is presented as Part II. The results show that the best insulating and moisture performance was obtained by utilizing the heat of the summer sun on the roof to vaporize and transfer to the room beneath any free moisture contained within the construction. Roof specimens made from moderately vapor-permeable materials without conventional vapor barriers were, in winter, able to accommodate the small quantity of slowly accumulated condensation without dripping or severe loss of insulating value. During the nine-year investigation, the performance characteristics of 73 insulated roof deck specimens were obtained and two new methods of measurement were developed. Criteria for the design of self-drying insulated flai roofs were developed and limits of the parameters containing the main variables that affect performance were suggested.

This paper presents complete results of the research which was sponsored jointly by the National Bureau of Standards, the Army, the Navy, and the Air Force.

BSS38. 1939 exposure test of porcelain enamels on steel 30-year inspection, M. A. Baker, Nat. Bur. Stand. (U.S.), Bldg. Sci. Ser. 38, 9 pages (Aug. 1971).

Key words: Acid resistance; color; gloss; porcelain enamel; weather resistance.

The weather resistance of 192 porcelain enameled panels representing 14 . enamel types was evaluated after being exposed for 30 years at Washington, D.C. A direct correlation was found between the acid resistance and weather resistance of the enamels tested. The porcelain enamel protected the base metal from corrosion if the initial coverage was complete.

Similar evaluations and findings were made on 58 panels representing 13 enamel types that were added to this test in 1947.

BSS39. Use of computers for environmental engineering related to buildings. Proceedings of a Symposium sponsored by the National Bureau of Standards, the American Society of Heating, Refrigerating and Air-Conditioning Engineers, Inc., and the Automated Procedures for Engineering Consultants, Inc., held at the National Bureau of Standards, Gaithersburg, Md. Nov. 30-Dec. 2, 1970, T. Kusuda, Editor, Nat. Bur. Stand. (U.S.), BIdg. Sci. Ser. 39, 826 pages (Sept. I971).
Key words: Building heat transfer analysis, energy usage environmental engineering; heating and air conditioning. use of computers.

This proceedings of the First Symposium on the Use of Computers for Environmental Engineering Related to Buildings contains all of the technical papers and invited addresses presented at the symposium, which was held November 30-December 2. 1970, at the National Bureau of Standards.

The fifty-nine papers deal with the application of the computer to such environmental engineering problems as building heat transfer calculations, heating and cooling load calculations, system simulations, energy usage analyses, computer graphics, air and smoke movement inside buildings, and weather data analyses for load and energy usage calculations.

BSS40. Engineering aspects of the 1971 San Fernando earthquake, H. S. Lew, E. V. Leyendecker, and R. D. Dikkers, Nat. Bur. Stand. (U.S.), Bldg. Sci. Ser. 40, 419 pages (Dec. 1971 ).

Key words: Bridge; building; codes; dams; disaster mitigation; earthquake damage; earthquakes; foundation geology; highways; hospital; housing; mobile home; seismic; standards; structural engineering.

Immediately following the San Fernando, California earthquake (February 9, 1971), a four-man team from the Building Research Division of the National Bureau of Standards' Institute for Applied Tecnnology, surveyed the damage to buildings and other structures. This report is based primarily on the data gathered during the survey but includes some data provided by other agencies and individuals. Based on study of these data and observations made during the survey, recommendations are made pertaining to the improvement of building and other structural design and construction practices.

BSS41. Performance of a single-stack DWV system utilizing lowangle stack-branch confluence and bottom shunt venting, $\mathrm{R}$. S Wyly and G. C. Sherlin, Nat. Bur. Stand. (U.S.). Bldg. Sci. Ser. 41, 24 pages (Apr. 1972).

Key words: Criteria for plumbing; hydraulic test loads; performance of plumbing; single stack plumbing.

Among the more important criteria for hydraulic and pneumatic performance of sanitary drain-waste-vent systems are (1) maintenance of water seals in fixture traps, (2) limitation of pneumatic pressures, (3) limitation of hydrostatic and hydrodynamic pressures, and (4) limitation of cross-flow between horizontal branches or trap arms.

Recent tests of a single-stack drainage system proposed for a high-rise apartment project in Fairfax County. Virginia have produced the following findings with respect to these performance criteria: (I) test loads (total discharge rates) ranging up to magnitudes greater than predicted loads yielded reasonable average trap-seal retention; (2) the use of trap-seal retention as a measure of performance appears to be more meaningful than the traditional pneumatic-pressure measure: (3) fitting geometry and branch arrangement can be more critical in single-stack systems than in conventional vented systems, and (4) present procedures for selecting test loads, for making tests, and for reporting and interpreting measured values need improvement and standardization.

BSS42. Design loads for inserts embedded in concrete, T. W Reichard, E. F. Carpenter, and E. V. Leyendecker, Nat. Bur. Stand. (U.S.), Bldg. Sci. Ser. 42,28 pages (May 1972).

Key words: Anchors: concrete slabs; design loads: fatigue: inserts: pull-out loads; sustained load.

Detailed test procedures are presented for a research program on cast-in-place inserts embedded in reinforced concrete. Three types of inserts, two of malleable iron and one of ductile steel. capable of receiving a $3 / 4$ inch threaded rod were tested. Other variables included concrete aggregate type, concrete strength. 
reinforcement cover and spacing, angular loading, flexural cracking, sustained load and fatigue loading.

It was found that the pull-out load for an insert could be approximated by a linear function of the concrete unit weight and square root of the compressive strength in a statically loaded reinforced concrete slab. The effect of other variables is related to the insert pull-out loads in these slabs. Design recommendations are presented.

BSS43. Paper honeycomb sandwich panels as lightweight structural components, T W. Reichard, Nat. Bur. Stand. (U.S.), Bldg. Sci. Ser. 43, 7 pages (Apr. 1972).

Key words: Adhesives; paper honeycomb; sandwich facings; sandwich panels.

This paper presents a resume of current practice in the U.S. with regard to the use of sandwich panels in single-story buildings. A description and the properties of typical paper honeycomb cores are given. Some of the factors which are considered in choosing sandwich facings and adhesives are given.

BSS44. Full scale test on a two-story house subjected to lateral load, F. Y. Yokel, G. Hsi, and N. F. Somes, Nat. Bur. Stand. (U.S.), Bldg. Sci. Ser. 44, 26 pages (Nov. 1972). SD Catalog No. C13.29/2:44.

Key words: Building damping; drift; dynamics; earthquake; frequency; housing; lateral resistance; racking; stiffness; structural deflections; vibration; wind load; wood frame construction.

Tests were carried out on a house to determine its deflection characteristics under lateral loads. The house is a two-story building of conventional wood-frame construction. Two series of tests were conducted. The first of these was to determine the stiffness of the house when subjected to a simulation of wind loading. The second was to determine the dynamic response of the house to a single impulse load.

The report presents the results of these tests from which the following primary conclusions were derived:

1. The measured second-story drift of the building under the test load was considerably less than the drift permitted for medium- and high-rise buildings by present design criteria for most areas of the United States.

2. Only a small portion of the distortion of the exterior walls was transmitted to the interior gypsum board.

3. The upper ceiling diaphragm experienced significant inplane deformation. On the other hand, the floor/ceiling diaphragm at the lower ceiling level tended to act as a rigid diaphragm and to translate as a rigid body when the building was subjected to lateral load.

4. The natural frequency of the structure was approximately $9 \mathrm{~Hz}$ and damping averaged approximately 6 percent of critical damping varying from 4 to 9 percent.

BSS45. Dynamic thermal performance of an experimental masonry building, B. A. Peavy, F. J. Powell, and D. M. Burch, Nat. Bur. Stand. (U.S.), Bldg. Sci. Ser. 45, 103 pages (July 1973) SD Catalog No. C13.29/2:45.

Key words: Building heat transfer; computer programs; dynamic thermal performance; heat flow analysis; heating and cooling loads; temperature predictions; thermal analysis; thermal behavior; transient heat flows.

Measurements of the dynamic heat transfer in an experimental masonry building were made in a large environmental chamber to explore the validity of a computer program developed at NBS, labeled NBSLD, for computing heating and cooling loads, and indoor air temperatures. This study was jointly supported by the
National Bureau of Standards and the Department of Housing and Urban Development, and is a part of a broader research program being supported by both agencies to improve performance test procedures and criteria for housing.

The experimental structure was a one-room house $20 \mathrm{ft}$ long $20 \mathrm{ft}$ wide, and $10 \mathrm{ft}$ high with walls of solid concrete blocks and a flat roof made of reinforced precast concrete slabs. During the tests changes were made in fenestration, the amount and location of insulation, and the indoor mass; and the building was exposed to a diurnal temperature cycle.

It was found that the combination of mass in the masonry walls and roof, and insulation placed on the outside of the masonry was very effective in reducing and controlling the variation of indoor air temperature. The NBSLD computer program realistically predicted the heat storage effects, and maximum heating loads during these tests. For five heating tests, the greatest difference between computed maximum heating load and measured values was 8 percent and the average difference was 4.3 percent. It was shown that steady-state methods of heating load calculation could result in oversizing heating equipment by 30 percent or more for this particular building and imposed exterior conditions if the lowest outdoor temperature was selected as the design temperature.

BSS46. Building practices for disaster mitigation. Proceedings of a workshop sponsored by The National Science Foundation, Research Applied to National Needs Program, and The National Bureau of Standards, held at the National Bureau of Standards, Boulder, Colo., Aug. 28-Sept. 1, 1972, R. Wright, S. Kramer, and C. Culver, Editors, Nat. Bur. Stand. (U.S.), Bldg. Sci. Ser. 46, 483 pages (Feb. 1973) SD Catalog No. C 13.29/2:46.

Key words: Building; disaster mitigation; earthquakes; hazards; land use; structural engineering; wind effects.

The national workshop on building practices for disaster mitigation was concerned with earthquakes, extreme winds, and similar dynamic hazards. These proceedings present recommendations derived at the workshop and addressed to policy makers in government and industry, as well as practitioners in engineering, architecture, land use planning, and the earth and meteorological sciences. The recommendations evaluate current building practices, define opportunities for improving current practice from documented research findings, and recommend research to fill gaps in knowledge. Recommendations are made for implementation of improved practices at professional and policy levels. The objectives include avoidance of human suffering, reduction of property loss, and maintenance of vital function in buildings under conditions threatening disaster. Fifteen review articles were prepared by experts in the professions and research disciplines to define the state-of-the-art in disaster mitigation and to guide discussions at the workshop. These articles are included in the proceedings as follows:

Workshop recommendations, BSS46, pp. 7-39 (Feb. 1973).

Values and costs, H. Kunreuther, BSS46, pp. 41-62 (Feb. 1973).

Approaches to implementation, P. E. Baseler, BSS46, pp. 63 81 (Feb. 1973).

Earthquake hazards for buildings, N. C. Donovan, BSS46, pp. 82-111 (Feb. 1973).

The problem of seismic zoning, S. T. Algermissen, BSS46, pp. 112-125 (Feb. 1973).

Wind hazards for buildings, J. W. Vellozzi and J. J. Healey, BSS46, pp. 126-138 (Feb. 1973).

Land use planning and natural disaster mitigation, W. J. Petak, M. McCoy, W. J. Monasch, J. E. Slosson, D. F. Moran, J. H. Wiggins, Jr., BSS46, pp. 139-178 (Feb. 1973).

Architectural approaches to hazard mitigation, E. C. Hillman Jr., A. E. Mann, BSS46, pp. 179-187 (Feb. 1973). 
Procedures and criteria for earthquake resistant design, $C$. W. Pinkham, BSS46, pp. 188-208 (Feb. 1973).

Procedures and criteria for earthquake resistant design, $\mathrm{N}$ M. Newmark and W. J. Hall, BSS46, pp. 209-236 (Feb. 197.3).

Procedures and criteria for wind resistant design, J. W. Vellozzi and J. J. Healey, BSS46, pp. 237-252 (Feb. 1973).

Criteria for building services and furnishings, J. M. Ayres and T.-Y. Sun, BSS46, pp. 253-285 (Feb. 1973).

Behavior of structural elements. A review, B. Bresler, BSS46, pp. 286-351 (Feb. 1973).

Behavior of structural systems under dynamic loads, R. 1 . Sharpe, G. Kost, and J. Lord, BSS46, pp. 352-394 (Feb. 1973).

Survey and evaluation of existing buildings, F. E. McClure, BSS46, pp. 395-426 (Feb. 1973).

Abnormal loading on buildings and progressive collapse, $N$. F. Somes, BSS46, pp. 427-470 (Feb. 1973).

BSS47. Structural deflections. A literature and state-of-the-art survey, T. V. Galambos, P. L. Gould, M. K. Ravindra, H. Suryoutomo, and R. A. Crist, Nat. Bur. Stand. (U.S.), Bldg. Sci. Ser. 47, 104 pages (Oct. 1973) SD Catalog No. C13.29/2:47.

Key words: Analysis; deflection; design; dynamic; experimental; human sensitivity; loading functions; specifications: static; structural engineering; subsystems; vibration.

A literature survey and state-of-the-art study was compiled using 233 primary source documents, research papers, and texts. Over 800 documents were scanned to arrive at the primary source documents. The problem of structural deflections is discussed and reviewed in its component areas of static and dynamic deflections as related to forcing functions and structural characteristics. Also the interactions of major structural deflections with building structures subsystems and human occupants is reviewed. Emphasis is placed on serviceability limit states of deflections. Detailed comparisons of human response to structural vibrations are also made. This report is broad in scope and covers the areas of analysis, design and experimentation.

BSS48. Design, siting, and construction of low-cost housing and community buildings to better withstand earthquakes and windstorms, W. F. Reps and E. Simiu, Eds., Nat. Bur. Stand. (U.S.), Bldg. Sci. Ser. 48, 152 pages (Jan. 1974) SD Catalog No. C13.29/2:48.

Key words: Buildings; construction; design; developing countries; disaster mitigation; earthquakes; low-cost housing; natural disasters; structures; windstorms.

The extensive loss of life and property caused in developing countries by earthquakes and windstorms (hurricanes, typhoons and tropical cyclones) may be reduced to a considerable degree by the adoption and implementation of improved design, siting and construction procedures practicable within the context of the cultural and socioeconomic constraints prevailing in these tountries.

The report provides technical information regarding characteristics of materials and building systems, and discusses the structural performance of buildings subjected to the action of earthquakes and wind forces with specific reference to structures typical of developing countries. 'Potential ways are described in which structures can be made more resistant to such action. Siting considerations are discussed from a geological, seismic and climatological view point, and recommendations relating to siting problems are made. Techniques of housing construction, both traditional and industrialized, are described and improvements resulting in better earthquake or windstorm resistance are suggested. Building codes, their improvement and their enforcement are also discussed.

The report discusses cultural and socio-economic constraints influencing the adoption of improved practices. describes vari- ous feasible technical improvements ol construction materlals composite systems and building systems, identifies nechisnisms for stimulating technicial improvements and discusses the role of institutions in this regard. Throughesut the repert. specufic references are made to Peru. the I'hilıppines and I urkey, countries which suffer from frequent devistiateon from nistural dis asters such as earthquakes and typhouns and which were selected as case studics for the purpose of this repurt.

BSS49. I.aboratory studies of the hydraulic performance of onestory and split-level residential plumbing systems with reducedsize vents, R. S. Wyly. C, (. Sherlın and R W Beausoliel Nat. Bur. Stand. (U.S.), Bldg. Sc1. Ser 49, 53 patges (Mar. 1974) SD C atalog No. ( 13.29/2.49

Key words: Hydraulic criteria for plumbing; hydraulic test loads; plumbing-vent sizing; reduced-size vents; sanitary DWV systems; secondary ventilation; testing plumbing systems; vents for plumbing.

A laboratory study on onc-story and split-level experimental drainagc systems where the vents in some cases were taried from one to six pipe-sizes smaller than those presently specified by codes showed satisfactory hydraulic and pneumatic per formance under various loading conditions. The research was originally sponsored by the National Association of Home Builders and the National Bureau of Standards and more recently by a program of the Department of Defense through the Tri-Services Investigational Committec on Building Materials. This paper presents criteria recommended for the design and evaluation of systems using reduced-sized vents and a sizing table for one- and two-story systems. The laboratory work also contributed to the development of analytical and test procedures needed for evaluating the application of reduced-size venting to a broad range of innovative drain-waste-vent designs for buildings of any height.

This work indicates that, in some circumstances, reduced-size venting might be a good alternative to other types of drainage systems for multistory buildings which use either conventional or innovative venting concepts. Because this study involved only a limited number of drainage system designs, it is recommended that ongoing field and laboratory studies be explored if code changes are contemplated to permit the use of smaller vents.

BSS50. Weather resistance of porcelain enamels - 15-year inspection of the 1956 exposure test, M. A. Baker, Nat. Bur. Stand. (U.S.), Bldg. Sci. Ser. 50, 15 pages (July 1974) SD Catalog No. C 13.29/2:50.

Key words: Acid resistance; color: gloss: pH: porcelaın enamel; relative humidity; weather resistance.

In 1956, and exposure test of porcelain enamels at + urban and 2 ocean shore sites in the continental United States was initiated by the National Bureau of Standards and the Porcelain Enamel 1 nstitute. After 15 years, all exposed specimens were returned to the Bureau and the changes in gloss and color determined. The gloss changes were found to be significantly different at all exposure sites except Pittsburgh, Los Angeles and Dallas. The most severe changes occurred at the Kure Beach. N.C. site nearest the ocean, while the least changes occurred at Pittsburgh. Los Angeles and Dallas. The differences in hehavior of the specimens correlated with both the average relative humidity and the $\mathrm{pH}$ of the suspended particulate matter at the different sites.

A correlation appeared to exist between the acid resistance of the enamels and changes in gloss and color. The regular, glosst. acid-resistant enamels on steel showed the hest weather resistance of the various types tested.

Comparison with enamel specimens exposed for 15 sears in an earlier test showed that porcelain enamels produced in the early 1950 's were equally resistant to changes in gloss and color as those produced in the late $1930^{\circ} \mathrm{s}$. 
BSS51. Structural evaluation of steel faced sandwich panels, J. H Pielert. T. W. Reichard, and L. W. Masters, Nat. Bur. Stand. (U.S.), Bldg. Sci. Ser. 51, 43 pages (Apr. 1974) SD Catalog No. C 13.29/2:51.

Key words: Accelerated aging; adhesive bond; ductility; flexural shear; housing systems; local buckling; material variability; moisture conditioning; Operation BREAKTHROUGH; paper honeycomb; structural sandwich; sustained load.

A series of structural evaluation tests performed on components and materials intended for use in one of the Operation BREAKTHROUGH housing systems is described. Four samples of steel faced, paper honeycomb, sandwich panel material and four full size prototype roof panels were evaluated

The samples of sandwich panel material were used to evaluate the variability of panel material properties and the effect of aging on tensile and shear strength. The roof panels were used to determine the behavior in service considering the effects of adverse environmental conditions on ultimate strength and mode of failure. In addition, the performance of one panel under sustained loading was evaluated.

BSS52. The effect of impact loadings on the performance of wood joist subflooring systems, H. S. Lew, Nat. Bur. Stand. (U.S.) Bldg. Sci. Ser. 52, 35 pages (May 1974) SD Catalog No. C13.29:2/52.

Key words: concentrated load; deflection; floor; hardboard; housing; impact energy; Operation BREAKTHROUGH; plywood; subfloors; underlayment; wood; wood joists.

This report presents the results of an experimental study of wood-joist subflooring systems subjected to impact load. Six different types of subflooring systems were tested following the test method described in the ASTM Standard Methods (ASTM Designation E-72). The magnitude of impact load was varied by dropping a 60 -lb bag from different heights.

A concentrated static load of $400 \mathrm{lb}$ was applied to the subfloor after it was exposed to impact load. It is suggested that the deflection under this concentrated load be used as a measure of the impact resistance of the subfloor. Supersedes NBSIR 73-187 (PB 221-188).

BSS53. Study of the local resistance of conventional plywood subfooring to concentrated load, F. Y. Yokel, Nat. Bur. Stand. (U.S.), Bldg. Sci. Ser. 53, 43 pages (May 1974) SD Catalog No. C 13.29:2/53

Key words: Evaluation criteria, floors; hardboard; load capacity; performance criteria; plywood subflooring; subflooring; underlayment; wood-frame construction.

Representative specimens, simulating the performance of five conventional plywood floor systems, were tested under concentrated load in order to compare their performance with that stipulated by performance criteria developed on the basis of anticipated occupancy loads.

In 24 out of 26 tests the performance of the specimens exceeded that required by the criteria. Data on failure loads, loaddeflection characteristics and failure modes are presented and discussed. Supersedes NBSIR 73-1 16 (PB 220-432/9).

BSS54. Health and medical facilities design. Proceedings of the First Federal Agency Workshop, held at the National Bureau of Standards Gaithersburg, Md., December 5, 1972, R. J. Kapsch, Ed., Nat. Bur. Stand. (U.S.), Bldg. Sci. Ser. 54, 87 pages (July 1974) SD Catalog No. C 13.29/2:54.

Key words: Architecture; design; hospital design; medical facilities; medical facility research.

The Federal Agencies have a large involvement in this area of Medical Facility Design; both in directly operated Federal facilities and indirectly through grant, loan and funding programs.
Because of the impact of technology and because of the very large cost for new medical facilities in the last few years, there has been the rise of a field best described as medical facility research. These papers, presented at a National Bureau of Standard's Federal Agency Workshop, describe the latest medical facility research efforts by the Federal Agencies including, the Department of Defense, Department of Health, Education, and Welfare, the Veterans' Administration and the National Bureau of Standards.

The new generation hospital, S. I. Gerber, BSS54, I-12 (July 1974).

Rationale for change-The Hill-Burton Program, J. W. Reese, BSS54, pp. 13-24 (July 1974).

Space planning and equipment requirements - application of advanced technologies to hospital design in the Veterans' Administration, H. J. Fogarty, BSS54, pp. 25-26 (July 1974).

Use of the computer in planning hospitals - application of advanced technologies to hospital design in the Veterans' Administration, B. D. Keane, BSS54, pp. 27-30 (July 1974).

Veterans' Administration Hospital Building System - application of advanced technologies to hospital design in the Veterans' Administration, J. C. Cook, BSS54, pp. 31-44 (July 1974).

Introduction-current issues in health care facility delivery, D. D. Boyle, BSS54, pp. 45-48 (July 1974).

Application-current issues in health care facility design, $J$. D. Russo, BSS54, pp. 49-62 (July 1974).

An evaluation methodology for hospital nursing units, $R$. Wehrli, BSS54, pp. 63-76 (July 1974).

BSS55. Preliminary performance criteria for bituminous membrane roofing, R. G. Mathey and W. C. Cullen, Nat. Bur. Stand. (U.S.), Bldg. Sci. Ser. 55, 16 pages (Nov. 1974) SD Catalog No. C 13.29/2:55.

Key words: Bituminous roof membranes; performance attributes; performance criteria; physical and engineering properties; test methods.

This report is the first in a series of publications on performance criteria for bujlt-up roof membranes. The development of a performance approach to bituminous built-up roof membranes is described and preliminary performance criteria are recommended. A number of test methods have been developed in order to obtain data to evaluate roofing membranes against the recommended criteria. Twenty attributes that effect the performance of roof membranes under service conditions are identified and laboratory tests are described for measuring the engineering properties of the membrane that pertain to many of these attributes. A level of performance is recommended for nine of the identified performance attributes.

BSS56. Development of improved design criteria for low-rise buildings in developing countries to better resist the effects of extreme winds, Proceedings of a Workshop held at the Dr. Paulino J. Garcia Memorial Hall, National Science Development Board, Manila, Philippines, Nov. 14-17, 1973, N. J. Raufaste, Jr., and R. D. Marshall, Eds., Nat. Bur. Stand. (U.S.), Bldg. Sci. Ser. 56, 171 pages (Oct. 1974) SD Catalog No. $13.29 / 2: 56$

Key words: Codes and standards; disaster mitigation; information transfer; low-rise buildings; pressure transducers; socioeconomic; structural design; technology implementation; wind effects; wind loads.

An International Workshop held in Manila. Philippines, on November 14-17, 1973, addressed the state-of-the-art in mitigating building damages from winds. The workshop was jointly sponsored by the United States Agency for International Development (USAID), the Philippine Advisory Committee (formed in conjunction with this research project), and the U.S. National Bureau of Standards (NBS). This report presents the proceedings derived from the workshop. The proceedings 
present recommendations, the workshop program, five reports, and nine technical articles. The technical articles addressed four primary topics which were used to guide subsequent workshop discussions. The topics addressed were: wind and aerodynamics, structural related technology, socio-economic and architectural considerations, and codes and standards.

The results of the workshop will serve a twofold purpose. The first suggests improved building practices for developing countries. This was accomplished through the development of recommendations designed to upgrade to a minimum acceptable level design critera for low-rise buildings. The second involves integrating appropriate workshop information into the overall three-year AID sponsored research project to develop improved design criteria for low-rise buildings in developing countries to better resist the effects of extreme winds. These proceedings include the following papers

Climatology and wind related problems in the Philippines, $\mathrm{R}$.

L. Kintanar, BSS56, pp. 28-62 (Oct. 1974).

Aerodynamics of structures and wind tunnel modeling, R. D. Marshall, BSS56, pp. 63-76 (Oct. 1974).

Some problems in the analysis of lateral wind force resisting systems, J. Ma. de Castro, BSS56, pp. 78-90 (Oct. 1974).

Socio-economic and architectural considerations il housing, G. V. Manahan and J. M. Ramos, BSS56, pp. 91-98 (Oct. 1974).

Lessons learned from post wind disaster investigation, $E$. $O$. Pfrang, BSS56, pp. 99-101 (Oct. 1974).

Low-rise low-cost housing and extreme wind related problems in Bangladesh, J. R. Choudhury, BSS56, pp. 102-120 (Oct. 1974).

Low-cost housing and extreme-wind-related problems in Jamaica, A. D. Adams, BSS56, pp. 123-139 (Oct. 1974).

Wind pressure provisions of the National Building Code Republic of the Philippines, A. R. Flores, BSS56, pp. 140-152 (Oct. 1974).

Standardization in the Philippines today, A. R. Flores, BSS56, pp. 153-155 (Oct. 1974).

Wind research in the United Kingdom, K. J. Eaton, BSS56, pp. 156-159 (Oct. 1974).

BSS57. Comparison of measured and computer-predicted thermal performance of a four bedroom wood-frame townhouse, B. A. Peavy, D. M. Burch, F. J. Powell, and C. M. Hunt, Nat. Bur. Stand. (U.S.), Bldg. Sci. Ser. 57, 62 pages (Apr. 1975) SD Catalog No. C 13.29/2:57,

Key words: Air leakage measurement; building heat transfer; computer programs; dynamic thermal performance; heat flow analysis; heating and cooling loads; temperature predictions; thermal analysis; thermostat setback; transient heat flows.

Measurements of the dynamic heat transfer in a four bedroom townhouse were made under controlled conditions in a large environmental chamber to explore the validity of a computer program developed at NBS, labelled NBSLD, for predicting heating and cooling loads and inside air temperatures. This study was supported jointly by the Department of Housing and Urban Development and the National Bureau of Standards, and is a part of a broader research program supported by both agencies to improve performance test procedures and criteria for housing.

The test house was a factory-produced four bedroom townhouse of modular design and of lightweight (wood) construction. Tests were performed with simulated outside summer, winter and fall diurnal temperature cycles. The inside temperature was maintained at about $75^{\circ} \mathrm{F}$. Also during the tests, the activities of a six-member family were simulated.
The time-varying energy requirements were measured, and these values were compared with computer predicted values For example, the disparity between predicted and meisured daily heating energy requirements averaged 3 I percent with a maximum departure of 4.9 percent for five tests. The computer program NBSI.D Was experimentally validaled for predicling the peak heating and cooling loads and the enerky requirements for the test house.

The air leakage of the house was measured by a tracer gas technique over a range of outdoor conditions. and algorithms were developed to account for its effect on healıng loads and energy requirements.

Separate tests were also performed to investigate the energy savings achieved by night temperature setback $A n X-h y$ t setback from $75^{\circ} \mathrm{F}$ produced an 11 percent diurnal savings in energy for an average nightlime temperature of 20 " $t$ and a $y$ percent savings in energy was achieved for the same setback when the average nighttime temperature was $2{ }^{\circ} \mathrm{F}$.

BSS58. State-of-the-art of structural test methods for walls, noors, roofs and complete buildings, C.W. C. Y ancey and L. E. ( attaneo, Nat. Bur. Stand. (U.S.), Bldg. Sci. Ser. 58. 136 páges (Nov. 1974) SD Catalog No. C 13.29/2:58

Key words: Building construction; complete buildings; Roors; roofs; standardization; test methods; walls.

As part of a comprehensive research program concerned with the structural testing of building components. conducted for the U.S. Department of Housing and Urban Development (HUD). a search for information was conducted. This search was undertaken in order to document existing information pertaining to structural testing of wall, floor and roof assemblies. Various information sources were consulted to trace the evolution of struc. tural testing of building construction from the 1930 's to the present time. This task was a prerequisite to defining the stateof-the-art and to identifying the test areas requiring fundamental research.

Based on information obtained from a review of the literature and from liaison with committees concerned with the development and revision of voluntary standards, it was found that there is a dearth of research information contributing directly to the development of test methods. Most of the research conducted on building components has been carried out either to observe the behavior of a sample of a particular type of construction or to evaluate the performance of a specimen against some performance requirements. However, helpful interferences can be made on the basis of some of the documentation, especially that contained in reports of full-scale tests on housing.

As a result of comparing the test methods used by the National Bureau of Standards in HUD project Operation BREAKTHROUGH with American Society for Testing and Materials (ASTM) Standard methods, several recommendations have been made by the authors for improving present structural test practice.

An up-to-date status report of voluntary test standards activities (in the U.S.) was prepared through verbal and uritten communication with members of the technical subcommittees of ASTM Committee E-6 on Performance of Building Construction.

BSS59. The adherence of porcelain enamel to aluminum, M. A. Baker, Nat. Bur. Stand. (U.S.), Bldg. Sci. Ser. 59, 39 pages (Nov. 1974) SD Catalog No. C13.29/2:59.

Key words: Adherence; aluminum; electron microprobe; electron microscope; porcelain enamel; spalling; $x$-ray diffraction.

Electron microscopy, electron microprobe, and $x$-ray diffraction techniques were used to determine the mechanisms of adherence of porcelain enamel to aluminum. Adherence appears to depend upon diffusion of aluminum into the enamel and further. 
the diffusion zone should be relatively free of reaction products for the enamel-metal system to retain good adherence after exposure to chemical solutions or to weathering. Round-robin testing of 6063 aluminum extrusions indicated that this alloy could be enameled if care were exercised in the selection of the enamel and the pretreatment.

BSS60. Hydraulic performance of a full-scale townhouse drainwaste- vent system with reduced-size vents. M. J. Orloski and R. S. Wyly, Nat. Bur. Stand. (U.S.), Bldg. Sci. Ser. 60, 43 pages (Aug. 1975) SD Catalog No. C13.29:2/60.

Key words: DWV; performance testing; reduced-size vents; trap-seal retention; venting; venting criteria; vents, reduced-size.

This report describes the experimental findings of tests on a full-scale two-story plumbing system with reduced-size vents under a range of operating conditions including tests with the vent terminals closed and the building drain submerged. Results indicate that dry vent piping in 1-2 story housing units can safely be smaller than presently allowed by design without jeopardizing the trap seals. On the basis of the current investigation and from earlier work on full-scale systems of substantially different geometry, criteria for sizing reduced-size vents are given for general application to conventional 1-2 stoly housing units. In addition to the practical evidence in terms of acceptable trap performance, the current study provided fundamental evidence of the excessive present design criteria. For the first time measurements were obtained which relate traditional design criteria (air flow and vent pressure) to presently recommended performance criteria (trap-seal retention) under dynamic conditions. These findings indicate that the vents can be sized on the basis of 1.5 in water gage (equals 372 pascals) suction in the vent rather than the 1.0 in W.G. (equals $248.8 \mathrm{~Pa}$ ) presently specified in the plumbing codes. Also air demands measured were significantly less than assumed in current practice for short stacks and for systems with vent networks.

BSS61. Natural hazards evaluation of existing buildings, C. G. Culver, H. S. Lew, G. C. Hart, and C. W. Pinkham, Nat. Bur. Stand. (U.S.), Bldg. Sci. Ser. 61, 958 pages (Jan. 1975) SD Catalog No. C13.29:2/61

Key words: Buildings; damage; disaster mitigation; dynamic analysis; earthquakes; hurricanes; natural hazards; structural engineering; tornadoes; wind.

A methodology is presented for survey and evaluation of existing buildings to determine the risk to life safety under natural hazard conditions and estimate the amount of expected damage. Damage to both structural and nonstructural building components resulting from the extreme natural environments encountered in earthquakes, hurricanes, and tornadoes is considered. The methodology has the capability of treating a large class of structural types including braced and unbraced steel frames, concrete frames with and without shear walls, bearing wall structures, and long-span roof structures. Three independent but related sets of procedures for estimating damage for each of the natural hazards are included in the methodology. The first set of procedures provides a means for qualitatively determining the damage level on the basis of data collected in field surveys of the building. The second set utilizes a structural analysis of the building to determine the damage level as a function of the behavior of critical elements. The third set is based on a computer analysis of the entire structure. All three sets of procedures are based on the current state of the art. The procedures are presented in a format which allows updating and refining. Numerical examples illustrating application of the procedures are included.

BSS62. Evaluation of structural properties of masonry in existing buildings (In preparation).
BSS63. Analysis of current technology on electrical connections in residential branch circuit wiring. W. J. Meese and R. L. Cilimberg, Nat. Bur. Stand. (U.S.), Bldg. Sci. Ser. 63, 23 pages (Mar. 1975) SD Catalog No. C13.29:2/63,

Key words: Contact resistance; electrical codes; electrical connections; fire safety; house wiring; materials properties; performance testing.

In the Operation BREAKTHROUGH research and demonstration program the U.S. Department of Housing and Urban Development became concerned with the inability to properly evaluate innovative electrical connections. Long life requirements, fire safety considerations, the lack of adequate technical information, and long established conventional practices and evaluation procedures have led to slow-changing regulations concerning electrical connections used in branch circuit wiring in housing. This report discusses the present methods of evaluating electrical connections, the technical parameters involved, and innovative electrical connection developments. Innovations involving electrical connections may lead to significant advancements in housing construction if it could be demonstrated that functional and safety requirements over the expected life of the electrical connections were adequately satisfied. Research is needed to enable prediction of long term performance of electrical connections based on the results of accelerated performance tests.

BSS64. Retrofitting existing housing for energy conservation: An economic analysis, S. R. Petersen, Nat. Bur. Stand. (U.S.) Bldg. Sci. Ser. 64, 76 pages (Dec. 1974) SD Catalog No. C13.29:2/64.

Key words: Benefit-cost analysis; building economics, building envelope; economic analysis; economic efficiency; energy conservation; engineering economics; insulation; life-cycle costs; marginal analysis; thermal efficiency.

This study examines the economic aspects of energy conservation techniques suitable for retrofitting into existing housing, including insulation, storm windows and doors, and weather stripping. The objective of this study is to determine that combination of techniques which will maximize net dollar savings in life-cycle operating costs for heating and cooling operations in existing homes, subject to specific climate conditions, fuel costs, and retrofitting costs. Using microeconomic marginal analysis we find that such a combination must be economically balanced (i.e., the ratio of savings to cost must be equal at the margin for each technique) and that each technique should be utilized up to the point where the present value of the life-cycle savings generated by the last increment will just cover the costs of that last increment. Thermal engineering data is combined with the economic analysis in a computer-assisted model which estimates such optimal combinations for a wide range of climatic conditions and fuel costs. These combinations include levels of application higher than what has been-previously recognized as "economical."

BSS65. Nonmetallic coatings for concrete reinforcing bars. J. R.

Clifton, H. F. Beeghly, and R. G. Mathey, Nat. Bur. Stand.

(U.S.), Bldg. Sci. Ser, 65, 42 pages (Aug. 1975) SD Catalog No. C13.29/2:65,

Key words: Bridge decks; chloride ions; concrete; corrosion; deicing salts; epoxy coatings; organic coatings; polyvinyl chloride coatings; steel reinforcing bars.

This work was undertaken to ascertain the feasibility of using organic coatings, especially epoxies, to protect the steel reinforcing bars embedded in concrete of bridge decks from rapid corrosion. This corrosion is caused by the chloride ions from the most commonly applied deicing salts, sodium chloride and calcium chloride. Altogether, 47 different coating materials were evaluated to some extent, consisting of 21 liquid and 15 powder epoxies; 5 polyvinyl chlorides; 3 polyurethanes; 1 polypropylene; 1 phenolic nitrile; and one zinc rich coating. The chemical and 
physical durabilities, chloride permeabilities, and protcctive qualities of coatings were assessed. The bonds between coatcd and uncoated bars and concrete were measured by both pullout and creep tests.

The results indicate that both epoxy and polyvinyl chloride coatings, if properly applied, should adequately protect stecl reinforcing bars from corrosion. However, only the epoxy coated bars had acceptable bond and creep characteristics when embedded in concrete. The powder epoxy coatings overall performed better than the liquid epoxies, and four powder epoxy coatings have been identified as promising materials to be used on reinforcing bars embedded in concrete decks of experimental bridges.

BSS66. Underground heat and chilled water distribution systems. T. Kusuda, Ed., Nat. Bur. Stand. (U.S.), Bldg. Sci. Ser. 66, 146 pages (May 1975) SD Catalog No. C13.29:2/66,

Key words: Corrosion of und erground pipes; district heating; hot and chilled water systems; insulation of underground pipes; specifications for underground systems.

This publication contains the keynote address and all the technical papers presented during the Symposium on Underground Heat and Chilled Water Distribution Systems, which was held on November 26 and 27, 1973 in Washington, D.C.

The Symposium was sponsored jointly by the National Bureau of Standards, the National Capital Chapter of the American Society of Heating, Refrigerating and Air-Conditioning Engineers, the Building Research Institute and the Association of Physical Plant Administrators

The subject matter covered in the papers includes energy, economics, design criteria, heat transfer, corrosion protection, specification, operation, and maintenance related to underground pipes

BSS67. Abnormal loading on buildings and progressive collapse. An annotated bibliography, E. V. Leyendecker, J. E. Breen, N. F. Somes, and M. Swatta, Nat. Bur. Stand. (U.S.), Bldg. Sci. Ser. 67, 60 pages (Jan. 1976) SD Catalog No. C13.29:2/67.

Key words: Abnormal loading; alternate path; annotated bibliography; bibliography; building code; building regulations; collapse; failures; progressive collapse; specific resistance.

This bibliography on the subjects of abnormal loading and progressive collapse is an annotated listing of articles that have appeared in the technical literature from 1948 through 1973. The entries have been arranged chronologically by year and alphabetically within years. Both subject and author indexes have been included. The references listed have been selected as most representative of the historical background and best representing the origin and present state-of-the-art of current practice without undue repetition of data.

References pertaining to characteristics, frequencies, incidents, tests, design procedures, and regulations for many types of abnormal loadings are included. Among these are various types of accidental impacts, construction loads, explosions, faulty practices, and extreme atmospheric loads. Heavy emphasis was placed on referencing applicable building codes and regulations pertaining to the subjects of progressive collapse and abnormal loadings. This bibliography also contains numerous references to contemporary professional opinion as expressed in editorials and discussions of the subject and, particularly, on the various regulations proposed. A large number of proposed analysis and design procedures, as well as applicable test results, are referenced. In addition to the general reference material, a careful search was made of the ten most recent

years (1964-1973) of Engineering News Record to identify and annotate possible progressive collapse examples from building failures reported by that publication.
B.) S68. Review of standards and other information on thermoplastic piping in residential plumbing. K. S. Wyly W J Parker, D. F. Korrer, J. K. Shaver, (J. ( Sherlin and $M$ Tryon, Nat. Bur. Stand. (U.S.), Bldg. Sc1. Ser. 6,8, 6,5 pakees (May 1975) SD) Catalog No. C 13.29:2/68.

Key words: Fire performance of piping; functional performance of piping; performance characteristics for piping; thermal/structural performance of piping; thermoplastic piping in plumbing.

The paper is a review of existing information on the physical characteristics of thermoplastic piping that are of particular in terest in considering its potential for use in rcsidential, above ground plumbing. The presentation is orrented to considerations of adequacy of functional performance of plumbing systems from the user's/owner's vicwpoint in contrast with the typical product-specifications orientcd format reflected in current stan dards.

Not only are the physical characteristics emphasized that re late most directly to the determination of functional performance of installed systems, but the importance of design and installation detail in the context is discussed.

In conclusion, this review indicates the need for better usc of existing knowledge as well as for some research and test development work particularly in the areas of thermal properties. response to building fires, and resistance to water hammer.

BSS69. NBSLD, the computer program for heating and cooling loads in buildings. (In preparation).

BSS70. Windows and people: A literature survey. Psychological reaction to environments with and without windows. $B$. L. Collins, Nat. Bur. Stand. (U.S.), Bldg. Sci. Ser. 70,93 pages (June 1975) SD Catalog No. C13.29/2:70,

Key words: Daylight; fenestration; psychological; solar glass; spaciousness; sunshine; view; windowless; windows.

An understanding of human requirements for windows in buildings can be developed through a survey of the literature on the reaction to environments with and without windows. Evaluation of the response to a variety of windowless situations reveals that although the attitudes toward a windowless space are often somewhat unfavorable, the most adverse reaction occurs in a small, restricted and essentially static environment. This sug gests that one function performed by a window is the addition of a dynamic, active quality to an interior environment. Consideration of the response to the actual presence of windows indicates that another essential function of a window is the provision of a view of the external world. Although almost any view is acceptable, there is some evidence that views with a high information content are preferable. In addition, windows admit illumination. in the form of daylight and sunshine which furnish a dynamic changing character to a room. Yet, the functions of windows extend beyond view and illumination to an enhancement of the basic character of a room, such that the mere presence of a win. dow may cause a room to appear more spacious. Finally, the optimum size and shape of a window for fulfilling these various functions is discussed.

BSS71. A proposed concept for determining the need for air conditioning for buildings based on building thermal response and human comfort. J. E. Hill, T. Kusuda, S. T. Liu, and F. J. Powell, Nat. Bur. Stand. (U.S.), BIdg. Sci. Ser. 7I, 155 pages (Aug. 1975) SD Catalog No. C13.29/2:71.

Key words: Air conditioning criteria; building thermal response; comfort indices; human comfort; predicted indoor habitability index.

Determining the need for air conditioning can be based on a wide variety of factors. To date, the only criteria that have been written and can be referenced are those of several federal organizations and many are not really criteria in the true sense of 
the word. They are guidelines to be used in the determination of fund allocation: in other words, provisions are made to air condition federal facilities in specific geographical locations if pertinent weather characteristics of that locality meet certain requirements. This paper presents the concept that a true criteria can be established based both on weather characteristics of the locality as well as characteristics of the building or structure under consideration.

The paper gives the details of a study showing the feasibility of such a scheme. A simulation was made of two proposed residences in several geographical localities. For the simulation, actual hour-by-hour weather data was used in conjunction with a sophisticated computer program. The results revealed for the non air-conditioned spaces, the extent and duration of undesirable indoor conditions based upon generally accepted comfort indices. The concept of a new "comfort" or "discomfort" index called Predicted Indoor Habitability Index (PIHI) is introduced. The authors indicate the way in which a criterion could be established that would be in the form of tables, indicating for a given specified building and geographical locality, whether mechanical cooling should or should not be installed.

BSS72. Fire endurance of gypsum board walls and chases containing plastic and metallic drain, waste and vent plumbing systems. W. J. Parker, M. Paabo, J. T. Scott, D. Gross, and I. A. Benjamin, Nat. Bur. Stand. (U.S.), Bldg. Sci. Ser. 72, 114 pages (Sept. 1975) SD Catalog No. C13.29/2:72.

Key words: ABS; DWV; tïre endurance; fire spread; fire test; gases; plastic pipe plumbing; PVC; smoke.

The use of plastic pipe in plumbing systems of multiple-occupancy buildings has raised considerations regarding fire safety. To provide needed data, ten full-scale fire endurance tests were performed involving a total of 39 plumbing chase and wall assemblies containing plastic and metal drain, waste, and vent (DWV) systems typical of installations serving one or two story buildings.

Two tests were conducted using plumbing chase configurations simulating kitchen sink drain systems. The PVC DWV piping in these installations did not contribute to spread of fire from one side of the construction to the other.

Six fire endurance tests were conducted in which the performance of ABS, PVC, copper, and iron was compared directly in kitchen sink drain systems as installed in wood-stud and gypsum-board walls. The stacks ranged from 2 inch to 4 inch in diameter and the laterals from $1-1 / 2$ inch to 4 inches. In these tests it was noted that the plumbing configuration and wall construction details, particularly the sealing of plumbing penetrations, seriously affected the fire endurance of the barrier. Satisfactory performance was achieved when certain conditions were met.

In the two tests involving nominal 2 by 4 steel-stud-and-gypsumboard walls it was determined that the one-hour fire resistance rating of the wall was reduced considerably when ABS or PVC DWV was installed within it using the construction details described in this report. These details included back to back 1-1/2-in diameter laterals feeding directly into 2-in diameter stacks.

BSS73. Structural performance of masonry walls under compression and flexure (In preparation).

BSS74. The buffeting of tall structures by strong winds, E. Simiu and D. W. Lozier, Nat. Bur. Stand. (U.S.), Bldg. Sci. Ser. 74, 90 pages (Oct. 1975) SD Catalog No. C13.29:2/74.

Key wor̈ds: Accelerations; buffeting; building codes; buildings; deflections; dynamic response; gust factors; structural engineering; wind engineering; wind loads.

Certain shortcomings of current procedures for computing alongwind structural response have been shown to result in unrealistic estimates of tall building behavior under the action of strong winds. Differences between predictions of fluctuating response based on various such procedures may be as high as $200 \%$. In recent years, advances in the state of the art have been made which provide a basis for significantly improved alongwind response predictions. The purpose of the present work is to present a procedure for calculating alongwind response which incorporates and utilizes these advances. The basic structural, meteorological and aerodynamic models employed are described, and expressions for the alongwind deflections and acclerations, consistent with those models, are derived. A computer program is presented for calculating the alongwind response of structures with unusual model shapes or for which the contribution of the higher modes to the response is significant. For more common situations, a simple procedure is presented which makes use of graphs and on the basis of which rapid manual calculations of the alongwind deflections and accelerations can be performed. Numerical examples are given to illustrate the use of the computer program and of the graphs. Results of numerical calculations are used to discuss some of the approximations and errors inherent in the models employed.

BSS75. History of building research at NBS: 1968 to 1974 (Provisional title, manuscript in preparation).

BSS76. Analysis of reinforced concrete beams subject to fire (in preparation)

BSS77. Acoustical and thermal performance of exterior residential walls, doors and windows. H. J. Sabine, M. B. Lacher, D. R. Flynn, and T. L. Quindry, Nat. Bur. Stand. (U.S.), Bldg. Sci. Ser. 77, 170 pages (Nov. 1975) SD Catalog No. CI3.29/2:77.

Key words: Acoustics; air infiltration; air leakage; architectural acoustics; building acoustics; doors; energy conservation; heat loss from buildings; heat transfer; sound transmission loss; thermal resistance; thermal transmittance, windows.

Laboratory tests of sound transmission loss, thermal transmittance, and rate of air leakage were conducted on full scale $(9$ feet high $\times 14$ feet wide; $2.7 \times 4.3$ meters) specimens of typical residential exterior wall constructions, either unbroken or penetrated by a door or window. The walls were of wood frame construction with gypsum board drywall interior finish and exterior finishes of wood siding, stucco, or brick veneer. Additional acoustical tests were run on a number of individual doors and windows. A total of 109 acoustical test and 48 thermal tests are reported. The resultant data are compared with literature data on similar constructions. Correlations developed among the several quantities measured will assist more rational design where both energy conservation and noise isolation must be considered.

BSS78. Pre-design analysis of energy conservation options for a multi-story demonstration office building. T. Kusuda, J. E. Hill, S. T. Liu, J. P. Barnett, and J. W. Bean. Nat. Bur. Stand. (U.S.), Bldg. Sci. Ser. 78, 64 pages (Nov. 1975) SD Catalog No. $\mathrm{Cl} 3.29 / 2: 78$.

Key words: Building design; building energy analysis; energy conservation options; heating and cooling load calculation; energy design optimization.

The design phase of the GSA-Manchester Building included extensive analysis of the building design and operation to determine the potential for energy conservation. Described in this report are highlights and a summary of the calculations performed during the design phase. The analysis included a study of the effect of the exterior snell, ventilation rate, lighting and occupancy levels, room temperature controls, and nighttime flushing of the building using outdoor air on the predicted yearly energy consumption of the building.

BSS79. Energy conservation potential of modular gas-fired boiler systems. G. E. Kelly and D. A. Didion. Nat. Bur. Stand. (U.S.), 
Bldg. Sci. Ser. 79, 54 pages (Dec. 1975) SD Catalog No. C13.29:2/79.

Key words: Boiler oversizing; efficiency versus heating load; modular boilers; modular concept; seasonal efficiency.

The modular concept of boiler operation was examined in a laboratory test of five gas-fired, cast iron, hydronic boilers. Four of the boilers, each having an input rating of 85,000 BTU per hour, were arranged so that they could either be operated like a single boiler (i.e., all of the boilers either on or off) or as a modular installation in which the boilers are sequentially fired to match the number in operation with the heating load. The fifth boiler had an input rating of 300,000 Btu per hour and was operated as a single boller installation. Efficiency versus heating load curves were obtained for the single boiler installation, the four small brolers run l ke a single boiler and the modular installation operated with and without water flowing through the "idle" modules. These elficiency curves were then used to theoretically predict the effect of the modular croncept and boiler oversizing on the seasonal efficiency of gas-fired heatung plants. It was found that under certain conditıons the use of a gasfired modular boiler installation instead of a single large boiler could result in considerable energy savings.

\section{TECHNICAL NOTES}

Technical Notes present data which are complete in themselves but are not as comprehensive in scope or as definitive in treatment of the subjects as reported in Building Science Series.

TN231. Solar heating, radiative eooling, and thermal movement. Their effeets on built-up roofing, W. C. Cullen, Nat. Bur. Stand. (U.S), Tech. Note 231, 33 pages.

Key words: Built-up roofing; nighttime cooling; radiative cooling; solar heating; thermal movement.

Twenty different built-up roof construction specimens, covered with five surfacing materials, were subjected to natural solar heating and nighttime cooling. The temperatuits and temperature changes observed during winter and summer exposures are discussed. The data indicate that the temperature attained in a roof membrane is influenced by the absorptance and emissivity of the surface as well as the thermal and physical properties of the substrate to which the roofing is applied. The data show that roofings placed over insulation may be heated to a temperature of $80^{\circ} \mathrm{F}$. above ambient due to solar heating and may be sub-cooled as much as $20^{\circ} \mathrm{F}$. below the ambient due to radiative cooling. The thermal movements which occur in the components of a roof system due to temperature change are discussed in relation to built-up roof performance and failures. Thermal expansion data are presented for some composite bituminous membranes. The data show that these membranes undergo greater thermal movements than most other components of a roof system and the rate of expansion is not linear but decreases as the temperature is increased.

TN253. Disclosures on a plumbing vent manifold, a microadjuster, a glass joint or stopeoek, and a miniature puller, D. Robbins, editor, Nat. Bur. Stand. (U.S.), Tech. Note 253, 9 pages

Key words: Devices, manifold; plumbing system; vent.

This Note presents four devices embodying interesting and unusual solutions to problems prevalent in their respective arts. These devices, developed at the National Bureau of Standards and the U.S. Weather Bureau, comprise a vent manifold for a plumbing system; a micro-adjuster providing purely rectilinear motion; a miniature gear, flange and bearing puller, and a glass joint or stopcock preventing capillary action.

TN473. Laboratory-field comparison of built-up roofing membranes, T. H. Boone, L. F. Skoda, and W. C. Cullen, Nat. Bur. Stand. (U.S.), Tech. Note 473, 15 pages (Dec. 1968).

Key words: Bituminous adhesive; bituminous built-up membranes; engineering properties; laboratory-field comparison; strength-thickness.
The values of breaking load, elongation and thermal expansion of nine bituminous built-up membranes prepared by roofing contractors under field conditions and by technicians in the laboratory were measured at subfreezing temperatures. The data indicated that the field-prepared specimens agreed favorably with laboratory-prepared specimens, although the samples from the field frequently reflected higher values for thermal-shock resistance than did their laboratory-prepared counterparts. The higher values were attributed to the smaller amounts of bitumen used between the plies of the field specimens. The results appeared to support the validity of the application of the "strengththickness rule" to bituminous built-up membranes.

TN477. The performance of roofing made with Asplund felts, $\mathrm{S}$. H. Greenfeld, Nat. Bur. Stand. (U.S.), Tech. Note 477.27 pages (Mar. 1969).

Key words: Asphalt; Asplund; felt; mineral-surfaced roll roofing; shingles; wood fibers.

A study of the durability of roofing made with Asplund wood fibers was conducted from 1942 to 1967 . Concentrations of 0 to 60 percent wood fibers (oak or pine) prepared by three variations of the Asplund process were evaluated. All the mineral-surfaced roll roofings and shingles were performing well after 25 years, with only four specimens showing more deterioration than the controls (only rags and paper in their felts). No differences in performance could be related to the felt composition.

TN558. Lubbock tornado: a survey of building damage in an urban area, N. F. Somes, R. D. Dikkers, and T. H. Boone. Nat. Bur. Stand. (U.S.), Tech. Note 558, 38 pages (Mar. 1971).

Key words: Anchorage; building performance; disaster mitigation; glazing; hailstones; masonry; mobile homes; roofs; structural engineering; wind load.

The Building Research Division of the National Bureau of Standards' Institute of Applied Technology sent a three-man team to investigate the damage to buildings and other structures caused by the tornado which struck Lubbock. Texas. on May I l, 1970. The team members - the authors of this report-carried out photographic surveys on the ground and from a helicopter on the days of May 14, 15, and 16, 1970. The report is based largely on data gathered during this period but includes some data provided by other agencies and individuals whose assistance is acknowledged in the report. The report concludes that current good practice in the design and construction of buildings and mubile homes would have greatly reduced the damage observed at Lubbock. It also notes that natural disasters provide full-scale tests of buildings and urges the development of performance criteria with respect to wind loads for certain building elements.

TN563. Surface pressure fluctuations near an axisymmetrie stagnation point, R. D. Marshall, Nat. Bur. Stand. (U.S.). Tech. Note 563.67 pages (Aug. 197I). 
Key words: Disk; pressure fluctuations; stagnation point; turbulence.

Surface pressure fluctuations on a circular disk placed normal to a turbulent air stream have been investigated. Turbulence intensities of approximately $10 \%$ were produced by a coarse grid installed at the test-section entrance. The turbulent field in the neighborhood of the disk was homogeneous and nearly isotropic.

Experimental results indicate that existing linear theories which do not consider distortion of the flow fail to predict the nature of surface pressure fluctuations on a bluff body. Only for wavelengths which are large compared to the body do these theories yield satisfactory results. A strong attenuation of the high frequency components occurs as the flow stagnates. This is xccompanied by a transfer of energy from short to long wavelengths. The opposite effect is observed as the flow attains a radial direction and approaches the edge of the disk. A neutral wavelength which undergoes little change in energy was observed. Integral scales of surface pressure fluctuations are much larger than the lateral integral scale of the free-stream turbu'ence.

Pressure-velocity correlations indicate the existence of two distinct regions, an inner region in which correlations and opimum delay times exhibit considerable change along the radius If the disk, and an outer region where there is little dependence on radial distance. Maximum values of the optimum correlations are found in the outer region. There is qualitative agreement between the experimental results and theoretical predictions which consider the effect of vortex stretching.

TN569. Hurricane Camille - August 1969. A survey of structural damage along the Mississippi Gulf Coast, R. D. Dikkers. R. D. Marshall, and H. C. S. Thom, Nat. Bur. Stand. (U.S.), Tech. Note 569.71 pages (Mar. 1971).

Key words: Buildings; disaster mitigation; failure; hurricanes; mobile homes; roofs; structural engineering; tides; wind.

One week after Hurricane Camille devastated the MississippiLouisiana Gulf Coast with $125 \mathrm{mph}$ winds and 20-ft tides on $\mathrm{Au}$ gust 17, 1969. a four-man NBS team investigated the damage to buildings and other structures. This report presents photographic survey data from this investigation along with additional data on wind speeds and storm surge. Based on these data, suggestions are mate pertaining to the improvement of building design and construction practices.

TN706. Structural performance evaluation of innovative building. systems, F. Y. Yokel and N. F. Somes, Nat. Bur. Stand. (U.S.), Tech. Note 706, 16 pages (Aug. 1972).

Key words: Building; connections; housing; neoprene; performance criteria; performance evaluation; performance testing; reinforced concrete; standard tests; structure, testing.

Considerable attention has recently been focused on the development of performance criteria. Performance criteria are presently used in the U.S. by the Building Research Division of the Institute for Applied Technology, National Bureau of Standards, to evaluate innovative building systems.

While building codes and design standards are usually related to specific building materials and design solutions, performance criteria are derived from user requirements and are independent of specific teclınological solutions.

Many attributes inherent in traditional building systems which are acceptable to the user may not be present in untried innovative systems. The performance criteria therefore address themselves to many aspects of structural performance which are not considered in present codes and design standards.

The successful application of performance criteria depends $\mathrm{cn}$ the feasibility of evaluating compliance.

Performance can be evaluated by analysis by judgment based un past experience, or by physical simulation. Deterioration with time must be considered, and performance criteria are viewed as minimum requirements which should be met at any time during the service life of a str'icture. An example is presented where physical testing was used to evaluate the performance of a highrise housing system.

TN707. Three-year inspection of nature-tone porcelain enamels on steel, M. A. Baker, Nat. Bur. Stand. (U.S.), Tech. Note 707, 16 pages (Dec. 1971).

Key words: Acid resistance; color; continuity of coating; porcelain enamel; weather resistance.

A weather exposure test on nature-tone porcelain enamels on steel was initiated by the National Bureau of Standards and the Porcelain Enamel Institute in 1966. Laboratory measurements for changes in gloss and color were made after the enamels had been exposed for $0.5,1$ and 3 years at Kure Beach, N.C., Miami, Fla. and Gaithersburg, Md. The average gloss and color retained for all 450 specimens exposed at 3 sites for 3 years were 90.5 and 99.1 respectively. There was a tendency for the enamels exposed at the marine sites to rust around pinhole-type defects. Scanning electron microscope studies of these defects showed a layer of readily corrodible enamel on the bottom of the defects. A highvoltage test for continuity of coating was effective in detecting specimens that were apt to rust during the first year's exposure.

TN708. Interlaboratory evaluation of smoke density chamber, $T$.

G. Lee, Nat. Bur. Stand. (U.S.), Tech. Note 708, 80 pages (Dec. 1971).

Key words: Building materials; fire tests; interlaboratory tests; optical density; round robin; smoke; smoke density chamber; statistical analysis.

Results are reported of an interlaboratory (round-robin) evaluation of the smoke density chamber method for measuring the smoke generated by solid materials in fire. A statistical analysis of the results from 10 material-condition combinations and 18 laboratories is presented. For the materials tested, the median coefficient of variation of reproducibility was 7.2 percent under non-flaming exposure conditions and 13 percent under flaming exposure conditions. A discussion of errors and recommendations for improved procedures based on user experience is given. A tentative test method description is included as an appendix.

TN710-1. Building research translation: Account of the principles of modular coordination: Industrialization in building, $G$. Blachère, Nat. Bur. Stand. (U.S.), Tech. Note 710-1, 15 pages (Mar. 1972).

Key words: Conventions; dimensional coordination; industrialized production; modular coordination; tolerance.

This paper is translated from the French original and is published under the Building Research Division/Centre Scientifique et Technique du Bâtiment information exchange program.

Modular coordination is indispensable to the industrialized production of units for assembly in buildings. It must be subject to the limitations which are strictly necessary to achieve this end. A large module must be chosen, the reference for the coordinating dimensions must be fixed, and the tolerance problem solved. This is the theme of the report.

TN710-2. Building research translation: An investigation of the protection of dwellings from external noise through facade walls, P. Gilbert, Nat. Bur. Stand. (U.S.), Tech. Note 710-2, 26 pages (Mar. 1972)

Key words: Facade; noise; sound insulation; sound pressure level; walls.

This paper is translated from the French original and is published under the Building Research Division/Centre Scientifique et Technique du Bâtiment information exchange program. 
An investigation was conducted to determine to what extent the installation of balconies and loggias at various angles of elevation from a noise source could improve the sound insulation of a facade wall. Measurements of the sound pressure level were first carried out on two types of facade, one incorporating traditional window joinery and the other incorporating sealed glazing. Following this, the sound insulation provided by facades fitted with open and closed balconies and loggias (with and without sound absorbent materials applied) was determined and compared with the previous measurements. 1t was found that for angles of elevation greater than $30^{\circ}$, both the closed balcony and the loggia fitted with absorbent materials appreciably improve the sound insulation, whereas the open balcony does not.

TN710-3. Building research translation: New regulation on ventilation of dwellings, fixed heating acilities, and flues. A. Chalandon, M. Schumann, and P. Dechartre, Nat. Bur. Stand. (U.S.), Tech. Note 710-3, 46 pages (May 1972).

Key words: Air infiltration and extraction, airtightness; discomfort index; duct system, collective and individual branch; flow rates; noise; pressure-loss-depression; thermal convection; ventilation.

Following studies on the ventilation of dwellings, the results of which have been published in CSTB "Cahiers," the CSTB has proposed certain changes in the regulations governing the ventilation of dwellings. At the same time, in the light of recent statistics on secondary emergency and relief heating, changes in the regulations governing fixed heating installations and flues were proposed. These proposals led to a new revised text of the French regulations, which we publish below, together with a new chapter on "ventilation" from the CSTB Technical Report.

TN710-4. Building research translation: Thermal comfort requirement adjacent to cold walls - application to glazed opening, J. Anquez and M. Croiset, Nat. Bur. Stand. (U.S.), Tech. Note 710-4, 54 pages (May 1972).

Key words: Curtains, effect of; environmental conditions; glazed openings; human response; thermal comfort requirement.

This paper is translated from the French original and is published under the Building Research Division/Centre Scientifique et Technique du Bâtiment information exchange program.

The thermal comfort of an individual inside a closed room in winter is essentially a function of the temperature of the air with which the human body transfers heat by convection, and also of the temperature of the room's walls with which the human body transfers heat by radiation. The presence of glazed openings (windows) which in winter are generally the coldest walls in a residence room, can thus be a source of discomfort.

The first part of the paper reports research conducted with a view to determining the thermal comfort requirement near to a cold wall. The research led to the definition of the "air-radiation requirement" for a plane surface element parallel to the wall, the requirement being that, at about $1 \mathrm{~m}$ from the wall, this temperature must remain above 16 or $17^{\circ} \mathrm{C}$.

The second part of the paper studies ways of satisfying the requirement near to glazed openings in a living room in winter. The solution to the problem will depend on numerous factors: climatic zone, average temperature of the room, position of heat sources, dimensions of the openings, type of glazing (single or double), presence or absence of curtains or screens.

TN710-5. Building research translation: Use of an air-to-air heat exchanger to recover heat from air exhausted by mechanical ventilation, P. Garrivier, Nat. Bur. Stand. (U.S.), Tech. Note 710-5, 62 pages (July 1972).

Key words: Exchanger dimensions; frost formation: heat exchanger; heating costs; mechanical systems pollution. pressure loss; ventilation.

When a building is equipped with a mechanical system which both exhausts and supplies outdoor air, it may he prolitable to in. stall a heat exchanger between the two circuits. The ( $S \mathrm{I} / \mathrm{B}$ has perfected such an exchanger, which meets the two principal requirements of the problem: good efficiencies and elimination of the polluted air intake. A method of calculating the optimal dimensions of the exchanger has also been devised.

TN710-6. Building research translation: Ventilation air inlets for dwellings, $M$. Croiset and $H$. Bizebard. Nat. Bur. Stand (U.S.). Tech. Note $710-6.62$ pages (Jan. 1973) SI) Catalog No. C13.46:710-6.

Key words: Air inlet; discomfor Index. draft: outside wall: ventilation; wind.

Preliminary tests have shown the existence of a "discumfort index," a function firstly of the difference between the tempera ture in the room and the temperature of the air current and. secondly of the speed of the air stream. "The permissihle limit for this index has been fixed at $2{ }^{\circ} \mathrm{C}$. at least in that part of the ruom situated more than $20 \mathrm{~cm}$ from the outside walls and less than 2 meters in height.

Systematic artificial tests have resulted in satisfactory solutions being found for the air inlets into the outside walls.

- An elongated aperture placed above a radiator and fitted with a deflector so that cold air entering the room mingles with the ascending warm air current.

- An aperture located behind a convector heater so that the same result is achieved as in the case of the radiator.

- A row of apertures located along the heated ceiling placed so that entering air is diffused into the warm air before reaching the occupied zone.

Some calculations aimed at determining the orders of magnitude of the necessary sections and the possible force of the air current in a high wind. have revealed the need for a manual or an automatic regulator where a wall is exposed to wind.

TN710-7. Building research translation: Weak thermal points or thermal bridges, J. Berthier. Nat. Bur. Stand. (U.S.). Tech.

Note 710-7.96) pages|(May 1973) SD Catalog No., C13.46:710-7

Key words: Floors and panels: moisture condensation: thermal bridges; thermal insulation: U-values of walls.

Uniformity of temperature on the internal face is one of the essential hygrothermal qualities for a wall.

Cold bridges, which are the cause of uneven temperatures. constitute a weakness which ought to be corrected.

The author describes a large number of tests carried out with various types of wall (dense walls and lightweight panels) in order to assess the importance of cold bridges and to determine the effectiveness of possible remedies: he shows that the accepted theory used in the calculation of U-coefficients is unsatisfactory when estimating surface temperatures. The results obtained can be explained. however. by means of two simple hypotheses: on the basis of these there are practical rules which can be used in establishing the importance of cold bridges, and recommendations for reducing them.

TN746. Estimates of the nature and extent of lead paint poisoning in the United States, J.F. Gilsinn, Nat. Bur. Stand. (U.S.), Tech. Note 746, 151 pages (Dec. 1972) SD Catalog No. C13.46:746.

Key words: Childhood diseases; estimation; health problems; lead; lead paint, lead paint poisoning; lead poisoning; mathematical modeling; models; urban health problems.

This report evaluates the nationwide magnitude and extent of pediatric lead poisoning resulting from the ingestion of lead- 
based paint. Estimates are given of the number of children who have elevated blood lead levels ( $40 \mu \mathrm{g}$ or more of lead per $100 \mathrm{ml}$ of whole blood) in each of 241 Standard Metropolitan Statistical Areas throughout the country. The mathematical models used to obtain these estimates are documented together with the assumptions and data upon which those models are based. Partial validation of both models and assumptions is also reported

TN755. Some aspects of the setting and hardening of gypsum plaster, J. R. Clifton. Nat. Bur. Stand. (U.S.). Tech. Note 755 33 pages (Jan. 1973) SD Catalog No. Ci3.46:755.

Key words: Colloidal theory; crystallization theory: gypsum; hydration; induction period; plaster of paris; setting mechanisms.

The mechanisms by which gypsum plaster sets and hardens have been investigated and the results generally are consistent with the crystallization theory. No evidence for the presence of colloidal intermediates has been found. The crystallization theory is modified to include, as an intermediate species, solvated calcium sulfate hemihydrate molecules. Evidence is presented that supports the belief that more than one reaction is responsible for the setting and hardening of gypsum plaster.

The roles of accelerators and retarders have been studied by calorimetric. differential thermal analysis. and scanning electron microscopic techniques. The cation is more effective than the anion in accelerating the setting and hardening of gypsum plasters; the catalytic order follows the sequence $\mathbf{M}^{+} \mathbf{M}^{2+} \mathbf{M}^{3+}$ Small amounts of retarders can severely retard the setting and hardening processes.

Influences of temperature, impurities, and production conditions on the setting rates of gypsum plasters are discussed.

TA 757. The smoke density chamber method for evaluating the potential smoke generation of building materials, T. G. Lee, Nat. Bur. Stand. (U.S.), Tech. Note 757, 20 pages (Jan. 1973) SD Catalog No C13.46:757.

Key words: Building materials; fire; fire services; smoke; smoke density chamber; smoke potential; test method; visibility.

The paper reviews the Smoke Density Chamber Test Method and illustrates its use and application to assess smoke generation of building materials in fire situations. It shows how test results may aid the Fire Services and code authorities in evaluating and reducing the potential light-obscuration hazard of smoke in buildings. An example is given for calculating visibility in a simplified fire situation involving material of known smoke generation. The smoke generation of some common interior finish and construction materials is given.

TN759. The NBS lead paint poisoning project: Housing and other aspects, H. W. Berger, Nat. Bur. Stand. (U.S.), Tech. Note 759, 25 pages (Feb. 1973) SD Catalog No.C13.46:759.

Key words: Hazard elimination; lead analysis; lead paint; lead poisoning.

The National Bureau of Standards is providing technical support required by the Department of Housing and Urban Development to carry out its research responsibilities under PL 91-695, The Lead Based Paint Poisoning Prevention Act. The program at NBS has involved three major areas of research: (1) an estimation of the numbers of children at risk and with excessive body burdens of lead and the geographical distribution of those children; (2) the capabilities and characteristics of analytical methods for the detection of lead in paint and other building materials; and (3) the identification and evaluation of materials, techniques and systems for removing or eliminating the lead paint hazard from housing. This paper is a brief presentation of the activities and conclusions of NBS in the areas listed above.
TN768. Nonmetallic coatings for concrete reinforcing bars. Coating materials, J. R. Clifton, H. F. Beeghly, and R. G. Mathey, Nat. Bur. Stand. (U.S.), Tech. Note 768,40 pages (Apr. 1973) SD Catalog No. C 13.46:768.

Key words: Chlorides; concrete; corrosion; epoxy coatings; organic coating; steel reinforcing bars

This work was undertaken in order to determine the feasibility of using organic coatings, especially epoxies, to protect steel reinforcing bars embedded in concrete from accelerated corrosion attributed to the depassivation of steel by chloride ions.

Coatings have been evaluated on the basis of their chemical and physical durabilities as weil as their protective qualities. In this study, attention has also been directed to the following: application methods; surface preparation of the steel reinforcing bar; and site of application.

TN770. Hazard elimination procedures for leaded paints in housing, D. Waksman, L. F. Skoda, and E. J. Clark, Nat. Bur. Stand. (U.S.), Tech Note 770, 99 pages (May 1973)SD|Catalog No. C13.46:770.

Key words: Building material; housing; leaded paint; lead hazard elimination methods; lead paint poisoning; performance attributes.

Methods currently used to control the hazard caused by leaded paints in housing vary in effectiveness from complete elimination of the hazard to a minimal effort that runs a high risk for recurrence of the hazard. A series of guidelines has been drawn up to acquaint municipal planners and other decision makers with the factors that should be considered in implementing a hazard elimination program. Formats are presented to describe attributes of the various methods that should be considered.

TN775. Coordinated evaluation system (CES) project, model documentation for building regulation, R. D. Dikkers, Nat. Bur. Stand. (U.S.), Tech. Note 775 (16 pages). SD Catalog No. C13.46:779

Key words: Building regulation; evaluation; inspection; manufactured building; mobile homes; model documents; state-of-art study.

Background information, objectives and the current status (February 1973) of various tasks and reports pertaining to the Coordinated Evaluation System (CES) project are described. The goal of the CES Project is to develop model informational documentation that will assist state building regulatory agencies in establishing a coordinated and uniform evaluation, approval and inspection system. The model documentation will be related to the following building regulatory functions: (1) data submittal, (2) evaluation, (?) approval, (4) compliance assurance (inspection), (5) installation, and (6) owner information.

TN778. Guidelines for selection of and use of foam polyurethane roofing systems, W. C. Cullen and W. J. Rossiter, Jr., Nat. Bur. Stand. (U.S.), Tech. Note 778, 46 pages (May 1973) SD Catalog No. C 13.46:778.

Key words: Durability; fire safety; performance guidelines; protective coatings; rigid polyurethane; roofing.

The use of spray-in-place polyurethane foam for roofing application in the United States is increasing at a rapid rate. Little unbiased information is available to guide the user in the specification, selection. application, and performance of this innovative roofing system. This report describes the current state-of-the-art of rigid polyurethane technology as applied to roofing systems. The performance parameters as observed during the field survey are discussed in terms of protective coatings, fire safety, durability and problem areas. Guidelines to assist the supplier and user alike in the use and selection of polyurethane foam roofing 
systems are given. Finally, a performance specification for spray-in-place polyurethane foam roofing system is suggested.

TN783. Durability and maintenance as related to the selection of flooring, W. C. Wolfe, R. F. Roberts, and M. Russell, Nat. Bur. Stand. (U.S.), Tech. Note 783, 68 pages (Aug. 1973) SD Catalog No. C13.46:783.

Key words: Carpets; durability: economics; field studies; flooring; floor coverings; life-cost; maintenance; user needs.

This report is addressed to the problem of selection and maintenance of flooring to the best advantage in terms of durability type and severity of service, appearance, comfort, and safety. The selection of flooring is discussed with respect to service life maintenance, obsolescence, and trade-off advantages. Two articles by maintenance administrators include information and discussion helpful in determining maintenance cost, trade-offs, and selection of flooring for different types of service. Field observations and preliminary field tests by the National Bureau of Standards indicate areas in which research is needed, as in laboratory tests for wear and slip resistance. Observations and field tests are impracticable to use for procurement.

This report is helpful in the selection and maintenance of flooring and floor finishes. More important, it points up areas in which research is needed to develop information for this purpose.

TN789. Technical options for energy conservation in buildings, National Conference of States on Building Codes and Standards and National Bureau of Standards Joint Emergency Workshop on Energy Conservation in Buildings held at the U.S. Department of Commerce Washington, D.C., June 19 , 1973, Nat. Bur. Stand. (U.S.), Tech. Note 789, 184 pages (July 1973) SD Catalog No. C13.46:789.

Key words: Building design; energy conservation; mechanical systems.

The purpose of this report is to provide reference material on the technical options for energy conservation in buildings. It was prepared for the National Conference of States for Building Codes and Standards-National Bureau of Standards Joint Emergency Workshop on Energy Conservation in Buildings held at the U.S. Department of Commerce in Washington, D.C. on June $19,1973$.

This report describes actions pertinent to existing buildings and new buildings. Regarding existing buildings, principal topics include summer cooling, winter heating, and other energy conserving features-i.e., insulation, fenestration, lighting, appliances, domestic hot water, and human comfort. Suggested actions include those which can be accomplished voluntarily or without expense, and also actions which require some modest effort or expense on the part of the building owner or occupant.

Regarding new buildings, energy conservation actions are described that deal with building design and mechanical systems. The report concludes with a summary of mechanisms for implementation of such actions and criteria for use in evaluation of them.

TN789-1. Emergency workshop on energy conservation in buildings. S. A. Berry, Nat. Bur. Stand. (U.S.), Tech. Note 789-1, 31 pages (July 1975) SD Catalog No. C13.46:789-1,

Key words: Building codes; buildings; energy conservation; standards.

This report contains the non-technical presentations given at the National Conference of States on Building Codes and Standards/National Bureau of Standards Joint Emergency Workshop on Energy Conservation in Buildings.

Presentations included in this document are those of other Federal Agencies, States, technical societies and industry organizations.
This document is a companion document to Nis I echnical Note 789, "rechnical Options for I:nergy (onservatuon in Buildings.

TN794. NBS corridor fire tests: Energy and radiatun models, IC.W. Fung, R. Suchomel, and P. L. ()glesby, Nat Bur. Stand. (U.S.), Tech. Note 794, 127 pages (Oct. 1973) SDCatalog No. C 13.46:794

Key words: C eiling radiation; corridor fires; critical energy input; flame spread, calculation, and observations: floor covering evaluations; heat balances; heat transfer mechanisms; models, energy balance, radiation, and scaling.

The NBS corridor fire program is a continuing program to investigate the growth and spread of fire and smoke through a corridor when fire is initiated in an adjoining room. Due to recent fires involving floor coverings [1], and controversies over current floor covering flammability test methods, floor coverings have received special attention during the first phase of the corridor fire program. Results of the NBS program on corridor fires are presented under the unifying concepts of energy and radiation models. The major findings are: (1) One type of carpet fire hazard has been identified as the rapid flame spread over pile surface: (2) The dominant mechanism that causes this flame spread is energy transfer from ceiling radiation. This is substantiated by measurements and calculations; (3) Carpet evaluation by critical cumulative energy input into the corridor has been found to be feasible and informative in terms of heat transfer mechanisms; (4) Finally, a radiant panel test appears to be a promising approach to simulate the corridor environment for second generation flooring tests.

TN807. Building performance in the 1972 Managua earthquake, R. N. Wright and S. Kramer, Nat. Bur. Stand. (U.S.). Tech. Note 807, 155 pages (Nov. 1973) SD Catalog No. C13.36:807.

Key words: Building codes; buildings; disaster mitigation; earthquakes; hazards; natural disasters; structures.

Following the Managua, Nicaragua, earthquake of Dec. 23. 1972, a team of engineers representing the U.S. Department of Commerce's National Bureau of Standards (NBS) and the National Academy of Engineering (NAE) performed field investigations in Managua, Nicaragua, from Dec. 26, 1972, to Jan. 4. 1973. The objectives were to assist the Nicaraguan government in surveying major buildings to determine whether each was suitable for emergency use, repairable, or appropriate for clearance. The team also viewed the patterns of successful performance and damage to identify needs for improvements in building practices for mitigation of earthquake hazards and opportunities for more detailed investigations which could provide information for future improvements in practices. In general, the damages cannot be attributed to unusual intensities of ground shaking or severity of surface faulting. Most damages appeared to result from deficiencies in building practices; deficiencies which had been exhibited many times before in previous earthquakes. deficiencies which would be avoided by implementation of up-to-date provisions for earthquake resistant design and construction. However, Managua did not emplov a building code with seismic design requirements appropriate to its earthquake risk, and furthermore, did not have a building regulatory system capable of effective implementation of its building code provisions. This report documents the observations of damages by the NBS/NAE team and points out relationships to inadequacies in the building practices employed. Most of these inadequacies have been well known: however, the Managuan experience may serve as an incentive to improvement of building practices $i_{1}$ many other areas which are subject to substantial earthquake risks and have not consistently accounted for these risks in their building codes and building regulatory system. 
TN808. Potential systems for lead hazard elimination: Evaluations and recommendations for use, D. Waksman, J. B. Ferguson, M. Godette, and T. Reichard, Nat. Bur. Stand. (U.S.), Tech. Note 808, 192 pages (Dec. 1973) SD Catalog No. C13.46: 808.

Key words: Abrasion; adhesion; colorfastness; covering; flame spread: flash point: impact resistance; lead paint poisoning: materials: performance; properties: scratch resistance; smoke generation; toxic combustion products; toxicity; washat ility; water vapor permeance.

The National Bureau of Standards is providing technical support to the Department of Housing and Urban Development which is required by Public Law 91-695 (the Lead Paint Poisoning Prevention Act) to carry out a research program to evaluate and make recommendations regarding technology for the removal of the lead based paint hazard from the Nation's housing.

Potential hazard elimination methods have been identified by means of a survey of available technology. This report describes testing and evaluation methodologies used to determine (1) the suitability for use of a series of removal and lead barrier systems, (2) the results of this evaluation, and (3) recommendations concerning the use of said systems.

Paint removal systems were evaluated in terms of the hazards that they present in the course of their use. Both the flammability and the toxicity of the solvents found in removers were considered. Covering systems were evaluated for their suitability for use as barrier layers over lead bearing paints in housing. The effectiveness of covering systems in protecting children from leaded paint, their fire hazard properties and functional properties which are related to their serviceability were considered in making this evaluation. The properties of the systems were assessed in terms of minimum acceptable performance levels and recommendations are given for their use in a field evaluation program.

TN811. Evaluation of the column comnections used in a precast concrete modular housing system, F. Y. Yokel and T. W.

Reichard, Nat. Bur. Stand. (U.S.), Tech. Note 811, 63 pages (Mar. 1974) SD Catalog No. C13.46:811.

Key words: Building system; column connection; concrete triaxial strength; ductility; neoprene bearing pad; Operation BREAKTHROUGH; performance test; precast concrete; structuraì design.

The column connections used in a housing system employing stacked precast concrete box modules were tested to evaluate their structural performance. The system was proposed for construction in Operation Breakthrough, a research and demonstration program sponsored by the Department of Housing and Urban Development. The system uses innovative structural design concepts, which include: confinement of the concrete in the vicinity of the column bearings by reinforcing ties in order to increase concrete compressive strength; neoprene pads between column bearings in the upper stories; steel-neoprene-steel sandwich in the lower stories; and a grouted dowel through the center of the columns to provide resistance to tension and shear.

The test program included the fo!lowing: tests to determine the effect of various bearing pads on the load capacity of the connection; iests to determine the load-deformation characteristics of the neoprene pads; a test to determine the performance of a lower-story connection using a steel-neoprene-steel sandwich and a grouted dowel; and tests to evaluate the strength and ductility of the connections when subjected to a shear force. The test results are presented and interpreted and the findings are summarized. Supersedes NBSIR 73-148 (PB 220366/7).

TN818. Occupant behavior in building fires, A. 1. Rubin and A. Cohen, Nat. Bur. Stand. (U.S.), Tech. Note 818,28 pages (Feb. 1974) SD Catalog No. C13.46:818.
Key words: Disaster research; high rise building fires; occupant safety.

Fire safety in buildings is important in building design and the formulation of codes and standards. However, an examination of the information concerning the needs of occupants in fire emergencies (as opposed to ensuring a degree of structural integrity for the building) indicates that the scientific information base is woefully inadequate. The increasing prominence of high rise buildings having many occupants intensifies the need for better information about the behavior of occupants during fire emergencies. Fire researchers have indicated that it is often not feasible to evacuate buildings because of time constraints. Instead, designers use techniques such as safe areas within buildings and requiring people to respond differentially, based on their particular location. This approach emphasizes communications and warning systems to transmit messages. These systems such as loud noises or blinking lights should be designed to "take advantage" of the usual responses made by people. Occupants can actively be a part of the fire warning and fighting system instead of being unwilling victims. This possibility is pursued and a human factors approach is taken to suggest some means of better understanding the capabilities of occupants.

TN822. A review of Federal and military specifications for floor coverings, W. C. Wolfe, Nat. Bur. Stand. (U.S.), Tech. Note 822, 99 pages (Apr. 1974) SD Catalog No. C13.46:822.

Key words: Carpets; floor coverings; government; performance; procurement; specifications; standards; tests; user needs.

In this manual, which is organized so as to aid ready reference, requirements and test methods in Federal and military specifications for flooring, or floor coverings are combined, indexed and reviewed. The manual covers carpet, resilient flooring, monolithic surfacings or seamless flooring, and polyurethane coatings related to seamless flooring. It also covers all serviceability requirements except those relating to flammability, fire safety and acoustical properties.

Physical and material requirements in Federal specifications for floor coverings are considered in separate sections. Military specifications for monolithic surfacings and Federal specifications for floor coverings and polyurethane coatings are summarized in comprehensive tables. Under each physical requirement, comments indicate whether it is a quality control or a performance requirement. Each comment is followed by a list of those Federal specifications which include the requirement and a brief description of the criteria and test methods in the specifications. Comments on materials requirements relate to their adequacy and applicability to the product for which they were written. Finally, recommendations are made for improvements in performance requirements which should be considered for inclusion in future flooring and floor covering specifications.

TN838. The use of weather and climatological data in evaluating the durability of building components and materials, L. W. Masters and W. C. Wolfe, Nat. Bur. Stand. (U.S.), Tech. Note 838,101 pages (Aug. 1974) SD Catalog No. C13.46:838.

Key words: Accelerated aging; building components and materials; climatological data; durability; environmental factors; long-term tests; short-term tests; weathering factors.

The durability of building components and materials is dependent, to a large extent, on the in-service environment to which they are subjected in service. Thus, the prediction of durability requires knowledge of the service environment.

Weathering factors, which comprise one group of environmental factors, are the subject of this report. The objectives of this report are to indicate how, in the present state of knowledge. weather and climate data can be used to aid in quantifying weathering factors so that durability tests for building components and materials may be designed. 
TN852. A study of wind pressures on a single-family dwelling in model and full scale, R. D. Marshall, Nat. Bur. Stind. (IIS.). Tech. Note 852, 40 pages (Oct. 1974) SD (altalog No. C 13.46:852.

Key words: Aerodynamics; boundary layers; buildings; codes and standard; wind loads; wind tunnels.

Wirid pressures measured on a single-family dwelling arc compared with results obtained from a 1:80 scale model placed in a turbulent boundary layer. It is shown that the fluctuating components of surface pressures far exceed the mean or steady pressures and are well correlated over sizeable roof areas. The consistently low fluctuating pressure coefficients obtained from the wind tunnel model are attributed to improper simulation of the lower portion of the atmospheric boundary layer. Comparisons etween actual loads and specified design loads suggest that cerain current provisions are marginal for tributary areas and excessive for localized areas such as ridges, eaves and corners. A procedure for expressing loads on both localized and extended roof areas in terms of mean pressure coefficients and a peak factor is described.

TN853. State building regulatory programs for mobile homes and manufactured buildings - a summary, P. W. Cooke, H. K. Tejuja, R. D. Dikkers, and L. P. Zelenka, Nat. Bur. Stand. (U.S.), Tech. Note 853, 35 pages (Sept. 1974) SD Catalog No. C13.46:853.

Key words: Building regulation; enforcement; evaluation; inspection; legislation; manufactured building; mobile homes; rules and regulations; state-of-the-art study.

Information describing State mobile home and manufactured building regulatory programs are presented in two series of summary tables. The tables provide information on salient elements of the enabling legislation and the administrative rules and regulations promulgated for each State program. Other features of the various enforcement programs, including the status of reciprocity for the interstate acceptance of mobile homes and manufactured buildings are also enumerated.

TN858. A program for survey of fire loads and live loads in office buildings, C. Culver and J. Kushner, Nat. Bur. Stand. (U.S.), Tech. Note 858, 229 pages (May 1975) SD Catalog No. 13.46:858,

Key words: Buildings; fire loads; occupancy live loads; load surveys; structural engineering; survey techniques.

The development of a survcy program for determining the fire loads and live loads in office buildings is described. Considerations involved in planning the program which is directed toward establishing the factors affecting the loads in buildings are presented. The type of data to be collected and a data collection technique which utilizes visually observed information on the characteristics of building content items to determine weight are discussed. Procedures employed to select buildings to be included in a nation-wide office building load survey being conducted by the National Bureau of Standards and a sampling plan for selecting rooms to be surveyed in these buildings are also discussed.

TN863. Fatigue tests of bituminous membrane roofing specimens, (;. F. Sushinsky and R. (;. Mathey. Nat. Bur. Stand. (U.S.). Tech. Note 863. 32 pages (Apr. 1975) SD Calatur No. C]3.46:863.

Key words: Bituminous roof membranes; fatigue testing; flexural fatigue; performance criteria; roofing temperature effects; tensile fatigue; test methods.

Tensile and flexural fatigue tests were performed on buili-up ront membrane specimens (ASTM Designalion: D2523-70) fabricaled from four different material systems. The tensile fairue lests were run under cyclic load contrul condituns while specimens tested in flexural fatique were run under cyclic midspan displacement control. Tesis were run at ambient laboratory comditions, generally $70 \pm 2 \%$

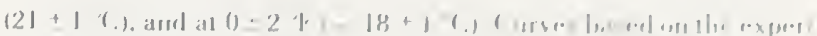

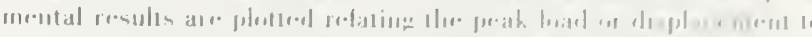

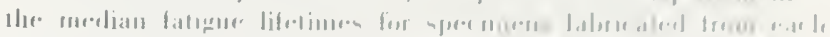

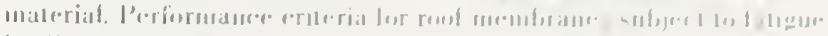

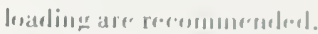

TN868. Statistical analysis of extreme winds. E. Simiu and J. J. Filliben. Nat. Bur. Stand. (U.S.), Tech. Note 868, 52 pages (June 1975) SD Catalog No. C13.46:868.

Key words: Building codes; extreme value distributions; hurricanes; probability distribution functions; reliability; risk; statistical analysis; storms; structrual engineering; wind loads; wind speeds

With a view to assessing the validity of current probabilistic approaches to the definition of design wind speeds, a study was undertaken of cxtreme wind spceds bascd on records taken at 21 U.S. wcather stations. For the purposc of analyzing cxtremc value data, a computer program was devcloped, which is described herein. The following results were obtained: (1) the assumption that a single probability distribution is universally applicable to all extreme wind data sets in a given type of climate was not confirmed, and (2) predictions of 100 -year wind spceds based on overlapping 20-year sets of data taken at the same station differed between themselves by as much as 100 percent. Similar predictions for 1000 -year winds differed by as much as a few hundred percent. Since wind pressures are proportional to the square of the wind speeds, errors of such magnitude are unacceptably high for structural design purposes. 1t is therefore suggested that while, in principle, probabilistic methods provide the most rational approach to specifying design and wind speeds, it is of the utmost importance that the possible errors inherent in this approach be carefully taken into account.

TN873. Electro-optical deflection measuring device, R. Crist, R.

Marshall, and H. Laursen, Nat. Bur. Stand. (U.S.), Tech. Note

873, 24 pages (Dec. 1975) SD Catalog No. C13.46:873.

Key words: Buildings, deflections; instrumentation; structural response; wind loads.

The development and testing of an electro-optical device for the direct measurement of lateral deflections of tall structures are described. The device utilizes a tracking telescope mounted on a fixed reference and a light source attached to the structure at the level for which lateral deflections are 10 be measured. Operating characteristics of the system are based on the results of tests carried out over a period of several months in one of the elevator shafts of a 12 story building.

TN883. Waterproofing materials for masonry. E. J. Clark. P. G Campbell, and G. Frohnsdorff, Nat. Bur. Stand. (U.S.), Tech. Note 883, 86 pages (Oct. 1975) SD Catalog No. C 13.46:883.

Key words: Accelerated weathering: durability of waterproofing materials; masonry: performance criteria: waterproofing materia!s: water repellent materials

The initial effectiveness and durability characteristics of filtyfive clear masonry waterproofing materials were evaluated using laboratory tests. This report contains the results of initial performance tests including water absorption, water vapor transmission, resistance to efflorescence and change in appearance. Durability tests, including periodic measurement of water absorption after exposures to accelerated weathering and outdoor exposures, were also conducted. Based on test results, performance criteria for clear waterproofing materials were developed. In addition, recommendations for the application of waterproofing materials were formulated. Finally, the report contains a summary of a survey concerning field experiences with uaterproofing and a brief theoretical discussion of water flow. 
TN885. A technical review of the Nicaraguan building regulatory system, R.N. Wright, and A. Lamana, Nat. Bur. Stnd. (U.S.), Tech. Note 885,85 pages (Oct. 1975) SD Catalog No. C13.46:885.

Key words: Architecture; building; building codes; building design; disaster mitigation; earthquakes; engineering; environmental hazards; housing; inspection and testing; safety.

This report on the Nicaraguan Building Regulatory System has been prepared under the auspices of the Organization of American States and the United States Agency for International Development. It presents an overview of the building regulatory system in Nicaragua; its activities in review of designs, issuance of building permits, inspection of construction, control of quality of materials, and issuance of occupancy permits. The technical bases for these activities are the building code and standards, the laboratory facilities for control of the quality of building materials, and the processes for development and application of codes and standards. Recommendations address the status and development of this system and its technical bases.

The losses in the December 23, 1972, Managua Earthquake provided dramatic evidence of the need for effective implementation of good building standards. Repetitions of these tragic losses elsewhere in Nicaragua and in a reconstructed Managua are certain unless a good building code is developed and adopted, its use and design by architects and engineers enforced by careful review of designs, and the implementation of these designs by the builders assured by inspection of construction and testing of building materials. A summary and critical review of U.S. building regulatory practices for areas with severe natural hazards is presented in Appendix B for guidance in building regulatory system planning and development. A survey of housing performance in Managua is presented in Appendix $\mathrm{C}$ to illustrate that earthquake resistant construction is feasible and economical for Nicaragua and other nations with comparable resources.

TN886. Modification of fluorescent luminaires for energy conser. vation, R. W. Beausoliel, W. J. Meese, and G. Yonemura, Nat. Bur. Stand. (U.S.), Tech. Note 886, 15 pages (Oct. 1975) SD Catalog No. C13.46:886,
Key words: Capacitors; energy conservation; fluorescent lamp; fluorescent luminaire; lighting efficiency; power factor.

Reducing energy consumption in existing buildings by reducing the number of lamps presents technical problems when more than one fluorescent lamp operates from a single ballast. A preliminary investigation was made whereby capacitors were substituted for one fluorescent lamp in a two-lamp luminaire which operated with a single ballast. Under optimum conditions, lighting efficiency (foot-candles per watt) was nearly as high at reduced power input as it was with two lamps operating normally. No failures in lighting equipment or capacitors occurred and no fire hazards, other safety hazards or other unsatisfactory occurrences were observed. A more thorough investigation involving a number of parameters is needed to ascertain the feasibility of this modification.

TN892. Retrofitting a residence for solar heating and cooling: The design and construction of the system, J. Hill and T. Richtmyer, Nat. Bur. Stand. (U.S.), Tech. Note 892,99 pages (Nov. 1975) SD Catalog No. C13.46:892.

Key words: Retrofitted solar residence; solar collector; solar heating and cooling system; solar-powered absorption refrigeration.

During 1972 and 1973, the National Bureau of Standards conducted controlled laboratory tests on a factory-built four-bedroom house having a floor area of $110 \mathrm{~m}^{2}\left(1200 \mathrm{ft}^{2}\right)$ equipped with a conventional gas furnace and a central electric air conditioner incorporated into a forced air distribution system. During 1974, the house was moved onto the NBS grounds and a solar heating and cooling system was designed to be added to the house. Calculations have been made to show that more than $75 \%$ of the yearly energy needs for heating, cooling, and supplying domestic hot water could be obtained from the sun.

This report deals with the design and construction of the retrofitted system. It consists of $45 \mathrm{~m}^{2}\left(485 \mathrm{ft}^{2}\right)$ of double-glazed, flatplate solar collector, $5.7 \mathrm{~m}^{3}$ (1500 gallons) of water storage, and a $10,000 \mathrm{~W}$ ( 3 ton) lithium bromide absorption air cooling unit.

\section{SPECIAL PUBLICATIONS}

This series includes proceedings of conferences sponsored by the Center, and other special publications appropriate to this grouping including project summaries, list of publications, wall charts, pocket cards, and bibliographies.

SP302. Thermal conductivity. Proceedings of the seventh conference held at the National Bureau of Standards, Gaithersburg, Md., November 13-16, 1967, D. R. Flynn and B. A. Peavy, Jr., Editors, Nat. Bur. Stand. (U.S.), Spec. Publ. 302, 820 pages (Sept. 1968).

Key words: Conductance; conductivity; contact conductance; contact resistance; electrical conductivity; electrical resistivity; heat transfer; Lorenz function; resistivity; temperature; thermal conductivity; thermal diffusivity; thermal resistivity; thermophysical properties.

The Seventh Conference on Thermal Conductivity was held at the National Bureau of Standards on November 13-16, 1967. This volume contains the texts of the papers presented. Topics covered include surveys of the present state of knowledge regarding the thermal conductivity of different materials, descrip. ions of different apparatuses for measuring thermal conductivity, new experimental data on the thermal conductivity or dif fusivity of a variety of materials, and correlations between ex perimental results and theoretical predictions.
SP329. Supplement 1. An index of U.S. voluntary engineering standards, W. J. Slattery, Editor, Nat. Bur. Stand. (U.S.), Spec. Publ. 329, Suppl. 1, 459 pages (Dec. 1972).

Key words: Engineering Standards, index of; index of standards, recommended practices, specifications, test methods; Key-Word-In-Context index of voluntary standards; standards, voluntary, index of.

This supplement contains the permuted titles of more than 6,300 standards, specifications, test methods, and recommended practices published by 225 U.S. technical societies, professional organizations and trade associations. Each title can be found under all the significant key words which it contains. These key words are arranged alphabetically down the center of each page together with their surrounding context. The date of publication or last revision, the standard number and an acronym designating the standards-issuing organization appear as part of each entry.

SP334. Industrialized building in the Soviet Union, (a report of the U.S. Delegation to the U.S.S.R.), J. R. Wright, Editor, Nat. Bur. Stand. (U.S.), Spec. Publ. 334, 81 pages (Dec. 1970).

Key words: Building economics; building systems; construction industry; housing: precast concrete; production 
capacity; production management; production methods; standardization; United Soviet Socialist Republics.

The 1969 Exchange delegation to the USSR reports the status of Soviet building industrialization, with emphasis on Soviet housing. The report describes the State management hierarchy, production of precast concrete components and housing construction procedures. The loadbearing panel system, the mainstay of Soviet prefabricated housing, is compared with the newer three-dimensional box system. Detailed analysis is made of the cost of a nine-story panel prefabricated apartment building in the USSR, and the cost of the same building if constructed in the U.S.

SP361. Volume 1. Performance concept in buildings. Invited papers. Proceedings of a symposium jointly sponsored by the International Union of Testing and Research Laboratories for Materials and Structures (RILEM), the American Society for Testing and Materials (ASTM), and the International Council for Building Research Studies and Documentation (C1B), Philadelphia, Pa., May 2-5, 1972, B. E. Foster, Editor, Nat. Bur. Stand. (U.S.), Spec. Publ. 361, Vol. 1, 819 pages (Feb. 1972).

Key words: Buildings; components; design procedures; experience in use; materials; performance evaluation; performance requirements; user requirements.

Volume 1 contains all of the invited papers accepted for the loint RILEM-ASTM-C1B Symposium on the Performance Concept in Buildings. Opening addresses and reports of the rapporteurs will be included in Volume 2. The Symposium was held in Philadelphia, Pa. on May 2-5, 1972. The subject matter covered in the papers includes physiological, anthropometrical, psychological, sociological, and economic human requirements and methods of evaluation; physical requirements and methods of evaluation in mechanical, acoustical, thermal, dimensional stability, compatibility, fire properties, and geometry areas; operation and maintenance require ments and methods of evaluation in such areas as maintenance, repair, replacement, and versatility; techniques and problems in applying the performance concept to design; and experience gained in application of the performance concept in design, building, and building use. These proceedings include the following papers:

Design specification - operational goals, parameters, synthesis, and performance criteria, J. F. Halldane, SP36I, Vol. I, pp. 1-12 (Feb. 1972).

Human requirements for buildings, T. Cronberg, $\AA$. Hallquist, R. Hansen, J. Nordan, and A. Saeterdal, SP361, Vol. I, pp. 13-22 (Feb. 1972).

On structuring performance requirements for buildings, $T$. Cronberg, A. Saeterdal, $\AA$. Hallquist, and J. Nordan, SP 36I, Vol. I. pp. 23-30 (Feb. 1972).

Performance requirements of the thermal environment for human occupancy, R. G. Nevins and P. E. McNall, Jr., SP36I Vol. 1, pp. 31-42 (Feb. 1972).

Performance requirements of buildings and the whole problem, W. M. Peña and J. W. Focke, SP36I, Vol. I, pp. 4355 (Feb. 1972).

Performance requirements of housing in response to the life cycle: a behavioral approach, L. A. Pastalan, SP361, Vol. I, pp. 57-62 (Feb. 1972).

Performance of systems of constructed facilities, A. C. Lemer and F. Moavenzadeh, SP36I, Vol. I, pp. 63-71 (Feb. 1972).

The relationship of the performance concept to the planning process-developing performance requirements for community mental health centers, D. B. Hattis, SP361, Vol. l, pp. 73-82 (Feb. 1972).

Institutional performance and buildlng performance: some implications of the Judicial Facilities Study, B. Handler, SP 36 I. Vol. 1, pp. 83-91 (Feb. 1972).
The complementary use of research and negotlations with users in the development of performunce standurds, T. Mann and R. Bender, SP36I, Vol. I, pp. 93-100) (Feb. 1972).

Applicatlon of unobtruslve observation technlyues in bullding performance appraisal, W. F. E. Preiser, SP36l, Vol. I, pp. 101-109 (Feb. 1972).

Verballzed user resnonse and the building performance concept: a case study in unlversity resldence hall evaluation, W. F E. Preiser, SP361, Vol. 1, pp. 111-119 (Feb. 1972).

Identification of performance criteria using multidimensional scallng of user evaluations, H. G. Blasdel, SP36l, Vol. $l$, pp. 121.129 (Feb. 1972).

Performance: the new language of design, D. J. Parsons, SP361,Vol. 1, pp. 131-139 (Feb. 1972)

Consideration of externalitles to the hasic performance/cust evaluation of buildings ln the deslgn process, G. S. Birrell, SP36I, Vol. l, pp. 141-148 (Feb. 1972).

Architectural economics related to comfort, productivity and glass, J. T. Malarky, SP361, Vol. 1, pp. 149-159 (Feb. 1972).

The notion of performance in building: building require. ments, G. Blachère, SP361, Vol. I, pp. 161-164 (Feb. 1972).

What are the natures of performance and evaluation for the three levels: building, components, materials, G. Blachère, SP36I, Vol. I, pp. 165-170 (Feb. 1972).

Techniques for developing performance specifications for buildings, M. Brill, SP361, Vol. l, pp. 171-180 (Feb. 1972).

A consistent basis for functional and ultimate criteria, R. N Wright and A. H.-S. Ang, SP36I, Vol. I, pp. 181-190 (Feb. 1972).

Performance concept and the system approach-some comments, 1. Karlén, SP36I, Vol. I, pp. 191-200 (Feb. 1972).

The performance concept in building: the working application of the systems approach to building, R. G. Robbie, SP361, Vol. l, pp. 201-206 (Feb. 1972).

The relationship between the performance concept and the systems concept, J. Vilett, SP361, Vol. 1, pp. 207-212 (Feb. 1972).

Computer based code systems and the performance concept, J. P. Eberhard, SP36I, Vol. 1, pp. 213-218 (Feb. 1972).

Performance analysis, Tenho Sneck, J. Saarimaa, and Timo Sneck, SP361, Vol. l, pp. 219-226 (Feb 1972).

Building performance appraisal, T. A. Markus, SP36I, Vol. I, pp. 227-235 (Feb. 1972).

A systems approach for the evaluation of performance of buildings in design process, S. G. Haider and N. Khachaturian, SP361, Vol. I, pp. 237-248 (Feb. 1972).

An innovative approach for building system analysis and design, M. J. Macalik, SP361, Vol. l, pp. 249-253 (Feb. 1972).

A general overview of operation BREAKTHROUGH, E. V Leyendecker, SP36I, Vol. 1, pp. 255-260 (Feb. 1972).

Philosophy and scope of structural performance criteria, F. Y. Yokel and N. F. Somes, SP361, Vol. 1, pp. 261-266 (Feb 1972).

Philosophy for physical simulation using performance criteria, N. F. Somes and F. Y. Yokel, SP361, Vol. I. pp. 267. 274 (Feb. 1972).

Field testing of conventional buildings for static and dynamic deflections, G. C. Hsi, H. S. Lew, F. Y. Yokel, and N. F. Somes, SP36I, Vol. I, pp. 275-288 (Feb. 1972).

Performance of components: a procedure for the preparation of specifications for building components, H. W. Harrison. SP361, Vol. I, pp. 289-296 (Feb. 1972).

User requirements and performance design, J. King, SP36I Vol. 1, pp. 297-301 (Feb. 1972). 
Paths to performance-some recent projects employing the performance concept, W. Meyer, R. Bender, and C. Arnold, SP361, Vol. I, pp. 303-315 (Feb. 1972).

The "Recherches en Aménagements Scolaires" (R.A.S.) project - a case study - strategy implemented for the development of a building system for educational facilities through the Performance Concept, M. Bezman, SP361, Vol. I, pp. 317-330 (Feb. 1972)

The development of performance criteria for university facilities, R. F. Hallenbeck, SP36/, Vol. I, pp. 331-337 (Feb. 1972)

Experience and lessons from an innovative housing project using the performance concept, W. Allen and P. Rich, SP36I, Vol. l, pp. 339-344 (Feb. 1972).

Evaluation process of performance and cost as applied to existing housing prior to rehabilitation, C. Forsberg and G. S. Birrell, SP361, Vol. I, pp. 345-356 (Feb. 1972).

Performance specifications for office space interiors, $T$. E. Ware, SP361, Vol. l, pp. 357-374 (Feb. 1972).

Performance requirements for windows, E. Paulsen, SP36I, Vol. I, pp. 375-384 (Feb. 1972).

Evaluation of window performance, A. G. Wilson and J. R. Sasaki, SP36I, Vol. I, pp. 385-394 (Feb. 1972 I.

Effect of envelope design on cost performance of office buildings, M. Anson, W. B. Kennedy, and J. W. Spencer. SP361, Vol. I, pp. 395-406 (Feb. 1972).

Use of modern computer programs to evaluate dynamic heat transfer and energy use processes in buildings, T. Kusuda and F. J. Powell, SP36I, Vol. l, pp. 407-418 (Feb. 1972).

The application of total energy systems to housing development, P. R. Achenbach and J. B. Coble, SP361, Vol. l, pp. 419.430 (Feb. 1972)

A morphological performance evaluation technique for moisture problems in buildings, J. Saarimaa, SP36I, Vol. 1 , pp. 431-449 (Feb. 1972).

Sizing of water heating equipment, L. G. Spielvogel, SP36I, Vol. I, pp. 451-463 (Feb. 1972).

The development of performance criteria and test procedures for the piping of sanitary drain, waste and vent systems in residential service, R. T. Holtz, SP361, Vol. 1, pp. 465-476 (Feb. 1972)

Simplified acoustical measurement procedures for building code enforcement, M. J. Kodaras, SP36I, Vol. I, pp. 477-481 (Feb. 1972).

The effect of ilsumination systems upon visual performance, I. Lewin and J. W. Griffith, SP36I, Vol. I, pp. 483-490 (Feb. I 972)

The performance concept in the service of technical evaluations of building innovations, D. E. Dobson, SP36I, Vol. I, pp. 491-502 (Feb. 1972)

Technical evaluation of components: agrément, G. Blachère SP36I, Vol. I, pp. 503-506 (Feb. 1972).

Performance requirements in a systematic method for selecting building materials, K. Shirayama, K. Imaizumi, K. Kamimura, K. Kondo, F. Saito, T. Nireki, K. I to, F. Tomosawa, S. Sugawara, H. Suzuki, K. Kawase, Y Takahashi, S. Oka, Y. Mimura, M. Ito,SP36l, Vol. l, pp. $507-$ 518 (Feb. 1972).

Proposed method of test for evaluating performance of buildings, building elements, and materials, K. Shirayama, K. Imaizumi, K. Kamimura, K. Kondo, F. Saito, T. Nireki, K. Ito, F. Tomosawa, S. Sugawara, H. Suzuki, K. Kawase, Y. Takahashi, S. Oka, Y. Mimura, M. Ito, SP36l, Vol. l, pp. 519. 529 (Feb. 1972)

Performance of components with special attention paid to the practical implementation, G. Christensen, SP36I, Vol. 1, pp. 529-534 (Feb. 1972).
Increasing the application efficiency of performance tests with analytic procedures, S. K. Suddarth and D. H. Percival, SP361, Vol. l, pp. $535-543$ (Feb. 1972).

Evaluation of structural concrete members penetrated by service systems, J. M. Hanson, W. G. Corley, and E. Hognestad, SP361, Vol. I. pp. 545-556 (Feb. 1972).

A performance approach to the design of fire-resistive buildings, L. G. Seigel. SP36/, Vol. I, pp. 557-566 (Feb. 1972).

The resistance of brick walls to lateral loading, H. W. H. West and H. R. Hodgkinson, SP36/, Vol. I, pp. 567-576 (Feb. 1972).

Experimental gas explosions in load-bearing brick structures, N. F. Astbury, H. W. H. West, and H. R. Hodgkinson. SP36I, Vol. 1, pp. 577-592 (Feb. 1972)

Performance characteristics for timber frame joist floors, $\mathrm{H}$. Hansen, SP36/, Vol. l, pp. 593-600 (Feb. 1972).

Performance requirements for floors, C. Bring, SP36/, Vol, I, pp. 601-612 (Feb. 1972).

Performance analysis of floors, J. Saarimaa, Tenho Sneck. and M. Wäänänen,SP36l, Vol. I, pp. 613-623 (Feb. 1972).

Strength criteria of glued-laminated timber, B. Bohannan, SP36l, Vol. l, pp. 625-632 (Feb. 1972).

Performance requirements for mechanical fasteners used in building, E. G. Stern, SP361, Vol. l, pp. 633-642 (Feb. 1972).

Performance criteria for composites in building, A. G. H. Dietz, SP361, Vol. 1, pp. 643-651 (Feb. 1972).

Basic problems and conditions of long term performance of materials and structures, O. Valenta, SP361, Vol. I, pp. 653668 (Feb. 1972).

Pore properties in the evaluation of materials, J. M. Haynes and Tenho Sneck, SP36I, Vol. I, pp. 669-675 (Feb. 1972).

The definition of a low intensity fire, D. Gross and J. B. Fang, SP361, Vol. I, pp. 677-686 (F̈eb. 1972).

The interaction between mortar and masonry units as a basis for standards for masonry mortars, Tenho Sneck, SP361, Vol. l, pp. 687-692 (Feb. 1972).

A performance evaluation of thin bed adhesive mortar in concrete masonry construction, L. A. Kuhlmann. SP36/, Vol. I, pp. 693-709 (Feb. 1972).

Performance requisites for concrete building components and their achievement with gap-graded concrete, S. Li, D. A. Stewart, and V. Ramakrishnan, SP36I, Vol. I, pp. 711-718 (Feb. 1972).

Relating materials quality to materials performance to structural performance of concrete, B. Mather, SP36/, Vol. I. pp. $719-724$ (Feb. 1972).

Proposed method for prediction of corrosion of reinforcement in concrete, J. Saarimaa, SP361, Vol. I, pp. $725-732$ (Feb. 1972).

The performance concept applied to building materials - an unattainable ideal, F. A. Blakey and K. G. Martin, SP36I, Vol. I, pp. 733-740 (Feb. 1972).

Evaluation of performance of materials performance and dimensional stability of resin binders, K. Gamski, SP361, Vol. l, pp. $741-750$ (Feb. 1972).

Natural and artificial weathering performance of rigid polyvinyl chloride (PVC) and other plastic materials, H. F. Stedman, SP361, Vol. I, pp. 751-760 (Feb. 1972).

Evaluation of structural adhesives for use in housing systems, T. W. Reichard, L. W. Masters, and J. H. Pielert, SP36l, Vol. 1, pp. 761-775 (Feb. 1972).

Performance requirements for bituminous roofings, A. J. Hoiberg SP36/, Vol. l, pp. $777-787$ (Feb. 1972). 
Abrasion test and wear resistance of concrete terrazzo flooring tiles, I. Soroka, SP361, Vol. I, pp. $789-797$ (Feb. 1972).

Performance tests for finish floors state-of-the-art, W. C. Wolfe, SP361, Vol. I, pp. 799-806 (Feb. 1972).

SP361. Volume 2. Performance concept in buildings. Opening ad dresses, rapporteur reviews, and discussions. Proceedings of a symposium jointly sponsored by the International Union ol Testing and Research Laboratories for Materials and Structures (RILEM), the American Society for Testing and Materials (ASTM), and the International Council for Building Research Studies and Documentation (C/B), Philadelphia, Pa., May 2-5, 1972, B. E. Foster, Editor, Nat. Bur. Stand. (U.S.), Spec. Publ. 361, Vol. 2, 169 pages (Sept. 1972).

Key words: Buildings: components; design procedures; experience in use; materials; performance evaluation: performance requirements; user requirements.

Volume 2 records the proceedings of the Joint RILEMASTM-C1B Symposium on the Performance Concept in Buildings which was held in Philadelphia on May 2-5, 1972. Volume 1 contains the 82 papers accepted for the Symposium and was published prior to the meetings. This second volume contains the opening addresses; the reports of the rapporteurs, which include a review of the papers and a general discussion in each of six areas; such discussion as was submitted in writing; a general summary of the Symposium with conclusions drawn by the closing rapporteur; and statements by representatives of the three sponsoring organizations outlining the present and probable future activity of these organizations in furthering the performance concept in buildings. The subject matter covered in the papers includes physiological, anthropometrical, psychological, sociological, and ecor:omic human requirements and methods of evaluation; physical requirements and methods of evaluation in mechanical, acoustical, thermal, dimensional stability, compatibility, fire properties, and geometry areas; operation and maintenance requirements and methods of evaluation in such areas as maintenance, repair, replacement, and versatility; techniques and problems in applying the performance concept to design; and experience gained in application of the performance concept in design, building, and building use.

SP393. Colorimetry and spectrophotometry: A bibliography of NBS publications January 1906 through January 1973, K.L. Kelly, Nat. Bur. Stand. (U.S.) Spec. Publ. 393, 54 pages (April 1974) SD Catalog No. C13.10:393.

Key words: Bibliography; color; color codes; color measurement; colorimetry; spectrophotometry; vision.

This bibliography of publications will serve as the key to the large amount of research into color measurement and specification, and color vision carried out by the staff of the National Hureau of Siandards ( $\mathrm{BBS}$ ) in colorimetry and spectrophotometry. Ihese 623 publications appeared in NBS publications and outside scientific and rechnical journals between January 1906 and January 1973. This malerial has been in constant demand by Bureau members as well as by oulside individuals and organizations. The practical value of this wealth of information lies in its ready accessibility 10 the scientific and iechnical fraternity by title, by key words or by author, in the 1.ıbrary of Congress and in depository libraries such as large public and university libraries. A short organizational chronology of the colorimetry and specirophotometry program is included.

SP429. Proceedings of the 7th Annual Conference of the National Conference of States on Building Codes and Standards. S. A. Berry, Ed., Nat. Bur. Stand. (U.S.), Spec. Publ. 429, 124 pages (Sept. 1975) SD Catalog No. C 13.10:429.

Key words: ASHRAE 90-P; building codes: mobile homes: NCSBCS.

The National Conference of States on Building Codes and Standards had its formal beginning in Wisconsin in 1967. Its formation represented a response by the States to recommendations for intergovernmental reforms in the area of building codes. prepared by the Advisory Commission on Intergovernmental Relations. The formative meeting he!d in Wisconsin was a direct outgrowth of an earlier exploratory meeting, involving several States, called by the National Bureau of Standards. At this meeting, the States represented discussed the idea of a national organization of the States similar to the National Conference of Weights and Measures, assisted by the National Bureau of Standards, leading to a cooperative solution regarding the multiple problems in the entire building regulatory system.

The Governor of Wisconsin issued an invitation to the States to gather in Wisconsin to address the problem, to develop an organization which could effectively respond to this national need. and to consider the offer of assistance of the National Bureau of Standards. Sixteen States attended this meeting and unanimously agreed to the formation of the NCSBCS and to accept the secretariat role of the National Bureau of Standards.

The Conference is structured to develop many technical and general recommendations in the field of comprehensive building code administration and its programs explore the entire system of this important segment of governmental regulatory service.

The secretariat of the National Conference of States on Build ing Codes and Standards located in the Office of Building Standards and Codes Services, Center for Building Technology. National Bureau of Standards, Washington, D.C. 20234.

\section{HANDBOOKS}

Recommended codes of engineering and industrial practice (including safety codes) developed in cooperation with interested industries, professional organizations, and regulatory bodies.

H115. Energy Conservation Program Guide for Industry and Commerce (EPIC), R. R. Gatts, R. G. Massey, and J. C. Robertson, Nat. Bur. Stand. (U.S.), Handb. 115, 212 pages (Sept. 1974) SD Catalog No. C 13.11:115.

Key words: energy conservation; energy conservation guide; energy conservation opportunities; energy conservation program; industrial energy conservation.

The Energy Conservation Program Guide for Industry and Commerce (EPIC) is a guide to assist business and industry to establish an on-going conservation program. EPIC outlines the steps in an energy conservation program and suggests specific ways to reduce energy use in manufacturing and commercial businesses. EPIC focuses on two aspects of energy conservation: (1) The key steps in an implementation plan for an energy conservation plan; (2) Energy Conservation opportunities which have been identified by industry. 
The Interagency Reports are a special series of interim or final reports on work generally performed by NBS for outside sponsors (both government and non-government). When released by the National Bureau of Standards and the Sponsor, initial distribution is handled by the Sponsor. Public availability is by the National Technical Information Service (NTIS), Springfield, Va. 22161. This series must be ordered from NTIS by the order number listed at the end of each entry.

NBSIR 73-102. Energy conservation through effective Utilization, C. A. Berg, 53 pages (February 1973). Order from NTIS as COM 73-19856.

\section{Key words: Effective utilization; energy conservation.}

In two major sectors of the economy (building services and industrial processes), accounting for approximately 75 percent of total national energy consumption, energy utilization is found to be inefficient. It is estimated that in these two sectors. as much as 25 percent of the energy consumed annually by the nation as a whole may be lost through ineffective practices. Possible reasons for existence of ineffective utilization are considered. and possible means of improving effectiveness of utilization are discussed. Three possible levels of effort to promote effective itilization of energy are identified; one promotes effective use of resent fuels in present processes; the second promotes utilization of presently unused energy sources; the third promotes more effective investment of energy in durable and maintainable products.

Substantial latitude for improvement of effectiveness is shown to be realizable through technological efforts at these three levels. It is finally recommended that a national program, incorporating efforts at the three levels identified, be undertaken with the ultimate goal of creating and implementing a technology of improved energy utilization.

NBSIR 73-105. Environmental evaiuation of polyurethane foam core sandwich panel construction, J. R. Shaver, L. W. Masters, T. W. Reichard, and J.H. Pielert, 47 pages (December 1972). Order from NTIS as PB 219-118.

Key words: Accelerated aging; compression; environmental conditions; flexure; housing system; Operation BREAKTHROUGH; polyurethane foam; sandwich construction; wall system.

An environmental evaluation of a sandwich panel bearing wall system for use in one of the Operation BREAKTHROUGH housing systems is described. Two samples of polyurethane foam core sandwich construction and four full size wall panels were evaluated.

The samples of the sandwich construction were used to evaluate the effect of extreme temperature and moisture on this type or sandwich construction. The full size panels were used to determine the behavior in service considering the effects of adverse environmental conditions on ultimate strength and mode of failure.

NBSIR 73-115. Analysis of the behavior of a freely burning fire in a quiescent atmosphere, J. B. Fang, 60 pages (Feb. 1973). Order from NTIS as PB 226-907.

Key words: Buoyant plume; diffusion flame; fire; flame height; mathematical modeling; turbulent flow.

A mathematical model which describes the physical and geometrical properties of a turbulent buoyant diffusion flame over a free burning fire has been set up for both axisymmetric and two dimensional cases. The mathematical simulation of the flame con- sists of a combustion zone near its source and a buoyant plume above and has been developed based on the assumptions of infinitely rapid rate of oxygen limited combustion reaction and "top hat" profiles representing vertical distributions of the velocity, temperature, and concentration of the flame gas. Analytical solutions are presented showing the effects of fuel mass-flow rate, physical properties of the fuel and ambient air, and the size and shape of burning area on the general characteristics of a buoyant flame. Experimental data on visable flame heights and flame emperature profiles obtained from burning several different fuels have been satisfactorily correlated by the derived expressions.

NBSIR 73-116. Study of the local resistance of conventional plywood subflooring to concentrated load, F. Y. Yokel, 64 pages (March 26, 1973). Order from NTIS as PB 220-432.

Key words: Concentrated-load capacity; evaluation criteria; floors: hardboard; load capacity; Operation BREAKTHROUGH; performance criteria; plywood subflooring: subflooring; underlayment; wood-frame construction.

Five conventional plywood floor systems, constructed in accordance with the requirements of the FHA "Minimum Property Standards" were tested under concentrated loads in order to compare their performance with that stipulated by performance criteria developed on the basis of anticipated occupancy loads.

In 24 out of 26 tests the performance of the floor systems exceeded that stipulated by the criteria. Data on failure loads, loaddeflection characteristics and failure modes are presented and discussed.

NBSIR 73-121. Structural tests of a wood framed housing module, C. W. Yancey and N. F. Somes, 111 pages (March 26, 1973). Order from NTIS as COM 73-10860.

Key words: Deflection; housing; laboratory: module: racking; stiffness: strength; structural tests; sustained load; transportation: vibration; wood-frame.

This paper reports the results of tests to determine the structural strength and stiffness characteristics of a prototype woodframe volumetric housing module. The series of six structural tests was performed at the NBS Structures Laboratory, Gaithersburg. Md., subsequent to a trial rail shipment, which included several coupling impacts. This report refers to the transportation study only to the extent that it concerns the module, and in particular, its condition at the start of the structural tests. The total sequence of the tests closely simulated the experience of a typical module as it undergoes manufacture, transportation, erection and in-service loading.

NBSIR 73-125. Interlaboratory evaluation of the tunnel test (ASTM E 84) Applied to Floor Coverings, T. G. Lee and C. Huggett, 56 pages (March 1973). Order from NTIS as COM 73-11189.

Key words: ASTM E 84; building materials; carpets; fire tests: flame spread tests; interlaboratory evaluation; round robin; statistical analysis; test method standard.

Results of an interlaboratory evaluation of the ASTM E 84 tunnel test method involving eleven laboratories and nine materials, including four carpets, are reported. Data on flame spread, smoke, and fuel contribution are analyzed statistically. Selected physical characteristics of each tunnel are tabulated and compared relative to specifications in the test method. The betweenlaboratory coefficient of variation (reproducibility) in flame 
spread classification (FSC) was found to range from 7 to $29 \%$ for the four carpets and from 18 to $43 \%$ for the other materials tested. The between-laboratory coefficients of variation for smoke developed and fuel contribution ranged from 34 to $85 \%$ and from 22 to $117 \%$ respectively for all materials tested. The causes of higher variability in smoke and fuel contribution measurement between laboratories is not definitely known but may reasonably be attributed to variations in tunnel construction. maintenance, and operation, in the location of photometers, and in the mounting of thermocouples in different laboratories. Some variability of results may possibly be due to variation in test specimens. Variation in construction and measurement techniques among tunnels may be minimized by updating the test method standard.

NBSIR 73-126. Structural tests of mechanical connections for concrete panels, L. E. Cattaneo and F. Y. Yokel, 118 pages (November 1972). Order from NTIS as PB 219-124.

Key words: Concrete panels; connections; ductility; floor diaphragms: housing systems; insert connectors; Operation BREAKTHROUGH; precast concrete.

Structural evaluation tests were performed on prototype steel insert connectors proposed for joining floor and wall panels of a precast concrete housing system included in Operation BREAKTHROUGH. Descriptions are given of 25 tests conducted with 5 different types of connectors. Specimen connections were laboratory tested under simulated design loading conditions to evaluate their load capacity and ductility.

NBSIR 73-127. Evaluation of lead paint hazard elimination methods part II, H. D. Waksman, L. F. Skoda, E. J. Clark, M. Godettee, 77 pages (March 1973). Order from NTIOS as PB 213-352.

Key words: Deleading methods: lead paint poisoning; performance: properties.

Four major classifications of procedures that should be considered when selecting a method for the elimination of the lead paint hazard are analyzed in this report. They are: surface repair methods, surface finish methods, cover up methods with unfinished membrane materials, and cover up methods with prefinished rigid materials. The attributes associated with each type of method were considered and analyzed in terms of inaccessibility of the leaded paint and implementation considerations. Recommendations are made for the in-use performance properties of surfaces.

NBSIR 73-132. State of the art on durability testing of building components and materials, L. W. Masters, W. C. Wolfe, W. J. Rossiter, Jr., and J. R. Shaver, 128 pages (March 1973). Order from NTIS as PB 222-300.

Key words: Accelerated aging; aging of buildings; building components: climate: criteria: deterioration: durability; materials; mechanisms; nondestructive testing; testing.

This report is a summary of the present knowledge pertaining to durability predictions for building components and materials which are subjected to the effects of outdoor exposure. The varisus chapters of the report include discussions of the nature of aging, the measurement of properties to predict durability, nondestructive evaluation techniques, outdoor exposure techniques. accelerated aging techniques, techniques for applying testing data to durability predictions and difficulties which arise in predicting durability. Conclusions and recommendations are also included.

An appendix, which summarizes ASTM Standards for durability testing of building components and materials, is included.
NBSIR 73-135. Fire endurance tests of steel sandwich panel exterior wall and roof/ceiling cunstructions, B. C. Son, 38 pages (December 1972). Order from NTIS as PB 221-310.

Key words: Exterior wall, fire endurance, fire test housing systems; Operation BREAKTHROU(JH. paper honeycomb; roof/ceiling asscmbly, structural sandwich panel.

As part of the evaluation of a housing system proposed under Operation BREAKTHROUGH. fire endurance lests were performed at the National Bureau of Standards on an exterior wall assembly and a roof/ceiling assembly. Both constructions were assemblies of sandwich panels composed of a paper honeycomb core with sheet steel facings.

The test method was in accordance with the requirements of ASTM E 119. Standard Methods of Fire Tests of Building C onstruction and Materials, for loadbearing structures. The applied live load was 237 pounds per linear foot (plf) for the wall assembly and 28.6 pounds per square foot (psf on a $13 \mathrm{ft} 5$ in span for the roof/ceiling assembly. The results of these tests are valid only for walls and roof/ceilings of such constructions described in this report and loaded at or below the stress levels developed by these loadings.

The fire endurance of the wall assembly was $7 \mathrm{~min} 50 \mathrm{sec}$ : and the roof/ceiling, $9 \mathrm{~min} 09 \mathrm{sec}$. In both cases, the failure was due to a maximum temperature rise of $181{ }^{\circ} \mathrm{C}\left(325^{\circ} \mathrm{F}\right)$ above the initial temperature on the unexposed surface.

NBSIR 73-140. Fire endurance test of plywood-faced walls for single family housing, B. C. Son, 24 pages (March 1973). Order from NTIS as PB 220-226.

Key words: Fire endurance: fire test: housing systems: interdwelling wall; Operation BREAKTHROUGH; single wall.

As a part of the testing and evaluation activities in Operation BREAKTHROUGH, a standard fire test conforming to ASTM E 119 was performed at the National Bureau of Standards on a wall assembly where half represented a nonbearing single exterior wall (as found in single family detached housing) and the other half represented a nonbearing double wall for an interdwelling separation which would occur at the interface of two parallel adjacent modules. Each wall contained a layer of gypsum board as an interior (room) surface and a layer of plywood as an exterior surface, and was framed with nominal $2 \times 4$ in wood studs on 16 in centers. No structural load was applied during the test.

The fire endurance of the single wall was $43 \mathrm{~min}$. The initial mode of failure was by excessive average temperature rise on the unexposed surface of the wall.

Although the test results of the interdwelling wall were inconclusive, its fire endurance was considered to be $1 \mathrm{hr}$. $02 \mathrm{~min}$. This fire endurance was based on visual observation during the test and was the time when the gypsum board on the unexposed side was observed to separate from the wood studs.

NBSIR 73-141. Fire endurance tests of plywood on steel joist floor assemblies, with and without ceiling, $H$. Shoub and B. C. Son, 35 pages (March 1973). Order from NTIS as PB 220-430.

Key words: Fire test: floor assembly: floor-ceiling assembly; housing systems; modular construction; Operation BREAKTHROUGH; steel framing: steel joist floor.

Fire endurance tests were conducted on two floor/ceiling assemblies intended for use in modular housing. One assembly simulated the combination of the floor of an upper story module with the ceiling assembly of the module beneath: the other assembly, the floor of a first floor module over a ceilingless crawl or foundation space. 
The floors were of plywood deck with vinyl or carpet overlay on light gage steel " $\mathrm{C}$ " joists. In the floor-ceiling assembly, the ceiling was separately supported on its own joists, contained simulated HVAC (Heating, Ventilation, and Air Condition) duct work and a layer of glass fiber batt insulation. During the tests which were conducted generally in accordance with the requirements of ASTM E 119-71, Fire Tests of Building Construction and Materials, the floors were loaded to represent the dead weight of structural parts bearing on them and a live load application of $40 \mathrm{psf}$. The test results are valid only for floors of similar construction loaded at or below the stress level developed by this loading.

Failure of the floor with the protective ceiling assembly occurred by flame-through to the unexposed surface at $29 \mathrm{~min}$, with extensive structural failure (collapse under load) following at $33 \mathrm{~min}$. The unprotected floor over the crawl space had a flame-through at $31 / 4 \mathrm{~min}$, and structural failure following at 3 $3 / 4 \mathrm{~min}$.

NBSIR 73-144. Climatological data at the proposed prototype sites in the United States for the evaluation of HUD Operation BREAKTHROUGH housing system, T. Kusuda, 136 pages (April 10, 1973). Order from NTIS as PB 220-849.

Key words: Air contamination; design conditions; earthquake risk; evaluation; ground temperature; humidity; noise level; Operation BREAKTHROUGH; precipitation; solar radiation; temperature; wind direction; wind speed.

The purpose of this report is to provide preliminary information on site climatology useful for the design and evaluation of HUD Operation BREAKTHROUGH experimental building systems. In order to evaluate the design as well as the performance of building systems, the following environmental parameters are considered essential and are included in this report for each of the selected sites: temperature, humidity, wind speed and direction, precipication (snow and rain), solar radiation (direct and diffuse), ground temperature (depth and frost), background noise level, air contamination, and earthquake risk.

NBSIR 73-146. Outdoor periormance of plastics X. final update of weathering data, W. J. Rossiter, Jr., 113 pages (March 1973). Order from NTIS as COM 73-10989.

Key words: Manufacturing Chemists' Association (MCS); performance of plastics outdoors; plastics; weathering of plastics.

Twenty plastics samples have been weathered in Arizona, Florida, and Washington, D.C. for 72 months. The weathering of these samples has been followed by measuring changes in the sperimen's color, tensile, flexure, gloss, and haze properties. Computer-generated graphs of these changes with time are presented.

NBSIR 73-148. Evaluation of the column connections used in a precast concrete modular housing system, F. Y. Yokel and T. W. Reichard, 90 pages (March 26, 1973). Order from NTIS as PB 220-366.

Key words: Building system; column connection; concrete triaxial strength; ductility; neoprene bearing pad; Operation BREAKTHROUGH; performance tests; precast concrete; structural design.

The column connections used in a housing system employing stacked precast concrete box modules were tested to evaluate their structural performance. The system was proposed for construction in Operation BREAKTHROUGH, a research and demonstration program sponsored by the Department of Housing and Urban Development. The system uses innovative struc- tural design concepts, which include: confinement of the concrete in the vicinity of the column bearings by reinforcing ties in order to increase concrete compressive strength; neoprene pads between column bearings in the upper stories; steelneoprene-steel sandwich in the lower stories; and a grouted dowel through the center of the columns to provide resistance to tension and shear.

The test program included the following: tests to determine the effect of various bearing pads on the load capacity of the connection; tests to determine the load-deformation characteristics of the neoprene pads; a test to determine the performance of a lower-story connection using a steel-neoprene-steel sandwich and a grouted dowel; and tests to evaluate the strength and ductility of the connections when subjected to a shear force. The test results are presented and interpreted and the findings are summarized.

NBSIR 73-161. Field test of hydraulic performance of a singlestack drainage system at the Operation BREAKTHROUGH prototype site in King County, Washington, R. S. Wyly and D. E. Rorrer, 66 pages (May 1973). Order from NTIS as PB 225-310.

Key words: Crossflow; field testing, plumbing; performance criteria, plumbing; performance, functional; single-stack drainage; siphonage, induced; siphonage, self; test loads, hydraulic; trap-seal reduction detector; trap-seal retention.

A procedure for measuring the hydraulic performance of drain-waste-vent (DWV) systems in the field is described, and the results obtained with this procedure in a field demonstration of the hydraulic performance of a single-stack DWV system are presented.

Among the most important criteria for hydraulic performance of drain-waste-vent systems are the following: (1) Trap-seal retention in idle fixtures; (2) Ability of the system to resist the rejection of suds, sewage, or foul gases due to hydrostatic or pneumatic pressures in the DWV system; (3) Absence of cross flow between fixtures; (4) Absence of self-siphonage in the individual fixture traps.

Considering the needs for minimization of maintenance in service and for the continuation of venting during cold weather, the following additional criteria can be identified: (5) Ability to maintain adequate hydraulic performance over a long period of service without excessive maintenance of branch piping; (6) Adequacy of performance under climatic conditions conducive to frost closure of vent terminals.

The procedures for selection and application of hydraulic loads, based on state-of-the-art guidelines, are described as applied to the soil and waste stacks evaluated for conformance to criteria (1) through (4) above.

The results show adequate performance in relation to criteria (1) through (4), with a single example of non-conformance on criterion (3), subject to the limiting condition that some uncertainty exists as to the degree of leak resistance of the DWV systems made available for the tests.

Recommendations are offered concerning further work that could provide information to confirm estimated conformance to criteria (5) and (6).

NBSIR 73-164. Fire endurance test of a steel sandwich panel floor construction, B. C. Son, 25 pages (April 1973). Order from NTIS PB 221-642.

Key words: Fire endurance; fire test: flame penetration; floor assembly; housing systems; Operation BREAKTHROUGH: paper honeycomb; structural panel.

As a part of the evaluation of a housing system proposed under 
Operation BREAKTHROUGH, a fire endurance test was performed at the Vational Bureau of Standards on a floor, made up of sandwich panels consisting of a paper honeycomb core with steel and plywood surfaces, supported on steel joists.

The test method was generally in accordance with the rcquirements of ASTM E 119, Fire Tests of Building Construction and Materials, for loadbearing floor constructions. The applied live load was 40 psf and the test results are valid only for floors of similar construction loaded at or below the stress level developed by this loading.

Failure occurred by flame-through of the floor assembly in 8 min $45 \mathrm{sec}$, with structural failure (inability to sustain the applied load) following immediately.

NBSIR 73-165. Fire endurance test on a steel tubular column protected with gypsum board, B. C. Son, 23 pages (April 1973). Order from NTIS as PB $221-474$.

Key words: Fire endurance; fire test; housing system; multifamily housing; Operation BREAKTHROUGH; single family attached housing; steel tube column.

As a part of the evaluation of housing systems for Operation BREAKTHROUGH a standard fire endurance test was performed at the National Bureau of Standards on a load-bearing steel column construction for use in single-family attached and multifamily low-rise housing. The test method was generally in accord with the requirements of ASTM E 119. Standard Methods of Fire Tests of Building Construction and Materials. for a loaded column. The applied load was 7110 pounds peI column and the test results are valid only for columns of such construction loaded at or below the stress level developed by this loading.

The 3 in $\times 2$ in $\times 3 / 16$ in rectangular hollow tubular steel column was protected with two layers of gypsum board.

The fire endurance of the column assembly was established at $59 \mathrm{~min}$, when structural failure occurred

NBSIR 73-166. Fire endurance test of an interdwelling double wall construction of paper honeycomb and gypsum board, B. C. Son, 24 pages (April 1973). Order from NTIS as PB 222-297.

Key words: Fire endurance; tire test; flame penetration; glass reinforced plastic; housing systems; interdwelling wall; modular construction; Operation BREAKTHROUGH; paper honeycomb; structural panel.

As a part of the evaluation of a housing system proposed under Operation BREAKTHROUGH, a fire endurance test was performed at the National Bureau of Standards on a double wall as. sembly intended as an interdwelling separation for single family attached housing. Each wall of the assembly contained a core of paper honeycomb surfaced on both sides with glass fabric impregnated with polyester resin, and protective layers of gypsum board.

The test method was generally in accordance with the requirements of ASTM E 119. Fire Tests of Building Construction and Materials. The applied live load was 636 plf on each panel and the results of this test are valid only for walls of similar construction loaded at or below the stress levels developed by this loading.

The fire endurance of the first (fire-exposed) wall panel was 65 min:30 sec, based on flame penetration through cracks and openings formed on the back face of the first wall. The overall fire resistance of the double wall assembly was $79 \mathrm{~min}$ when pieces of the structural glass fabric of the front face of the second wall were observed falling into the furnace.
NBSIR 73-167. Fire endurance test of a roof/celling construction of paper honeycomb and gypsum board, B. C. Son, 20 pages (January 1973). Order from NTIS as PB 222-298.

Key words: Fre endurance, firc test, llamie-1hrough fatilure. structural panel: glass-fibric reinforced plastlc: housing systems: (Operallion BKLAKJHR()U(,H, pitper honeycomb; rouf/ceilıng assembly. structural panel.

In a program of evaluation of various housing systems proposed under Operation BRI:AKIHROL(1H. a lire en durance lest was performed at the Natlonial Burcalu of Slandards on a roof/ceiling assembly consistung of a paper honeycumb structural core surfaced both sides with gliss-fabric impregnuled with polyester resin and outer layers of gypsum board

The test method was generally in aceordance with the requirements of ASTM F 119. Fire Tests of Building Cunstruction and Materials, for loadbearing rool assemblies. The applied load was $15.9 \mathrm{psf}$ and the test results are valid only for roof/ceilings of similar construction loaded at or below the stress level developed by this loading.

Under a loading of 15.9 psf on a $13 \mathrm{ft} 5$ in span. which produced a stress equivalent 10 the application of 20 psf on a 12 $\mathrm{ft}$ span, failure occurred by flame-through of the roof/ceiling as sembly at $37 \mathrm{~min} 13 \mathrm{sec}$.

NBSIR 73-168. Fire endurance test of a fiber glass reinforced polyester double wall assembly, B. C. Son, 26 pages (April 1973). Order from NTIS as PB 221-184.

Key words: Fire endurance; fire test; glass fiber-reinforced plastic; housing systems; interdwelling wall: Operation BREAKTHROUGH.

As a part of the evaluation of a housing system proposed under Operation BREAKTHROUGH a standard fire endurance test was performed on a double wall assembly comprising a loadbearing interdwelling (party) wall for single family attached housing. The test method was in accordance with the requirements of ASTM E 119, and the applied load was 700 pounds per linear foot $(p / f)$ per wall. The test results are valid only for wails of similar construction loaded at or below the stress level developed by this loading.

The double wall, representative of an interdwelling (party wall) separation. was made up of two identical parallel panels from two adjacent modules separated by a $21 / 4$ in air space. Each wall assembly contained glass fiber-reinforced polyester (GRP) sheet faces, glued to a corrugated GRP stiffener core. The GRP core members were painted with an intumescent type fire retardant paint and the core spaces were filled with mineral wool insulation.

The fire endurance of the first (fite-exposed) wall was 27 $\min : 25 \mathrm{sec}$ with the initial mode of failure by siructural collapse.

The second (unexposed) wall failed at $42 \mathrm{~min}$ when a hot (charred) spot was observed on the unexposed surface.

NBSIR 73-169. Fire endurance test of a wood stud interdwelling double wall construction, B. C. Son, 21 pages (April 1973). Order from NTIS as PB 221-185.

Key words: Fire endurance: fire test; flame-through failure of walls; housing systems; interdwelling wall: Operation BREAKTHROUGH.

As a part of the evaluation of a housing sy'stem proposed under Operation BREAKTHROUGH a standard fire endurance test was performed on a double wall construction representing a nonload-bearing interdwelling wall for single family attiched housing. The test was conducted at the National Bureau of Standards and followed the requirements of ASTMI E 119. Fire Tests of Building Construction and Materials. 
The double wall which represented an interdwelling separation between two adjacent modules, was made up of two identical parallel walls separated by a $1 / 2$ in air space. Each wall contained two layers of fire-rated gypsum board attached to wood stud framing on the dwelling room side.

Since the test assembly represented a nonbearing wall, no load was applied during this test.

The failure of the first (fire exposed) wall occurred at I $h: 17$ min when a joint in the second layer of gypsum board opened to allow passage of flame.

The second (unexposed) wall failed at $2 \mathrm{hr} 19 \mathrm{~min}$ when the temperature rise at one point on the exposed surface exceeded the maximum allowable.

NBSIR 73-170. Fire endurance test of an interdwelling double wall constructed of polyurethane focm-filled sardwich panels, B. C. Son, 27 pages (April 1973). Order from NTIS as PB 221-193.

Key words: Fire endurance; fire test; housing systems; interdwelling wall: load failure; modular construction; Operation BREAKTHROUGH; polyurethane foam; toxic gases.

As a part of the evaluation of housing systems for Operation BREAKTHROUGH, a standard ASTM E 119 fire endurance test was performed on a double wall assembly comprising a loadbearing interdwelling (party) wall for single family attached housing.

The test was generally in accordance with the requirements of ASTM E 1 19, Fire Test of Building Construction and Materials. The applied live load was 678 pounds per linear foot (plf) per Nall and the test results are valid only for walls of similar construction loaded at or below the stress level developed by this loading.

The fire endurance of the first (fire exposed) wall, based on structural load failure, was $1 \mathrm{hr}$ and $4 \mathrm{~min}$. The test was discontinued at $1 \mathrm{hr}: 06$ min because of untenable conditions in the test building resulting from smoke and combustion gases released by the polyurethane foam insulation in the wall.

NBSIR 73-173. Fire endurance tests of double module walls of gypsum board and steel studs, B. C. Son, and H. Shoub, 32 pages (April 1973). Order from NTIS as COM 73-10844.

Key words: Fire endurance; fire tests; housing systems; modular construction; Operation BREAKTHROUGH: steel framing.

Standard fire endurance fire tests were conducted on two 8-ft high by 16-ft long assemblies, each consisting of double modular partition walls. In these tests, the applied loads represented the weight of modules supported by the walls, and other applicable design live loads. The partitions were of gypsum board on metal studs and simulated the juxtaposition of walls of two adjoining housing modules. As each of the parallel module walls was an independent load bearing member both were required to meet a specified fire endurance under the applied load in tests conducted in accordance with the requirements of ASTM E 1 19-71. Fire Tests of Building Construction and Materials.

The load applied was 1078 pounds per linear foot (plf) per wall and the test results are valid only for walls of similar construction loaded at or below the stress level developed by this loading.

The fire exposed wall of the first test specimen (with 3 in " $\mathrm{C}$ " type studs) failed structurally at $42 \mathrm{~min}$ and the outer wall failed structurally at $1 \mathrm{hr} 13 \mathrm{~min}$. In the second test specimen, with tubular studs for increased strength, the fire exposed wall failed structurally at $1 \mathrm{hr} 7 \mathrm{~min}$ and the outer wall failed at $1 \mathrm{hr} 37 \mathrm{~min}$ by passage of hot gas.
NBSIR 73-177. Comparison of the fire performance of meoprene and flame retardant polyurethane mattresses, W. J. Parker, 46 pages (Apr. 1973). Order from NTIS as COM 7510336 ,

Key words: Fire retardant; fire test; heat release ignition; mattress; smoke; toxic gases.

Full scale fire tests of a neoprene and two different types of flameretardant polyurethane mattresses were performed in a room-sized compartment at the National Bureau of Standards. The mattresses were tested in two orientations, horizontal and vertical and with two types of coverings, a fire retardant treated cotton and a high temperature nylon ticking, in addition to the bare matiress insert. In addition to the visual observations, the burning rates, ceiling temperatures, optical density of the smoke, and the toxic gas concentrations were measured. This series of tests were repeated on small mattress sections to examine the relevance of small scale tests as a means of predicting full scale behavior. The flame spread index was measured with the radiant panel (ASTM E162); and the smoke and toxic gas concentrations were measured in the NBS smoke density chamber. Measurements were also performed in the heat release rate calorimeter and the ease of ignition test apparatus.

NBSIR 73-187. The effect of impact loadings on the performance of wood joist subflooring systems, H. S. Lew, 49 pages (May 1973). Order from NTIS as PB 221-188.

Key words: Concentrated loads; deflection; floor hardboard; housing; impact energy; Operation BREAKTHROUGH; plywood; subfloors; underlayment: wood; wood joists.

This report presents the results of an experimental study of wood-joist subflooring systems subjected to impact load. Six different types of subflooring systems were tested following the test method described in the ASTM Standard Methods (ASTM Designation E-72). The magnitude of impact load was varied by dropping a 60-lb bag from different heights.

A concentrated static load of $400 \mathrm{lb}$ was applied to the subfloor after it was exposed to impact load. It is suggested that the deflection under this concentrated load be used as a measure of the impact resistance of the subfloor.

NBSIR 73-188. Structural tests on housing components of glass fiber reinforced polyester laminate, T. W. Reichard, W. E. Greene, Jr., L. E. Cattaneo, and L. W. Masters, 98 pages (April 1973). Order from NTIS as PB 221-183.

Key words: Adhesive bond: aging; composites; compression; flexure; glass fiber; housing system; innovations; laminate; Operation BREAKTHROUGH; racking: reinforced plastics; reinforced polyester: sustained loading; tensile shear.

This report describes a series of structural evaluation tests performer on housing components made with a glass fiber reinforced polyester (FRP) laminate. The components tested were: (1) the FRP laminate used for the facings and the corrugated ore of the basic panel; (2) the adhesive bond between the facing and core; (3) typical wall panels; and (4) typical roof panels. Test data include: (1) the effect of temperature and moisture on the iensile and compressive strength of the FRP laminate; (2) the effect of temperature, accelerated aging and sustained loads on the tensile shear strength of the facing-to-core polyester adhesive bond; (3) the short-term strength of the wall panels under compressive and in-plane shear loading; (4) the long-term strength of the wall panels under sustained compressive loading; and (5) the short-term and long-term performance of the roof panels under flexural loading. 
NBSIR 73-190. Acoustical evaluation of a single family attached steel frame modular housing system constructed on an Operation BREAKTHROUGH prototype site, T. L. Quindry, 21 pages (April 1973). Order from NTIS as PB 221-189.

Key words: Acoustics; noise isolation class: Operation BREAKTHROUGH.

The acoustical performance of a single family attached steelframe modular housing system was tested on an Operation BREAKTHROUGH prototype site.

Test results are given concerning the noise isolation of interdwelling walls, the noise isolation of intradwelling walls and floor-ceiling assemblies.

NBSIR 73-191. Acoustical evaluation of a single family attached wood-frame modular housing system constructed on an Operation BREAKTHROUGH prototype site, T. L. Quindry, 21 pages (April 1973). Order from NTIS as PB 221-695.

Key words: Acoustics; field impact insulation class: noise criterion curve; noise isolation class: Operation BREAKTHROUGH.

The acoustical performarice of a single family attached woodframe modular housing system was tested on an Operation BREAKTHROUGH prototype site.

Test results are given concerning the noise isolation of intradwelling walls and floor-ceilings, as well as the noise levels within living units.

NBSIR 73-192. Acoustical evaluation of a single family detached honeycomb panel housing system constructed on an Operation BREAKTHROUGH prototype site, T. L. Quindry, 19 pages (April 1973). Order from NTIS as PB 222-231.

Key words: Acoustics: noise criterion curves; noise isolation class: Operation BREAKTHROUGH

The acoustical performance of a single family detached honeycomb panel housing system was tested on an Operation BREAKTHROUGH prototype site.

Test results are given concerning the noise isolation of intradwelling walls and the noise levels within living units.

NBSIR 73-208. Residential buildings and gas-related explosions, E. F. P. Burnett, N. F. Somes, and E. V. Leyendecker, 32 pages (June 1973). Order from NTIS as COM 74-10127.

Key words: Building; explosion; frequency; gas; gas industry; progressive collapse; risk; statistics; structure.

The findings of an analysis of available statistics concerning the frequency of gas-related explosions in residential buildings are presented. The study was confined to incidents involving piped gas systems as they affect residential and commercial buildings. Though due regard has to be taken of the limitations inherent in the available statistics, it is concluded that in the USA the probability of occurrence of an explosion capable of causing significant structural damage could be 2.2 per million housing units per year.

NBSIR 73-220. Test of a polyester composite wall panel for moisture accumulation and potential removal of moisture through venting, C. I. Siu, W. M. Ellis, and T. Kusuda, 18 pages (May 1973). Order from NTIS as PB 222-437.

Key words: Composite wall panel: condensation: humidity: moisture; pressure: temperature.

A polyester composite exterior wall panel was exposed to ac- celerated winter temperature and humidity eondistors for the purpose of determining performanee with respect fo mossture ac cumulation and release as at resiste of pessure and teinperature differences. No moisture contensation within the wall sy stem was detected from visual exarninations made at vartous tunes of the testing period: no significant increase in pross weypt of the wall was found from the direct weighıngs of the wall system Results also indicate that a wet insulatson in such is wall system is unlikely to be dried out by natural thermal action and eonvee tive motion.

NBSIR 73-221. Abnormal loading on buildings and progressive collapse, N. F. Somes, 76 pages (May 1973). Order from NTIS as PB 220-849.

Key words: Abnormal loading: huilding: codes. design criteria: multistory: progressive collapse: risk: stabılıty standards: strength: United States.

The document is an interim report of ongoing studies at the National Bureau of Standards. It defines the several aspects of abnormal loading on buildings and the problem of propressive collapse. It documents the extent to which present $L$ S Codes and Standards address the problem.

Abnormal loadings are identified, classified and discussed with regard to their characteristics and frequencies of occurrence. The report reviews the state of international knowledge of the characteristics of abnormal loadings and the response of buildings and building elements to these loadings. The latter includes discussion of several incidents in which multistory buildings have collapsed progressively.

Using currently available statistics an estimate is rade of the combined frequency of abnormal loading, on residential buildings in the U.S. For buildings susceptible to progressive collapse. the corresponding risk of fatality is compared with the levels of risk that society will generally accept. The risk is further compared with the rish of mortality associated with fire in res. idential buildings, an area of considerable public concern and expenditure.

It is concluded that U.S. standards-writing bodies should adopt appropriate rational criteria as soon as possible to reduce the risks of progiessive cullapse. There are several areas in which criteria might be introduced to reduce the risk of progressive collapse. These are discussed; particular attention is given to the philosophies behind the structural criteria implemented in the USA and other countries.

NBSIR 73-228. Summary of fame spread and smoke generation tests conducted for Operation BREAKTHROUGH, J. B. Ferguson, 27 pages (July 1973). Order from NTIS as PB $222-425$.

Key words: Carpets: flame spread: kitchen cabinets: Operation BREAKTHROUGH: smoke generation: wall and ceiling.

This document is a listing of the flame spread and smoke generation results of a range of materials that were tested under the Operation BREAKTHROUGH housing evaluation program. The test results reported here were obtained under differing conditions and should not be considered the results of a comprehensive and unified research program for evaluation of interior finish materials. Tables of test results and a brief discussion of the resulks are presented for walls, ceilings. kitchen cabinets and floor coverings.

NBSIR 73-231. Response characteristics of a portable x-ray nuores. cence lead detector: Detection of lead in paint. J.C. Spurgeon. 31 pages (June 1973) Order from NTIS as PB-224-645.

Key words: Leaded paint detection; portable $x$-ray tuorescence lead detector; portable $\mathrm{x}$-ray fluorescence lead calibration standards. 
The objective of this investigation was to obtain an indication of the validity of the field data resulting from the use of portable $\mathrm{x}$-ray fluorescence lead detectors by local lead paint detection programs. This report is intended to provide guidance in the use of portable $\mathrm{x}$-ray fiuorescence lead detectors by housing and/or health authorities who are responsible for the collection and interpretation of field data as part of lead paint control programs.

The response characteristics of such an instrument to conditions that are related to those encountered in the field have been investigated and the results are presented in this report. The affects of calibration standards, state of charge, paint overlayers, substrate, and distance on instrument response are discussed, in addition to the limit of detection and precision. The accomplishment of these tasks required the development of panel-type lead calibration standards. These standards encompass the concentration range from $0.1 \mathrm{mg} / \mathrm{cm}^{2}$ to $9.0 \mathrm{mg} / \mathrm{cm}^{2}$.

NBSIR 73-242. Pilot demonstration of lead based paint hazard elimination methods, T. H. Boone, T. R. Ray, W. G. Street, 38 pages (June 1973). Order from NTIS as PB 224-654.

Key words: Cost analysis; hazard elimination; housing; lead based paint; materials; surface preparation; surface refinishing.

This report describes the elimination of the hazard of lead bearing paints in a one bedroom apartment using materials and procedures that are undergoing laboratory and field evaluation by the National Bureau of Standards (NBS). Paint removal was used to eliminate the hazard from some surfaces and two nonhazardous membrane type coverings were installed as barrier materials over the residual leaded paint on other surfaces. The preparation and refinishing of the interior surfaces are described and work rates and cost data are presented.

This pilot demonstration is the first of a series of studies that will be used to determine the merits of various lead based paint hazard elimination methods when applied to actual housing conditions.

Final recommendations for further use of materials and systems, described in this report, are not presented due to the preliminary nature of this work. The completion of the projected series of demonstrations and the long term evaluation of the inuse performance of the materials and systems will be required befre final recommendations can be made.

NBSIR 73-25i. Analytical methods for the detection of toxic elements in dry paint matrices - a literature survey, M. Paabo, 42 pages (July 1973). Order from NTIS as PB 224-688.

Key words: Analytical methods; antimony; arsenic; cadmium; lead; mercury; review; selenium; toxic elements in paints.

This report is a summary description of the chemical procedures currently available for the analysis of selected toxic elements in dried paint. The elements included in this report are lead, mercury, cadmium, antimony, aisenic, and selenium. The literature search upon which this report is based was directed primarily toward references pertaining to the analysis of dried paint. A bibliography of 57 references to wet chemical analysis, colorimetry, atomic absorption spectroscopy, electrochemistry, neutron activation analysis, and $\mathrm{x}$-ray emission analysis is presented.

NBSIR 73-263. Fire endurance tests of unprotected wood-floor constructions for single-family residences, B. C. Son, 65 pages (July 1973). Order from NTIS as PB 225-284.

Key words: Fire endurance; fire test; flame through; full scale; housing; Operation BREAKTHROUGH; single family residence; small scale; thermal resistance; wood floor; wood joist.

Fire endurance tests were performed on two full-scale and twelve small scale wood floor constructions. The fire endurance ratings on unfinished wood joist and plywood subfloor constructions varied from 10 to 13 minutes and were mainly determined by the time to "flame through." In small-scale tests, the addition of carpeting with a hair pad delayed the time of "flame through" approximately 8 minutes. Time to "flame through" may be estimated from the thermal resistance of the construction, and may be modified by the effects of applied load or construction details such as gaps, joints, and penetrations.

NBSIR 73-266. Fire spread on exterior walls due to flames emerging from a window in close proximity to a reentrant wall corner, B. C. Son and J. B. Fang, 25 pages (April 1973). Order from NTIS as PB 225-286.

Key words: Exterior wall; fire spread; fire test; ignition; Operation BREAKTHROUGH; reentrant corner.

As a part of the research program concerning the recommended criteria for fire safety in Operation BREAKTHROUGH, two full scale fire tests were performed on a mockup of a reentrant corner, i.e., the interior corner formed at the intersection of the exterior walls of adjacent buildings, such as townhouses and garden apartments.

In each test, two wall specimens representing exterior walls were erected perpendicular to a wall containing a window opening into a fire room. One wall was located 1 foot east and the other one 5 feet west of the edges of the window. The objective of the reentrant corner fire test was to study the potential ignition and spread of fire from the room to an adjacent exterior combustible wall.

In the first test, charring on the east wall, but no surface ignition was observed during the test. The peak temperature measured did not exceed $350^{\circ} \mathrm{C}\left(660^{\circ} \mathrm{F}\right)$. In the second test, surface ignition occurred on the east wall 9 minutes after the wood crib. representing the combustible contents of the room, was ignited. No significant changes were observed on the west wall during either test.

The instantaneous heat tlux incident on the east wall just prior to ignition and the total heat energy absorbed were estimated to be on the order of $1.0 \mathrm{~W} / \mathrm{cm}^{2}$ and $175 \mathrm{~J}$ oules $/ \mathrm{cm}^{2}$ respectively.

NBSIR 73-267. Report of fire tests on flexible connectors in HVAC systems, L. A. Isen, 67 pages (July 1973). Order from NTIS as COM 73-11955.

Key words: Aluminum; ductwork; fabric; fiberglass; fire tests; high rise buildings; HVAC systems; steel; terminal units.

The contemporary high rise building with its control air conditioning system and high content of synthetic materials presents a higher hazard than those erected prior to 1950. The ability of the duct work to resist fire breaking into it and spreading through the duct system is an important factor affecting the integrity of the building. Since they penetrate fire barriers, the flexible connectors between the main ducts and the terminal units are important elements in maintaining the desired fire resistance. Flexible connectors made of four different materials (aluminum, galvanized steel, felted fiberglass and woven fiberglass fabric) and two attachment techniques were subjected to fire tests in accordance with ASTM E119. The results show that the materials of the connectors must withstand the fire exposure, the connectors must remain tightly attached to the main duct, and the penetrations through the fire barrier must be suitably blocked in order to prevent fire from breaking into the duct system. The tests also showed that rubber and plastic materials in the terminal units can produce significant amounts of irritating smoke.

NBSIR 73-277. Evaluation of a pressurized stairwell smoke control system for a 12 story apartment building, F. C. W. Fung, 53 pages (June 1973). Order from NTIS as PB 225-278. 
Key words: Analysis; basic correlation formulas; computer calculations; high-rise building fire; Operation BREAKTHROUGH: pressurized stairwell; quantitative experiment; smoke control; smoke simulation.

An NBS study to evaluate the effectiveness of a pressurized stairwell smoke control system in a high rise apartment building is summarized and discussed in the light of experimental results, analysis, and computer prediction. A quantitative experimental technique of smoke simulation and smoke movement measurement is described, supplemented by basic physical laws necessary for correlation with small fires, and illustrated by the results of an actual field experiment. Experiments were conducted in a 12 story apartment building constructed on the Operation BREAKTHROUGH prototype site in St. Louis, Missouri. The experimental results are then further extended to a wider range of ambient weather conditions by way of computer prediction calculations. General conclusions and relevant recommendations as a result of the siudy are also presented.

NBSIR 73-288. Swiss building and housing research activities, $\mathrm{H}$.

R. Treschsel, 63 pages (August 1973). Order from NTIS as COM 73-11861.

Key words: Building research; buildings; cooperation; nousing; international; Switzerland.

Following up earlier contacts of CBT management with representatives of Swiss building research organizations, the author visited Switzerland in the Fall of 1972 for two weeks.

This report discusses the results of meetings with representatives of the Swiss Federal Commission for Housing Research (FKW), major educational and research establishments, architects, contractors, builders, and local building officials. Topics covered in the discussions included building economics, modular coordination, pre-evaluation of performance of housing projects, pre-evaluation of research projects, building design, land use and planning, transportation, and building laws, codes, and standards.

It appears that cooperative programs in any or all of these areas could be profitable to NBS, and to the corresponding Swiss organizations.

NBSIR 73-294. Cost sharing as an incentive to attain the objectives of shoreline protection, H. E. Marshall, 70 pages (Dec. 1973). Order from NTIS as COM 74-10541.

Key words: beach erosion control; cost sharing; economics; efficiency; equity; incentives: shoreline protection.

The nation's shorelines are being eroded by high winds and waves. Nonfederal interests have traditionally received Federal help in the form of cost sharing for protective structures. This study provides the Army Corps of Engineers with an evaluation of alternative cost-sharing rules for shoreline protection with respect to efficiency, equity, and administrative feasibility.

Existing cost-sharing rules are described for hurricane, beach erosion, and emergency protection. The present cost-sharing system appears to induce local interests to choose (1) costly techniques of protection, e.g., engineering rather than management techniques, and (2) overbuilt projects in terms of the efficient scale.

It is concluded that the Association Rule, which requires local beneficiaries of shoreline protection to share in all of the costs of a project purpose in the proportion that local benefits bear to national benefits at the margin, should be applied to all shoreline protection programs. All techniques of protection should be subject to the same percentage cost-sharing rule. It is also concluded that all categories of project costs should have the same percentage cost share apply to them. Finally, Federal cost sharing might be used as an incentive to encourage local interests to comply with minimum land use requirements that would prevent shoreline damages.
NBSIR 73-295. Interim report No. 7, chemical reslatance and physical durability testing of coutlng materlats, J K. Clifton, H. F. Beeghley, and R. G. Mathey, 22 pages (August 1973). Order from NTIS as CUM 74-10471

Key words: Bridge decks, corrosion. creep teslong epsxy coatings; polyvinylchloride coatıngs slect reinforsing bars.

The possibilities of protecting steel renforctng hars embedded in concrete of briclge decks from eorrosion by using erganic har rier-type coatings arc being investigeted in this project I hiscor. rosion is accelerated by the chloride ions of the two mest com monly applied deicing materials. sodium chloride and cialcum chloride.

In this report, physiochemical studies performed on coatings and coated bars are discussed. including immerst in studies of coatings in corrosive solutions: inpact and embedded in concrete.

NBSIR 73-407. Report on a pre-test of a survey plan for estimating incidence of lead based paint, L. S. Joel and H.W Berger, 86 pages (Dec. 1973). Order from NTIS as COM 74-11078.

Key words: lead, leid paint poisuning: patmes: pulsuning. retail inventory; statistics; survey.

Lead in paint has been indicled als a major callse of lead poisoning of children. Federal rezulations halve been established to limit the amount of lead which may be added to paints that are intended for residential use. The intent of such a limitation is to curtail the incidence of present and future leat hased paint poisoning of children.

This report presents the results of at "pre-test" for a nattonwide survey plan that would be used to determine the availability, to the public, of paints that may contitin lead compounds in hazardous quantities. Statistical summaries of the chemical analysis of 250 paints purchased by random selection al five relail outlets, are presented along with comments regatrdng the posstble implications of those results. Recommendations are made about survey action beyond the pre-test described herein.

NBSIR 73-421. An overview of the factors impacting metrication of the U.S. housing industry, R. G. Hendrickson and D. W. Corrigan, 35 pages (Dec. 1973). Order from NTIS as COM 74-11224.

Key words: codes: construction conference; domestic housing, U.S.; foreign metrication; levels of conversion; metrication; problems of metrication.

This report describes the work undertaken by the National Bureau of Standards for the Department of Housing and Urban Development to ascertain and delineate major problems associated with the metrication of the domestic housing industry of the United States. Source material for the study included, principally, the foreign experiences of Great Britain and Australia: information obtained from interviews with businesses and associations; depositions provided to the 1970 Construction Conference, held for the purposes of the U.S. Metric Study; and documents, both foreign and domestic, pertaining to aspects of metrication.

The results of the study indicate the critical impact of metrication will be the redefinition or accommodation of the 15.000 codes at the local level, and the coordination of the 127 standardsetting organizations in the United States to define, develop and implement standards consonant with requirements and desired industry goals.

NBSIR 74-432. 1972 International activities Center for Building Technology, C. C. Raley, 68 pages (Aug. 1973). Order from NTIS as COM 74-10751.

Key words: Cooperative programs; foreign visitors; information exchange; international building technology; interna- 
tional organization memberships; professional interaction.

This report summarizes the Center for Building Technology's 1972 international activities including formal cooperative programs, exchange programs, special projects, international organization memberships, foreign guests at CBT, and CBT foreign travel.

NBSIR 74-438. Pilot demonstration of lead based paint hazard elimination methods, T. H. Boone, T. R. Ray, and W. G. Street, 26 pages (Dec. 1973). Order from NTIS as COM 7410980.

Key words: Cost analysis; housing; lead based paint, lead poisoning; surface preparation; surface refinishing; water wash paint removal.

This report describes the removal of lead base paint from exterior surfaces of a single family attached house using alkaline/solvent thixotropic liquid paint removers followed by a high-pressure/low-volume water spray

The extent of the reduction of the lead based paint hazard, the cost of the process and the observed problems and merits of this water wash paint removal system are presented.

NBSIR 74-444. A review of natural stone preservation, G. A. Sleater, 40 pages (Dec. 1973). Order from NTIS as COM $74-$ 10548 .

Key words: Air pollution; historic structures; laboratory evaluation; natural weathering;stone decay; stone preservation.

With increased interest in stone preservation, it is desirable to know what causes stone to decay, and what materials can be used to preserve stone. This review covers the following topics: causes of stone decay, including faults in the stone, salts, natural weathering factors, air pollution, living organisms, and most importantly, water action; various materials that have been used to preserve stone, including paints, waxes, oils, inorganic chemical surface treatments and impregnants, silicones, siliconates, and synthetic organic polymers; methods of evaluating stone preservatives. Field and laboratory procedures for testing stone preservatives, the cleaning of stone, a glossary, and a bibliography are given in appendices.

NBSIR 74-449. Fire endurance tests on walls and plumbing chases containing either metallic or nonmetallic drain waste and vent systems, W. J. Parker, 83 pages (Nov. 1973). Order from NTIS as COM 75-10049.

Key words: ABS; drain; fire endurance; fire spread; fire test; plastic pipe; PVC; smoke; toxic gases; vent; waste.

Two full scale E-1 19 fire endurance tests were performend on "fire-rated" plumbing chase and wall assemblies containing PVC drain, waste, and vent (DWV) systems typical of installations serving two or more stories. The installations duplicated some of the kitchen sink drain systems employed in the Operation BREAKTHROUGH housing program. For the PVC DWV systems constructed and installed according to plans approved by the BREAKTHROUGH Office, the PVC piping did not contribute to the spread of fire through the plumbing chase from one side of the wall or chase to the other during the test which lasted 50 minutes. Although there was a wall failure not associated with the plastic pipes, there was no indication that there would have been a failure due to the plumbing if the test had continued for one hour.

Three full scale E-1 19 fire endurance tests were also run in which the performances of ABS, PVS, copper, and iron DWV piping were compared directly in kitchen sink drain systems installed in wood stud and gypsum board walls.

Neither PVC nor ABS piping contributed to fire spread in a DWV system consisting of 2 inch stacks and 1-1/2 inch back to back "poke through" laterals in a 2 x 6 fir stud and gypsum board wall. In one test in which the stacks and laterals were 4 in. in diameter and in another test in which the distance between wall surfaces was de- creased by using $2 \times 4$ studs, the effective fire endurance rating of che wall assenby was reduced by the installation of the plastic piping.

NBSIR 74-452. Design and evaluation criteria for energy conservation in new buildings, J. Heldenbrand, editor 99 pages (Feb. I974). Order from NTIS as PB 204-586.

Key words: Design criteria; energy conservation; evaluation criteria; new buildings; requirements.

This document is a set of design and evaluation criteria for energy conservation in most types of new buildings. The National Conference of States on Building Codes and Standards (NCSBCS) requested that the National Bureau of Standards (NBS) develop such a document with the intent that it could serve as a basis for a national standard developed through the voluntary consensus process.

The design and evaluation critera focus on building sublements and service system arrangements. Special provisions offer added flexibility for both conventional and innovative designs. The technical portions of the document are organized into four complementary sections: requirements, criteria, evaluation, and commentary. Existing standards and procedures promulgated by organizations such as the American Society of Heating, Refrigerating and Air Conditioning Engineers (ASHRAE), the American Society for Testing and Materials (ASTM), and the American National Standards Institute, Inc. (ANSI) are referenced whenever possible. The evaluation statements describe how to verify that candidate solutions meet the stipulated criteria and, in a number of cases, explain how the criteria were selected.

NBSIR 74-456. Evaluation of the fire performance of a dibromotetrafluoroethane-blown rigid polyurethane foam, $\mathrm{T}$. G. Lee, W. J. Parker, and M. Tryon, 17 pages (Apr. 1974). Order from NTIS as COM 74-1 1793.

Key words: Dibromotertrafluoroethane; fire tests; flame spread index; heat release rate; ignition temperature; rigid urethane foam; smoke.

The fire performance characteristics of a dibromotetrafluoroethane-blown rigid polyurethane foam were measured by several laboratory test methods. Measurements included: surface flammability, smoke and gases generated at elevated temperature and during combustion, ignition temperature, rate of heat release, and fire growth. The maximum concentration of the blowing agent in the specimen was approximately $13 \mathrm{Wt} \%$. Specimen density was $0.046 \mathrm{~g} / \mathrm{cm}^{3}$. As a function of temperature, release of blowing agent from collapsed cells began at about $60^{\circ} \mathrm{C}$ and became considerable at $135^{\circ} \mathrm{C}$. The material had a flame spread index (ASTM E-162) of 11 with smoke levels of 170 and 480 (maximum specific optical density) under nonflaming and flaming exposures, respectively. The measured rate of heat release was $8.8 \mathrm{~W} / \mathrm{cm}^{2}$, about 5 times that of a fibrous glass insulation. The measured flash ignition temperature was $530^{\circ} \mathrm{C}$ for the material.

NBSIR 74-467. Simulated solar heat tests on M.U.S.T. air-inflatable, double-wall hospital ward shelters, L. W. Masters, J. W. Grimes, and R. A. Crist, 64 pages (May 1974). Order from NTIS as COM 74-11754.

Key words: Adhesives; air-inflatable shelter sections; cloth webs; polyester and nylon fabrics; sewn seams; sewn seam strapping; solar heat load; test procedure.

At the request of the United States Army Natick Laboratories (USANLABS), the Center for Building Technology conducted solar heat load tests on five sections of M.U.S.T. air-inflatable, double-wall hospital ward shelters. The purpose of the tests was to evaluate the effect of solar heat load, as simulated by infrared heat lamps, on various materials and construction designs proposed for use in shelters. 
NBSIR 74-473. Natural disasters: Some empirical and economlc considerations, G. T. Sav, 72 pages (Feb. 1974). Order from NTIS as COM 74-11719.

Key words: Benefit-cost analysis; disaster mitigation; earthquakes; 'economics; efficient; floods; hurricanes; natural disasters; optimal; tornadoes; total cost minimization.

This study examines the extent of some of the losses resulting from natural disasters. An estimate of these losses is necessary in order to determine the potential benefits that might be realized from mitigating the negative economic impacts from natural disasters. Absolute and relative losses resulting from hurricanes, floods, earthquakes, and tornadoes are examined. This data will help individuals, communities, and the Federal government make better decisions as to how and what extent protection against disasters should be provided. The application of benefitcost analysis for choosing the optimal level of protection against disasters is also discussed. Recommendations are made for further research in determining the economic feasibility of various techniques designed to mitigate the losses from disasters.

NBSIR 74-479. Analysis of cost-sharing programs for pollution abatement of municipal wastewater, H. E. Marshall and R. T. Ruegg, 145 pages (Sept. 1974) Order from NTIS as COM 7411769.

Key words:Cost sharing; efficiency; equity; financing; nonplant treatment; sewage treatment, user fees; water pollution.

This study evaluates existing cost-sharing programs for wastewater pollution abatement as described in the Federal Water Pollution Control Act Amendments of 1972, describes alternative cost-sharing programs that provide improvements in terms of national cificiency and equity criteria as defined herein, and suggests related areas for further research. Emphasis is on how Federal cost sharing biases communities in favor of certain kinds of techniques. The approach is to describe the current cost-sharing programs for both plant and nonplant techniques; to examine cost-sharing, legal, and other institutional biases against certain techniques; to analyze efficiency and equity effects of alternative cost-sharing programs; and to describe the incentive effects of cost-sharing on nonfederal interests with respect to their choices among abatement techniques. Findings of the study are that more efficient abatement will result if the sume percentage cost share applies to all plant and nonplant techniques of abatement; the sume percentage also applies to all categories of cost (e.g., capital, land, operation and maintenance) for a given technique; the same percentage applies to large and small communities; institutional constraints on the selection of nonplant techniques are removed; and if the program provides for Federal cost sharing of every abatement technique that is technically viable.

NBSIR 74-495. Development of a radlant panel test for flooring materials, L. G. Hartzell, 79 pages (May 1974). Order from NTIS as COM 74-11575.

Key words: Carpet; fire test; flammability; flooring; heat flux; ignition; radiant panel.

This paper summarizes the work of a year long program to continue the development of a radiant panel type test for flooring materials, the original concept of which was developed at the Armstrong Cork Company's Research and Development Center in Lancaster, Pennsylvania. This program at the National Bureau of Standards had as its goal, the further development of the test for possible adoption as a standard ASTM test method.

The program work was divided into five phases. During the first phase, an attempt was made to duplicate the performance of the original apparatus in a similar one at the National Bureau of Standards Laboratory. The proof of this duplication was shown in replicate testing using a wide range of flooring on both apparati.

In the second phase of the program, a new set of test conditions were found in an attempt to eliminate some of the more serious equipment and procedural problems of the test I these new conditions provided the test with the ibslity (o) rite flesoring materials according to their ability to resstst the surface spread flames.

Under the third and fourth phases of the program, the effects of changes in some test parameters was investagated and uther test characteristics were measured. Phase V, the datis atnislysis and report, concluded the program.

NBSIR 74-497. US/LK Jolnt complementary research program In bullding, (wlnd loads, water supply, nre detectlon), July 1972 June 1973, C. C. Raley, I. A. Benjamin, R. D. Marshall, and J. E. Snell, 24 pages (Oct. 1973). Order from NTIS as COM 74. 11269.

Key words: Cooperative programs; fire safety; hydraulics; international building technology; wind loads.

This is a status report of the progress achieved under the "Joint Complementary Research Program" sponsored by the Building Research Establishment (UK) and the (entcr for Build. ing Technology (US), during the period July 1972 through June 1973. The program includes three projects: Wind Loads on Buildings. Design of Water Supply and Drainage Installattons in Buildings, and Fire Detection in Buildings, each of whuh is discussed in the report.

NBSIR 74-514. 1973 international activities. Center for Buildin Technology, C. C. Raley, 54 pages (July 1974). Order from NTIS as COM 75-10102,

Key words: Cooperative programs; foreign visitors; information exchange; international building technology; international organization memberships; professional interaction.

This report summarizes the Center for Building Technology's 1973 international activities including formal cooperative programs, exchange programs, special projects, international organization memberships, foreign guests at CBT, and CBT foreign travel.

NBSIR 74-520. Evaluation of structural properties of masonry in exlsting buildings, S. G. Fattal and L. E. Cattaneo, 127 pages (July 1974). Order from NTIS as COM 74-1 | 480

Key words: Analysis; compressive strength; deflection; design; flexural strength; masonry walls; racking strength; seismic loading; shear strength; shear wall; stiffness

The current state of knowledge on the structural behavior of masonry is synthesized to develop a methodology for the evaluation of the load capacity of masonry walls in existing buildings. A procedure is described for direct sampling and testing of specimens removed from masonry walls of buildings to determine their strength in shear. flexure and compression, and to measure their load-deformation characteristics. A documentation of strength and stiffness properties obtaincd from a ailable test data is included to provide an atternate source of informatton on masonry of comparable construction. Sample calculations of masonry building analysis for seismic lorces are given in Appendices $\mathrm{A}$ and $\mathrm{B}$.

NBSIR 74-526. Analysis of non-reinforced masonry building response to abnormal loading and resistance to progressive collapse. W. McGuire and E. V. Leyendecker, 67 pages (Nov. 1974). Order from NTIS as COM $75-10087$.

Key words: Abnormal loading; building; gas explosion: load bearing masonry; load-bearing walls; masonry; masonry research; progressive collapse.

Five case studies of susceptibility to progressive collapse uere made of non-reinforced masonry bearing wall buildings. All were assumed to comply with governing building codes. Based on the assumed failure mechanisms, analysis indicated that two of the structures had excellent resistance to progressive collapse. one was marginal, and two had little resistance to progressive collapse. Analytical approaches used are illustrated and areas of needed research are identified. 
NBSIR 74-531. Review of performance characteristics, standards and regulatory restrictions relating to the use of thermoplastic piping in residential plumbing. R. S. Wyly, W. J. Parker, D. E. Rorrer, J. R. Shaver, G. C. Sherlin, and J. Tryon, 68 pages (Mar. 1975).

Key words: Fire performance of piping; functional performance of piping; performance characteristics for piping; thermal/structural performance of piping; thermoplastics in plumbing.

The paper is a review of existing information on the physical characteristics of thermoplastic piping that are of particular interest in considering its potential for use in residential, aboveground plumbing. The presentation is oriented to considerations of adequacy of functional performance of plumbing systems from the user's/owner's viewpoint in contrast with the typical product-specification oriented format reflected in current standards.

Not only are the physical characteristics emphasized that relate most directly to the determination of functional performance of installed systems, but the importance of design and installation detail in this context is discussed.

In conclusion, this review indicates the need for better use of existing knowledge as well as for some research and test development work particularly in the areas of thermal properties, response to building fires, and resistance to water hammer.

NBS1R 74-542. Economics of protection against progressive collapse, R. E. Chapman and P. F. Colwell, 34 pages (Sept. 1974). Order from NT1S as COM 75-10081,

Key words: Benefit-cost analysis; building safety; economics; progressive collapse; standards.

Public and government concern about the progressive collapse of buildings caused by abnormal loading has resulted in the development of draft standards to provide protection against progressive collapse. From society's viewpoint, standards for protection against progressive collapse should result in a level of protection which is more efficient (i.e., the net social benefits from protection should be increased). An economic model utilizing the principles of benefit-cost analysis is developed which establishes a methodology for determining the efficiency of various levels of protection against progressive collapse. An application of the model to a partial evaluation of a specific standard demonstrates some of the capabilities of the model. Recommendations are made for a complete evaluation of this standard and for the further refinement of the model.

NBSIR 74-567. FY 74 progress report on design criteria and methodology for construction of low-rise buildings to resist typhoons and hurricanes, N. J. Raufaste, Jr., and R. D. Marshall, 276 pages (July 1, 1974). Order from NTIS as COM 74. 11631 .

Key words: Buildings; construction; data acquisition equip. ment; design criteria; disaster mitigation; extreme winds; information transfer; instrumentation; wind loads; wind tunnel modeling.

This report gives the major accomplishments of the second phase of a three year project to provide engineering and technical assistance to the Agency for International Development (AID), Department of State in developing improved design criteria for low-rise buildings to better resist extreme winds. During FY 74, the Center for Bunding Technology project staff members commenced several tasks. These tasks will serve as major inputs to the development of improved design criteria. The principal tasks include: 1) selecting a second and third field test site in the Philippines, 2) instrumenting four full scale houses, at the sites, 3) instrumenting the University of Philippines wind tunnel facility, 4) participating in an International Workshop at Manila during November 1973, and 5) developing, in conjunction with short-term consultants in Bangladesh and Jamaica, a methodology for the transfer of technology.
NBSIR 74-574. NBSLD, computer program for heating and cooling loads in buildings, T. Kusuda, 414 pages (Nov. 1974). Order from NTIS as PB 246-184.

Key words: ASHRAE Task Group on Energy Requirements; conduction transfer functions; heating and cooling load; National Bureau of Standards Heating and Cooling Load Computer Program.

A comprehensive computer program called NBSLD, the National Bureau of Standards Load Determination program, has been developed at NBS to reflect the time change of the many building parameters which are pertinent to accurate estimation of energy usage for heating and cooling. Current status of heating and cooling load techniques is reviewed. Of general interest are unique features of NBSLD which are not available in existing computer programs. A summary of various subroutines of NBSLD is given along with the detailed procedures for them. These subroutines constitute the recommended subroutine algorithms of the ASHRAE Task Group on Energy Requirements. Complete Fortran listing of NBSLD and data preparation forms are given for those who wish to use the program. The NBSLD computation is on the basis of the detailed solution of simultaneous heat balance equations at all the interior surfaces of a room or space. Transient heat conduction through exterior walls in the interior structures is handled by using conduction transfer functions. The use of heat balance equations, although time consuming in calculation, can avoid the vagueness and uncertainties inherent in the more popularly used weighting factor approach. In addition, it is more accurate for a specific building design.

NBS1R 74-582. FY 1973 progress report on design criteria and methodology for construction of low-rise buildings to better resist typhoons and hurricanes, N. J. Raufaste and R. D. Marshall, 31 pages (July 2, 1973). Order from NT1S as COM 74-11645.

Key words: Construction; design criteria; disaster mitigation; extreme winds; full-scale test buildings; housing; instrumentation; wind tunnel.

This report highlights the major accomplishments of the initial phase of a three fiscal year project to provide engineering technical assistance to the Agency for International Development (A1D) for the development of design criteria for low-cost/lowrise buildings to better withstand the effects of extreme winds. This phase represents approximately a 3 month level of effort. During this period CBT project staff members commenced six introductory tasks. These tasks will set the pace for the second fiscal year level of effort. The tasks included: initiate dialogue with local organizations and institutes in developing countries, establish a local Philippine advisory committee; conduct on-site visits to developing countries to identify local professional candidates for short term consultating; conduct on-site visits to developed countries to collect information from research centers; purchase initial wind tunnel and full-scale field test instrumentation; and commence library search of related subject documents.

NBSIR 74-610. Investigation of procedures for determination of thermal performance characteristics of plastic piping used in housing. M. Tryon, 36 pages (Nov. 1974). Order from NTIS as COM 75-10072,

Key words: Chlorinated polyvinyl chloride; hardness; internal stress; polyvinyl chloride; thermal mechanical analysis (TMA); thermal properties; thermogravimetric analysis ( $T$ GA); thermoplastic pipe.

The rapid growth of the use of thermoplastic pipe for plumbing in housing has prompted a study to determine the critical factors affecting the performance of the pipe materials. The emphasis in this preliminary study is on thermal properties such as the softening point, relaxation of thermal stress, glass transition temperature, hardness-temperature relationship, and decomposition 
temperature. The techniques used were thermal mechanical analysis (TMA), thermogravimetric analysis (TGA), and hardness. Preliminary results obtained on several pipe samples of PVC and CPVC commercial samples are reported.

NBSIR 74-613. Preliminary study of the slipperiness of flooring. A. P. Cramp and L. W. Masters, 42 pages (July 1974). Order from NTIS as COM 75-10059,

Key words: Floor slipperiness; resilient flooring; slipperiness standards; frictional tests; slip test; coefficient of friction; human perambulation.

The National Commission on Product Safety reported in 1970 , that falls in the home each year kill about 12,000 and injure $6,000,000$ in the U.S.A. Slippery floors are listed as a large con. tributor to these very high casualty figures. Although there are some standardized test methods that are or might be suitable for such standards, there are no slipperiness standards for flooring. Thus, there is an immediate need for studies aimed at the development and establishment of such standards. Consequently, a preliminary study of fioor slipperiness was sponsored by the Building Safety Section of the Center for Building Technology. The study included a state-of-the-art investigation on flooring slipperiness research and a laboratory evaluation of three existing test methods for measuring floor slipperiness. Samples of the three most commonly used resilient flooring materials, namely: vinyl asbestos, vinyl and linoleum were used in the study. The sliding material components for the frictional tests were leather and a commonly used styrene butadiene sole and heel rubber. The tests were performed both dry and wet. The results from this study were used in planning a large comprehensive study, which would lead to the development of accepted floor slipperiness standards. This report contains the results of the preliminary study.

NBSIR 74-618. US/UK joint complementary research program in building (wind loads, water supply, fire detection) July 1973-Junf 1974, C.C. Raley, I.A.Benjamin, L.S. Galowin, and R.D. Marshall, 23 pages (October 1974) Order from NT1S as COM 75-I1014.

Key words: Building technology; cooperation; fire safety; hydraulics; wind loads.

This is a status report of the progress achieved under the "Joint Complementary Research Program" sponsored by the Building Research Establishment (UK) and the Institute for Applied Technology (US), during the period July 1973 through June 1974. The program includes three projects: Wind Loads on Buildings, Design of Water Supply and Drainage Installations in Buildings, and Fire Detection in Buildings, each of which is discussed in the report.

NBSIR 74-629. Thermal properties of selected plastic piping used in housing, M. Tryon, 28 pages (April 1975). Order from NTIS as COM 75-11281.

Key words: ABS; coefficient of expansion; CPVC; glass transition temperature; hardness; polybutene; $\mathrm{PB}$; polyvinyl chloride; PVC; residual stress; thermoplastic piping.

In a study of four thermoplastic piping materials, the following performance-related properties were measured: " coefficient of thermal expansion, glass transition temperature; residual stress; hardness, and hardness-temperature coefficient. The purpose of the study was to determine typical values of these properties for each of the piping materials.. Results are given with recommendations for performance tests and changes in previously-proposed interim performance criteria.

NBSIR 74-634. Method of testing for rating thermal storage devices based on thermal performance, G. E. Kelly and J. E. Hill, 45 pages (May 1975). Order from NTIS as COM 7410685 ,

Key words: Solar energy; standard; standard test; thermal performance; thermal storage; thermal test.
A study has been made at the National Bureals of Standards of the different techniques that could be used for testung thermal storage devices and ratung them on the hasls of thermal per formance. This document outlnes a proposed standard test procedure based on that study. It is written in the format of a standard of the Ainerican Socicty of Heating. Refrigerating, and Air Conditioning Engineers and specifies the recommended ap paratus, instrumentation, and test procedure

NBSIR 74-635. Method of testing for rating solar collectors basted on thermal performance. I E. Hill, T. Kusuda, 63 piages (I)ec 1974). Order from NTIS as (OM 75-101276,

Key words: Solar collector; solar energy; sular radiation; standard; standard test; thermal performance.

The National Bureau of Standards has made a study of the different techniques that could be used for testing solar collectors and rating them on the basis of thermal performance. This document outlines a standard test procedure based on that study. It is written in the format of a standard of the American Society of Heating, Refrigerating, and Air Conditioning Engineers and specifies the recommended apparatus, instrumentation, and test procedure.

NBS1R 75-641. Performance of mohile homes data acquisition and analysis methodology, J. H. Pielert. W. E. Greene. Jr., L. F. Skoda, and W. G. Street, 75 pages (Feb. 1975). Order from NTIS as COM 75-1 1209.

Key words: Construction; Hurricane Agnes; housing; mobile homes; mobile home parks; performance data; regulatory process; standards

In a study at the National Bureau of Standards (NBS), funded by the Department of Housing and Urban Development (HUD), methods for inspecting mobile homes to identify performance problems, recording the problems and analyzing the problem data were developed. Maintenance work orders for 2881 mobile homes, a part of 12,500 provided by HUD for emergency housing in the aftermath of Hurricane Agnes, at Wilkes-Barre, Pa. were reviewed and computer coded by an interdisciplinary team of engineers. Also, performance data were obtained from State and other Federal agencies for over 967 privately owned mobile homes. A second task was the field inspection of 257 mobile homes to assist in the determination of the causes and consequences of the problems identified in the data acquisition task. Computer techniques were developed to process the data and print out problem summation tables, graphs to establish trends, compile data on obvious problems and ferret out those problems which may not be obvious. This first report documenting the data acquisition and analysis methodology will be followed by a series of reports which will present results and relate them to current standards, the regulatory and insurance processes.

NBSIR 75-672. A preliminary approach to performance requirements and criteria for electrical connections in residential branch circuit wiring. W. J. Meese, R. L. Cilimberg, and A. A. Camacho, 37 pages (Mar. 1975). Order from NTIS as COM 75- 10338 ,

Key words: Branch circuits; contact resistance; electrical codes; electrical connections; fire safety: housewiring; performance testing.

During the Operation BREAKTHROUGH Research and Demonstration program the U.S. Department of Housing and Urban Development became conceried with the inability to properly evaluate innovative electrical connections. Innovation in electrical connections has been very slow because of the longlife requirements, stringent fire safety requirements, long established conventional practices and evaluation procedures and lack of a performance base for describing requirements. This preliminary report presents the framework for a proposed method to evaluate electrical connections on a performance basis and supplements information contained in a previous re- 
port on current technology of electrical connections used in residential branch circuit wiring. Innovations involving electrical connections may lead to significant advancements in housing construction if it can be demonstrated that functional and safety requirements over the expected life of electrical connections were adecuately satisfied. Research is needed to enable predic tion of long-term performance of electrical connections based on the results of accelerated performance tests.

NBSIR 75-678. Analysis of construction systems for the thermal classification of residential buildings, S. T. Liu, 58 pages (Nov. 1975). Order from NTIS as PB 248-687.

Key words: Building classification, building thermal mass; building thermal performance; building thermal time constant; housing systems; industrialized housing, mass per unit area; Operation BREAKTHROUGH; U-value

This report is the result of a study to classify various kinds of residential buildings in relation to their thermal behavior. A collection of various building data and construction systems taken from the proposals of 18 of 22 Housing System Producers participating in the Department of Housing and Urban Development (HUD) Operation BREAKTHROUGH Program is presented. Thermal performance parameters of buildings, such as; U-value, thermal mass, thermal time constant, and mass per unit area were computed and analyzed. The report recommends one way in which construction systems could be classified. Since the housing systems studied represented a cross section of the conventional residential construction systems in the building industry, it is felt that a realistic classification procedure for typical residential buildings can be established and based upon the parameter: mass per unit area. A more refined procedure of subdividing the building within each mass class on the basis of the building thermal time constant is also discussed.

NBSIR 75-680. Mobile home construction standards adopted by state regulatory programs - an analysis, P. W. Cooke, L. P. Zelenka, and H. K. Tejuja, 107 pages (Mar. 1975). Order from NTIS as COM 75-10423.

Key words: Enforcement; legislation; mobile homes; regulation; standards; state-of-the-art study.

This study examines the extent to which the nationally recognized standard for the construction of mobile homes (i.e., ANSI Standard A 1 19.1/NFPA 501 B) has been adopted and amended by the individual States that have implemented enforcement programs for the regulation of mobile homes. Summary data is presented on the existing status of the various versions of the standard adopted in each State. State-adopted amendments to the technical requirements in the national standard are compiled by State and construction discipline for comparative analysis.

NBSIR 75-688. Performance of mobile homes - A field inspection study, L. F. Skoda, J. H. Pielert, W. E. Greene, and W. G. Street, 119 pages (June 1975). Order from NTISas COM75-11222

Key words: Enforcement process; field inspection; house trailers; housing; Hurricane Agnes; mobile homes; performance data; standards.

A field inspection study of mobile homes was conducted for the Department of Housing and Urban Development. The objective of the study was to evaluate the causes of mobile home problems by physically inspecting available units at various locations in the United States. A total of 257 units were inspected consisting mostly of mobile homes purchased by HUD and used as temporary housing for victims of the 1972 Hurricane Agnes disaster. The total number of problems found was 3,528 for the 257 units inspected. Of these problems, 2120 were directly related to inadequacies in the ANS1 A119.1 Standard for Mobile Homes or the mobile home enforcement process (plan review, certification of designs, plant inspection), 934 were routine maintenance problems, and 374 were attributed to mechanical/electri- cal appliances and equipment. This report presents a computer listing of all problems plus photographic examples of observed problems.

The number of mobile homes included in this study is small when compared to the total number of mobile homes now in use in the United States. Additionally, this was a problem oriented study and did not attempt to document the many areas of satisfactory mobile home performance.

NBS1R 75-690. A compilation of problems related to the performance of mobile homes, W. G. Street, W. E. Greene, J. H. Pielert, and L. F. Skoda, 86 pages (Apr. 1975). Order from NTIS as COM 75-11207,

Key words: Computer techniques; enforcement process; housing; hurricane Agnes; mobile home parks; mobile homes; performance data; standards.

Performance of inobile homes as housing units is of broad concern to mobile home owners. This study report prepared at the National Bureau of Standards (NBS) and funded by the Department of Housing and Urban Development (HUD) presents mobile home problem data obtained from two separate data sources. The first data base for 2881 units was selected from maintenance records retained by HUD on 12,500 mobile homes used as emergency housing following the Hurricane Agnes disaster at Wilkes-Barre, Pennsylvania. The second source consisted of data for 967 privately-owned units collected from the files of various Federal, state, and private agencies responsible for regulation or consumer protection functions with regard to mobile homes. The mobile home performance problem data was processed using computer techniques to produce problem summation tables which facilitated evaluation. Although the mobile home problems experienced in various categories are highlighted in this report, no attempt was made to relate these results to current standards, regulatory or mortgage insurance (durability) processes. Analyses of this kind are planned for future reports in this series.

NBSIR 75-703. A failure hypothesis for masonry shearwalls, F.

Y. Yokel and S. G. Fattal, 38 pages (May 1975). Order from NTIS as COM 75-11278,

Key words: Brick; failure; failure theories; masonry; shear strength; shear test; shear walls; stress distribution; stresses; structural engineering.

Various failure hypotheses for wall panels subjected simultaneously to diagonal compressive load and to vertical compressive edgeload are compared with the results of thirty-two tests on four types of brick masonry walls which were published elsewhere. 1 it is concluded that failure can occur by joint separation or by splitting. A failure hypothesis is advanced which is shown to be in good agreement with the test results examined.

NBS1R 75-711. Site analysis and field instrumentation for an apartment application of a total energy plant. J. B. Coble and P. R. Achenbach, 65 pages (May 1975). Order from NTIS as COM 75-10689

Key words: Air conditioning; air pollution; central utility systems; data acquisition systems; efficiencies; electrical power; energy conservation; energy costs; fuel utilization; heat recovery; total energy systems; utilities for housing; utility system performance.

Under sponsorship of the Department of Housing and Urban Development, the National Bureau of Standards developed criteria in a feasibility study to select a site for, and to evaluate the requirements of a total energy system on one or more OPERATION BREAKTHROUGH housing sites. The total energy system produces its own electrical, heating and cooling energy services independent of the local utility system. Six OPERATION BREAKTHROUGH sites were selected for the feasibility study: Jersey City, N.J.: Macon, Ga.: Memphis, 
Tenn.: Indianapolis, Ind.: St. Louis, Mo.: and Sacramento, Cálif. Ranking parameters for final selection were: number of dwelling units, density of dwelling units, climatic factors, energy utilization, owning and operating costs, and developer's attitude.

The Jersey City site was chosen as the location for the installation, evaluation, and field study of the total energy system. The site covers six acres, has four apartment buildings containing 488 dwelling units, a 50,000-sq.ft commercial building, an elementary school, a swimming popl, and the total energy plant.

The buildings and the total energy plant are being extensively instrumented to provide data on fuel utilization, system efficiencies, electrical and thermal energy generation, energy utilized and rejected. The environmental impact of the total energy plant with respect to noise, vibration, air pollution, and esthetics is under evaluation. The installed system will be compared with several types of conventional energy systems.

NBSIR 75-712. Solar heating and cooling in buildings: Methods and economic evaluation, R. T. Ruegg, 47 pages (July 1975). Order from NTIS as COM 75-11070,

Key words: Economic optimization; HVAC systems; lifecycle cost analysis; solar energy; solar heating and cooling.

This report addresses economic issues important to the design, and evaluation of solar heating and cooling systems in buildings. It explains and illustrates with simple, but realistic examples the use of life-cycle cost analysis and benefit-cost analysis to evaluate and compare the economic efficiency of solar and conventional energy systems. It also explains the conditions for making cost-effective tradeoffs in solar system/building design. By presenting the basic methods and assessing the appropriateness of alternative assumptions, the paper provides a resource document for researchers and analysts.

NBSIR 75-715. The implementation of a provision against progressive collapse, F. Y. Yokel, J. H. Pielert, and A. R. Schwab, 23 pages (Aug. 1975). Order from NTIS as COM 75 11208 ,

Key words: Building systems; housing systems; large-panel structure; precast concrete construction; progressive collapse; structural design; structural joists.

The design solutions used by five U.S. precast concrete housing systems to comply with a provision against progressive collapse are studied and compared. Some common characteristics of the design solutions are identified.

NBSIR 75-721. Economic Objectives of Utility Companies and Developers in Evaluating a MIUS, B. J. Bartter, 40 pages (Nov. 1975). Order from NTIS as PB 266-864.

Key words: Economic incentives; housing development; integrated utilities; MIUS; utilities.

This report provides information to the Department of Housing and Urban Development-Modular Integrated Utility System (HUD-MIUS) program about the economic decision-making process for implementation of a MIUS by utility companies, developers, and a combination of these two groups.

Information was obtained through informal telephone interviews from these participant groups about their economic analysis of utility investment alternatives. The content of these conversations was synthesized into economic criteria which are perceived by each participant to be most important in evaluating alternative utility investments. From the analysis of these economic criteria, the possible combinations of participants and roles in the implementation of a MIUS are specified. These combinations are ranked, according to the degree of likelihood that each method will actually be employed.

The conclusion of this report is that a MIUS is most likely to be implemented by a governmental body, such as a municipal utility or governmental developer.
NBSIR 75-729. Nondestructive tests to determince concrete strength - A status report. J.K. Clifton, 42 pages (July 1975) (or V1/5 as l'b $246-858$

Key words: Compressive strength; concrele, llexural strength formwork removal; nondestructive testang surface hardness.

Individual and combined nondestructue test methods have been critically reviewed as potental methods to determ ne safe formuork removal times. The techniques reviewed are the Windsor probe, the Schmidt Rehound flammer, pull-out measurements, push-cut measurements, push-out cylinders, ultrasonic pulse velocity measurements, and the maturity and equivalent age concepts. I he indiudual methods. themselves. do not give good estimates of the in sllu strengths of concretcs and it is recommended that fusure rescarch emphasec combbined methods.

A proposed rescarch program which emphasaes combined nondestructive test methods has been developed.

NBSIR 75-747. Building energy authority and regulations survey: State activity. R. M. Eisenhard, 25 pages (June 1975). Order from NTIS as COM 75-11131,

Key words: Authority; building; energy; legislation; regula tions; state.

Information describing the status of State regulations and authority to regulate energy use in new and existing buildings is presented in tabular form. The tables reference available information on pending bills, acts, or general authority which is embodied in a State Building Code Act. Programs relating to solar energy, insulation, and other building energy items are also listed.

NBSIR 75-761. The demonstration of experimental lead paint hazard abatement methods in Washington. D.C.. T. H. Boone, H. W. Berger, A. P. Cramp, and H. A. Jackson, 102 pages (June 1975). Order from NTIS as COM 75-11377

Key words: Abatement; barrier materials; building materials; housing; lead-based paint; lead poisoning; paint removal.

This report describes the first stage of an experimental lead paint hazard abatement program carried out in 30 dwelling units in Washington, D.C. The entire program will ultimately involve the abatement of lead paint hazards in a total of approximately 250 dwelling units located in three or more cities.

The procedures, demonstrated in Washington, included: paint removal methods using chemical solvents and a heat producing device; the replacement of components such as windows, doors and wood trim; and the installation of flexible sheet and rigid board barrier materials over existing lead paint on wall.

The report presents procedures and the forms used in inspect ing and selecting dwellings for lead paint hazard abatement. evaluations of the suitability and implementation characteristics of the abatement methods and recommendations for their use

Subsequent reports will present the results of comparable programs in additional cities and a final report will compare the cost effectiveness of the alternative abatement methods

NBSIR 75-767. A methodoliuy for establishing conditioning requirements for the building materials and composites, L. W Masters and M. Tryon, 35 pages (Oct. 1975). ()reler from \TIS as PB 246-879

Key words: Building composite; building material; conditioning; equilibration; gypsum wallboard; methodology; relative humidity; structural sandwich panel; temperature; testing.

The measured properties of bıilding materials and their composites sometimes reflect the conditions to which they have been exposed while being prepared for test. Conditioning these materials to some standard reference state is sometimes used to minimize this effect.

A methodology for establishing conditioning requirements for 
building composites and materials is presented and its use illus trated by applying it to two building composites.

The composites to which the methology is applied are: 1) gypsum wallboard and 2) a structural sandwich wall panel.

NBSIR 75-779. The development of an improved compression test method for wall panels, C. Yancey and L. Cattaneo, 107 pages (Dec. 1975). order from NTIS as PB 249-935.

Key words: Compression; eccentric loading; flat-end; kern; loading rate; pin-end; test method; wall panels; walls.

An experimental and analytical investigation of the primary factors involved in the testing of prototype wall panels under axial compression loading is reported. The objective of the investigation was to develop a method of testing wall specimens that incorporates the best features of ASTM Standard method E 72 while at the same time incorporating improvements in the area of deficiency in the Standard. Tweinty-five laboratory tests were conducted on samples composed of five types of wall panel construction. The panels were tested to failure under either of two different eccentricities of load, while being supported with one of two types of idealized end conditions. Selected test results and detailed descriptions of the laboratory procedures used are presented. A computer-aided analytical study of the variables affecting the degree of uniformity of loading was conducted. Equations based on the analogy of beams supported on elastic foundations were used in the analysis. A study of the statistical parameters commonly used to interpret test results was conducted to establish useful guidelines for predicting structural performance on the basis of small sample test results. A compression test method applicable to traditional and innovative wall constructions is presented. The principal additions in the revised test method are as follows: (a) a provision for variable eccentricity, (b) a procedure for selecting a load distribution assembly which will be compatible with the test panel.

NBSIR 75-790. FX75 Progress report on design criteria and methodology for construction of low-rise buildings to better resist typhoons and hurricanes, R. Marshall, N. Raufaste, Jr., E. Simiu, S. G. Fattal, J. Kowalski, S. Kliment, G. Sherwood, T. Wilkenson, and J. H. Choudhury, 358 pages (Nov. 1975). Order from NTIS as PB 250-848.

Key words: Buildings, codes and standards; disaster mitigation; housing; hurricanes; low-rise buildings; natural disaster; structural connections; typhoons; wind loads.

The annual progress report presents major NBS accomplishments and activities during the third phase (FY75) of a forty month project concerned with developing improved design criteria for lowrise buildings in developing countries to better resist extreme winds. The research study, sponsored by the Agency for International Development, commenced in March 1973. Two other progress reports: NBSIR 74-582 FY73 Progress Report (first phase of the research-4 months) and NBSIR 74-567 FT74 Progress Report (second phase of the research-12 months), document the first 16 month level of effort. During FY75, 6 major tasks were completed; instrumentation of remaining two of six test houses, continuation of technician training, analysis of extreme wind data, development of draft reports describing project results, participation in regional conference in Manila and schedule a regional conference in Jamaica during November 1975. During FY76, data collection and analysis activities will be completed. A final report will be published by the end of the fiscal year.

NBSIR 75-795. Recommended criteria for retrofit materials and products eligible for tax credit, W. J. Rossiter and R. G. Mathey, 44 pages (Nov. 1975). Order from NTIS as PB 246-866.

Key words: Caulks and sealants; clock thermostats; energy conservation; insulation; retrofitting; storm doors; storm windows; tax credit; vapor barriers; weatherstripping.
The Federal Energy Administration requested the National Bureau of Standards to develop criteria for retrofitting for possible use by the Internal Revenue Service in implementing the Presidential initiative authorizing tax credit to homeowners. Criteria are recommended for materials and products considered eligible for proposed tax credit for retrofitting one and two family residences to conserve energy. The materials considered include insulation and vapor barriers, storm windows and doors, caulking and weatherstripping, and clock thermostats. A list of these retrofit materials was compiled by generic type and recommendations made on their installation.

In addition to recommended criteria for materials and products eligible for tax credit, desired levels of performance for the retrofit materials are presented as a guide to homeowners to achieve maximum benefits in energy conservation through retorfitting.

NBSIR 75-923. Corrosion of metallic piping on military bases - a survey, P. W. Brown and J. R. Clifton, 20 pages (Nov. 1975). Order from NTIS as PB 250-767.

Key words: Corrosion; corrosion control; metallic piping; nondestructive evaluation; survey; water hardness.

The results of surveys of the extent of corrosion of metallic piping systems at selected military installations have been analyzed. Potable water, fire protection, heat distribution, cooling, and natural gas distribution systems are included in these surveys and the types of protection applied are discussed. General recommendations regarding continuation and extension of these surveys are given.

NBSIR 75-951. Correlation of foor vibration to human response,

J. R. Shaver, 32 pages (Dec. 75). Order from NTIS as PB 249-094.

Key words: Analysis; experimental; floor systems; human response; random process; spectral analysis; vibration.

A new approach to the problem of perceptible floor vibrations is presented based on the assumption that human activity, which produces the vibration, and human response to vibration are random variables. Techniques for data reduction are discussed and a detailed description of one approach is given along with the associated computer programs. Data from floor vibration is compared with current criteria for human response.

NBSIR 75-955. Durability and related tests for selected elements and material used in the exterior envelope of buildings, $\mathrm{L}$. Masters, E. Clark, G. Sleater, and A. Hockman, 150 pages (Nov. 1975). Order from NTIS as PB 248-685.

Key words: Aging test; building elements and materials; degradation factors; durability; property measurement test; standard test methods.

This report contains a compendium of state-of-the-art methods to aid in the durability testing of selected elements and materials used in the exterior envelope of buildings. The purposes of the report are to identify currently available property measurement tests and aging tests that can be used for durability testing and to identify the degradation factors included in each aging test. The report will form the basis for selecting specific elements and materials for inclusion in subsequent comprehensive durability studies. These additional studies are needed because existing shortterm methods are seldom fully adequate for predicting long-term performance.

The sources of the methods include the American Society for Testing and Materials (ASTM), the American National Standards Institute (ANSI), building industry trade associations, Federal Specifications and Federal Standards. Indications are made for each test method to show if the methods described include a property measurement test, an aging test or both. If the method contains an aging test, the degradation factors included in the test are listed. 


\section{NBS Reports}

National Bureau of Standards Reports are generally a progress report or preliminarly report for use by the project sponsor. They were published from 1950 through 1972 and were succeeded by the National Bureau of Standards Interagency Report. The reports listed below are available from the National Technical Information Service.

9668. Public building systems project status report, R. W. Blake and M. Brill, 150 pages (Dec. 1967). Order from NTIS as PB 176-959.

9849. The performance concept: A study of its application to housing. Volume one, Performance standards for housing, J. P. Eberhard, Editor, 353 pages (June 1968). Order from NTIS as PB 184-458.

9850. The Performance concept: A study of its application to housing. Volume two, Appendices, J. P. Eberhard, Editor, 188 pages (June 1968). Order from NTIS as PB 184-876.

9851. The Performance concept: A study of its application to housing. Volume three, Supplementary documents, J. P. Eberhard, Editor, 371 pages (June 1968). Order from NTIS as PB 184-459.

10200. Guide criteria for the design and evaluation of: Operation BREAKTHROUGH housing systems, E. O. Pfrang, Editor, 1,500 pages approx. in five volume set (Dec. 1970). Order from NT1S as:

Vol. I Multifamily high rise

Vol. II Multifamily low rise

PB 212-055

Vol. III Single family attached

PB 212-056

PB 212-057

Vol. IV Single family detached

PB 212-058

Vol. V Quality assurance program provisions PB 212-538

10213. Guide and format for the preparation of a housing system testing and analysis program for: Operation BREAKTHROUGH housing systems. A preliminary report, E. O. Pfrang, Editor, 400 pages approx. in four volume set (June 1970). Order from NTIS as:

Vol. I Multifamily high rise

PB 214-460

Vol. II Multifamily low rise

PB 214-461

Vol. III Single family attached

PB 214-462

Vol. IV Single family detached

PB 215-463

10214. References from the guide criteria for Operation BREAKTHROUGH housing systems, E. O. Pfrang, 61 pages (Aug. 1972 Rev.). Order from NTIS as PB 212-059.

10215 Cross-index: Operation BREAKTHROUGH matrix, J. L. Haecker, 14 pages (Aug. 1972. Rev.). Order from NTIS as PB 212.060 .

10216. Health and safety guide criteria, E. O. Pfrang, 24 pages (Aug. 1972 Rev.). Order from NTIS as PB 212-061.

10248. Transient vibration tests on wood joist floors, H. S. Lew, 46 pages (Aug. 1972). Order from NTIS as PB 211-854.

10314. Impact tests on gypsum wallboard, H. S. Lew, 20 pages (Aug. 1972 Rev.). Order from NTIS as PB 211-847.

10317. Report on study of evaluation criteria for floors under concentrated load, F. Y. Yokel, 30 pages (Aug. 1972 Rev.). Order from NTIS as PB 212-297.

10319. An overview of Operation BREAKTHROUGH guide criteria, E. O. Pfrang, 27 pages (Aug. 1967 Rev.). Order from NTIS as PB 212-062.

10407. Fire endurance test of a conventional plywood faced, wood exterior wall containing fiberglass insulation batts, B. C. Son, 16 pages (Oct. 1972 Rev.). Order from NTIS as PB 214-781.

10408. Fire endurance tests of a fiberglass wall assembly for single family housing, B. C. Son, 19 pages (Oct. 1972 Rev.). Order from NTIS as PB 214-784.
10409. Structural evaluation of stcel faced sandwich panels, J. II Piclert, 45 pages (Sept. 1972 Rev.). Order from vTIS as f'ls 213-240

10410. Floor vibration tests Kalamazoo, Michigan, BRF.AK THROUGH site, R. A. Crist, 23 pages (Feb. 1972). (irder from NTIS as PB 216-501

10411. Acoustical evaluation of a multifamily low rise wordrarne modular construction system on an Operation BRF.AK. THROUGH prototype site, T. L. Quindry, 25 pages (June 1972). Order from NTIS as PB 212-785.

10412. Tests of the fire resistance of inturnescent-painted structural elements, L. A. Issen, 25 pages (April 1973). Order from NT1S as PB 213-053

10413. Full scale test on two-story house subjected to lateral load, F. Y. Yokel, 72 pages, (Nov. 1972). Order from NTIS as PB 213-143.

10414. Structural test for a housing system using sandwich panels with gypsum board surfacings, W. E. Grecne, 40 pages, (Nov. 1972). Order from NTIS as PB 214-336.

10.415. Fire endurance test of a mechanical/electrical core assembly for use in multifamily housing, B. C. Son, 19 pages, (Dec. 1972). Order from NTIS as PB 217-362.

10416. Fire endurance test of an exterior sandwich panel wall assembly, B. C. Son, 20 pages, (Oct. 1972). Order from NTIS as PB 217-363.

10417. Fire endurance test of an interdwelling do:ıble wall assembly for single family housing, B. C Son, 21 pages, (Dec. 1972). Order from NTIS as PB 217-364.

10418. Fire endurance test of a corrugated aluminum sheet and gypsum board exterior wall assembly, B. C. Son, 21 pages, (Dec. 1972). Order from NTIS as PB 217-365.

10499. The nature of the lead paint peisoning hazard, J. Gilsinn, B. Nocks, B. Reismen a-r' I: Clark, 17 pages (Nov. 1971). Order from NTIS as PB 212-017?

10632. Identification of poicntial building material sources of lead poisoning, E. J. Clark, 32 pages, (Nov. 1971). Order from NTIS as PB 213-014.

10649. Report on literature review, survey, and conferences lead paint poisoning hazard detection methods, B. Greifer, 23 pages (Dec. 1971). Order from NTIS as PB 213-351.

10651. National estimates of lead based poisoning of children (estimated by standard metropolitan statistical area), J. Gilsinn, 17 pages (Dec. 1971). Order from NTIS as PB 213-354.

10654. A model to estimate the incidence of lead paint poisoning, 41 pages, (Dec. 1971). Order from NTIS as PB 213-566.

10658. Procedures for lead paint removal and detoxification: guidelines and attributes, D. B. Hattis, 25 pages (Dec. 1971). Order from NTIS as PB 213-535.

10667. Report on lead based paint detection methous chosen for evaluation (milestone 1C), B. Greifer, 20 pages (Dec. 1971). Order from NTIS as PB 213-353.

10676. The effects of the Fairbanks Alaska flood on residentia! construction, W. C. Cullen, 33 pages (Jan. 1972).

10917. Testing the validity of models to predict the incidence of lead paint poisoning, J. Gilsinn, 59 pages, (Sept. 1972). Order from NTIS as PB 213-662.

10961. Field investigation of the natural gas pipeline accident ai Canterbury Woods, Annandale, Virginia, R. W. Beausoliel, 52 pages (Dec. 1972). Order from NTIS as COM 73-11285.

10972. Hospital bedrooms and nursing units a systems approach. R. Wehrli, 246 pages (Sept. 1972). Order from NTIS as PB $218-975 / 1$. 


\section{CONSUMER INFORMATION SERIES}

This series presents practical information, based on the Center's research and experience, covering areas of interest to the consumer in easily understandable language and illustrations to provide useful background knowledge for shopping in today's technological marketplace.

CIS6. Color in our daily lives. D. B. Judd, Nat. Bur. Stand.(U.S.), Consum. inf. Ser. 6, 32 pages (Mar. 1975) SD Catalog No. C13.53:6

Key words: Color; environment; experimenting with; harmony; hues; illumination; light; personal uses; relationships; uses.

If you are like most consumers, color is at once a delight, a challenge, and a problem. Color is a delight because it can convert an otherwide drab costume, scene, or room into a thing of beauty. It is a challenge because it brings out our creative ability and enables us to brighten and enliven our surroundings at a comparatively cheap cost. It is a problem because, improperly used, it can fail in its purpose, and if we are unsure of the ways in which colors go together, the choice of the tie, a lipstick, a drapery fabric, or a wall paint to match furriture and carpet can become an unpleasant chore.

Because of the importance of color in our daily lives, and the widespread lack of knowledge about the relationship of colors, we are pleased to bring you this extraordinary booklet as a part of our Consumer lnformation Series. It has been written in simple language, but in its scientific accuracy, and in the precise selection and printing of illustrative colors, it meets the exacting standards of a scientific treatise. Although it was designed to be of practical value to you in solving everyday color problems, we believe Color in Our Daily Lives will also become a treasured possession.

C1S8. Making the most of your energy dollars in home heating and cooling, M. Jacobs and S. Petersen, Nat. Bur. Stand. (U.S.) Consum. Inf. Ser. 8, 20 pages (June 1975).

Key words: building economics; consumer information; energy conservation; home economics; home improvements; insulation.

This booklet is a consumer-oriented adaptation of BSS-64 (Retrofitting Existing Housing for Energy Conservation: An Economic Analysis) which provides basic energy conservation information of an economic nature to homeowners. It is concerned primarily with energy conservation improvements which will decrease heating and cooling costs in houses. Investment in insulation, storm windows and doors, and weatherstripping/caulking is examined with regards to different climates and different energy prices in order to determine the combination of these improvements which will provide the greatest long-run economies in space heating and cooling to the homeowner. Information of a general nature on the proper use of such improvements is outlined and furtlier references are listed.

\section{THE JOURNAL OF RESEARCH}

Section C of the Journal of Research, entitled Engineering and instrumentation, reported research results primarily of interest to the engineer and applied scientist. It included new developments in instrumentation resulting from NBS work in physical measurement, test method development, acoustics, applied mathematics, and building research. The publications below address building research. The series was discontinued in the Spring of 1972.

A test apparatus for the study of forced air mixing devices, T. K. Faison, J. C. Davis, and P. R. Achenbah, J. Res. NBS, $70 \mathrm{C}$ 1-218 pp. 25-31 (Jan.-Mar. 1966).

Key words: Air-conditioning capacity, air-mixing devices, forced air-mixing, turbulence, mixer effectiveness, apparatus design, air properties, temperature measurement.

The National Bureau of Standards has initiated a study of mixing devices for air streams to improve the techniques for measuring the capacity of air-conditioning, heating, and refrigeration equipment. Better mixers in these test apparatus will reduce the amount of instrumentation required, and increase the accuracy in capacity determinations that are based on enthalpy change of the air passing through the equipment. An apparatus for measuring the effectiveness of mixing devices, a small-scale apparatus for visually observing the mixing process, and some illustrative results are presented. The apparatus for measuring mixer effectiveness generates a stream of moving air of known and reproducible non uniformity of temperature or humidity, provides for the installation of one or more mixers in a measuring section, and incorporates the means for measuring static pressure, velocity pressure, temperature, and humidity upstream and downstream of the mixer. The flow-visualization apparatus provides a qualitative visual evaluation of the effectiveness of smallscale models of mixers as a basis for selecting the specimens for the more elaborate measurements. Graphic material is included which illustrates the performance of the apparatus and the methods used in determining effectiveness of mixing devices.
A note on the numerical evaluation of thermal radiation characteristics of diffuse cylindrical and conical cavities, B. A. Peavy, J. Res. NBS, 70C 2-224, pp. 139-147 (Apr.-June, 1966).

Key words: Conical, cylindrical, emissivity, nonisothermal.

Presented are methods that avoid the need to employ an extrapolation technique in the region of the critical points for evaluation of the apparent emmissivity of diffuse cylindrical and conical cavities. The methods involve appropriate substitutions in the integrands of integral equations that are used in analytical solutions for determining the thermal radiation characteristics of diffuse and conical cavities. Equations for either isothermal surface temperature conditions are provided in a direct form for computations. Numerical results are presented for a general linear temperature distribution along the length of a cylindrical cavity. The method is equally applicable for the solution of other problems in integral equations where discontinuities are encountered.

Least squares technique for the analysis of periodic temperatures of the earth's surface region, T. Kusuda, J. Res. NBS, $71 \mathrm{C1}$ 442, pp. 43-50 (Jan.-Mar. 1967).

Key words: Earth temperature; least squares technique; thermal diffusivity of earth.

A least squares technique has been applied to periodic earth temperature data for the purpose of determining basic characteristics of earth temperature cycles, such as thermal diffusivity, average temperature, amplitude, and phase angle of the temperature cycle. A new procedure was developed for obtaining a single thermal diffusivity which represents an average over time and depth at a particular temperature site. This thermal diffusivity was obtained as a nonlinear part of least squares constants which yielded a best-fit harmonic curve to a given set of observed earth temperatures. The thermal diffusivity thus calculated and the calculation method developed are preferred to those obtained by current practice, which yields 
two thermal diffusivities, one based on amplitude decay and another on phase angle shift.

Determination and smoothing of Fourier coefficients representing piecewise continuous functions, B. A. Peavy, J. Res. NBS, 71C2-248, pp. 93-100 (Apr.-June 1967).

Key words: Continuous function; Fourier series; piecewise; smoothing.

This paper presents a method of solving for Fourier coefficients where the dependent variable can be expressed as a piecewise continuous function, when various conditions of continuity and smoothing are assumed. An example is included to show the effect of smoothing in the region of a discontinuity for a system composed of two materials that exhibit a discontinuity at their interface and surrounded by a third material which does not have a discontinuity. An advantage to be gained from smoothing is an increase in the convergence of a finite Fourier series representation of a piecewise continuous function in the region of the discontinuities.

Heat flow in a right circular cylinder with internal heat generation: Applications to the determination of thermal conductivity, D. R. Flynn.J. Res. NBS 7IC4-260. pp. 293-298 (Oct.-Dec. 1967).

Key words: Heat conduction: heat generation: heat transfer; neutron absorption: radioactive decay: thermal conductivity.

Expressions are developed which permit calculation of the temperature-dependent thermal conductivity of a cylindrical specimen in which heat is generatted internally $E$ eg by radioactive decay. The information needed consists of the experimentally determined temperature distributions on the surfaces of the cylinder, the heat flow through at central circular area it one end of the cylinder, and the rate of internal heat generation (which in general may be position-dependent). Numerical coefficients are tabulated for the case of un form internal heat generation. The application of this calculation procedure to published methods of thermal conducisvity determination is shown and an example is given.

Analytical studies of probe conduction errors in ground temperature measurements, B. A. Peavy, J. Res. N. B. S. (U.S.), 72C , No. 4, 243-247 (Oct.-Dec. 1968).

Key words: Earth temperature; probe conduction errors; steady periodic heat flow.

Vertical probes with temperature sensing elements placed at fixed positions along their length are commonly used for meisuring earth temperature variations with time. Mainly for structural reasons, the probes are comprised of materials whose thermal properties are not the same as those of the surrounding earth, so that the temperatures as measured at a given time by the probe are not the same as that for the undisturbed earth. A mathematical analysis for steady periodic, two-dimensional heat flow in a two body composite has been made to determine the probe conduction errors in ground temperature measurements. Several examples are given to show the relative magnitude of probe conduction errors. 



\section{Key word Index}

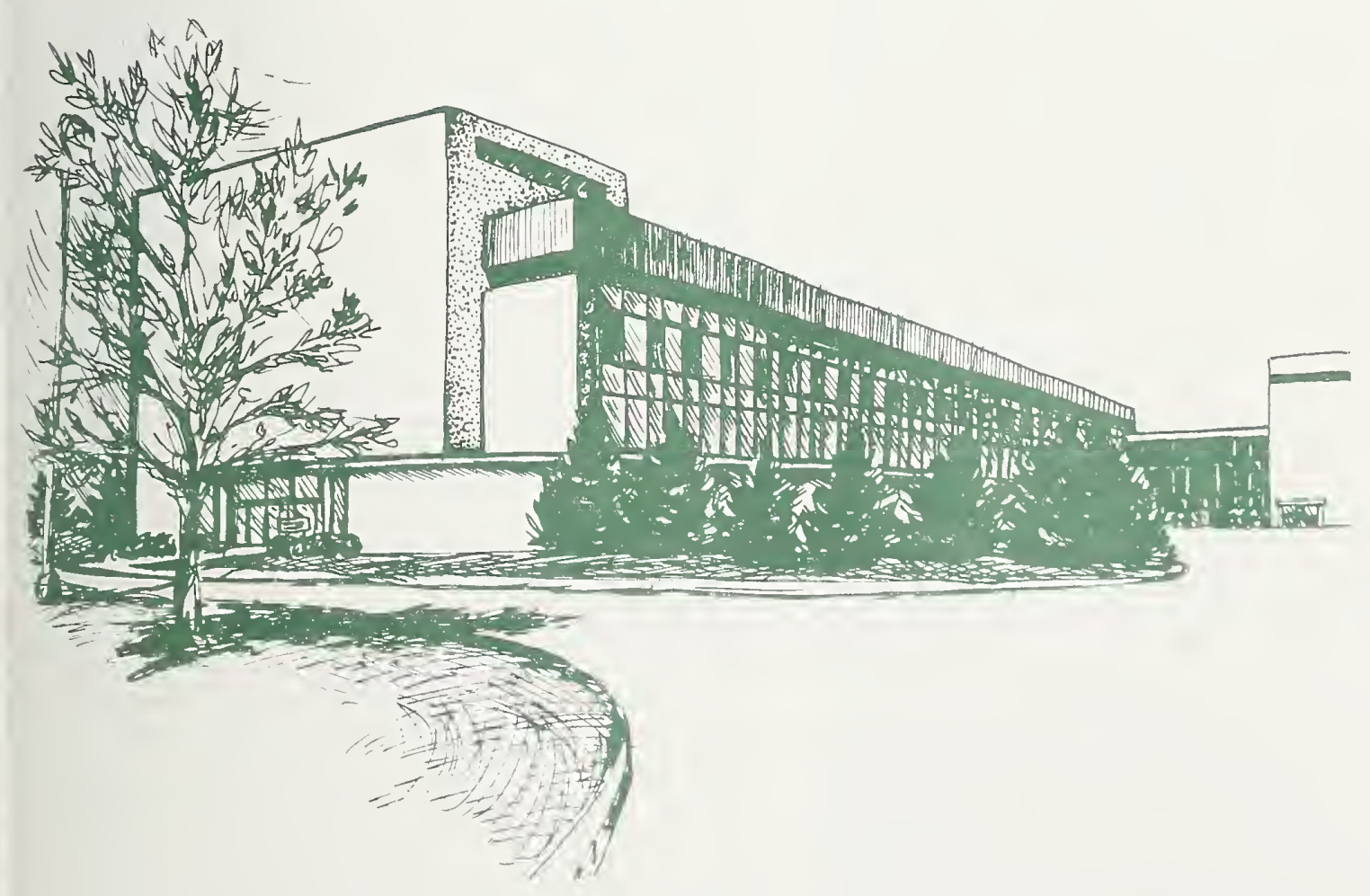





\section{KEY WORD INDEX}

\section{A}

Abatement; Barrier materials; Building materials; Housing; Leadbased paint; Lead poisoning; Paint removal; NBSIR 75-761.

Abnormal loading; Alternate path; Annotated bibliography; Bibliography; Building code; Building regulations; Collapse; Failures; Progressive Collapse; Specific resistance; BSS67.

Abnormal loading; Building; Codes; Design criteria; Multistory; Progressive collapse; Risk; Stability; Standards; Strength; United States; NBSIR 73-221.

Abnormal loading; Building; Gas explosion; Load-bearing masonry; Load-bearing walls; Masonry; Masonry research; Progressive collapse; NBSIR 74-526.

Abrasion; Adhesion; Colorfastness; Covering; Materials; Flash point; Flame spread; Impact resistance; Lead paint poisoning; Materials; Performance; Properties; Scratch resistance; Smoke generation; Toxic combustion products; Toxicity; Washability; TN808.

Abrasion resistance; Chemical resistance; Cigarette-burn reistance; Cleanability and soilability; Concentrated static-load capacity; Performance characteristics; Performance level; Sanitary plumbing fixtures; Scratch resistance; Stain resistance; Surface-impact resistance; Test methods; BSS22.

ABS; Coefficient of expansion; CPVC; Glass transition temperature; Hardness; Polybutene; PB; Polyvinyl chloride; PVC; Residual stress; Thermoplastic piping; NBSIR 74-629.

ABS; Drain; Fire endurance; Fire spread; Fire test; Plastic piping; PVC; Smoke; Toxic gases; Vent; Waste; NBSIR 74-449.

ABS; DWV; Fire endurance; Fire spread; Fire test; Gases; Plastic pipe plumbing; PVC; Smoke; BSS72.

Absorption; Asphalts; Felts; Moisture; Roofing; Saturation; BSS19.

Absorption; Autogenous healing; Durability factor; Dynamic modulus of elasticity; Saturation coefficient; BSS35.

Accelerated aging; Adhesivc bond; Ductility; Flexural shear; Housing systems; Local buckling; Material variability; Moisture conditioning; Operation BREAKTHROUGH; Paper honeycomb; Structural sandwich; Sustained load; BSSSI.

Accelerated aging; Aging of buildings; Building components; Climate; Criteria; Deterioration; Durability; Materials; Mechanisms; Nondestructive testing; Testing; NBSIR 73-132.

Accelerated aging; Building components and materials; Climatological data; Durability; Environmental factors; Long-term tests; Short-term tests; Weathering factors; TN838.

Accelerated aging; Compression; Environmental conditions; Flexure; Housing system; Operation BREAKTHROUGH; Polyurethane foam; Sandwich construction; Wall system; NBSIR 73-105.

Accelerated curing of cements; Autoclave curing of portland cement mortars; Chemical composition; Compressive strength of portland cement; Compressive strength of steam-cured cements; Fineness; Heat of hydration; Steam curing of portland cement mortars; Strength gain of portland cements; Trace elements; BSS8.

Accelerated laboratory tests; Double-glazed window units; Factory-sealed insulating glass units; Field performance tests, correlation with laboratory tests; Sealant performance; Standardized testing; Test methods; BSS20.

Accelerated weathering; Durability of water-proofing materials; Masonry; Performance criteria; Water-proofing materials; Water-repellent materials; TN883.

Accelerations; Buffeting; Building codes; Buildings; Deflections; Dynamic response; Gust factors; Structural engineering; Wind engineering; Wind loads; BSS74.
Acid resistance; Color; Continuty of coatung; Porcelatlı enamel: Weather resistancc; TN7(1)

Acid resistance; Color; Gloss; pH; Porcelaın enamel, Relatıve humidity; Weather resistancc; B.S.S4.

Acid resistance; Color; Gloss; Porcelain enamel, Weather rcsistance; BSS38

Acid resistance; Color; Gloss; pH; Porcclain enamel; relauve humidity; Weather rcsistance; BSSSO

Acoustics; Air infiltration; Air lcakage; Architectural acoustics, Building acoustics; Doors; Energy conservation; Heat loss from buildings; Heat transfer; Sound transmission losscs; Thermal resistance; Thermal transmittancc; Windows; BSSS77.

Acoustics; Ficld impact insulation class; Noise critcrion curve; Noise isolation class; Operation BREAK 1 HROUGH NBSIR 73-191.

Acoustics; Noise criterion curvcs; Noise isolation class; Operation BREAKTHROUGH; NBSIR 73-192.

Acoustics; Noise isolation class; Operation BREAKTHROUGH NBSIR 73-190.

Additivie; Asphalt; Durability; Felt; Stabilizer; Weathering; BSS24.

Adhesive bond; Aging; Composites; Compression; Flexure; Glass fiber; Housing system; Innovations; Laminate; Operation BREAKTHROUGH; Racking; Reinforced plastics; Reinforced polyester; Sustained loading; Tensile shear; NBSIR 73-188.

Adhesion; Colorfastness; Covering; Flame spread; Flash point; Impact resistance; Lead paint poisoning; Materials; Performance; Properties; Scratch resistance; Smoke generation; Toxic combustion products; Toxicity; Washability; Water vapor permeance; Abrasion; TN808.

Adhesives; Paper honeycomb; Sandwich facings; Sandwich panels: BSS43.

Adherence; Aluminum; Electron microprobe; Electron microscope; porcelain enamel; Spalling; X-ray diffraction; BSS59.

Adhesive bond; Ductility; Flexural shear; Housing systems; Local buckling; Material variability; Moisture conditioning; Operation BREAKTHROUGH; Paper honeycomb; Structural sandwich; Sustained load; Accelerated aging; BSS51.

Adhesives; Air'inflatable shelter sections; Cloth webs; Polyester and nylon fabrics; Sewn seams; Sewn Seam strapping; Solar heat load; Test procedure; NBSIR 74-467.

Aerodynamic forces, Atmospheric boundary layer; Disaster migitation; Structural design; Turbulence; Wind effects; Wind loads; BSS30.

Aerodynamics; Boundary layers; Buildings; Codes and Standards: Wind loads; Wind tunnels; TN852.

Aging; Composites; Compression; Flexure; Glass fiber; Housing system; Innovations; Laminate; Operation BREAKTHROUGH; Racking; Reinforced plastics; Reinforced polyester; Sustained loading; Tensile shear; Adhesive bond;

Aging of buildings; Building components; Climate; Criteria; Deterioraıun; Durability; Materials; Mechanisms; Nondestructive testing; Testing; Accelerated aging; NBSIR 73-132.

Aging test; Building elements and materials; Degradation factors: Durability; Property measurement test; Standard test methods: NBSIR 75-955.

Air-conditioning; Air pollution; Central utility systems; Data acquisition system; Efficiencies; Electrical power; Energy conservation; Energy costs; Fuel utilization; Heat recovery; Total energy systems; Utilities for housing; Utility system performance; NBSIR 75-711.

Air-conditioning capacity; Air-mixing devices; Forced air-mixing; Turbulence; Mixer effectiveness; Apparatus design; Air properties; Temperature measurement; J. Res. IBS. $70 \mathrm{C}$. Yo. Air-conditioning criteria; Building thermal response; Comfort 
indices; Human comfort; Predicted indoor habitability index; BSS71.

Air contamination; Design conditions; Earthquake risk; Evaluation; Ground temperature; Humidity; Noise level; Operation BREAKTHROUGH; Precipitation; Solar radiation; Temperature; Wind direction; Wind speed; NBSIR 73-144.

Aircraft materials; Combustion products; Fire tests; Interior finish; Smoke; Toxic gases; BSS18.

Air infiltration; Air leakage; Architectural acoustics; Building acoustics; Doors; Energy conservation; Heat loss from buildings; Heat transfer; Sound transmission loss; Thermal resitance; Thermal transmittance; Windows; Acoustics; BSS77.

Air infiltration and extraction, airtightness; Discomfort index; Duct system, collective and individual branch; Flow rates; Noise; Pressure-loss-depression; Thermal convection; Ventilation; TN710-3.

Air-inflatable shelter sections; Cloth webs; Polyester and nylon fabrics; Sewn seams; Sewn seam strapping; Solar heat load; Test procedure; Adhesives; NBSIR 74-467.

Air inlet; Discomfort index; Draft; Outside wall; Ventilation; Wind; TN710-6.

Air leakage; Architectural acoustics; Building acoustics; Doors; Energy conservation; Heat loss from buildings; Heat transfer; Sound transmission loss; Thermal resistance; Thermal transmittance; Windows; Acoustics; Air infiltration; BSS77.

Air leakage measurement; Building heat transfer; Computer programs; Dynamic thermal performance; Heat flow analysis; Heating and cooling loads; Temperature predictions; Thermal analysis; Thermostat setback; Transient heat flows; BSS57.

Air-mixing devices; Forced air-mixing; Turbulence; Mixer Effectiveness; Apparatus design; Air properties; Temperature measurement; Air-conditioning capacity; J.Res. NBS, 70 C No.1.

Air pollution; Central utility systems; Data acquisition system; Efixciencies; Electrical power; Energy conservation; Energy costs; Fuel utilization; Heat recovery; Total energy systems; Utilities for housing; Utility system performance; Air- conditioning; NBSIR 75-7II.

Air pollution; Historic structures; Laboratory evaluation; Natural weathering; Stone decay; Stone preservation; NBSIR 74-444.

Air properties; Temperature measurement; Air-conditioning capacity; Air-mixing devices; Forced air-mixing; Mixer effectiveness; Apparatus design; J. Res. NBS, 70C No. I.

Alternate path; Annotated bibliography; Bibliography; Building code; Building regulations; Collapse; Failures; Progressive collapse; Specific resistance; Abnormal loading; BSS67.

Aluminum; Ductwork; Fabric; Fiberglass; Fire tests; High-rise buildings; HVAC systems; Steel; Terminal units; NBSIR 73-267.

Aluminum; Electron microprobe; Electron microscope; Procelain enamel; Spalling; X-ray diffraction; Adherence; BSS59.

Analysis; Basic correlation forumlas; Computer calculations; High-rise building fire; Operation BREAKTHROUGH; Pressurized stairwell; Quantitative experiment; Smoke control; Smoke simulation; NBSIR 73-277.

Analysis; Compressive strength; Deflection; Design; Flexural strength; Masonry wal!s; Racking strength; Seismic loading; Shear strength; Shear wall; Stiffness; NBSIR 74-520.

Analysis; Deflection; Design; Dynamic; Experimental; Human sensitivity; Loading functions; Specifications; Static; Structural engineering; Subsystems; Vibration; BSS47.

Analysis; Experimental; Floor systems; Human response; Random process; Spectral analysis; Vibration; NBSIR 75-95I.

Analytical methods; Antimony; Arsenic; Cadmium; Lead; Mercury; Review; Selenium; Toxic elements in paints; NBSIR 73-251.

Anchorage; Building performance; Disaster mitigation; Glazing: Hailstones; Masonry; Mobile homes; Roofs; Structural engineering; Wind load; TN558.
Anchors; Concrete slabs; Design loads; Fatigue; Inserts; Pullout loads; Sustained load; BSS42.

Annotated bibliography; Bibliography; Building code; Building regulations; Collapse; Failures; Progressive collapse; Specific resistance; Abnormal loading; Alternate path; BSS67.

Apartment dwelling; Burnout test; Fire load; Fire performance; Flame penetration; Potential heat; Structural load; BSSIO.

Antimony; Arsenic; Cadmium; Lead; Mercury; Review; Selenium; Toxic elements in paints; Analytical methods; NBSIR 73-251.

Apparatus design; Air properties; Temperature measurement; Airconditioning capacity; Air-mixing devices; Forced air-mixing; turbulence; Mixer effectiveness; J. Res. NBS, 70C No.l

Application; Coatings; Coating systems; Corrosion-inhibiting; Federal specifications; Fire-retardant; Lacquer; Latex; Multicolor; Organic coatings; Paint; Pigments; Polymers; Properties; Resins; Selection; Substrates; Surface preparation; Varnish; Water thinned; BSS7.

Architectural acoustics; Building acoustics; Doors; Energy conservation; Heat loss from buildings; Heat transfer; Sound transmission loss; Thermal resistance; Thermal transmittance; Windows; Acoustics; Air infiltration; Air leakage; BSS77.

Architecture; Building; Building codes; Building design; Disaster mitigation; Earthquakes; Engineering; Environmental hazards; Housing; Inspection and testing; Safety; TN885.

Architecture; Design; Hospital design; Medical facilities; Medical facility research; BSS54.

Arsenic; Cadmium; Lead; Mercury; Review; Selenium; Toxic elements in paint; Analytical methods; Antimony; NBSIR 73-251.

ASHRAE 90-P; Building codes; Mobile homes; NCSBCS: SP 429.

ASHRAE Task Group on Energy Requirements; Conduction transfer functions; Heating and cooling load; National Bureau of Standards Heating and Cooling Load Computer Program; NBSIR 75-574.

Asphalt; Asplund; Felt; Mineral-surfaced roll roofing; Shingles; Wood fibers; TN477.

Asphalt; Durability; Felt; Stabilizer; Weathering; Additive; BSS24.

Asphalt shingles; Built-up roofing; Hail; Roofing; Shingles; Storm damage; BSS23.

Asphalts; Felts; Moisture; Roofing; Saturation; Absorption; BSS19.

Asplund; Felt; Mineral-surfaced roll roofing; Shingles; Wood fibers; Asphalt; TN477.

ASTM E 84; Building materials; Carpets; Fire tests; Flame spread tests; Interlaboratory evaluation; Round robin; Statistical analysis; Test method standard; NBSIR 73-125.

Atmospheric boundary layer; Disaster mitigation; Structural design; Turbulence; Wind effects; Wind loads; Aerodynamics; BSS30.

Authority; Building; Energy; Legislation; Regulations; State; NBSIR 75-747.

Autoclave curing of portland cement mortars; Chemical composition; Compressive strength of portland cement; Compressive strength of steam-cured cements; Fineness; Heat of hydration; Steam curing of portland cement mortars; Strength gain of portland cements; Trace elements; Accelerated curing of cements; BSS8.

Autoclave expansion; Cement; Concrete; Heat of hydration; Portland cement; Sulfate expansion; BSS5.

Autogenous healing; Durability factor; Dynamic modulus of elasticity; Saturation coefficient; Absorption; BSS35.

\section{B}

Barrier materials; Building materials; Housing; Lead-based paint; Lead poisoning; Paint removal; Abatement; NBSIR 75-761. 
Barriers; Combustibility; Fire; Smoke; Radiation flux measurements; Doors; BSS3.

Basic correlation forumlas; Computer calculations; High-rise building fire; Operation BREAKTHROUGH; Pressurized stairwell; Quantitative experiment; Smoke control; Smoke simulation; Analysis; NBSIR 73-277.

Beach erosion control; Cost sharing; Economics; Efficiency; Equity; Incentives; Shoreline protection; NBSIR 73-294.

Bearing pads; Bearing walls; Brick masonry; Design of bearing walls; Eccentricity of applied loads; BSS14.

Bearing walls; Brick masonry; Design of bearing walls; Eccentricity of applied loads; Bearing pads; BSS14.

Benefit-cost analysis; Building economics; Building envelope; Economic analysis; Economic efficiency; Energy conservation; Engineering economics; Insulation; Life-cycle costs; Marginal analysis; Thermal efficiency; BSS64.

Benefit-cost analysis; Building safety; Economics; Progressive collapse; Standards; NBSIR 74-452.

Benefit-cost analysis; Disaster migitation; Earthquakes; Economics; Efficient; Floods; Hurricanes; Natural disasters; Optimal; Tornadoes; Total cost minimization; NBSIR 74-473.

Bibliography; Building code; Building regulations; Collapse; Failures; Progressive collapse; Specific resistance; Abnormal loading; Alternate path; Annotated bibliography; BSS67.

Bibliography; Color; Color codes; Color measurement; Colorimetry; Spectrophotometry; Vision; SP 393.

Bituminous adhesive; Bituminous built-up membranes; Engineering properties; Laboratory-field comparison; Strengththickness; TN473.

Bituminous built-up membranes; Engineering properties; Laboratory-field comparison; Strength-thickness; Bituminous adhesive; TN473.

Bituminous built-up roofing; Build-up roofing membranes; Roofing membranes; Thermally induced forces; Thermal-shock resistance factor; BSS9.

Bituminous roof membranes; Fatigue testing; Flexural fatigue; Performance criteria; Roofing temperature effects; Tensile fatigue; Test methods; TN863.

Bituminous roof membranes; Performance attributes; Performance criteria; Physical and engineering properties; Test methods; BSS55.

Boiler oversizing; Efficiency versus heating load; Modular boilers; Modular concept; Seasonal efficieincy. BSS79.

Boundary layers; Buildings; Codes and standards; Wind loads; Wind tunnels; Aerodynamics; TN852.

Branch circuits; Contact resistance; Electrical codes; Electrical connections; Fire safety; Housewiring; Performance testing; NBSIR 75-672.

Brick; Cavity Walls; Composite walls; Compressive strength; Concrete block; Flexural strength; Masonry; Mortar; Slenderness effects; Standards; Structural stability; Walls; BSS34.

Brick; Failure; Failure theories; Masonry; Shear strength; Shear test; Shear walls; Stress distribution; Stresses; Structural engineering; NBSIR 75-703.

Brick masonry; Design of bearing walls; Eccentricity of applied loads; Bearing pads; Bearing walls; BSS14.

Bridge; Building codes; Dams; Disaster mitigation; Earthquake damage; Earthquakes; Foundation geology; Highways; Hospital; Housing; Mobile homes; Seismic; Standards; Structural engineering; BSS40.

Bridge; Building; Codes; Dams; Earthquake damage; Earthquakes; Foundation geology; Highways; Hospital; Housing; Mobile home; Seismic; Standards; Structural engineering; BSS40.

Bridge decks; Chloride ions; Concrete corrosion; Deicing salts; Epoxy coatings; Organic coatings; Polyvinyl chloride coatings; Steel reinforcing bars; 'BSS65.

Bridge decks; Corrosion; Creep testing; Epoxy coatings; Polyvinylchloride coatings; Steel reinforcing bars; NBSIR 73-295.
Buckling; Compressive strength; Concrete block: wall flastic stability; Flexural strength; Masonry walls; Rc nforced concrete masonry walls; Slenderness effect; Structural stability, BS5.33

Buffeting; Building codes; Buildıngs; Deflectıons; Dynamic responsc; Gust factors; Siructural engineering. Wind engincering; Wind loads; Accclerations; R.S.S74

Building acoustics; Doors; Energy conservation, Heal lesss from buildings; Heat transfer; Sound transmission less, Thermal resistance; Thermal transmittancc; Windows; Acoustics, Air infiltration; Air lcakage; Architcctural acoustics; B.5.577.

Building; Building codes; Building desing; Disaster mıtıgation; Earthquakes; Engincering; Environmental hazards; Housıng; Inspection and tcsting; Safety; Architecture; TN885.

Building classification; Building thermal mass; Buildıng thermal performance; Building thermal timc constant; Housing systems: Industrialized housing; Mass per unit arca; Operation BREAK THROUGH; U-value; NBSIR 75-678.

Building code; Building regulations; Collapsc; Failures; Progressive collapse; Specific resistance; A bnormal loading; Alternatc Path; Annotated bibliography; Bibliography; BSS67.

Building codes; Building design; Disaster mitigation; Earthquakes; Engineering; Environmental hazards; Housing; Inspection and testing; Safety; Architecture; Building; TN885.

Building codes; Buildings; Deflections; Dynamic responsc; Gust factors; Structural engineering; Wind engineering; Wind loads; Accelerations; Buffeting; BSS74.

Building codes; Buildings; Disaster mitigation; Earthquakes: Hazards; natural disasters; Structures; TN807.

Building codes; Buildings; Energy conservation; Standards; TN789-1.

Building; Codes; Dams; Disaster migitation; Earthquake damage; Earthquakes; Foundation geology; Highways; Hospital; Housing; Mobile homes; Seismic; Standards; Structural engineering; Bridge; BSS40.

Building; Codes; Design criteria; Multistory; Progressive collapse; Risk; Stability; Standards; Strength; United States; Abnormal loading; NBSIR 73-221.

Building codes; Mobile homes; ASHRAE 90-P; NCSBCS: SP 429.

Building codes; Extreme value distributions; Hurricanes; Probability distribution functions; Reliability; Risk; Statistical analysis; Storms; Structural engineering; Wind loads; Wind speeds; TN868.

Building components and materials; Climatological data; Durability; Environmental factors; Long-term tests; Short-term tests; weathering factors; Accelerated aging; TN838.

Building components; Climate; Criteria; Deterioration; Durability; Materials; Mechanisms; Nondestructive testing; Testing; Accelerated aging; Aging of buildings; NBSIR 73-132.

Building; Components; Precoordination; Standards; BSS32.

Building; Connections; Housing; neoprene; Performance criteria; Performance evaluation; performance testing; Reinforced concrete; Standard tests; Structure testing; TN706.

Building composite; Building material; Conditioning; Equilibration; Gypsum wallboard; Methodology; Relative humidity; Structural sandwich panel; Temperature; Testing; NBSIR 75-767.

Building construction; Complete buildings; Floors; Roofs: Standardization; Test methods; Wálls; BSS58.

Building damping; Drift; Dynamics; Earthquake; Frequency; Housing; Lateral resistance; Racking; Stiffness; Structural deflections; Vibration; Wind load; Wood frame construction; BSS44.

Building design; Building energy analysis; Energy conservation options; Heating and cooling load calculations; Energy design optimization; BSS78.

Building design; Disaster mitigation; Earthquakes; Engineering; Environmental hazards; Housing; Inspecting and testing; Safety; Architecture; Building; Building codes: TN885. 
Building design: Energy conservation: Mechanıcal systems: TN789.

Building; Disaster mitigation; Earthquakes; hazards; Land use; Structural engineering; Wind effects; $B S S 46$.

Building economics; building envelope; economic analysis; economic efficiency; energy conservation; engineering economics; insulation; life-cycle costs: marginal analysis; thermal efficiency; benefit-cost analysis; BSS64.

Building economics; Building systems; Construction industry; Housing; Precast concrete; Production capacity; Production management; Production methods; Standardization: United Soviet Socialist Republics; SP334.

Building economics; Consumer information; Energy conservation; Home economics; Home improvements; Insulation; CIS 8.

Building elements and materials; Degradation factors; Durability; Property measurement test; Standard test methods; Aging test; NBSIR 75-955.

Building energy analysis; Energy conservation options; Heating and cooling load calculation; Energy design optimization; Building design; $B S S 78$.

Building; Energy; Legislation; Regulations; State; Authority; NBSIR 75-747.

Building envelope; economic analysıs; economic efficiency; energy conservation; engineering economics; insulation; lifecycle costs; marginal analysis; thermal efficiency; benefit-cost analysis; building economics; $B S S 64$.

Building; Explosion; Frequency; Gas; Gas industry; Progressive collapse; Risk; Statistics; Structure; NBSIR 73-208.

Building; Gas explosion; Load-bearing masonry; Load-bearing walls; Masonry; Masonry research; Progressive collapse; Abnormal loading; NBSIR 74-526.

Building heat transfer analysis; Energy usage; Environmental engineering: Heating and air conditioning; Use of computers; BSS 39 .

Building heat transfer: Computer programs; Dynamic thermal performance: Heat flow analysis: Heating and cooling loads: Temperature predictions; Thermal analysis: Thermal hehavior: Transient heat flows: $B S S 45$.

Building heat transfer; Computer programs; Dynamic thermal performance; Heat flow analysis; Heating and cooling loads; Temperature predictions; Thermal analysis; Thermostate setback; Transient heat flows; Air leakage measurement; BSS57.

Building material; Conditioning; Equilibration; Gypsum wallboard; Methodology; Relative humidity; Structural sandwich panel; Temperature; Testing; Building composite; NBSIR 75-767.

Building material; Housing; Leaded paint; Lead hazard elimination methods; Lead paint poisoning; Performance attributes; TN770.

Building materials; Building performance; Building research: Building systems; Building technology; History; BSSO.

Building materials; Carpets; Fire tests; Flame spread tests; Interlaboratory evaluation; Round robin; Statistical analysis; Tes1 method standard; ASTM E 84; NBSIR 73-125.

Building materials: Fire: Fire services; Smoke; Smoke density chamber: Smoke potential: Test method: Visibility: $T N 757$

Building materials: Fire tests: Interlaboratory tests; Optical density: Round robin: Smoke: Smoke density chamber: Statistical analvsis: $T N 708$.

Building materials; Housing; Lead-based paint; Lead poisoning; Paint removal; Abatement; Barrier materials; NBSIR 75-761.

Building performance; Building research: Building systems; Building technology; History; Building materials; BSSO.

Building performance; Disaster mitigation; Glazing; Hailstones; Masonry; Mobile homes; Roofs; Structural engineering; Wind load; Anchorage; TN558

Building performance; Glazing; Hailstones; Masonry; Mobile homes; Roofs; Structural engineering; Wind load; Anchorage: TN558

Building regulation; enforcement; evaluation; inspection; legisla- tion; manufactured building; mobile homes; rules and regulations; state-of-the-art study; TN853.

Building regulation; Evaluation; Inspection; Manufactured building: Mobile homes; Model documents; State-of-art study: $T N 775$

Building regulations; Collapse; Failures; Progressive collapse; Specific resistance; Abnormal loading; Alternate path; Annotated bibliography; bibliography; Building code; BSS67.

Building research; Building systems; Building technology; History; Building materials; Building performance; BSSO.

Building research; Buildings; Cooperation; Housing; International; Switzerland; NBSIR 73-288.

Building safety; Economics; Progressive collapse; Standards; Benefit-cost analysis; NBSIR 74-452.

Buildings; Codes and standards; Disaster mitigation; Housing; Hurricanes; Low-rise buildings; Natural disaster; Structural connections; Typhoons; Wind loads; NBSIR 75-790.

Buildings; codes and standards; wind loads; wind tunnels; aerodynamics; boundary layers; $T N 852$.

Buildings; Components; Design procedures; Experience in use; Materials; Performance evaluation; Performance requirements: User requirements; SP361. Volume I.

Buildings; Components; Design procedures; Experience in use; Materials; Performance evaluation; Performance requirements; User requirements; SP361. Volume 2.

Buildings; Construction; Data acquisition equipment; Desigr. criteria; Disaster mitigation; Extreme winds; Information transfer; Instrumentation; Wind loads; Wind tunnel modeling; NBSIR74-567.

Buildings; Construction; Design; Developing countries; Disaster mitigation; Earthquakes; Low-cost housing; Natural disasters; Structures; Windstroms; BSS48.

Buildings; Cooperation; Housing; International; Switzerland; Building research; NBSIR 73-288.

Buildings; Damage; Disaster mitigation; Dynamic analysis; Earthquakes; Hurricanes; natural hazards; Structural engineering; Tornadoes; Wind; BSS61.

Buildings; Deflections; Dynamic response; Gust factors; Structural engineering; Wind engineering; Wind loads; Accelerations; Buffeting; Building codes; BSS74.

Buildings; Deflections; Instrumentation; Structural response; Wind loads; $T N 873$.

Buildings; Disaster mitigation; Earthquakes; Hazards; Natural disasters; Structures; Building codes; TN807.

Buildings; Disaster mitigation; Failure; Hurricanes; Mobile homes; Roofs; Structural engineering; Tides; Wind; TN569.

Buildings; Earthquakes; Hazards: Natural disasters; Structures: Building codes; TN 807 .

Buildings; Energy Conservation; Standards; Building codes; TN789-1.

Buildings; Failure; Hurricanes; Mobile homes; Roofs; Structural engineering; Tides; Wind; TN569.

Buildings; Fire loads; Occupancy live loads; Load surveys; Structural engineering; Survey techniques; TN858.

Building system; Column connection; Concrete traixial strength; Ductility; Neoprene bearing pad; Operation BREAKTHROUGH; Performance tests; Precast concrete; Structural design; NBSIR 73-148.

Building system; column connection; concrete triaxial strength: ductility; neoprene bearing pad; Operation Breakthrough: performance test; precast concrete; structural design; TN 811 .

Building systems: Building technology; History; Building materials: Building performance; Building research: BSSO.

Building systems; Construction industry; Housing: Precast concrete; Production capacity: Production management: Production methods; Standardization; United Soviet Socialist Reoublics; Building economics; SP334. 
Building systems; Housing systems; Large-panel structure; Precast concrete construction; Progressive collapse; Structural design; Structural joists; NBSIR 75-715.

Building systems; Low-income housing: Performance criteria: Performance testing: BSS25.

Building systems: Performance of buildings: Standards: Test methods: N rban planning: User needs: BSS I

Building technology; Cooperation; Fire safety; Hydraulics; Wind loads; NBSIR 74-618.

Building technology; History: Building materials; Building performance; Building research; Building systems; BSSO.

Building thermal mass; Building thermal performance; Building thermal time constant; Housing systems; Industrialized housing; Mass per unit area; Operation BREAKTHROUGH; U-value; Building classification; NBSIR 75-678.

Building thermal performance; Building thermal time constant; HOusing systems; Industrialized housing; Mass per unit area; Operation BREAKTHROUGH; U-value; Building classification; Building thermal mass; NBSIR 75-678.

Building thermal response; Comfort indices; Human comfort; Predicted indoor habitability index; Air-conditioning criteria; BSS71.

Building thermal time constant; Housing systems; Industrialized housing; Mass per unit area; Operation BREAKTHROUGH; u-value; Building classification; Building thermal mass; Building thermal performance; NBSIR 75-678.

Built-up roofing; Hail; Roofing; Shingles; Storm damage; Asphalt shingles; $B S S 23$

Built-up roofing membranes; Roofing membranes; Thermally induced forces; Thermal-shock resistance factor; Bituminous built-up roofing; BSS9.

Built-up roofing; Nighttime cooling; Radiative cooling; Solar heating; Thermal movement. TN231.

Burnout test; Fire load; Fire penormance; Flame penetration; Potential heat; Structural load; A partment dwelling; BSSIO.

Burnout tests; Fire endurance; Fire severity; Floor tests; Steel plate floors; BSS 11 .

Buoyant plume; Diffusion flame; Fire; Flame height; Mathematical modeling; Turbulent flow; NBSIR 73-115.

\section{C}

Cadmum; Lead; Mercury; Review; Selenium; Toxic elements in paints; Analytical methods; Antimony; Arsenic; NBSIR 75-251.

Calcium aluminoferrite hydrates; Calcium Sulfate reaction with calcium aluminoferrite hydrates; DT A of calcium aluminoferrite hydrates; X-ray patterns of calcium aluminoferrite hydrates; BSS6.

Calcium sulfate reaction with calcium aluminoferrite hydrates; DTA of calcium aluminoferrite hydrates; X-ray patterns of calcium aluminoferrite hydrates; Calcium aluminoferrite hydrates; $B S S 6$.

Capacitors; Energy conservation; Fluorescent lamp; Fluoressent luminaire; Lighting efficiency; Power factor; TN886.

Carpet; Fire test; Flammability; Flooring; Heat flux; Ignition; Radiant panel; NBSIR 74-495.

Carpets: Durability; Economics: Field studies; Flooring: Floor coverings: l.ife-cost: Maintenance: User needs: TN78.3.

Carpets; Fire tests; Flame spread tests; Interlaboratory evaluation; Round robin; Statistical analysis; Test method standard; ASTM E 84; Building materials; NBSIR 73-125.

Carpets; Flame spread; Kitchen cabinets; Operation BREAKTHROUGH; Smoke generation; Wall and ceiling; NBSIR 73-228.

Carpets; floor coverings: government; performance; procurement; specifications; standards; tests; user needs; TN822.
Caulks and sealants; Clock thermostats; Energy conservation; Insulation; Retrofitting; Storm doors; Storm windows; I ax credit; Vapor barriers; Weatherstripping; NR.S/R 75-795.

Cavity walls; Composite walls; Compressive strength; Concrete block: Flexural strength; Masonry: Mortar; Slenderness ef fects; Standards; Structural stábility; Walls; Brick; BS.S34

Ceiling radiation: ( orridor fires: Crutcal enerey inpul Flame spread. Calculation. and observations, l- loor covering cevalua. tions: Heat balances: Heat transfer mechanisms. Models. energy balance. radiation. and scaling: 1 N744

Cement; Cement mortar; Cement paste: Farly strength: False set; Hardening of cement: Hydration: Shear resistance Theory of cement hardening: Time of sel: Vane-shear ap paratus; $B S . S 28$.

Cement; Chemical composition; Concrete; Durability; Material properties: Physical properties; BSS36.

Cement Composition; Chemical Composition of portland cements; Cracking of portland cements; Cracking resistance of cements; Expansion-shrinkage ratios; portland cement; portland cement concrete; Shrinkage of concrete; Shrinkage of portland cements; Trace elements; BSS15

Cement; Concrete; Heat of hydration; Portland cement; Sulfate expansion; Autoclave expansion; BSS5.

Cement; Concrete; Material properties; Physical properties; Trace Elements; Portland cement; Spectrographic analyses; BSS2.

Cement mortar: Cement paste; Early strength: False set Hardening of cement; Hydration; Shear resistance; Theory of cement hardening: Time of set; Vane-shear apparatus: $C e-$ ment; $B S S 28$.

Cement paste; Early strength; False sct; Hardening of cement; Hydration: Shear resistance: Theory of cement hardening: Time of set: Vane-shear apparatus: Cement: Cement mortar: BSS28.

Central utility systems; Data acquisition system; Efficiencies; Electrical power; Energy conservation; Energy costs; Fuel utilization; Heat recovery; Utilities for housing; Utility system performance; Air-conditioning; Air pollution; NBSIR 75-711.

Chemical analyses; Physical tests; Portland cement; BSS 17

Chemical composition; Compressive strength of portland cement; compressive strength of steam-cured cements; Fineness; Heat of hydration; Steam curing of portland cement mortars; strength gain of portland cements; Trace elements; Accelerated curing; of cements; autoclave curing of portland cement mortars; BSS8.

Chemical composition; Concrete; Durability; Material properties; Physical properties; Cement; BSS36.

Chemical composition of portland cements; Cracking of portland cements; Cracking resistance of cements; Expansion-shrinkage ratios; Portland cement; Portland cement concrete; Shrinkage of concrete; Shrinkage of portland cements; Trace elements; Cement composition; BSS15.

Chemical resistance; Cigarette-burn resistance: Cleanability and soilability; Concentrated static-load capacity; Perform. ance characteristics; Performance level; Sanitary plumbing fixtures; Scratch resistance; Stain resistance; Surface-impact resistance; Test methods; Abrasion resistance; BSS22.

Childhood diseases; Estimation; Health problems; Lead; Lead paint; Lead paint poisoning; Lead poisoning; Mathematical modeling; Models; Urban health problems; TN746.

Chloride ions; Concrete corrosion; Deicing salts; Epoxy coatings; organic coatings; Polyvinyl chloride coatings; Steel reinforcing bars; Bridge decks; BSS65.

Chlorides; Concrete; Corresion; Epoxy coatings; Organic coating; Steel reinforcing bars; $T N 768$.

Chlorinated polyvinyl chloride; Hardness; Internal stress; Polyviny] chloride; Thermal mechanical analysis (TMA); Thermal properties; Thermogravimetric analysis (TGA); Thermoplastic pipe; NBSIP 74-610. 
Cigarette-burn resistance: Cleanability and soilability; Concentrated static-load capacity; Performance characteristics; Performance level; Sanitary plumbing fixtures; Scratch resistance; Stain resistance; Surface-impact resistance; Test methods: Abrasion resistance; Chemical resistance; BSS22.

Cleanability and soilability: Concentrated static-load capacity; Performance characteristics: Performance level: Sanitary plumbing fixtures: Scratch resistance: Stain resistance: Surface-impact resistance: Test methods; Abrasion resistance; Chemical resistance; Cigarette-burn resistance; $B S S 22$

Climate; Criteria; Deterioration; Durability; Materials; Mechanisms; Nondestructive testing; Testing; Accelerated aging; Aging of buildings; Building components; NBSIR 73-132.

Climatological data; durability; environmental factors; long-term tests; short-term tests; weathering factors: accelerated aging; building components and materials: $T N 838$.

Clock thermostats; Energy conservation; Insulation; Retrofitting; Storm doors; Storm windows; Tax credit; Vapor barriers; Westherstripping; Caulks and sealants; NBSIR 75-795.

Cloth webs; polyester and nylon fabrics; sewn seams; sewn seam strapping: solar heat load; test procedure; adhesives; airinflatable shelter sections; NBSIR 74-467.

Coatings; Coating systems; Corrosion-inhibiting; Federal specifications; Fire-retardant; Lacquer; Latex; Multicolor; Organic coatings; Paint; Pigments; Polymers; Properties; Resins; Selection; Substrates; Surface preparation; Varnish; Water thinned; BSS7.

Coating systems; Corrosion-inhibiting; Federal specifications: Fire-retardant; Lacquer; Latex; Multicolor; Organic coatings; Paint; Pigments; Polymers; Properties; Resins; Selection; Substrates; Surface preparation; Varnish; Water-thinned; BSS7.

Codes and standards; Disaster mitigation; Housing; Hurricanes; Low-rise buildings; Natural disaster; Structural connections; Typhoons; Wind loads; Buildings; NBSIR 75-790.

Codes and standards; Disaster mitigation; Information transfer; Low-rise buildings; Pressure transducers; Socio-economic Structural design; Technology implementation; Wind effects; Wind loads; BSS56.

Codes and standards; wind loads; wind tunnels; aerodynamics; boundary layers; buildings: TN852 .

Codes; construction conference; domestic housing, U.S.; foreign metrication; levels of conversion; metrication; problems of metrication; NBSIR 73.421.

Codes; Dams; Disaster mitigation; Earthquake damage; Earthquakes; Foundation geology; Highways; Hospital; Housing; Mobile home; Seismic; Standards; Structural engineering; Bridge; Building; BSS40.

Codes; Dams; Earthquake damage; Earthquakes; Foundation geology; Highways; Hospital; Housing; Mobile home; Seismic; Standards; Structural engineering; Bridge; Building; BSS 40 .

Codes; Design criteria; Multistory; Progressive collapse; Risk; Stability; Standards; Strength; United States; Abnormal loading; Building; NBSIR 73-221.

Coefficient of expansion; CPVC; Glass transition temperature; Hardness; Polybutene; PB; Polyvinyl chloride; PVC; Residual stress; Thermoplastic piping; ABS; NBSIR 74-629.

Coefficient of friction; Floor slipperiness; Frictional tests; Human perambulation; Resilient flooring; Slipperiness standards; Slip test; NBSIR 74-613.

Collapse, Failures; progressive collapse; Specific resistance; Abnormal loading; Alternate path; Annotated bibliography; bibliography; Building code; Building regulations; BSS67.

Colloidal theory; Crystallization theory; Gypsum; Hydration; Induction period; Plaster of paris: Setting mechanisms; TN755.

Color codes; Color measurement; Colorimetry; Spectrophotometry; Vision; Bibliography; Color; SP 393.
Color; Color codes; Color measurement; Colorimetry; Spectrophotometry; Vision; Bibliography; SP 393.

Color; Continuity of coating; Porcelain enamel; Weather resistance; Acid resistance; TN707.

Color; Environment; Experimenting with; Harmony; Hues; Illumination; Light; Personal uses; Relationship; Uses; CIS6.

Colorfastness; Covering; Flash point; Flame spread; Impact resistance; Lead paint poisoning; Materials; Performance; Properties; Scratch resistance; Smoke generation; Toxic combustion products; Toxicity; Washability; Water vapor permeance; Abrasion; Adhesion; TN808.

Color; Gloss; pH; Porcelain enamel; Relative humidity; Weather resistance; Acid resistance; $B S S 4$.

Color: gloss; $\mathrm{pH}$; porcelain enamel; relative humidity; weather resistance: acid resistance; $B S S 50$.

Color: Gloss; Porcelain enamel on aluminum; Weather resistance; $B S S 29$

Color; Gloss; Porcelain enamel; Weather resistance; Acid resistance; $B S S 38$.

Colorimetry; Spectrophotometry; Vision; Bibliography; Color; Color codes; Color measurement; SP 393.

Color measurement; Colorimetry; Spectrophotometry; Vision; Bibliography; Color; Color codes; SP 393.

Column connection; concrete triaxial strength; ductility; neoprene bearing pad; Operation Breakthrough; performance test: precast concrete; structural design; building system; TN811.

Column connection; Concrete traixial strength; Ductility; Neoprene bearing pad; Operation BREAKTHROUGH; Performance tests; Precast concrete; Structural design; Building system; NBSIR 73-148.

Combustibility; Fire; Smoke; Radiation flux measurements; Doors; Rarriers: $3 S S 3$.

Combustion products; Fire tests; Interior finish; Smoke; Toxic gases: Aircraft materials: BSS 18 .

Comfort indices; Human comfort; Predicted indoor habitability index; Air-conditioning criteria; Building thermal response; BSSTl.

Complete buildings; floors; roofs; standardization; test methods; walls; building construction; BSS58.

Components; Design procedures; Experience in use; Materials; Performance evaluation; Performance requirements; User requirements; Buildings; SP361. Volume 1.

Components; Design procedures; Experience in use; Materials; Performance evaluation; Performance requirements; User requirements; Buildings; SP361. Volume 2.

Components; Precoordination; Standards; Building; BSS32.

Composites; Compression; Flexure; Glass fiber; Housing system; Innovations; Laminate; Operation BREAKTHROUGH; Racking; Reinforced plastics; Reinforced polyester; Sustained loading; Tensile shear; Adhesive bond; Aging; NBSIR 73-188.

Composite concrete construction: Prestressed concrete beams; Tee-beams: BSS3I

Composite walls: Compressive strength; Concrete block; Flexural strength; Masonry; Mortar; Slenderness effects; Standards: Structural stability; Walls; Brick: Cavity walls; BSS34.

Composite wall panel; Condensation; Humidity; Moisture; Pressure; Temperature; NBSIR 73-220.

Compression; Eccentric loading; Flat-end; Kern; Loading rate; Pin-end; Test method; Wall panels; Walls; NBSIR 75-779.

Compression; Environmental conditions; Flexure; Housing system; Operation BREAKTHROUGH; Polyurethane foam; Sandwich construction; Wall system; Accelerated aging; NBSIR 73-105.

Compression; Flexure; Glass fiber; Housing system; Innovations; Laminate; Operation BREAKTHROUGH; Racking; Reinforced plastics; Reinforced polyester; Sustained loads; Tensile shear; Adhesive bond; Aging; Composites; NBSIR 73-188.

Compressive strength; Concrete block; Flexural strength: 
Masonry: Mortar: Slenderness effects; Standards; Structural stability; Walls; Brick; Cavity walls; Composite walls; BS S34.

Compressive strength; Concrete block walls; Elastic stability: Flexural strength; Masoriry walls; Reinforced concrete masonry walls; Slenderness effect: Structural stability; Buckling: BSS33.

Compressive strength; Concrete; Flexural strength; Formwork removal; Nondestructive testing; Surface hardness; NBSIR 75-729.

Compressive strength; Deflection; Design; Flexural strength; Masonry walls; Racking strength; Seismic loading; Shear strength; Shear walls; Stiffness; Analysis; NBSIR 74-520

Compressive strength of portland cement; Compressive strength of steam-cured cements; Fineness; Heat of hydration; Steam curing of portland cement mortars; Strength gain of portland cements; Trace elements; Accelerated curing of cements; autoclave curing of portland cement mortars; Chemical composition, BSS58.

Compressive strength of steam-cured cements; Fineness; Heat of hydration; Steam curing of portland cement mortars; strength gain of portland cements; Trace elements; Accelerated curing of cements; Autoclave curing of portland cement mortars; Chemical Composition; Compressive strength of portland cement; BSS8.

Computer algorithm; Psychrometrics; Saturated and unsaturated moist air; Thermodynamic properties; BSS21.

Computer calculations; High-rise building fire; Operation BREAKTHROUGH; Pressurized stairwell; Quantitative experiment; Smoke control; Smoke simulation; Analysis; Basic correlation formulas; NBSIR 73-277.

Computer programs; Dynamic thermal performance; Heat flow analysis; Heating and cooling loads; Temperature predictions; Thermal analysis; Thermal behavior; Transient heat flows; Building heat transfer: BSS 45 .

Computer programs; Dynamic thermal performance; Heat flow analysis; Heating and cooling loads; Temperature predictions; Thermal analysis; Thermostate setback; Transient heat flows; Air leakage measurement; Building heat transfer; BSS57.

Computer techniques; Enforcement process; Housing; Hurricane Agnes; Mobile home parks; Mobile homes; Performance data; Standards; NBSIR 75-690.

Concentrated-load capacity; Evaluation criteria; Floors; Hardboard; Load capacity; Operation BREAKTHROUGH; Performance criteria; Subflooring; Underlayment; Wood-frame construction; NBSIR 73-116.

Concentrated load; deflection; floor; hardboard; housing; impact energy; Operation BREAKTHROUGH; plywood; subfloors; underlayment; wood; wood joists; BSS52.

Concentrated loads; Deflection; Floor hardboard; Housing; Impact energy; Operation BREAKTHROUGH; Plywood; Subfloors; Underlayment; Wood; Wood joists; NBSIR 73-187.

Concentrated static-load capacity; Performance characteristics: Performance level: Sanitary plumbing fixtures: Scratch resistance: Stain resistance; Surface-impact resistance; Test methods; Abrasion resistance: Chemical resistance; Cigarette-burn resistance; Cleanability and soilability; BSS22.

Concrete block; Flexural strength; Masonry; Mortar; Slenderness effects; Standards: Structural stability; Walls; Brick: Cavity walls: Composite walls; Compressive strength; BSS34.

Concrete block walls; Elastic stability; Flexural strength: Masonry walls; Reinforced concrete inasonry walls; Slenderness effect: Structural stability; Buckling; Compressive strength: BSS33.

Concrete; Corrosion: Epoxy coatings: Organic coating; Steel reinforcing bars: Chlorides: TN768.

Concrete corrosion; Deicing salts; Epoxy coatings; Organic coatings; polyvinyl chloride coatings; Steel reinforcing bars; Bridge decks; Chloride ions; BSS65.

Concrete; Durability; Material properties; Physical properties; Cement: Chemical composition; BSS36.
Concrete; Flexural strength; Formwork remuval; Nondestructive testing; Surface hardness; Cumpressive strength; NRSSIR 75-72y.

Concrete; Heat of hydration; Portland cement; Sulfate expansion; Autoclave expansion; Cement; BS.S5.

Concrete; Material properties; Physical properties; Trace elements; Portland cement; Spectrographic analyses; Cement; B.S.S2.

Concrete panels; Connections; Ductibility; Floor diaphragms; Housing systems; Insert connectors; Operation BREAKTHROUGH; Precast concrete; NBSIR 73-I26.

Concrete slabs; Design loads; Fatigue; Inserts; Pull-out loads; Sustained load; Anchors; BSS 42

Concrete traixial strength; Ductility; Neoprene bearing pad; Operation BREAKTHROUGH; Performance tests; Precast concrete; Structural design; Building system; Column connection; Building system; Column connection; NBSIR 73-148.

Concrete triaxial strength: ductility: neoprenc bearing pad: Operation Breakthrough; performance test; precast concrete: structural design; building system: column connection TN 811 .

Condensation; Humidity; Moisture; Pressure; Temperature: Composite wall panel; NBSIR 73-220.

Conditioning; Equilibration; Gypsum wallboard; Methodology; Relative humidity; Structural sandwich panel; Temperature; Testing; Building composite; Building material; NBSIR 75-767.

Conductance; Conductivity; Contact conductance; Contact resistance; Electrical conductivity; Electrical resistivity; Heat transfer; Lorenz function; Resistivity; Temperature; Thermal conquctivity; Thermal diffusivity; Thermal resistivity; Thermophysical properties; SP302.

Conduction error; Radiation error; Resistance thermometer Temperature measurement; Thermistor; Thermocouple: BSS26.

Conduction transfer functions; Heating and cooling load; National Bureau of Standards heating and Cooling Load Computer Program; ASHRAE Task Group on Energy Requirements; NBSIR 74-574.

Conductivity; Contact conductance; Contact resistance; Electrical conductivity; Electrical resistivity; Heat transfer; Lorenz function; Resistivity; Temperature; Thermal conductivity; Thermal diffusivity; Thermal resistivity; Thermophysical properties; Conductance; SP302.

Conical, Cylindrical, Emissivity, Nonisothermal. J. Res. NBS; 70C No. 2.

Connections; Ductibility; Floor diaphragms; Housing systems; Insert connectors; Operation BREAKTHROUGH; Precast concrete; Concrete panels; NBSIR 73-I26.

Connections; Housing; Neoprene; Performance criteria; Performance evaluation; Performance testing; Reinforced concrete; Standard tests; Structure, testing; Building; TN706.

Construction conference; domestic housing, U.S.; foreign metrication; levels of conversion; metrication; problems of metrication; codes; NBSIR 73-421.

Construction; Data acquisition equipment; design criteria; Disaster mitigation; Extreme uinds; Information transfer; Instrumentation; Wind loads; Wind tunnel modeling; Buildings; NBSIR 74-567.

Construction; Design criteria; Disaster mitigation; Extreme winds; Full-scale test buildings; Housing; Instrumentation; Wind Tunnel; NBSIR 74-582.

Construction; Design; Developing countries; Disaster mitigation; Earthquakes; Low-cost housing; Natural disasters; Structures; Windstorms; Buildings; BSS48.

Construction; Hurricane Agnes; Housing; Mobile homes; Mobile home parks; Performance data; Regulatory process; Standard; NBSIR 75-641.

Construction industry; Housing: Precast concrete: Production capacity: Production management: Production methods: Stan- 
dardization: United Soviet Socialist Republics; Building economics; Building systems; SP334.

Consumer information; Energy conservation; Home economics; Home improvements; Insulation; Building economics; CIS 8.

Contact conductance; Contact resistance; Electrical conductivity; Electrical resistivity; Heat transfer; Lorenz function; Resistivity; Temperature; Thermal conductivity; Thermal diffusivity; Thermal resistivity; Thermophysical properties; Conductance; Conductivity; SP302.

Contact resistance; Electrical codes; Electrical connections; Fire safety; House wiring; Materials properties; Performance testing; BSS63.

Contact resistance; Electrical codes; Electrical connections; Fire safety; Housewiring; Performance testing; Branch circuits; NBSIR 75-672.

Contact resistance; Electrical conductivity; Electrical resistivity; Heat transfer; Lorenz function; Resistivity; Temperature; Thermal conductivity; Thermal diffusivity; Thermal resistivity; Thermophysical properties; Conductance; Conductivity; Contact conductance; SP302.

Continuity of coating; Porcelain enamel; Weather resistance; Acid resistance: Color: $T N 707$.

Continuous function; Fourier series; Piecewise; Smoothing. J. Res. NBS, $71 C$ No. 2.

Conventions; Dimensional coordination; Industrialized próduction; Modular coordination; Tolerance; TN710-1.

Cooperation; Fire safety; Hydraulics; Wind loads; Building technology; NBSIR 74-618.

Cooperative programs; fire safety; hydraulics; international building technology; wind loads; NBSIR 74-497.

Cooperation; Housing; International; Switzerland; Building research; Buildings; NBSIR 73-288.

Cooperative programs; foreign visitors; information exchange; international building technology; international organization memberships; professional interaction; NBSIR 74-432.

Cooperative programs; Foreign visitors; Information exchange; International building technology; International organization memberships; Professional interaction; NBSIR 74-514.

Corridor fires: Critical energy input; Flame spread, calculation. and observations: Floor covering evaluations; Heat balances: Heat transfer mechanisms: Models, energy balance, radiation. and scaling: Ceiling radiation: $T N 794$

Corrosion control; Metallic piping; Nondestructive evaluation; Survey; Water hardness; Corrosion; NBSIR 75-923.

Corrosion; Corrosion control; Metallic piping; Nondestructive evaluation; Survey; Water hardness; NBSIR 75-923.

Corrosion; Creep testing; Epoxy coatings; Polyvinylchloride coatings; Steel reinforcing bars; Bridge decks; NBSIR 73-295.

Corrosion; Ep oxy coatings; Organic coating; Steel reinforcing bars; Chlorides; Concrete; TN768.

Corrosion-inhibiting: Federal specifications; Fire-retardant: Lacquer; Latex: Multicolor; Organic coatings: Paint; Pigments: Polymers: Properties: Resins; Selection; Substrates: Surface preparation; Varnish; Water-thinned; Application; Coatings; Coating systems; BSS7.

Corrosion of underground pipes; District heating; Hot and chilled water systems; Insulation of underground pipes; Specifications for underground systems; BSS 66.

Cost analysis; Housing; Lead based paint, lead poisoning; Surface preparation; Surface refinishing; Water wash paint removal; NBSIR 74-438.

Cost analysis; Hazard elimination; Housing; Lead based paint; Materials; Surface preparation; Surface refinishing; NBSFK 73-242.

Cost sharing; economics; efficiency; equity; incentives: shoreline protection; beach erosion control; NBSIR 73-294.

Cost sharing; efficiency; equity; financing; nonplant treatment; sewage treatment; user fees; water pollution; NBSIR 74-479.

Covering; Flash point, Flame spread; Impact resistance; Lead paint poisoning; Materials Performance; Properties; Scratch resistance; Smoke generation; Toxic combustion products; Toxicity; Washability; Water vapor permeance; Abrasion; Adhesion; Colorfastness; TN808.

Covering: Materials: Flash point: Flame spread: Impact resistance; Lead paint poisoning: Materials; Performance: Properties: Scratch resistance: Smoke generation: Toxic combustion products: Toxicity: Washability: Water vapor permeance: Abrasion: TN808.

CPVC; Glass transition temperature; Hardness; Polybutene; PB; Polyvinyl chloride; PVC; Residual stress; Thermoplastic piping; ABS; Coefficient of expansion; NBSIR 74-629.

Cracking of portland cements; Cracking resistance of cements; Expansion-shrinkage ratios; Portland cement; Portland cement concrete; Shrinkage of concrete; Shrinkage of portland cements; Trace elements; Cement composition; Chemical composition of portland cements; BSS15.

Cracking resistance of cements; Expansion-shrinkage ratios; POrtland cement; Portland cement concrete; Shrinkage of concrete; Shrinkage of portland cements; Trace elements; Cement composition; Chemical composition of portland cements; Cracking of portland cements; BSS15.

Creep; Loss of prestress; Prestressed concrete: Relaxation: Shrinkage: Variable prestress: $B S S / 3$.

Creep testing; Epoxy coatings; Polyvinylchloride coatings; Steel reinforcing bars; Bridge decks; Corrosion; NBSIR 73-295.

Criteria; Deterioration; Durability; Materials; Mechanisms; Nondestructive testing; Testing; Accelerated aging; Aging of buildings; Building components; Climate; NBSIR 73-132.

Criteria for plumbing; Hydraulic test loads; Performance of plumbing; Single stack plumbing; $B S S 4 I$

Critical energy input: Flame spread. calculation. and observations: Floor covering evaluations: Heat balances: Heat transfer mechanisms: Models. energy balance. radiation, and scaling: Ceiling radiation: Corridor fires; $T N 794$.

Crossflow; Field testing, plumbing; Performance criteria, plumbing; Performance, functional; Single-stack drainage; Siphonage, induced; Siphonage, self; Test loads; Hydraulic; Trap-seal reduction detector; Trap-seal retention; NBSIR 73-161.

Crystallization theory: Gypsum: Hydration; Induction period: Plaster of paris; Setting mechanisms: Colloidal theory: TN 755 .

Curtains, effect of; Environmental conditions; Glazed opcnings: Human response; Thermal comfort requirement: $T N 7 / 0-4$.

Cylindrical, Emissivity, Nonisothermal, Conical. J. Res. NBS, 70C No. 2.

\section{D}

Damage; Disaster mitigation; Dynamic analysis; Earthquake; Hurricanes; Natural hazards; Structural engineering; Tornadoes; Wind; Buildings; BSS61.

Dams; Disaster mitigation; Earthquake damage; Earthquakes; Foundation geology; Highways; Hospital; Housing; Mobile home; Seismic; Standards; Structural engineering; Bridge; Building; Codes; BSS40.

Data acquisition equipment; Design criteria; Disaster mitigation; Extreme winds; Information transfer; Instrumentation; Wind loads; Wind tunnel modeling; Buildings; Construction; NBSIR 74-567.

Data acquisition system; Efficiencies; Electrical power; Energy conservation; Energy costs; Fuel utilization; Heat recovery; Total energy systems; Utilities for housing; Utility system performance; Air-conditioning; Air pollution; Central utility systems; NBSIR 75-711.

Daylight; Fenestration; Psychological; Solar glass; Spaciousness; 
Sunshine; View; Windowless; Windows; BSS70

Deflection; Design; Dynamic; Experimental; Human sensitivity; Loading functions; Specifications: Static; Structural engineering: Subsystems; Vibration; Analysis; RSS47.

Deflection; design; flexural strength; masonry walls; racking strength; seismic loading; shear strength; shear wall; stiffness; analysis: compressive strength: NBSIR 74-520.

Deflection; floor; hardboard; housing; impact energy: Operation BREAKTHROUGH; plywood; subfloors; underlayment; wood; wood joists; concentrated load; BSS52.

Deflection; Floor hardboard; Housing; Impact energy; Operation BREAKTHROUGH; Plywood; Subfloors; Underlayment; Wood; Wood joists; Concentrated loads; NBSIR 73-187.

Deflection; Housing; Laboratory; Module; Racking; Stiffness; Strength; Structural tests; Sustained load; Transportation; Vibration; Wood-frame; NBSIR 73-121.

Deflections; Dynamic response; Gust factors; Structural engineering; Wind engineering; Wind loads; Accelerations; Buffeting; Building codes; Buildings; BSS74.

Deflections; Instrumentation; Structural -response; wind loads; Buildings; TN873.

Degradation factors; Durability; Property measurement test; Standtest methods; Aging test; Building elements and materials; NBSIR 75-955.

Deicing salts; Epoxy coatings; Organic coatings; Polyvinyl chloride coatings; Steel reinforcing bars; Bridge decks; Chloride ions; Concrete corrosion; BSS65.

Deleading methods; Lead paint poisoning; Performance; Properties; NBSIR 73-127.

Design criteria; Energy conservation; Evaluation criteria; New buildings; Requirements; NBSIR 74-452.

Design criteria; Disaster mitigation; Extreme winds; Full-scale test buildings; Housing; Instrumentation; Wind tunnel; Construction; NBSIR 74-582.

Design criteria; Disaster mitigation; Extremen winds; Information transfer; Instrumentation; Wind loads; Wind tunnel modeling; Buildings; Construction; Data acquisition equipment; NBSIR 74-567.

Design criteria; Multistory; Progressive collapse; Risk; Stability; Standards; Strength; United States; Abnormal loading; Building; Codes; NBSIR 73-221

Design conditions; Earthquake risk; Evaluation; Ground temperature; Humidity; Noise level; Operation BREAKTHROUGH; Precipitation; Solar radiation; Temperature; Wind direction; Wind speed; Air contamination; NBSIR 73-144.

Design; Developing countries; Disaster mitigation; earthquakes; Low-cost housing; Natural disasters; Structures; Windstorms: Buildings; Construction; BSS48.

Design; Disaster mitigation; Developing countries; Earthquakes; Low-cost housing; Natural disasters; Structures; Windstroms Buildings; Construction; BSS48.

Design; Dynamic: Experimental: Human sensitivity; Loading functions: Specifications: Static: Structural engineering: Subsystems: Vibration: Analysis: Deflection: BSS47.

Design; flexural strength; masonry walls; racking strength; seismic loading; shear strength; shear wall; stiffness; analysis; compressive strength; deflection; NBSIR 74-520

Design; hospital design; medical facilities; medical facility research; architecture: BSS54

Design loads; Fatigue; Inserts; Pull-out loads; Sustained load; Anchors; Concrete slabs; BS\$42

Design of bearing walls; Eccentricity of applied loads: Bearing pads; Bearing walls; Brick masonry: BSSI4.

Design procedures; Experience in use: Materials: Performance evaluation: Performance requirements; User requirements: Buildings; Components: SP361. Volume 1.

Design procedures: Experience in use; Materials; Performance evaluation: Performance requirements; User requirements; Buildings; Components; SP361. Volume 2.
Deterioration; Durability; Materials; Mechanısms; Nondestructıve testing; Testing; Accelerated aging; Aging of buildings; [suilding components; Climate; Critera; NBS/R 73-132

Developing countries; Disaster mitigation; Earthquakes; Lowcost housing; Natural disasters; Structures; Windstorms; Isuildings; Construction; I Jesıgn; B.S.S48

Devices; manifold; Plumbing system; Vent; TN253.

Diameter ratio; Mixing effectiveness, Square-edged orifice. Temperature measurement: I emperature pattern. B.5.5/2

Dibromotetrafluorocthane; fire tests; flame spread index. heat release rate; ignition temperature; rigid urethane foam, smoke. NBSIR 74-456.

Diffusion flame; Fire; Flame height; Mathematical modeling; Turbulent flow; Buoyant plume; NBSIR 73-11S

Dimensional coordination; Industrialized production: Modular coordination; Tolerance: Conventions: TN710-1.

Disaster mitigation; Dynamic analysis; Earthquakes; Hurricanes; Natural hazards; Structural Engineering; Tornadoes; Wind; Buildings; Damage; BSS6I

Disaster mitigation; Earthquake damage; Earthquakes; Foundation geology; Highways; Hospital; Housing; Mobile homes; Seismic; Standards; Structural engineering; Bridge; Building Codes; Dams; BSS40.

Disaster mitigation; earthquakes; economics; efficient; floods: hurricanes; natural disasters; optimal; tornadoes; total cost minimization; benefit-cost analysis; NBSIR 74-473

Disaster mitigation; Earthquakes; Engineering; Environmental hazards; Housing; Inspection and testing; Safety; Architecture; Building; Building codes; Building design; TN885.

Disaster mitigation; Earthquakes; Hazards; Land use; Structural engineering; Wind effects; Building; BSS46.

Disaster mitigation; Earthquakes; Hazards; natura! Disasters; Structures; Building codes; Buildings; TN807.

Disaster mitigation; Earthquakes; Low-cost housing; Natural disasters; Structures; Windstorms; Buildings; Construction; Design; Developing countries; BSS48.

Disaster mitigation; Extreme winds; Full-scale test building; Housing; Instrumentation; Wind tunnel; Construction; Design Criteria; NBSIR 74-582.

Disaster mitigation; Extreme winds; Information transfer; Instrumentation; Wind loads; Wind tunnel modeling; Buildings; Construction; Data acquisition equipment; design criteria NBSIR 74-567.

Disaster mitigation; Failure; Hurricanes; Mobile homes; Roofs; Structural engineering; Tides; Wind; Buildings; TN569.

Disaster mitigation; Glazing; Hailstones; Masonry; Mobile homes; Roofs; Structural engineering; Wind load; Anchorage; Building performance; TN558.

Disaster mitigation; Housing; Hurricanes; Low-rise buildings; Natural disaster; Structural connections; Typhoons; Wind loads; Buildings; Codes and standards; NBSIR 75-790.

Disaster mitigation; Information transfer; Low-rise buildings; Pressure transducers; Socio-economic; Structural design; Technology implementation; Wind effects; Wind loads; Codes and standards; BSS56.

Disaster mitigation; Structural design; Turbulence; W'ind effects Wind loads; Aerodynamic forces; Amospheric boundary layer BSS30.

Disaster research; high rise building fires; occupant safety: TN818

Discomfort index: Draft: Outside wall: Ventilation: Wind: Air inlet: $T N 710-6$.

Discomfort index: Duct system, collective and individual branch; Flow rates; Noise; Pressure-loss-depression: Thermal convection: Ventilation; Air infiltration and extraction, airtightness; $T N 710-3$.

Disk: Pressure fluctuations: Stagnation point: Turbulence: TN563. 
District heating; Hot and chilled water systems; Insulation of underground pipes; Specifications for underground systems; Corrosion of underground pipes BSS 66 .

Domestic housing, U.S.; foreign metrication; levels of conversion; metrication; problems of metrication; codes; construction conference; NBSIR 73-42I.

Doors; Barriers; Combustibility, Fire; Smoke; Radiation flux measurements; BSS3.

Doors; Energy conservation; heat loss from buildings; Heat transfer; Sound transmission loss; Thermal resistence; Thermal transmittance; Windows; Acoustics; Air infiltration; Air leakage; Architectural acoustics; Building acoustics; BSS77.

Double-glazed window units; Factory-sealed insulating glass units; Field performance tests, correlation with laboratory tests; Sealant performance; Standardized testing; Test methods: Accelerated laboratory tests; $B S S 20$.

Draft; Outside wall; Ventilation; Wind; Air inlet; Discomfort index: $T N 710-6$

Drain; Fire endurance; Fire spread; Fire test; Plastic piping; PVC; Smoke; Toxic gases; Vent; Waste; ABS; NBSIR 74-449.

Drift; Dynamics; Earthquake; Frequency; Housing; Lateral resistance; Racking; Stiffness; Structural deflections; Vibration; Wind load; Wood frame construction; Building damping; $B S S 44$.

DTA of calcium aluminoferrite hydrates; X-ray patterns of calcium aluminoferrite hydrates; Calcium aluminoferrite hydrates; Calcium sulfate reaction with calcium aluminoferrite hydrates; BSS6.

Ductibility; Floor diaphragms; Housing systems; Insert connectors; Operation BREAKTHROUGH; Precast concrete; Concrete panels; Connections; NBSIR 73-126.

Ductility; flexural shear; housing systems; local buckling; material variability; moisture conditioning; Operation BREAKTHROUGH; paper honeycomb; structural sandwich; sustained load; accelerated aging; adhesive bond; BSS5I.

Ductility; neoprene bearing pad; Operation Breakthrough; performance test; precast concrete; structural design; building system; column connection; concrete triaxial strength; TN8II.

Ductility; Neoprene bearing pad; Operation BREAKTHROUGH; Performance tests; Precast concrete; Structural design; Building system; Column connection; Concrete traixial strength; NBSIR 73-148.

Duct system, collective and individual branch; Flow rates; Noise: Pressure-loss-depression; Thermal convection; Ventilation: Air infiltration and extraction, airtightness; Discomfort index: TN710-3.

Ductwork; Fabric; Fiberglass; Fire tests; High-rise buildings; HVAC systems; Steel; Terminal units; Aluminum; NBSIR 73-267.

Durability; Economics; Field studies; Flooring; Floor coverings; Life-cost; Maintenance; User needs; Carpets: TN783.

Durability; Environmental factors; Long-term tests; Short-term tests; Weathering factors; Accelerated aging; Building components and materials; Climatological data; TN838.

Durability factor; Dynamic modulus of elasticity; Saturation coefficient; Absorption; Autogenous healing; BSS35.

Durability; Felt; Stabilizer: Weatkering; Additive; Asphalt; BSS24

Durability; Fire safety: Performance guidelines; Protective coatings; Rigid polyurethane; Roofing: TN778.

Durability; Material properties; Physical properties; Cement; Chemical composition; Concrete; BSS36.

Durability; Materials; Mechanisms; Ncndestructive testing; Testing; Accelerated aging; Aging of buildings; Building components; Climate; Criteria; Deterioration; NBSIR 73-132.

Durability of water-proofing materials; Masonry; Performance criteria; Water-proofing materials; Water-repellent materials; Accelerated weathering; TN883.
Durability; Property measurement test; Standard test methods; Aging test; Building elements and materials; Degradation factors; NBSIR 75-955.

DWV; Fire endurance; Fire spread; Fire test; Gases; Plastic pipe plumbing; PVC; Smoke; ABS; BSS72.

DWV; Performance testing; Reduced-size vents; Trap-seal retention; Venting; Venting criteria; Vents, reduced size; BSS60.

Dynamic analysis; Earthquakes; Hurricanes; Natural hazards; Structural engineering; Tornadoes; Wind; Buildings; Damage; Disaster mitigation; BSS61.

Dynamic; Experimental; Human sensitivity; Loading functions; Specifications; Static; Structural engineering; Subsystems; Vibration; Analysis; Deflection; Design; $B S S 47$.

Dynamic modulus of elasticity; Saturation coefficient; Absorption; Autogenous healing; Durability factor; $B S S 35$.

Dynamic response; Gust factors; Structural engineering; Wind engineering; Wind loads; Accelerations; Buffeting; Building codes; Buildings; Deflections; BSS74.

Dynamic thermal performance; Heat flow analysis; Heating and cooling loads; Temperature predictions; Thermal analysis: Thermal behavior; Transient heat flows; Building heat transfer; Computer programs; BSS45.

Dynamic thermal performance; Heat flow analysis; Heating and cooling loads; Temperature predictions; Thermal analysis; Thermostate setback; Transient heat flows; Air leakage measurement; Building heat transfer; Computer programs; BSS57.

Dynamics; Earthquake; Frequency; Housing; Lateral resistance; Racking; Stiffness; Structural deflections; Vibration; Wind load; Wood frame construction; Building damping; Drift: $B S S 44$

\section{$\mathbf{E}$}

Early strength; False set; Hardening of cement; Hydration; Shear resistance; Theory of cement hardening; Time of set; Vane-shear apparatus; Cement; Cement mortar; Cement paste; BSS28.

Earthquake damage; Earthquakes; Foundation geology; Highways; Hospital; Housing; Mobile home; Seismic; Standards; Structural engineering; Bridge; Building; Codes; Dams; Disaster mitigation; BSS40.

Earthquake; Frequency; Housing; Lateral resistance; Racking; Stiffness; Structural deflections; Vibration; Wind load; Wood frame construction; Building damping; Drift; Dynamics; BSS44.

Earthquake risk; Evaluation; Ground temperature; Humidity; Noise level; Operation BREAKTHROUGH; Precipitation; Solar radiation; Temperature; Wind direction; Wind speed; Air contamination; Design conditions; NBSIR 73-144.

Earthquakes; economics: efficient; floods; hurricanes: natural disasters: optimal; tornadoes; total cost minimization: benefitcost analysis; disaster mitigation; NBSIR 74-473.

Earthquakes; Engineering; Environmental hazards; Housing; Inspection and testing; Safety; Architecture; Building; Building codes; Building design; Disaster mitigation; TN 885.

Earthquakes; Foundation geology; Highways; Hospital; Housing; Mobile home; Seismic; Standards; Structural engineering; Bridge; Building; Codes; Dams; Disaster mitigation; Earthquake damage; BSS40.

Earthquakes; hazards; Land use; Structural engineering; Wind effects; Building; Disaster mitigation; BSS46.

Earthquākes; Hazards; Natural disasters; Structures; Building codes; Buildings; Disaster mitigation; TN807.

Earthquakes; Hurricanes; Natural hazards; Structural engineering; Tornadoes; Wind; Buildings; Damage; Disaster mitigation; Dynamic analysis; BSS61.

Earthquakes; Low-cost housing; Natural disasters; Structures; 
Windstorms; Buildings; Const ruction; Design; Developing countries; Disaster mitigation; BSS48.

Earth temperature; Least squares techniques; Thermal diffusivity of earth; J. Res. NBS, 71 C No. I.

Earth temperature; Probe conduction errors; Steady periodic heat flow. J. Res. NBS, 72 C No. 4.

Eccentric loading; Flat-end; Kern; Loading rate; Pin-end; Test method; Wall panels; Walls; Compression; NBSIR 75-/79.

Eccentricityøof applied loads; Bearing pads; Bearing walls; Brick masonry; Design of bearing walls; BSS 14 .

Economic analysis; economic efficiency; energy conservation; engineering economics; insulation; life-cycle costs; marginal analysis; thermal efficiency; benefit-cost analysis; building economics; building envelope; BSS64.

Economic efficiency; energy conservation; engineering economics; insulation; life-cycle costs; marginal analysis; thermal efficiency; benefit-cost analysis; building economics; building envelope; economic analysis; BSS64.

Economic incentives; Housing development; Integrated utilities; MIUS; Utilities; NBSIR 75-721.

Economic optimization; HVAC systems; Life-cycle cost analysis; Solar energy; Solar heating and cooling; NBSIR 75-712.

Economics; efficiency; equity; incentives; shoreline protection; beach erosion control; cost sharing; NBSIR 73-294.

Economics; efficient; floods; hurricanes; natural disasters; optimal; tornadoes; total cost minimization; benefit-cost analysis; disaster mitigation; earthquakes; NBSIR 74-473.

Economics; Field studies; Flooring; Floor coverings; Life-cost: Maintenance; User needs; Carpets; Durability; TN783.

Economics; Progressive collapse; Standards; Benefit-cost analysis; Building safety; NBSIR 74-452.

Effectiveness; Forced mixing: Mixing device; Pressure drop: Temperature; Uniformity; BSS27.

Effective utilization; Energy conservation; NBSIR 73-102.

Efficiencies; Electrical power; Energy conservation; Energy costs; Fuel utilization; Heat recovery; Total energy systems; Utilities for housing; Utility system performance; Air-conditioning; Air pollution; Central utility systems; Data acquisition system; NBSIR 75-7II.

Efficiency; equity; financing; nonplant treatment; sewage treatment; user fees; water pollution; cost sharing; NBSIR 74-479.

Efficiency; equity; incentives; shoreline protection; beach erosion control; cost sharing; economics; NBSIR 73-294.

Efficiency versus heating load; Modular boilers; Modular concept; Seasonal efficiency; Boiler oversizing; BSS79.

Efficient; floods; hurricanes; natural disasters; optimal; tornadoes; total cost minimization; benefit-cost analysis; disaster mitigation; earthquakes; economics; NBSIR 74-473.

Elastic stability; F.exural strength; Masonry walls; Reinforced concrete masonry walls; Slenderness effect; Structural stability; Buckling; Compressive strength; Concrete block walls; BSS33.

Electrical codes; Electrical connections; Fire safety; House wiring; Materials properties; Performance testing; Contact resistance; BSS63.

Electrical codes; Electrical connections; Fire safety; Housewiring; Performance testing; Branch circuits; Contact resistance; NBSIR 75-672.

Electrical conductivity; Electrical resistivity; Heat transfer; Lorenz function; Resistivity; Temperature; Thermal conductivity; Thermal diffusivity; Thermal resistivity; Thermophysical properties; Conductance; Conductivity; Contact conductance; Contact resistance; SP302.

Electrical connections, Fire safety; House wiring; Materials properties; Performance testing; Contact resistance; Electrical codes; $B S S 63$.

Electrical connections; Fire safety; Housewiring; Performance testing; Branch circuits; Contact resistance; Electrical codes; NBSIR 75-672.
Electrical power; Energy conservation; Energy costs; Fuel utilization; Heat recovery; Total energy systems; Utilities for housing; Utility system performance; Air-conditioning; Alr pollution; Central utility systems; Data acquisition system; Efficiencies; NBSIR 75-711.

Electrical resistivity; Heat transfer; Lorenz function; Resistıvity; Temperature; Thermal conductivity; Thermal diffusivity; Thermal resistivity; Thermophysical properties; Conductance; Conductivity; Contact conductance; Contact resistance; Electrical conductivity; SP302.

Electron microprobe; electron microscope; porcelain enámel: spalling; $x$-ray diffraction; adherence; aluminum; BSSS9.

Electron microscope; porcelain enamel; spalling; $x$-ray diffraction; adherence; aluminum; electron microprobe; BSS 59.

Emissivity; Nonisothermal; Conical, Cylindrical. J. Res. NBS, $70 \mathrm{C}$ No. 2.

Energy conservation; Effective utilization; NBSIR 73-102.

Energy conservation; energy conservation guide; energy conservation opportunities; energy conservation program; industrial energy conservation; H115.

Energy conservation; Energy costs; Fuel utilization; Heat recovery; Total energy systems; Utilities for housing; Utility system performance; Air-conditioning; Air pollution; Central utility systems; Data acquisition system; Efficiencies; Electrical power; NBSIR 75-711.

Energy conservation; engineering economics; insulation; lifecycle costs; marginal analysis; thermal efficiency; benefit-cost analysis; building economics; building envelope; economic analysis; economic efficiency; BSS64.

Energy conservation; Evaluation criteria; New buildings; Requirements; Design criteria; NBSIR 74-452.

Energy conservation; Fluorescent lamp; Fluorescent luminaire; Lighting efficiency; Power factor; Capacitors; TN886.

Energy conservation guide; energy conservation opportunities; energy conservation program; industrial energy conservation; energy conservation; HI15.

Energy conservation; Heat loss from buildings; Heat transfer; Sound transmission loss; Thermal resistance; Thermal transmittance; Windows; Acoustics; Air infiltration; Air leakage; Architectural acoustics; Building acoustics; Doors; BSS77.

Energy conservation; Home economics; Home improvements; Insulation; Building economics; Consumer information; CIS 8 .

Energy conservation; Insulation; Retrofitting; Storm doors; Storm windows; Tax credit; Vapor barriers; Weatherstripping; Caulks and sealants; Clock thermostats; NBSIR 75-795.

Energy conservation; Mechanical systems; Building design: TN789.

Energy conservation opportunities; energy conservation program; industrial energy conservation; energy conservation; energy conservation guide; $H I 15$

Energy conservation options; Hea ting and cooling load calculation; Energy design optimization; Building design; Building energy analysis; $B S S 78$.

Energy conservation prugram; industrial energy conservation; energy conservation; energy conservation guide; energy conservation opportunities; $H I 15$.

Energy conservation; Standards; Building codes; Buildings; TN789-1.

Energy costs; Fuel utilization; Heat recovery; Total energy systems; Utilities for housing; Utility system performance; Air-conditioning; Air pollution; Central utility systems; Data acquisition system; Efficiencies; Electrical power; Energy conservation; NBSIR 75-711.

Energy design optimization; Building design; Building energy analysis; Energy conservation options; Heating and cooling load calculation; BSS78.

Energy; Legislation; Regulations; State; Authority; Building: NBSIR 75-747. 
Energy usage: Environmental engineering; Heating and air conditioning; Use of computers; Building heat transfer analysis; BSS39.

Enforcement; evaluation; inspection; legislation; manufactured building; mobile homes; rules and regulations; state-of-the-art study; building regulation; $T N 853$.

Enforcement; Legislation; Mobiles homes; Regulation; Standards; State-of-the-art study; NBSIR 75-680.

Enforcement process; Field inspection; House trailers; Housing; Hurricane Agnes; Mobile homes; Performance data; Standards; NBSIR 75-688.

Enforcement process; Housing; Hurricane Agnes; Mobile home parks; Mobile homes; Performance data; Standards; Computer techniques; NBSIR 75-690.

Engineering economics; insulation; life-cycle costs; marginal analysis; thermal efficiency; benefit-cost analysis; building economics; building envelope; economic analysis; economic efficiency; energy conservation; $B S S 64$.

Engineering; Environmental hazards; Housing; Inspection and testing; Safety; Architecture; Building; Building codes; Building design; Disaster mitigation; Earthquakes; TN 885.

Engineering properties; Laboratory-field comparison; Strengththickness; Bituminous adhesive; Bituminous built-up membranes; TN473.

Engineering standards, index of; Index of standards, recommended practices, specifications, test methods; Key-word-in-context index of voluntary standards; Standards, voluntary index of; SP 329, Suppl. 1.

Environmental conditions; Flexure; Housing system; Operation BREAKTHROUGH; Polyurethane foam; Sandwich construction; Wall system; Accelerated aging; Compression; NBSIR 73-105.

Environmental conditions; Glazed openings; Human response; Thermal comfort requirements; Curtain, effect of; TN710-4

Environmental engineering; Heating and air conditioning; Use of computers; Building heat transfer analysis; Erergy usage; BSS39.

Environmental factors; long-term tests; short-term tests; weathering factors; accelerated aging; building components and materials; climatological data; durability; TN838.

Environmental hazards; Housing; Inspection and testing; Safety; Architecture; Building; Building codes; Building design; Disaster mitigation; Earthquakes; Engineering; $T N 885$

Envirolıment; Experimenting with; Harmony; Hues; Illumination; Light; Personal uses; Relationship; Uss; Color; CIS6.

Epoxy coatings; Organic coating; Steel reinforcing bars; Chlorides: Concrete; Corrosion: TN768.

Epoxy coatings; orga nic coat ings; Polyvinyl chloride coatings; Steel reinforcing bars; Bridge decks; Chloride ions; Deicing salts; $B S \$ 65$.

Epoxy coatings; Polyvinylchloride coatings; Steel reinforcing bars; Bridge decks; Corrosion; Creep testing; NBSIR 73-295.

Equilibration; Gypsum wallboard; Methodology; Relative humidity; Structural sandwich panel; Temperature; Testing; Building composite; Building material; Conditioning; NBSIR 75-767

Equity; financing; nonplant treatment; sewage treatment; user fees; water pollution; cost sharing; efficiency; NBSIR 74-479.

Equity; incentives; shoreline protection; beach erosion control; cost sharing; economics; efficiency; NBSIR 73-294.

Estimation; Health problems; Lead; Lead paint; Lead paint poisoning; Lead poisoning; Mathematical modeling; Models; urban health problems; Childhood diseases; TN746.

Evaluation criteria; Floors; Hardboard; Load capacity; Operation BREAKTHROUGH; Performance criteria; Plywood subflooring; Subflooring; Underlayment; Wood-frame construction; Concentrated-load capacity; NBSIR 73-116.

Evaluation criteria; floors; hardboard; load capacity, performance criteria; plywood subflooring; subflooring; underlay- ment; wood-frame construction; BSS53.

Evaluation criteria; New buildings; Requirements; Design criteria; Energy conservation; NBSIR 74-452.

Evaluation; Ground temperature; Humidity; Noise level; Operation BREAKTHROUGH; Precipitation; Solar radiation; Temperature; Wind direction; Wind speed; Air contamination; Design conditions; Earthquake risk; NBSIR 73-144.

Evaluation; inspection; legislation; manufactured building; mobile homes; rules and regulations; state-of-the-art study; building regulation; enforcement; $T N 853$.

Evaluation; Inspection; Manufactured building; Mobile homes; Model documents; State-of-art study; Building regulation; TN775.

Exchanger dimensions; Frost formation; Heat exchanger; Heating costs; Mechanical systems; Pollution; Pressure loss; Ventilation: TN7/0-5.

Expansion-Shrinkage ratios; Portland cement; Portland cement concrete; Shrinkage of concrete; Shrinkage of portland cements; Trace elements; Cement composition; Chemical composition of portland cements; Cracking of portland cements; Cracking resistance of cements; BSS15.

Experience in use; Materials; Performance evaluation; Performance requirements; User requirements; Buildings; Components; Design procedures; SP361. Volume I.

Experience in use; Materials; Performance evaluation; Performance requirements; User requirements; Buildings; Components; Design procedures; SP361. Volume 2.

Experimental; Floor systems; Human response; Random process; Spectral analysis; Nibration; Analysis; NBSIR 75-951.

Experimental; Human sensitivity; Loading functions; Specifications; Static; Structural engineering; Subsystems; Vibration; Analysis; Deflection; Design; Dynamic; BSS47.

Experimenting with; Harmony; Hues; Illumination; Light; Personal uses; Relationship; Uses; Color; Environment; CIS6.

Explosion; Frequency; Gas; Gas industry; Progressive collapse; Risk; Statistics; Structure; Building; NBSIR 73-208.

Exterior wall; Fire endurance; Fire test; Housing systems; Operation BREAKTHROUGH; Paper honeycomb; Roof/ceiling assembly; Structural sandwich panel; NBSIR 73-135.

Exterior wall; Fire spread; Fire test; Ignition; Operation BREAKTHROUGH; Reentrant corner; NBSIR 73-266.

Extreme value distributions; Hurricanes; Probability distribution functions; Reliability; Risk; Statistical analysis; Storms; Structural engineering; Wind loads; Wind speeds; Building codes; TN868.

Extreme winds; Full-scale test buildings; Housing; instrumentation; Wind tunnel; Construction; Design criteria; Disaster mitigation; NBSIR 74-582.

Extreme winds; Information transfer; Instrumentation; Wind loads; Wind tunnel modeling; Buildings; Construction; Data acquisition equipment; design criteria Disaster mitigation; NBSIR 74-567.

\section{F}

Fabric; Fiberglass; Fire tests; High-rise buildings; HVAC systems; Steel; Terminal units; Aluminum; Ductwork; NBSIR 73-267.

Facade; Noise; Sound insulation; Sound pressure level; Walls; TN710-2.

Factory-sealed insulating glass units; Field performance tests, correlation with laboratory tests; Sealant performance; Standardized testing; Test methods; Accelerated laboratory tests; Double-glazed window units; BSS20.

Failure; Failure theories; Masonry; Shear strength; Shear test; Shear walls; Stress distribution; Stresses; Structural engineering; Brick; NBSIR 75-703.

Failure; Hurricanes; Mobile homes; Roofs; Structural engineering; 
Tides; Wind; Buildings; Disaster mitigation; TN569.

Failure theories; Masonry; Shear strength; Shear test; Shear walls; Stress distribution; Stresses; Structural engineering; Brick; Failure; NBSIR 75-703.

Failures; Progressive collapse; Specific resistance; Abnormal loading; Alternate path; Annotated bibliography; bibliography; Building code; Building regulations; Collapse; BSS67.

False set; Hardening of cement; Hydration; Shear resistance; Theory of cement hardening; Time of set; Vane-shear apparatus; Cement; Cement mortar; Cement paste; Early strength; BSS28.

Fatigue; Inserts; Pull-out loads; Sustained load Anchors; Concrete slabs; Design loads; BSS 42.

Fatigue testing; Flexural fatigue; Performance criteria; Roofing temperature effects; Tensile fatigue; Test methods; Bituminous roof membrnes; TN863.

Federal specifications; Fire-retardant; Lacquer; Latex; Multicolor; Organic coatings; Paint; Pigments; Polymers; Properties; Resins; Selection; Substrates; Surface preparation; Varnish; Water-thinned; Application; Coatings; Coating systems; Corrosion-inhibiting; BSS7.

Felt; Mineral-surfaced roll roofing; Shingles; Wood fibers; A sphalt; Asplund; TN477.

Felt; Stabilizer; Weathering; Additive; Asphalt; Durability; BSS24.

Felts; Moisture; Roofing; Saturation; Absorption; Asphalts; BSS 19 .

Fenestration; Psychological; Solar glass; Spaciousness; Sunshine; View; Windlowless; Windows; Daylight; BSS70.

Fiberglass; Fire tests; High-rise buildings; HVAC systems; Steel; Terminal units; Aluminum; Ductwork; Fabric; NBSIR 73-267.

Field impact insulation class; Noise criterion curve; Noise isolation class; Operation BREAKTHROUGH; Acoustics; NBSIR 73-191.

Field inspection; House trailers; Housing; Hurricane Agnes; Mobile homes; Performance data; Standards; Enforcement process; NBSIR 75-688.

Field performance tests, correlation with laboratory tests; Sealant performance; Standardized testing; Test methods; Accelerated laboratory tests; Double-glazed window units; Factory-sealed insulating glass units; BSS20.

Field studies; Flooring; Floor coverings; Life-cost; Maintenance; User needs; Carpets; Durability: Economics; TN783.

Field testing, plumbing; Performance criteria, plumbing; Performance, functional; Single-stack drainage; Siphonage, induced; Siphonage, self; Test loads; Hydraulic; Trap-seal reduction; Trap-seal retention; Crossflow; NBSIR 73-161.

Financing; nonplant treatment; sewage treatment; user fees; water pollution; cost sharing; efficiency; equity; NBSIR 74479.

Fineness; Heat of hydration; Steam curing of portland cement mortars; Strength gain of portland cements; Trace elements; Accelerated curing of cements; Autoclave curing of portland cement mortars; Chemical Composition; Compressive strength of portland cement; Compressive strength of steam-cured cements; BSS8.

Fire endurance; Fire severity; Floor tests; Steel plate floors; Burnout tests; BSSII

Fire endurance; Fire spread; Fire test; Gases; Plastic pipe plumbing; PVC; Smoke; ABS; DWV; BSS72.

Fire endurance; Fire spread; Fire test; Plastic piping; PVC; Smoke; Toxic gases; Vent; Waste; ABS; Drain; NBSIR 74-449.

Fire endurance; Fire test; Flame penetration; Glass reinforced plastic; Housing systems; Interdwelling wall; Modular construction; Operation BREAKTHROUGH; Paper honeycomb; Structural panel; NBSIR 73-166.

Fire endurance; Fire test; Flame penetration; Floor assembly; Housing systems; Operation BREAKTHROUGH; Paper honeycomb; Structural panel; NBSIR 73-164.

Fire endurance; Fire test; Flame-through failure of walls; Housing systems; Interdwelling wall; Operation BREAKTHROUGH; NBSIR 73-169.

Fire endurance; Fire test; Flame-through failure, structural panel; Glass-fabric reinforced plastic; Housing system; Operation BREAKTHROUGH; Paper honeycomb; Roof/ceilıng assembly; Structural panel; NIBSIR 73-167.

Fire endurance; Fire test; Flame through; Full scale; Housing; Operation BREAKTHROUGH; Single-family residences; Small scale; Thermal resistance; Wood floor; Wood joist; NBSIR 73-263.

Fire endurance; Fire test; Glass fiber-reinforced plastics; Housing systems; Interdwelling wall; Operation BREAKTHROUGH; NBSIR 73-168.

Fire endurance; Fire test; Housing systems; Interdwelling wall; Load failure; Modular construction; Operation BREAKTHROUGH; Polyurethane foam; Toxic gases; NBSIR 73-I70.

Fire endurance; Fire test; Housing system; Multifamily housing; Operation BREAKTHROUGH; Single-family attached housing; Steel tube column; NBSIR 73-165.

Fire endurance; Fire test; Housing systems; Interdwelling wall; Operation BREAKTHROUGH; Single wall; NBSIR 73-I40.

Fire endurance; Fire test; Housing systems; Operation BREAKTHROUGH; Paper honeycomb; Roof/ceiling assembly; Structural sandwich panel; Exterior wall; NBSIR 73-I35.

Fire; Fire services; Smoke; Smoke density chamber; Smoke potential; Test method; Visibility; Building materials; TN757.

Fire; Flame height; Mathematical modeling; Turbulent flow; Buoyant plume; Diffusion flame; Fire; NBSIR 73-/15.

Fire load; Fire performance; Flame penetration; Potential heat; Structural load; A partment dwelling; Burnout test; BSSIO.

Fire loads; Live floor loads; Loads survey techniques; Occupancy loads; BSS 16.

Fire loads; Occupancy live loads; Load surveys; Structural engineering; Survey techniques; Buildings; TN858.

Fire performance; Flame penetration; Potential heat; Structural load; Apartment dwelling; Burnout test; Fire load; BSSIO.

Fire performance of piping; Fire performance of piping; Performance characteristics for piping; Thermal/structural performance of piping; Thermoplastics in plumbing; NBSIR 74-531.

Fire performance of piping; Functional performance of piping; performance characteristics for piping; Thermal/structural performance of piping; Thermoplastic piping in plumbing; BSS68.

Fire retardant; Fire test; Heat release ignition; Mattress; Smoke; Toxic gases; NBSIR 73-I77.

Fire-retardant; Lacquer; Latex; Multicolor; Organic coatings; Paint; Pigments; Polymers; Properties; Resins; Selection: Substrates; Surface preparation; Varnish; Water-thinned; Application; Coatings; Coating systems; Corrosion-inhibiting; Federal specifications; $B S S 7$.

Fire safety; House wiring; Materials properties; Performance testing; Contact resistance; Electrical codes; Electrical connections; BSS63.

Fire safety; Housewiring; Performance testing; Branch circuits; Contact resistance; Electrical codes; Electrical connections; NBSIR 75-672.

Fire safety; hydraulics; international building technology; wind loads; cooperative programs; NBSIR 74-497.

Fire safety; Hydraulics; Wind loads; Building technology; Cooperation; NBSIR 74-6I8.

Fire safety; Performance guidelines; Protective coatings: Rigid polyurethane; Roofing: Durability; TN778.

Fire severity; Floor tests; Steel plate floors; Burnout tests; Fire endurance; BSS 11 .

Fire services; Smoke; Smoke density chamber: Smoke potential; Test method: Visibility; Building materials; Fire; TN757.

Fire; Smoke; Radiation flux measurements; Doors; Barriers; Combustibility; BSS3. 
Fire spread; Fire test; Gases; Plastic pipe plumbing; PVC; Smoke; ABS; DWV; Fire endurance; BSS72.

Fire spread; Fire test; Ignition; Operation BREAKTHROUGH; Reentrant corner; Exterior wall; NBSIR 73-266.

Fire spread; Fire test; Plastic piping; PVC; Smoke; Toxic gases; Vent; Waste; ABS; Drain; Fire endurance; NBSIR 74-449.

Fire test; Gases; Plastic pipe plumbing; PVC; Smoke; ABS; DWV; Fire endurance; Fire spread; BSS72.

Fire test; Flame penetration; Floor assembly; Housing systems; Operation BREAKTHROUGH; Paper honeycomb; Structural panel; Fire endurance; NBSIR 73-I64.

Fire test; Flame penetration; Glass reinforced plastic; Housing system; Interdwelling wall; Modular construction; Operation BREAKTHROUGH; Paper honeycomb; Structural panel; Fire endurance; NBSIR 73-I66.

Fire test; Flame-through failure of walls; Housing systems; Interdwelling wall; Operation BREAKTHROUGH; Fire endurance; NBSIR 73-169.

Fire test; Flame-through failure, structural panel; Glass-fabric reinforced plastic; Housing system; Operation BREAKTHROUGH; Paper honeycomb; Roof/ceiling assembly; Structural panel; Fire endurance; NBSIR 73-167.

Fire test; Flame through; Full scale; Housing; Operation BREAKTHROUGH; Single-family residences; Small scale; Thermal resistance; Wood floor; Wood joist; Fire endurance; NBSIR 73-263.

Fire test; Flammability; Flooring; Heat flux; Ignition; Radiation panel; Carpet; NBSIR 74-495.

Fire test; Floor assembly; Floor-ceiling assembly; Housing systems; Modular construction; Steel framing; Steel joint floor; NBSIR 73-14I.

Fire test; Gases; Plastic pipe plumbing; PVC; Smoke; ABS; DWV; Fire endurance Fire spread; BSS72.

Fire test; Glass fiber-reinforced plastics; Housing systems; Interdwelling wall; Operation BREAKTHROUGH; Fire endurance; NBSIR 73-I68.

Fire test; Heat release ignition; Mattress; Smoke; Toxic gases; Fire retardant; NBSIR 73-177.

Fire test; Housing system; Multifamily housing; Operation BREAKTHROUGH; Single-family attached housing; Steel tube column; Fire endurance; NBSIR 73-I65.

Fire test; Housing systems; Interdwelling wall; Load failure; Modular construction; Operation BREAKTHROUGH; Polyurethane; Toxic gases; Fire endurance; NBSIR 73-170.

Fire test; Housing systems; Interdwelling wall; Operation BREAKTHROUGH; Single wall; Fire endurance; NBSIR 73-140.

Fire test; Housing systems; Operation BREAKTHROUGH; Paper honeycomb; Roof/ceiling assembly; Structural sandwich panel; Exterior wall; Fire endurance; NBSIR 73-135.

Fire test; Ignition; Operation BREAKTHROUGH; Reentrant corner; Exterior wall; Fire spread; NBSIR 73-266.

Fire test; Plastic piping; PVC; Smoke; Toxic gases; Vent; Waste; ABS; Drain; Fire endurance; Fire spread; NBSIR 74-449.

Fire tests; Flamc spread index; Heat release rate; Ignition temperature; Rigid urethane foam; Smoke; Dibromotetrafluoroethane; NBSIR $74-456$

Fire tests; Flame spread tests; Interlaborator y evaluation; Round robin; Statistical analysis; Test method standard; ASTM E 84; Building materials; Carpets; NBSIR 73-125.

Fire tests; High-rise buildings; HVAC systems; Steel; Terminal units; Aluminum; Ductwork; Fabric; Fiberglass; NBSIR 73-267.

Fire tests; Interior finish; Smoke; Toxic gases; Aircraft materials: Combustion products; BSS 18 .

Fire tests; Interlaboratory tests; Optical density; Round robin; Smoke; Smoke density chamber; Statistical analysis; Building materials; $T N 708$.

Flame height; Mathematical modeling; Turbulent flow; Buoyant plume; Diffusion flame; Fire; Flame height; NBSIR 73-II5.

Flame penetration; Floor assembly; Housing systems; Operation BREAKTHROUGH; Paper honeycomb; Structural panel; Fire endurance; Fire test; NBSIR 73-164.

Flame penetration; Glass reinforced plastic; Housing systems; Interdwelling wall; Modular construction; Operation BREAKTHROUGH; Paper honeycomb; Structural panel; Fire endurance; Fire test; NBSIR 73-166.

Flame penetration; Potential heat; Structural load; Apartment dwelling; Burnout test; Fire load; Fire performance; BSSIO.

Flame spread, calculation, and observations; Floor covering evaluations; Heat balances; Heat transfer mechanisms; Models, energy balance radiation, and scaling, ceiling radiation; Corridor fires; Critical energy input; TN794.

Flame spread; Flash point; Impact resistance; Lead paint poisoning; Materials; Performance; Properties; Scratch resistance; Smoke generation; Toxic combustion products; Toxicity; Washability; Water vapor permeance; Abrasion; Adhesion; Colorfastness: Covering: $T$ N 808 .

Flame spread index; heat release rate: ignition temperature; rigid urethane foam; smoke; dibromotetrafluoroethane; fire tests: NBSIR 74-456.

Flame spread; Kitchen cabinets; Operation BREAKTHROUGH; Smoke generation; Wall and ceiling; Carpets; NBSIR 73-228.

Flame spread tests; Interlaboratory evaluation; Round robin; Statistical analysis; Test method standard; ASTM E 84; Building materials; Carpets; Fire tests; NBSIR 73-125.

Flame-through failure of walls; Housing systems; Interdwelling wall; Operation BREAKTHROUGH; Fire endurance; Fire test; NBSIR 73-169.

Flame-through failure, structural panel; Glass-fabric reinforced plastic; Housing system; Operation BREAKTHROUGH; Paper honeycomb; Roof/ceiling assembly; Structural panel; Fire endurance; Fire test; NBSIR 73-167.

Flame through; Full scale; Housing; Operation BREAKTHROUGH; Single-family residences; Small scale; Thermal resistance; Wood floor; Wood joist; Fire endurance; Fire test; NBSIR 73-263.

Flammability; Flooring; Heat flux; Ignition; Radiation panel; Carpet; Fire test; NBSIR 74-495.

Flash point; Flame spread; Impact resistance; Lead paint poisoning; Materials; Performance; Properties: Scratch resistance; Smoke generation; Toxic combustion products; Toxicity; Washability; Water vapor permeance; Abrasion; Adhesion; Colorfastness; Covering; TN808.

Flat-end; Kern; Loading rate; Pin-end; Test method; Wall panels; Walls; Compression; Eccentric loading; NBSIR 75-779.

Flat roofs; Heat transfer; Moisture transfer; Thermal insulation; BSS 37 .

Flexural fatigue; Performance criteria; Roofing; temperature effects; Tensile fatigue; Test methods; Bituminous roof membranes; Fatigue testing; TN863.

Flexural shear; Housing systems; Local buckling; Material variability; Moisture conditioning; Operation BREAKTHROUGH; Paper honeycomb; Structural sandwich; Sustained load; Accelerated aging; Adhesive bond; Ductility; BSS5I.

Flexural strength; Formwork removal; Nondestructive testing; Surface hardness; Compressive strength; Concrete; NBSIR 75-729.

Flexural strength; Masonry; Mortar; Slenderness effects; Standards; Structural stability; Walls; Brick; Cavity walls; Composite walls; Compressive strength; Concrete block: BSS 34 rlexural strength; masonry walls; racking strength; seismic loading; shear strength; shear wall; stiffness; analysis; compressive strength; deflection; design; N BSIR 74-520.

Flexural strength; Masonry walls; Reinforced concrete masonry walls; Slenderness effect; Structural stability: Buckling; Compressive strength; Concrete block walls; Elastic stability; BSS33. 
Flexure; Glass fiber; Housing system; Innovations; Laminate; Operation BREAKTHROUGH; Racking; Reinforced plastics; Reinforced polyester; Sustained loads; Tensile shear; Adhesive bond; Aging; Composites; Compression; NBSIR 73-188.

Flexure; Housing system; Operation BREAKTHROUGH; Polyurethane foam; Sandwich construction; Wall system; Accelerated aging; Compression; Environmental conditions; NBSIR 73-105.

Floods; hurricanes; natural disasters; optimal; tornadoes; total cost minimization; benefit-cost analysis; disaster mitigation; earthquakes; economics; efficient: NBSIR 74-473.

Floor assen, wly; Floor-ceiling assenbly; Housing systems; Modular construction; Operation BREAKTHROUGH; Steel framing; Steel joist floor; Fire test; NBSIR 73-141.

Floor assembly; Housing systems; Operation BREAKTHROUGH; Paper honeycomb; Structural panel; Fire endurance; Fire test; Flame penetration; NBSIR 73-164.

Floor-ceiling assembly; Housing systems; Modular construction; Operation BREAKTHROUGH; Steel framing; Steel joist floor; Fire test; Floor assembly; NBSIR 73-141.

Floor covering evaluations; Heat balances; Heat transfer mechanisms; Models, energy balance radiation, and scaling, ceiling radiation; Corridor fires; Critical energy input; Flame spread, calculation, and observations; TN794.

Floor coverings; government; performance; procurement; specifications; standards; tests; user needs; carpets; TN822.

Floor coverings; Life-cost; Maintenance; User needs; Carpets; Durability: Economics; Field studies; Flooring: TN783.

Floor diaphragms; Housing systems; Insert connectors; Operation BREAKTHROUGH; Precast concrete; Concrete panels; Connections; Ductibility; NBSIR 73-126

Floor; Hardboard; Housing; Impact energy; Operation BREAKTHROUGH: Plywood; Subfloors; Underlayment; Wood; Wood joists; Concentrated load; Deflection; BSS52.

Floor hardboard; Housing; Impact energy; Operation BREAKTHROUGH; Plywood; Subfloors; Underlayment; Wood; Wood joists; Concentrated loads; Deflection; NBSIR 73-187.

Floor slipperiness; Frictional tests; Human perambulation; Resilient flooring; Slipperiness standards; Slip test; Coefficient of friction; NBSIR 74-613.

Floor systems; Human response; Random process; Spectral analysis; Vibration; Analysis; Experimental; NBSIR 75-951.

Floor tests; Steel plate floors; Burnout tests; Fire endurance; Fire severity; BSSII.

Flooring; Floor coverings; Life-cost; Maintenance; User needs; Carnets: Durability; Economics; Field studies; TN783.

Flooring; Heat flux; Ignition; Radiation panel; Carpet; Fire test; Flammability; NBSIR 74-495.

Floors and panels; Moisture condensation; Thermal bridges; Thermal insulation; U-values of walls; TN710-7.

Floors; Hardboard; Load capacity; Operation BREAKTHROUGH; Performance criteria; Plywood subflooring; Subflooring; Underlayment; Wood-frame construction; Concentrated; Evaluation criteria; NBSIR 73-/16.

Floors; hardboard; load capacity, performance critena; plywood subflooring: subflooring; underlayment; wood-frame construction; evaluation criteria; BSS53.

Floors; roofs; standardization; test methods; walls; building construction; complete buildings; BSS 58 .

Flow rates; Noise; Pressure-loss-depression; IIhermal convection; Ventilation; Air infiltration and extraction, airtightness; Discomfort index; Duct system, collective and individual branch; TN710-3.

Fluorescent luminaire; Lighting efficiency; Power factor; Capacitors; Energy conservation; Fluorescent lamp; TN886.

Forced air-mixing, turbulence, mixer effectiveness, apparatus design, air properties, temperature measurement, air-conditioning capacity, air-mixing devices. J. Res. NBS, 70C No. 1 .
Fored mixing: Mixing device. Pressure drop Temperature Uniformity; Effectivencss; 13.5.527.

Foreign metrication; levels of conversion, metrication, problems of metrication; codes: construction conference, domestic housing, U.S.; NBSIR 73.421

Foreign visitors; information exchange; international building technology; international organization memberships: professional interaction; cooperative programs; NBSIR 74-432.

Foreign visitors; Informatıon cxchange, International building technology; International organization memberships; l’rofessional interaction; Coopcrative programs; NB.S/R 74.514.

Formwork removal; Nondestructive testing; Surface hardness; Compressive strength; Concretc; Flexural strength; NBSIK $75-729$.

Foundation geology; Highways; Hospital; Housing; Mobile home; Seismic; Standards; Structural engineerıng; Bridge; Buildıng; Codes; Dams; Disaster mitigation; Earthquake damage; Earth quakes; BSS40.

Fourier series; Piecewise; Smoothing; Continuous functions. J. Res. NBS, 7IC No. 2

Frequency; Gas; Gas industry; Progressive collapse; Risk; Statistics; Structure; Building; Explosion; NBSIR 73-208.

Frequency; Housing; Lateral resistance; Racking; Stiffness; Structural deflections; Vibration: Wind load: Wood frame construction; Building damping; Drift; Dynamics: Earthquake; BSS44.

Frictional tests; Human perambulation; Resilient flooring; Slipperiness standards; Slip test; Coefficient of friction; Floor slipperiness; NBSIR 74-613.

Frost formation; Heat exchanger; Heating costs; Mechanical systems; Pollution; Pressure loss; Ventilation; Exchanger dimensions; TN710-5.

Fuel utilization; Heat recovery; Total energy systems; Utilities for housing; Utility system performance; Air-conditioning; Air pollution; Central utility systems; Data acquisition system; Efficiencies; Electrical power; Energy conservation; Energy costs; NBSIR 75-7II.

Full scale; Housing; Operation BREAKTHROUGH; Single-family residences; Small scale; Thermal resistance; Wood floor; Wood joist; Fire endurance; Fire test; Flame through; NBSIR 73-263.

Full-scale test buildings; housing; instrumentation; wind tunnel; construction; design criteria; disaster mitigation; extreme winds; NBSIR 74-582.

Functional performance of piping; Performance characteristics for piping; Thermal/structural performance of piping; Thermoplastics in plumbing; Fire performance of piping; NBSIR 74-53I.

Functional performance of piping; Performance characteristics for piping; Thermal/structural performance of piping; Thermoplastic piping in plumbing; Fire performance of piping; BSS68.

\section{G}

Gases; Plastic pipe plumbing; PVC; Smoke; ABS; DWV; Fire endurance; Fire spread; Fire test; BSS72.

Gas explosion; Load-bearing masonry; Load-bearing walls; Masonry; Masonry research; Progressive collapsc; Abnormal load; Building; NBSIR 74-526.

Gas; Gas industry; Progressive collapse: Risk; Statistics; Structure; Building; Explosion; Frequency; NBSIR 73-208.

Gas industry; Progressive collapse; Risk; Statistics; Structure; Building; Explosion; Frequency; Gas; N'BSIR 73-208

Glass-fabric reinforced plastic; Housing system; Operation BREAKTHROUGH; Paper honeycomb; Roof ceiling assembly; Structural panel; Fire endurance; Fire test; Flamethrough failure, structural panel; NBSIR 73-167.

Glass fiber; Housing system; Innovations; Laminate; Operation BREAKTHROUGH; Racking; Reinforced plastics; Rcinforced polyester; Sustained loads; Tensile shear; Adhesive bond: Aging: 
Ccmposites; Compression; Flexure; NBSIR 73-188

Glass fiber-reinforced plastics; Housing systems; Interdwelling wall; Operation BREAKTHROUGH; Fire endurance; Fire test; NBSIR 73-168.

Glass reinforced plastic; Housing systems; Interdwelling wall; Modular cons!ruction; Operation BREAKTHROUGH; Paper honeycomb; Structural panel; Fire endurance; Fire test; Flame penetration; NBSIR 73-166.

Glass transition temperature; Hardness; Polybutene; PB; Polyvinyl chloride; PVC; Residual stress; Thermoplastic piping; ABS; Coefficient of expansion; CPVC; NBSIR 74-629.

Glazed openings; Human response; Thermal comfort requirement; Curtains, effect of; Environmental conditions; TN7104.

Glazirig; Hailstones; Masonry; Mobile homes; Roofs; Structural engineering; Wind load; Anchorage; Building performance; Disaster mitigation; TN558.

Gloss; pH; Porcelain Enamel; Relative humidity; Weather resistance; Acid resistance; Color; BSS4.

Gloss: $\mathrm{pH}$; porcelain enamel; relative humidity; weather resistance; acid resistance; color; BSS5O.

Gloss: Porcelain enamel; Weather resistance; Acid resistance; Color; BSS38.

Gloss: Porcelain enamel on aluminum; Weather resistance; Color; BSS29.

Government; performance; procurement; specifications; standards; tests; user needs; carpets; floor coverings; TN822.

Ground temperature; Humidity; Noise level; Operation BREAKTHROUGH; Precipitation; Solar radiation; Temperature; Wind direction; Wind speed; Air contamination; Design conditions; Earthquake risk; Evaluation; NBSIR 73-144.

Gust factors; Structural engineering; Wind engineering; Wind loads; Accelerations; Buffeting; Building codes; Buildings; Deflections; Dynamic response; $B S S 74$.

Gypsum; Hydration; induction period; Plaster of paris; Setting mechanisms; Colloidial theory; Crystallization theory; TN755.

Gypsum wallboard; Methodology; Relative humidity; Structural sandwich panel; Temperature; Testing; Building composite; Building material; Conditioning; Equilibration; NBSIR 75-767.

\section{$\mathbf{H}$}

Hail; Roofing; Shingles; Storm damage; Asphalt shingles; Built up roofing: $B S S 23$

Hailstones; Masonry; Mobile homes; Roofs; Structural engineerinf; Wind load; Anchorage; Building performance; Disaster mitigation; Glazing; TN558.

Hardboard; Housing; Impact energy; Operation BREAKTHROUGH: Plywood; Subfloors; Underlayment; Wood; Wood joists; Concentrated load; Deflection; Floor; BSS52.

Hardboard; Load capacity; Operation BREAKTHROUGH; Performance criteria; Plywood subflooring; Subflooring; Underlayment; Wood-frame construction; Concentrated-load capacity; Evaluation criteria; Floors; NBSIR 73-116.

Hardboard; load capacity, performance criteria; plywood subflooring; subflooring; underlayment; wood-frame construction; evaluation criteria; floors; BSS 53.

Hardening of cement: Hydration; Shear resistance; Theory of cement hardening: Time of set; Vane-shear apparatus; Cement; Cement mortar; Cement paste; Early strength; False set; $B S S 28$

Hardness; internal stress; Polyvinyl chloride; Thermal mechanical analysis (TMA); Thermal properties; Thermogravimetric analysis (TGA); Thermoplastic pipe; Chlorinated polyvinyl chloride; NBSIR 74-610.

Hardness; Polybutene; PB; Polyvinyl chloride; PVC; Residual stress; Thermoplastic piping; ABS; Coefficient of expansion; CPVC; Glass transition temperature; NBSIR 74-629.
Harmony; Hues; Illumination; Light; Personal uses; Relationship; Uses; Color; Environment; Experimenting with; CIS6.

Hazard elimination; Housing; Lead based paint; Materials; Surface preparation; Surface refinishing; Cost analysis; NBSIR 73-242.

Hazard elimination; Lead analysis; Lead paint; Lead poisoning; TN759.

Hazards; Land use; Structural engineering; Wind effects; Building; Disaster mitigation; Earthquakes; BSS46.

Hazards; Natural disasters; Structures; Building codes; Buildings; Disaster mitigation; Earthquakes; TN807.

Health problems; Lead; Lead paint, lead paint poisoning; Lead poisoning; Mathematical modeling; Models; Urban health problems; Childhood diseases; Estimation; TN746.

Heat balances; Heat transfer mechanisms; Models, energy balance, radiation, and scaling: Ceiling radiation; Corridor fires; Critical energy input; Flame spread, calculation, and observations; Floor covering evaluations; TN794.

Heat conduction; Heat generation; Heat transfer; Neutron absorption; Radioactive decay; Thermal conductivity. J. Res. NBS $7 I C$ No. 4 .

Heat exchanger; Heating costs; Mechanical systems; Pollution; Pressure loss; Ventilation; Exchanger dimensions; Frost formation; TN710-5.

Heat flow analysis; Heating and cooling loads; Temperature predictions; Thermal analysis; Thermal behavior; Transient heat flows; Building heat transfer; Computer programs; Dynamic thermal performance; BSS 45 .

Heat flow analysis; Heating and cooling loads; Temperature predictions; Thermal analysis; Thermostat setback; Transient heat flows; Air leakage measurement; Building heat transfer; Computer programs; Dynamic thermal performance; BSS57.

Heat flux; Heat flux; Radiation panel; Carpet; Fire test; Flammability; Flooring; NBSIR 74-495.

Heat generation; Heat transfer; Neutron absorption; Radioactive decay; Thermal conductivity; heat conduction. J. Res. NBS, $71 \mathrm{C}$ No. 4.

Heating and air conditioning; Use of computers; Building heat transfer analysis; Energy usage; Environmental engineering; BSS 39 .

Heating and cooling load calculation; Energy Design optimization; Building design; Building energy analysis; Energy conservation options; BSS78.

Heating and cooling load; National Bureau of Standards Heating and Cooling Load Computer Program; ASHRAE Task Group on Energy Requirements; Conduction transfer functions; NBSIR 74-574.

Heating and cooling loads; Temperature predictions; Thermal analysis; Thermal behavior; Transient heat flows; Building heat transfer; Computer programs; Dynamic thermal performance; Heat flow analysis; BSS 45 .

Heating and cooling loads;Temperature predictions; Thermal analysis; Thermostat setback; Transient heat flows; Air leakage measurement; Building heat transfer; Computer programs; Dynamic thermal performance; Heat flow analysis BSS57.

Heating costs; Mechanical systems; Pollution; Pressure loss; Ventilation; Exchanger dimensions; Frost formation; Heat exchanger; $T N 710-5$.

Heat loss from buildings; Heat transfer; Sound transmission loss; Thermal resistance; Thermal transmittance; Windows; Acoustics; Air infiltration; Air leakage; Architectural acoustics; Building acoustics; Doors; Energy conservation; BSS77.

Heat of hydration; Steam curing of portland cement mortars, Strength gain of portland cements; Trace elements; Accelerated curing of cements; Autoclave curing of portland cement mortars; Chemical composition; Compressive strength of portland cement; Compressive strength of steam-cured cements; Fineness; BSS8.

Heat of Hydration; Portland cement; Sulfate expansion; Autoclave 
expansion; Cement; Concrete; BSS5.

Heat recovery; Total energy systems; Utilities for housing; Utility system performance; Air-conditioning; Air pollution; Central utility systems; Data acquisition system; Efficiencies; Electrical power; Energy conservation; Energy costs; Fuel utilization; NBSIR $75-7 I 1$.

Heat release ignition; Mattress; Smoke; Toxic gases; Fire retardant; Fire test; NBSIR 73-177.

Heat release rate; ignition temperature; rigid urethane foam; smoke; dibromotetrafluoroethane; fire tests; flame spread index; NBSIR 74-456

Heat transfer; Lorenz function; Resistivity; Temperature; Thermal conductivity; Thermal diffusivity; Thermal resistivity; Thermophysical properties; Conductance; Conductivity; Contact conductance; Contact resistance; Electrical conductivity; Electrical resistivity; SP 302.

Heat transfer mechanisms; Models, energy balance, radiation, and scaling; Ceiling radiation; Corridor fires; Critical energy input; Flame spread, calculation, and observations; Floor covering evaluations; Heat balances; T N794

Heat transfer; Moisture transfer; Thermal insulation; Flat roofs; BSS37.

Heat transfer; Neutron absorption; Radioactive decay; Thermal conductivity; Heat conduction; Heat generation. J. Res. NBS, $71 \mathrm{C} \mathrm{No} .4$

Heat transfer; Sound transmission loss; Thermal resistance; Thermal transmittance; Windows; Acoustics; Air infiltration; Air leakage; Architectural acoustics; Building acoustics; Doors; Energy conservation; Heat loss from buildings; BSS77.

High rise building fires; occupant safety; disaster research: TN818.

High-rise building fire; Operation RREAKTHROUGH; Pressurized stairwell; Quantitative experiment; Smoke control; Smoke simulation; Analysis; Basic correlation forumlas; Computer calculations; NBSIR 73-277.

High-rise buildings; HVAC systems; Steel; Terminal units; Aluminum; Ductwork; Fabric; Fiberglass; Fire tests; NBSIR 73-267.

Highways; Hospital; Housing; Mobile home; Seismic; Standards; Structural engineering; Bridge; Building; Codes; Dams; Disaster mitigation; Earthquake damage; Earthquakes; Foundation geology; BSS40.

Historic structures; laboratory evaluation; natural weathering; stone decay; stone preservation; air pollution: NBSIR 74-444.

History; Building materials; Building performance; Building research; Building systems; Building technolog:; BSSO.

Home economics; Home improvements; Insulation; Building economics; Consumer information; Energy conservation; $C / 38$.

Home improvements; Insulation; Building economics; Consumer information; Energy conservation; Home economics; CIS 8.

Hospital design; medical facilities; medical facility research; architecture; design; BSS54.

Hospital: Housing; Mobile home; Seismic; Standards; Structural engineering; Bridge; Building; Codes; Dams; Disaster mitigation; Earthquake damage; Earthquakes; Foundation geology; Highways; $B S S 40$.

Hot and chilled water systems; Insulation of underground pipes; Specifications for underground systems; Corrosion of underground pipes; District heating; BSS 66.

House trailers; Housing; Hurricane Agnes; Mobile homes; Performance data; Standards; Enforcement process; Field inspection; NBSIR 75-688.

House wiring; Materials properties; Performance testing; Contact resistance; Electrical codes; Electrical connections; Fire safety; BSS63.

Housewiring; Performance testing; Branch circuits; Contact resistance; Electrical codes; Electrical connections; Fire safety; NBSIR 75-672.
Housing development; Integrated utilities; MIUS, Vulıtes Economic incentives; N/BSSIR 75-721.

Housing; Hurricane Agnes; Mobıle home parks; Mobile homes Performance data; Standards; Computer techniques, Fnforciment process; NBSIR 75-69().

Housing; Hurricane Agnes; Mobile homes; I'erformance data Standards; Enforcement process; Field inspection, House trailers; NBSIR 75-688.

Housing; Hurricanes; Low-rise buildıngs; Natural disaster, Structural connections; Typhoons; Wind loads; Buildings; Codes and standards; Disaster mitigation; NBSIR 75-79().

Housing; impact energy: Operation BREAKTHR()UGH plywood; subfloors; underlayment; wood, wood jousts. con. centrated load; deflection; floor; hardboard: 13.5.5.52.

Housing; Impact energy; Operation BREAKTHROUGH: Ply wood; Subfloors; Underlayment; Wood; Wood joists, Concentrated loads; Deflection; Floor hardboard; NBSIR 73-187.

Housing; Inspection and testing; Safety; Architecture; Building; Building codes; Building design; Disaster mitigation; Earthquakes; Engineering; Environmental hazards; TN 885 .

Housing; lnstrumentation; Wind tunnel; Construction; Design criteria; Disaster mitigation; Extreme winds; Full-scale test buildings; NBSIR 74-582.

Housing; International; Switzerland; Building research; Buildings; Cooperation; NBSIP: 73-288

Housing; Laboratory; Module; Racking: Stiffness; Strength: Structural tests; Sustained load; Transportation; Vibration; Wood-frame; Deflection; NBS/R 73-121.

Housing: Lateral resistance: Racking: Stiffness: Structural deflections; Vibration; Wind load: Wood frame construction Building damping: Drift; Dynamics: Earthquake: Frequency: BSS 44 .

Housing; Lead-based paint; Lead poisoning; Paint removal; Abatement; Barrier materials; Building materials; NBS/R 75-761.

Housing; Lead based paint, lead poisoning; Surface preparation: Surface refinishing; Water wash paint removal; Cost analysis; NBSIR 74-438.

Housing; Lead based paint; Materials; Surface preparation; Surlace refinishing; Cost analysis; Hazard elimination; NBSIR 73-242.

Housing: Leaded paint; Lead hazard elimination methods: Lead paint poisoning: Performance attributes: Building material: TN770.

Housing; Mobile home; Seismic; Standards; Structural engineering; Bridge; Building; Codes; Dams; Disaster mitigation; Earthquake damage; Earthquakes; Foundation geology; Highways; hospital; BSS40.

Housing; Mobile homes; Mobile home parks; Performance data: Regulatory process; Standard; Construction; Hurricane Agnes: NBSIR 75-64I.

Housing; Neoprene; Performance criteria; Performance evaluation; Performance testing: Reinforced concrete; Standard tests; Structure, testing; Building; Connections; TN706.

Housing; Operation BREAKTHROUGH; Single-family residences; Small scale; Thermal resistance; Wood floor; Wood joist: Fire endurance; Fire test; Flame through; Full scale: NBS/R 73-263.

Housing; Precast concrete: Production capacity; Production management: Production methods: Standardization; United Soviet Socialist Republics: Building economics: Building systems; Construction industry: SP334.

Housing system; Innovations; Laminate; Operation BREAKTHROUGH; Racking; Reinforced plastics; Reinforced polyester: Sustained loads; Tensile shear; Adhesive bond; Aging: Composites; Compression; Flexure; Glass fiber; NBSIR 73-189

Housing system; Multifamily housing; Operation BREAKTHROUGH; Single-family attached housing; Steel tube column; Fire endurance; Fire test; Y BSIR 73-165. 
Housing system; Operation BREAKTHROUGH; Paper honeycomb; Roof/ceiling assembly; Structural panel; Fire endurance; Fire test; Flame-through failure, structural panel; Glass-fabric reinforced plastic; NBSIR 73-167.

Housing system; Operation BREAKTHROUGH; Polyurethane foam; Sandwich construction; Wall system; Accelerated aging; Compression; Environmental conditions; Flexure; NBSIR 73-105.

Housing systems; Industrialized housing; Mass per unit area; Operation BREAKTHROUGH: U-value; Building classification; Building thermal mass; Building thermal performance; Building thermal time constant; NBSIR 75-678.

Housing systems; Insert connectors; Operation BREAKTHROUGH; Precast concrete; Concrete panels; Connections; Ductibility; Floor diaphragms; NBSIR 73-126.

Housing systems; Interdwelling wall; Load failure; Modular construction; Operation BREAKTHROUGH; Polyurethane foam; Toxic gases; Fire endurance; Fire test; NBSIR 73-170.

Housing systems; Interdwelling wall; Modular construction; Operation BREAKTHROUGH; Paper honeycomb; Structural panel; Fire endurance; Fire test; Flame penetration; Glass reinforced plastic; NBSIR 73-166.

Housing systems; Interdwelling wall; Operation BREAKTHROUGH; Fire endurance; Fire test; Flame-through failure of walls; NBSIR 73-169.

Housing systems; Interdwelling wall; Operation BREAKTHROUGH; Fire endurance; Fire test; Glass fiber-reinforced plastics; NBSIR 73-168.

Housing systems; Interdwelling wall; Operation BREAKTHROUGH; Single wall; Fire endurance; Fire test; NBSIR 73-140.

Housing systems; Large-panel structure; Precast concrete construction; Progressive collapse; Structural design; Structural joists; Building systems; NBSIR 75-715.

Housing systems; local buckling; material variability; moisture conditioning; Operation BREAKTHROUGH; paper honeycomb; structural sandwich; sustained load; accelerated aging; adhesive bond; ductility; flexura! shear; BSS5I.

Housing systems; Modular construction; Operation BREAKTHROUGH; Steel framing; Steel joist floor; Fire test; Floor assembly; Floor-ceiling assembly; NBSIR 73-141.

Housing systems; Operation BREAKTHROUGH; Paper honeycomb; Roof/ceiling assembly; Structural sandwich panel; Exterior wall; Fire endurance; Fire test; NBSIR 73-135.

Housing systems; Operation BREAKTHROUGH; Paper honeycomb; Structural panel; Fire endurance; Fire test; Flame penetration; Floor assembly; NBSIR 73-164.

Hues; Illumination; Light; Personal uses; Relationship; Uses; Color; Environment; Experimenting with; Harmony; CIS6.

Human comfort; Predicted indoor habitability index; Air-conditioning criteria; Building thermal response; Comfort indices; BSS71.

Human perambulation; Resilient flooring; Slipperiness standards; Slip test; Coefficient of friction; Floor slipperiness; Frictional tests; NBS!R 74-613.

Human response; Random process; Spectral analysis; Vibration; Analysis; Experimental; Floor systems; NBSIR 75-95I.

Human response; Thermal comfort requirement; Curtains, effect of; Environmental conditions; Glazed openings; TN7104.

Human sensitivity: Loading functions: Specifications; Static; Structural engineering; Subsystems; Vibration; Analysis; Deflection: Design; Dynamic; Experimental; BSS47.

Humidity; Moisture; Pressure; Temperature; Composite wall panel; Condensation; NBSIR 73-220.

Humidity; Noise level; Operation BREAKTHROUGH; Precipitation; Solar radiation; Temperature; Wind direction; Wind speed; Air contamination; Design conditions; Earthquake risk; Evalua- tion; Ground temperature; NBSIR 73-144.

Hurricane Agnes; Housing; Mobile homes; Mobile home parks; Performance data; Regulatory process; Standard; Construction; NBSIR 75-641.

Hurricane Agnes; Mobile home parks; Mobile homes; Performance data; Standards; Computer techniques; Enforcement process; Housing; NBSIR 75-690.

Hurricane Agnes; Mobile homes; Performance data; Standards; Enforcement process; Field inspection; House trailers; Housing; NBSIR 75-688.

Hurricanes; Low-rise buildings; Natural disaster; Structural connections; Typhoons; Wind loads; Buildings; Codes and standards; Disaster mitigation; Housing; NBSIR 75-790.

Hurricanes; Mobile homes; Roofs; Structural engineering; Tides; Wind; Buildings; Disaster mitigation; Failure; TN569.

Hurricanes; natural disasters; optimai; tornadoes; total cost minimization; benefit-cost analysis; disaster mitigation; earthquakes; economics; efficient; floods; NBSIR 74-473.

Hurricanes; Natural hazards; Structural engineering; Tornadoes; Wind; Buildings; Damage; Disaster mitigation; Dynamic analysis; earthquakes; $B S S 61$.

Hurricanes; Probability distribution functions; Reliability; Risk; Statistical analysis; Storms; Structural engineering; Wind loads; Wind speeds; Building codes; Extreme value distributions; TN868.

HVAC systems; Life-cycle cost analysis; Solar energy; Solâr heating and cooling; Economic optimization; NBSIR 75-712.

HVAC systems; Steel; Terminal units; Aluminum; Ductwork; Fabric; Fiberglass; Fire tests; High-rise buildings; NBSIR 73-267.

Hydration: 1nduction period; Plaster of paris; Setting mechanisms; Colloidal theory: Crystallization theory: Gypsum: TN755.

Hydration; Shear resistance; Theory of cement hardening; Time of set; Vane-shear apparatus; Cement; Cement mortar; Cement paste; Early strength: False set; Hardening of cement; BSS 28.

Hydraulic criteria for plumbing; hydraulic test loads; plumbingvent sizing; reduced-size vents; sanitary DWV systems; secondary ventilation; testing plumbing systems; vents for plumbing; BSS49.

Hydraulics; international building technology; wind loads; cooperative programs; fire safety; NBSIR 74-497.

Hydraulics; Wind loads; Building technology; Cooperation; Fire safety; NBSIR 74-618.

Hydraulic test loads; Performance of plumbing; Single stack plumbing; Criteria for plumbing; $B S S 4 I$.

Hydraulic test loads; plumbing-vent sizing; reduced-size vents; sanitary DWV systems; secondary ventilation; testing plumbing systems; vents for plumbing; hydraulic criteria for plumbing; $B S S 49$.

Hydraulic; Trap-seal reduction detector; Trap-seal retention; Crossflow; Field testing, plumbing; Performance criteria, plumbing; Performance, functional; Single-stack drainage; Siphonage, induced; Siphonage, self; Test loads; NBSIR 73-161.

\section{I}

Ignition; Operation BREAKTHROUGH; Reentrant corner; Exterior wall; Fire spread; Fire test; NBSIR 73-266.

Ignition; Radiation panel; Carpet; Fire iest; Flammability; Flooring; Heat flux; NBSIR 74-495.

Ignition temperature; rigid urethane foam; smoke: dibromotetrafluoroethane; fire tests; flame spread index: heat release rate; NBSIR 74-456.

Illumination; Light; Personal uses; Relationship; Uses; Color; Environment; Experimenting with; Harmony; Hues; CIS6.

Impact energy; Operation BREAKTHROUGH; plywood; sub- 
floors; underlayment; wood; wood joists; concentrated load; deflection: floor; hardboard; housing; BSS52.

Impact energy; Operation BREAKTHROUGH; Plywood; Subfloors; Underlayment; Wood; Wood joists; Concentrated loads; Deflection; Floor hardboard; Housing; NBSIR 73-187.

Impact resistance; Lead paint poisoning; Materials; Performance; Properties; Scratch resistance; Smoke generation: Toxic combustion products; Toxicity; Washability; Water vapor permeance; Abrasion; Adhesion; Colorfastness; Covering; Flame spread; Flash point; TN808.

Incentives; shoreline protection; beach erosion control; cost sharing; economics; efficiency; equity; NBSIR 73-294.

Index of standards, recommended practices, specifications, test methods; Key-word-in-context index of voluntary standards; Standards, voluntary index of; Engineering standards, index of; SP 329, Suppl. $i$.

Induction period; Plaster of paris: Setting mechanisms; Colloida theory; Crystallization theory; Gypsum; Hydration; TN755.

Industrial energy conservation; energy conservation; energy conservation guide; energy conservation opportunities; energy conservation program; $H I I 5$.

Industrialized housing; Mass per unit area; Operation BREAKTHROUGH; U-value; Building classification; Building thermal mass; Building thermal performance; Building thermal time constant; Housing systems; NBSIR 75-678.

Industrialized production; Modular coordination; Tolerance; Conventions; Dimensional coordination; TN7IO-I.

Information exchange; international building technology; international organization memberships; professional interaction; cooperative programs; foreign visitors; NBSIR 74-432.

Information exchange; International building technology; International organization memberships; Professional interaction; Cooperative programs; Foreign visitors; NBSIR 74-5/4.

Information transfer; Instrumentation; Wind loads; Wind tunnel modeling; Buildings; Construction; Data acquisition equipment; Design criteria; Disaster mitigation; Extreme winds; NBSIR 74-567.

Information transfer; Low-rise buildings; Pressure transducers; Socio-economic; Structural design; Technology implementation; Wind effects; Wind loads; Codes and Standards; Disaster mitigation; BSS56.

Innovations; Laminate; Operation BREAKTHROUGH; Racking; Reinforced plastics; Reinforced polyester; Sustained loads; Tensile shear; Adhesive bond; Aging; Composites; Compression; Flexure; Glass fiber; Housing system; NBSIR 73-188.

Insert connectors; Operation BREAKTHROUGH; Precast concrete; Concrete panels; Connections; Ductibility; Floor diaphragms; Housing systems; NBSIR 73-I26.

Inserts; Pull-out loads; Sustained load; Anchors; Concrete slabs; Design loads; Fatigue; BSS42.

Inspection; legislation; manufactured building; mobile homes; rules and reguiations; state-of-the-art study; building regulation; enforcement; evaluation; TN853.

Inspection and testing; Safety; Architecture; Building; Building code; Building design; Disaster mitigation; Earthquakes; Engineer; Environmental hazards; Housing; TN 885.

Inspection; Manufactured building; Mobile homes; Model documents: State-of-art study; Building regulation; Evaluation; TN775.

Instrumentation; Wind tunnel; Construction; Design criteria; Disaster mitigation; Extreme winds; Full-scale test buildings; Housing; NBSIR 74-582.

Instrumentation; Structrual response; Wind loads; Buildings; Deflections; $T N 873$.

Instrumentation; Wind loads; Wind tunnel modeling; Buldings; Construction; Data acquisition equipment; Design criteria; Disaster mitigation; Extreme Winds; Information transfer; NBSIR 74-567.
Insulation; Building economics; Consumer information; Energy conservation; Home econcmics; Home improvements; C1.5 8 .

Insulation: life-cycle costs; marginal analysis; thermal efficien. cy; benefit-cost analysis; building economics; building en velope; economic analysis; economic efficiency; encrgy conservation; engincering economics, 13.5.5\% 4

Insulation of underground pipes; Specifications for underground systems; Corrosion of underground pipes; I)istrict heating; Hot and chilled watcr systems; BSS 60.

Insulation; Retrofitting; Storm doors; Storm windows; Tax credit; Vapor barriers; Weatherstripping; Caulks and scalants; Clock thermostats; Encrgy conservation; NBSTR 75-795.

Intcgrated utilities; MIUS; Utilities; Economic incentives; Housing development; NBSIR 75-721.

Interdwelling wall; Load failure; Modular construction; Operation BREAKTHROUGH; Polyurethanc foam; Toxic gases; Fire endurance; Fire test; Housing systems; NBSIR 73-170.

Interdwelling wall; Modular construction; Operation BREAKTHROUGH; Paper honeycomb; Structural panel; Fire endurance; Fire test; Flame penetration; Glass reinforced plastic; Housing systems; NBSIR 73-166.

Interdwelling wall; Operation BREAKTHROUGH; Fire endurance; Fire test; Flame-through ‘́ailure of walls; Housing systems; NBSIR 73-169.

Interdwelling wall; Operation BREAKTHROUGH; Fire endurance; Fire test; Glass fiber-reinforced plastics; Housing systems; NBSIR 73-I68.

Interdwelling wall; Operation BREAKTHROUGH; Single wall; Fire endurance; Fire test; Housing systems; NBSIR 73-140.

Interior finish; Smoke; Toxic gases; Aircraft materials; Combustion products; Fire tests; BSS 18.

Interlaboratory evaluation; Round robin; Statistical analysis; Test mcthod standard; ASTM E 84; Building materials; Carpets; Fire tests; Flame spread tests; NBSIR 73-125.

Interlaboratory tests; Optical density; Round robin; Smoke: Smoke density chamber: Statistical analysis: Building materials: Fire tests: $T N 708$.

Internal stress; Polyvinyl chloride; Thermal mechanical analysis (TMA); Thermal properties; Thermogravimetric analysis (TGA); Thermoplastic pipe; Chlorinated polyvinyl chloride; Hardness; NBSIR 74-6I0.

International building technology; international organization memberships; professional interaction; cooperative programs: foreign visitors; information exchange; NBSIR 74-432.

International building technology; International organization memberships; Professional interaction; Cooperative programs; Foreign visitors; Information exchange; NBSIR 74-5/4.

International building technology; wind loads; cooperative programs; fire safety; hydraulics; NBSIR 74-497.

International organization memberships: professional interaction; cooperative programs; foreign visitors; information exchange; international building technology; NBSIR 74-432.

International organization memberships; Professional interaction; Cooperative programs; Foreign visitors; Information exchange; International building technology; NBSIR 74-5/4.

International; Switzerland; Building research; Buildings; Cooperation; Housing; NBSIR 73-288.

None Listed

Kern; Loading rate; Pin-end; Test method; Wall panels; Walls; Compression; Eccentric loading; Flat-end; VBSIR 75-779. 
Key-word-in-context index of voluntary standards; Standards, voluntary index of; Engineering standards, index of; Index of of standards, recommended practices, specifications, test methods; SP 329, Suppl. 1 .

Kitchen cabinets; Operation BREAKTHROUGH; Smoke generation; Wall and ceiling; Carpets; Flame spread; NBSIR 73-228.

\section{$\mathbf{L}$}

Laboratory evaluation; natural weathering; stone decay; stone preservation; air pollution; historic structures; NBSIR 74444

Laboratory-field comparison; Strength-thickness; Bituminous adhesive; Bituminous built-up membranes; Engineering properties; TN473.

Laboratory; Module; Racking; Stiffness; Strength; Structural tests: Sustained load; Transportation; Vibration; Wood-frame; Deflection; Housing; NBSIR 73-121.

Lacquer; Latex; Multicolor; Organic coatings; Paint; Pigments; Polymers; Properties; Resins; Selection; Substrates; Surface preparation; Varnish; Water-thinned; Application; Coatings; Coating systems; Corrosion-inhibiting; Federal specifications; Fire -retardants; BSS7.

Laminate; Operation BREAKTHROUGH; Racking; Reinforced plastics; Reinforced polyester; Sustained loads; Tensile shear; Adhesive bond; Aging; Composites; Compression; Flexure; Glass fiber; Housing system; Innovations; NBSIR 73-188.

Land use; Structural engineering; Wind effects; Building; Disaster mitigation; Earthquakes; Hazards; BSS46.

Large-panel structure; Precast concrete construction; Progressive collapse; Structural design; Structural joists; Building systems; Housing systems; NBSIR 75-715.

Lateral resistance; Racking; Stiffness; Structural deflections; Vibration; Wind load; Wood frame construction; Building damping; Drift; Dynamics; Earthquake; Frequency; Housing; BSS 44 .

Latex; Multicolor; Organic coatings; Paint; Pigments: Polymers; Properties; Resins: Selection: Substrates; Surface preparation; Varnish; Water-thinned; Application; Coatings; Coating systems; Corrosion-inhibiting; Federal specifications; Fire-retardant; Lacquer; BSS7.

Lead analysis; Lead paint; Lead poisoning; Hazard elimination: TN759.

Lead-based paint; Lead poisoning; Paint removal; Abatement; Barrier materials; Building materials; Housing; NBSIR 75-761.

Lead based paint, lead poisoning; Surface preparation; Surface refinishing; Water wash paint removal; Cost analysis; Housing; NBSIR 74-438.

Lead based paint; Materials; Surface preparation; Surface refinishing; Cost analysis; Hazard elimination; Housing; NBSIR 73-242.

Leaded paint detection; Portable X-ray fluorescence lead detector; Portable x-ray fluorescence lead calibration standards; NBSIR 73-231.

Leaded paint; Lead hazard elimination methods; Lead paint poisoning; Performance attributes; Building material; Housing: TN770.

Lead hazard elimination methods; Lead paint poisoning: Performance attributes; Building material; Housing; Leaded paint; $T N 770$

Lead; lead paint poisoning; paints; poisoning; retail inventory; statistics; survey; NBSIR 73-407.

Lead; Mercury; Review; Selenium; Toxic elements in paints; Analytical methods; Antimony; Arsenic; Cadmium; NBSIR 73-251.

Lead paint, lead paint poisoning; Lead poisoning; Mathematical modeling; Models; Urban health problems; Childhood diseases; Estimation; Health problems; Lead; TN746.

Lead paint; Lead poisoning; Hazard elimination; Lead analysis; TN759.
Lead paint poisoning; Materials; Performance; Properties; Scratch resistance; Smoke generation; Toxic combustion products; Toxicity; Washability; Water vapor permeance; Abrasion; Adhesion; Colorfastness; Covering; Flame spread; Flash point; Impact resistance; TN808.

Lead paint poisoning; paints: poisoning; retail inventory: statistics; survey; lead; NBSIR 73-407.

Lead paint poisoning; Performance attributes: Building material; Housing; Leaded paint; Lead hazard elimination methods; TN770.

Lead paint poisoning; Performance; Properties; Deleading methods; NBSIR 73-127.

Lead poisoning; Hazard elimination; Lead analysis; Lead paint; TN759.

Lead poisoning; Mathematical modeling; Models; Urban health problems; Childhood diseases; Estimation; Health problems; Lead; Lead paint, Lead paint poisoning; TN746.

Lead poisoning; Paint removal; Abatement; Barrier materials; Building materials; Housing; Lead-based paint; NBSIR 75-761.

Least squares techniques; Thermal diffusivity of earth; Earth temperature; J. Res. NBS, 71 C No. 1.

Legislation; manufactured building; mobile homes; rules and regulations; state-of-the-art study; building regulation; enforcement; evaluation; inspection; TN853.

Legislation; Mobiles homes; Regulation; Standards; State-of-theart study; Enforcement; NBSIR 75-680.

Legislation; Regulations; State; Authority; Building; Energy; NBSIR 75-747.

Levels of conversion; metrication; problems of metrication; codes: construction conference; domestic housing, U.S.; foreign metrication: NBSIR 73-421.

Life-cost; Maintenance; User needs; Carpets; Durability; Economics; Field studies; Flooring; Floor coverings; TN783.

Life-cycle cost analysis; Solar energy; Solar heating and cooling; Economic optimization; HVAC systems; NBSIR 75-712.

Life-cycle costs; marginal analysis; thermal efficiency; benefitcost analysis: building economics; building envelope: economic analysis; economic efficiency; energy conservation; engineering economics; insulation; BSS64.

Lighting efficiency; Power factor; Capacitors; Energy conservation; Fluorescent lamp; Fluorescent luminaire; TN886.

Light; Personal uses; Relationship; Uses; Color; Environment; Experimenting with; Harmony; Hues; Illumination; CIS6.

Live floor loads; Loads survey techniques; Occupancy loads: Fire loads; BSS 16

Load-bearing masonry; Load-bearing walls; Masonry; Masonry research; Progressive collapse; Abnormal loading; Building; Gas explosion; NBSIR 74-526.

Load-bearing walls; Masonry; Masonry research; Progressive collapse; Abnormal loading; Building; Gas explosion; Loadbearing masonry; NBSIR 74-526.

Load capacity; Operation BREAKTHROUGH; Performance criteria; Plywood subflooring; Subflooring; Underlayment; Wood-frame construction; Concentrated-Ioad capacity; Evaluation criteria; Floors; Hardboard; NBSIR 73-116.

Load capacity, performance criteria: plywood subflooring; subflooring; underlayment; wood-frame construction; evaluation criteria; floors; hardboard; BSS53

Load failure; Modular construction; Operation BREAKTHROUGH; Polyurethane foam; Toxic gases; Fire endurance; Fire test; Housing systems; Interdwelling wall; NBSIR 73-170.

Loading functions; Specifications; Static; Structural engineering; Subsystems; Vibration; Analysis; Deflection; Design; Dynamic; Experimental: Human sensitivity; BSS47.

Loading rate; Pin-end; Test method; Wall panels; Walls; Compression; Eccentric loading; Flat-end; Kern; NBSIR 75-779.

Load surveys; Structural engineering; Survey tecniques; Buildings; Fire loads; Occupancy live loads; TN858. 
Loads survey techniques; Occupancy loads: Fire loads: Live floor loads; BSS 16

Local buckling; material variability: moisture conditioning: Operation BREAKTHROUGH; paper honeycomb; struc tural sandwich; sustained load; accelerated aging; adhesive bond; ductility; flexural shear: housing systems: BSS5I

Long-term tests; short-term tests; weathering factors: ac celerated aging; building components and materials; climatological data; durability: environmental factors: TN838.

Lorenz function; Resistivity; Temperature; Thermal conductivity; Thermal diffusivity; Thermal resistivity; Thermophysical properties; Conductance; Conductivity; Contact conductance; Contact resistance; Electrical conductivity; Electrical resistivity; Heat transfer; SP302.

Loss of prestress; Prestressed concrete; Relaxation; Shrinkage Variable prestress; Creep; BSS13.

Low-cost housing; Natural disasters; Structures; Windstorms; Buildings; Construction; Design; Developing countries; Disaster mitigation; Earthquakes; BSS48.

Low-income housing; Performance criteria; Performance testing; Building systems; BSS25.

Low-rise buildings; Natural disaster; Structural connections; Typhoons; Wind loads; Buildings; Codes and standards; Disaster mitigation; Housing; Hurricanes; NBSIR 75-790.

Low-rise buildings; Pressure transducers; Socio-economic; Structural design; Technology implementation; Wind effects; Wid loads; Codes and Standards; Disaster mitigation; Information transfer; BSS56.

\section{$\mathbf{M}$}

Maintenance; User needs; Carpets; Durability; Economics; Field studies; Flooring; Floor coverings; Life-cost; TN783.

Manifold; Plumbing System; Vent; Devices; TN253.

Manufactured building; Mobile homes; Model documents; State-of-art study; Building regulation; Evaluation; Inspection: TN775.

Manufactured building: mobile homes: rules and regulations: state-of-the-art study; building regulation; enforcement: evaluation; inspection; legislation: TN853.

Manufacturing Chemist's Association (MCS); Performance of plastics outdoors; Plastics; Weathering of plastics; NBSIR 73-146.

Marginal analysis; thermal efficiency; benefit-cost analysis: building economics; building envelope; economic analysis: economic efficiency; energy conservation; engineering economics; insulation; life-cycle costs: BSS64.

Masonry; Masonry research; Progressive collapse; Abnormal loading; Building; Gas explosion; Load-bearing masonry; Loadbearing walls; NBSIR 74-526.

Masonry; Mobile homes; Roofs; Structural engineering; Wind load; Anchorage; Building performance; Disaster mitigation; Glazing; Hailstones; TN558.

Masonry; Mobile homes; Roofs; Structural engineering: Wind load: Anchorage; Building performance; Glazing: Hailstones; TN558.

Masonry; Mortar; Slenderness effects; Standards; Structural stability; Walls; Brick; Cavity walls; Composite walls; Compressive strength; Concrete block; Flexural strength; BSS34.

Masonry; Performance criteria; Water-proofing materials; Waterrepellent materials; Accelerated weathering; Durability of waterproofing materials; TN883.

Masonry research; Progressive collapse; Abnormal loading; Building; Gas explosion; Load-bearing masonry; Load-bearing walls; Masonry; NBSIR 74-526.

Masonry; Shear strength; Shear test; Shear walls; Stress distribution; Stresses; Structural engineering; Brick; Failure; Failure theories; NBSIR 75-703.
Masonry walls; racking strength: selsmic loading ,hear strength; shear wall; stiffness; analysis: compressive sirength. deflection: design: flexural strength: NBS.S/R 74-520)

Masonry walls; Reinforced concrete masonry walls: Slendernes effect: Structural stability; Buckling; Compressive strength. Concrete block walls; Flastic stability; Flexural strength: BSS 33 .

Mass per unit area; Operation BREAKTHROUGH; U-value; Building classification; Building thermal mass; Bulding thermal performance; Building thermal time constant; Housing systems; Industrialized housing; NBSIR 75-678.

Material properties: Physical properties: Cement; (hemical composition: Concrete; Durability; BSS 36.

Material properties; Physical properties; Trace elements; Portland cement; Spectrographic analyses; Cement; Concrete; BSS2.

Material variability; Moisture conditioning; Operation BREAKTHROUGH: Paper honeycomb; Structural sandwich; sustained load; Accelerated aging; Adhesive bond; Ductility; Flexural shear; Housing systems; Local buckling; BSS51.

Materials; Mechanisms; Nondestructive testing; Testing; Accelerated aging; Aging of buildings; Building components; Climate; Criteria; Deterioration; Durability; NBSIR 73-132.

Materials; Performance evaluation; Performance requirements: User requirements; Buildings; Components; Design procedures; Experience in use; SP361. Volume I.

Materials; Performance evaluation; Performance requirements: User requirements; Buildings; Components; Design procedures; Experience in use; SP361. Volume 2.

Materials; Yerformance; Properties; Scratch resistance; Smoke generation; Toxic combustion products; Toxicity; Washability; Water vapor permeance; Abrasion; Adhesion; Colorfastness, Covering; Flame spread; Flash point; Impact resistance; Lead paint poisoning; TN808.

Materials: Performance; Properties; Scratch resistance: Smoke generation: Toxic combustion products: Toxicity; Washability: Water vapor permeance; Abrasion; Adhesion; Colorfastness: Covering: Materials: Flash point: Flame spread: TN808.

Materials properties; Performance testing, Contact resistance; Electrical codes; Electrical connections; Fire safety; House wiring; SS63.

Materials; Surface preparation; Surface refinishing; Cost analysis; Hazard elimination; Housing; Lead based paint; NBSIR 73-242.

Mathematical modeling; Models; urban health problems; Childhood diseases; Estimation; Health problems; Lead; Lead paint, lead paint poisoning; Lead poisoning; TN746.

Mathematical modeling; Turbulent flow; Buoyant plume; Diffusion flame; Fire; Flame height; NBSIR 73-1/5.

Mattress; Smoke; Toxic gases; Fire retardant; Fire test; Heat release ignition; NBSIR 73-177.

Mechanical systems; Building design; Energy conservation: $T N 789$.

Mechanical systems; Pollution; Pressure loss; Ventilation; Exchanger dimensiors; Frost formation; heat exchanger; Heating costs; TN710-5.

Mechanisms; Nondestructive testing; Testing; Accelerated aging; Aging of buildings; Building components; Climate; Criteria; Deterioration; Durability; Materials; NBSIR 73-132.

Medical facility research; Architecture; Design; Hospital design; Medical facilities; BSS54.

Medical facilities; medical facility research; architecture; design: hospital design: BSS54.

Mercury; Reviews; Selenium; Toxic elements in paints; Analytical methods; Antimony; Arsenic; Cadmium; Lead; NBSIR 73.251.

Methodology; Relative humidity; Structural sandwich panel; Temperature; Testing; Building composite; Building material; Conditioning; Equilibration; Gypsum wallboard; VBSIR 75-767. 
Metallic piping; Nondestructive evaluation; Survey; Water hardness; Corrosion; Corrosion control; NBSIR 75-923.

Metrication; problems of metrication; codes; construction conference; domestic housing. U.S.; foreign metrication; levels of conversion; NBSIR 73.421 .

Mineral-surfaced roll roofing; Shingles; Wood fibers; Asphalt; Asplund; Felt; TN477.

MIUS; Utilities; Economic incentives; Housing development; Integrated utilities; NBSIR 75-721.

Mixer effectiveness; Air properties; Temperature measurement; Air-conditioning capacity; Air-mixing devices; Forced airmixing; Turbulence. J. Res. NBS, 70C No. 1 .

Mixing device; Pressure drop: Temperature; Uniformity; Effectiveness; Forced mixing; BSS27.

Mixing effectiveness: Square-edged orifice; Temperature measurement: Temperature pattern: Diameter ratio; BSS 12

Mobile home; Seismic; Standards; Structural engineering; Bridge; Building; Codes; Dams; Disaster mitigation; Earthquake damage; Earthquakes; Foundation geology; Highways; Hospitasl; Housing; BSS40.

Mobile homes; ASHRAE 90-P; Building codes; NCSBCS: SP 429.

Mobile homes; Mobile home parks; Performance data; Regulatory process; Standard; Construction; Hurricane Agnes; Housing; NBSIR 75-64I.

Mobile home parks; Mobile homes; Performance data; Standards; Computer techniques; Enforcement process; Housing; Hurricane Agnes; NBSIR 75-690.

Mobile homes; Model documents; State-of-art study; Building regulation; Evaluation; Inspection; Manufactured building; TN775.

Mobile homes; Performance data; Standards; Computer techniques; Enforcement process; Housing; Hurricane Agnes; Mobile home parks; NBSIR 75-690.

Mobile homes; Performance data; Standards; Enforcement process; Field inspection; House trailers; Housing; Hurricane Agnes; NBSIR 75-688.

Mobiles homes; Regulation; Standards; State-of-the-art study; Enforcement; Legislation; NBSIR 75-680.

Mobile homes; Roofs; Structural engineering; Tides; Wind; Buildings; Disaster mitigation; Failure; Hurricanes; TN569.

Mobile homes; Roofs; Structural engineering; Wind load; Anchorange; Building performance; Disaster mitigation; Glazing; Hailstones; Masonry; TN558.

Mobile homes; rules and regulations; state-of-the-art study; building regulation; enforcement; evaluation; inspection; legislation; manufactured building; $T N 853$.

Model documents; State-of-art study; Building regulation; Evaluation; 1nspection; Manufactured building; Mobile homes; TN775.

Models; Urban health problems; Childhood diseases; Estimation; Health problems; Lead; Lead paint, lead paint poisoning; Lead poisoning; Mathematical modeling; TN746.

Models, energy balance, radiation, and scaling; Ceilıng radiation; Corridor fires; Critical energy input; Flame spread, calculation, and observations; Floor covering evaluations; Heat balances; Heat transfer mechanisms: TN794.

Modular Boilers; Modular concept; Seasonal efficiency; Boiler oversizing; Efficiency versus heating load; BSS79.

Modular concept; Seasonal efficiency; Boiler oversizing; Efficiency versus heating load; Modular boilers; BSS79.

Modular construction; Operation BREAKTHROUGH; Paper honeycomb; Structural panel; Fire endurance; Fire test; Flame penetration; Glass reinforced plastic; Housing systems; Interdwelling wall; NBSIR 73-166.

Modular construction; Operation BREAKTHROUGH; Steel framing; Steel joist floor; Fire test; Floor assembly; Floor-ceiling assembly; Housing systems; NBSIR 73-141.

Modular construction; Operation BREAKTHROUGH; Polyure- thane foam; Toxic gases; Fire endurance; Fire test; Housing systems; Interdwelling wall; Load failure; NBSIR 73-170.

Modular coordination; Tolerance; Conventions; Dimensional coordination; Industrialized production; TN710-1.

Module; Racking; Stiffness; Strength; Structural tests; Sustained load; Transportation; Vibration; Wood-frame; Deflection; Housing; Laboratory; NBSIR 73-121.

Moisture condensation; Thermal bridges; Thermal insulation; U-values of walls; Floors and panels; TN710-7.

Moisture conditioning; Operation BREAKTHROUGH; paper honeycomb; structural sandwich; sustained load; accelerated aging; adhesive bond; ductility; flexural shear; housing systems; local buckling; material variability; BSSSI.

Moisture; Pressure; Temperature; Composite wall panel; Condensation; Humidity; NBSIR 73-220.

Moisture: Roofing; Saturation; Absorption; Asphalts; Felts; BSS 19 .

Moisture transfer; Thermal insulation; Flat roofs; Heat transfer; BSS37.

Mortar: Slenderness effects: Standards: Structural stability; Walls; Brick; Cavity walls; Composite walls: Compressive strength: Concrete block; Flexural strength: Masonry: BSS34.

Multicolor: Organic coatings; Paint: Pigments: Polymers: Properties; Resins; Selection; Substrates; Surface preparation: Varnish: Water-thinned: Application; Coatings; Coating systems; Corrosion-inhibiting; Federal specifications; Fire-retardant; Lacquer; Latex; BSS7.

Multifamily housing; Operation BREAKTHROUGH; Singlefamily attached housing; Steel tube column; Fire endurance; Fire test; Housing system; NBSIR 73-165.

Multistory; Progressive collapse; Risk; Stability; Standards; Strength; United States; Abnormal loading; Building; Codes; Design criteria; NBSIR 73-221.

National Bureau of Standards Heating and Cooling Load Computer Program; ASHRAE Task Group on Energy Requirements; Conduction transfer functions; Heating and cooling load; NBSIR 74-574.

Natural disaster; Structural connections; Typhoons; Wind loads; Buildings; Codes and standards; Disaster mitigation; Housing; Hurricanes; Low-rise buildings; NBSIR 75-790.

Natural disasters; optimal; tornadoes: total cost minimization; benefit-cost analysis; disaster mitigation; earthquakes; economics; efficient; floods; hurricanes; NBSIR 74-473.

Natural hazards; Structural engineering; Tornadoes; Wind; Buildings; Damage; Disaster mitigation; Dynamic analysis; Earthquakes; Hurricanes; BSS61.

Natural disasters; Structures; Building codes; Buildings; Disaster mitigation; Earthquakes; Hazards; TN807.

Natural disasters; Structures; Windstorms; Buildings; Construction; Design; Developing countries; Disaster mitigation; Earthquakes; Low-cost housing; BSS48.

Natural weathering; stone decay; stone preservation; air pollution; historic structures; laboratory evaluation; NBSIR 74444.

NCSBCS; ASHR AE 90-P; Building Codes; Mobile homes; SP429.

Neoprene bearing pad; Operation Breakthrough; performance test; precast concrete; structural design; building system; column connection; concrete triaxial strength; ductility; TN811.

Neoprene bearing pad; Operation BREAKT̈HROUGH; Performance tests; Precast concrete; Structural design; Building system; Column connection; Concrete traixial strength; Ductility; NBSIR 73-148.

Neoprene; Performance criteria: Performance evaluation; Performance testing; Reinforced concrete; Standard tests; Struc- 
ture, testing; Building; Connections; Housing; TN706.

Neutron absorption; Radioactive decay; Thermal Conductivity, Heat conduction; heat generation; Heat transfer. J. Res. NBS, 71 C No. 4.

New buildings; Requirements; Design criteria; Energy conservation; Evaluation criteria; NBSIR 74-452.

Nighttime cooling; Radiative cooling; Solar heating; Thermal movement; Built-up roofing; TN231.

Noise criterion curve; Noise isolation class; Operation BREAKTHROUGH; Acoustics; Field impact insulation class; NBSIR 73-191.

Noise criterion curves; Noise isolation class; Operation BREAKTHROUGH; Acoustics; NBSIR 73-192.

Noise isolation class; Operation BREAKTHROUGH; Acoustics; Field impact insulation class; Noise criterion curve; NBSIR 73-191.

Noise isolation class; Operation BREAKTHROUGH: Acoustics; NBSIR 73-190.

Noise isolation class; Operation BREAKTHROUGH; Acoustics; Noise criterion curves; NBSIR 73-192.

Noise level; Operation BREAKTHROUGH; Precipitation; Solar radiation; Temperature; Wind direction; Wind speed; Air contamination; Design conditions; Earthquake risk; Evaluation; Ground temperature; Humidity; NBSIR 73-144.

Noise; Pressure-loss-depression; Thermal convection; Ventilation; Air infiltration and extraction, airtightness; Discomfort index; Duct system, collective and individual branch; Flow rates; TN710-3.

Noise; Sound insulation; Sound pressure level; Walls; Facade; TN710-2.

Nondestructive evaluation; Survey; Water hardness; Corrosion; Corrosion control; Metallic piping; NBSIR 75-923.

Nondestructive testing; Surface hardness; Compressive strength; Concrete; Flexural strength; Formwork removal; N BSIR 75-729.

Nondestructive testing; Testing; Accelerated aging; Aging of buildings; Building components; Climate; Criteria; Deterioration; Durability; Materials; Mechanisms; NBSIR 73-132.

Nonisothermal; Conical; Cylindrical, Emissivity. J. Res. NBS, 70C No. 2.

Nonplant treatment: sewage treatment; user fees; water pollution; cost sharing; efficiency; equity: financing; NBSIR 74479.

\section{O}

Occupancy live loads; Load surveys; Structural engineering; Survey techniques; Buildings; Fire loads; TN858.

Occupancy loads; Fire loads; Live floor loads; Loads survey techniques; BSS 16 .

Occupant safety; disaster research; high rise building fires; TN818.

Operation BREAKTHROUGH; Acoustics; Field impact insulation Noise criterion curve; Noise isolation class; NBSIR 73-191.

Operation BREAKTHROUGH; Acoustics; Noise criterion curves; Noise isolation class; NBSIR 73-192.

Operation BREAKTHROUGH: Acoustics; Noise isolation class; NBSIR 73-190.

Operation BREAKTHROUGH; Fire endurance; Fire test; Flamethrough failure of walls; Housing systems; Interdwelling wall; NBSIR 73-169.

Operation BREAKTHROUGH; Fire endurance; Fire test; Glass fiber-reinforced plastics; Housing systems; Interdwelling wall; NBSIR 73-168.

Operation BREAKTHROUGH; Paper honeycomb; Roof/ceiling assembly; Structural panel; Fire endurance; Fire test; Flamethrough failure, structural panel; Glass-fabric reinforced plastic; Housing system; NBSIR 73-167.
Operation BREAKTHROU(;H; Paper honeycomb; Roof ceiling assembly; Structural sandwich panel; Exterior wall; Fire endurance; Fire test; Housing systems; N BSS/R 73-/35

Operation BREAKTHROUGH; Paper honcycomb; Structural panel; Fire endurance; Fire test; Flame penetration; Floor assembly; Housing systems; NBSIR 73-164

Operation BREAKTHROUGH; Paper honeycomb; Structural panel; Fire endurance; Fire test; Flame penetration; (jlass reinforced plastic; Housing systems; Interdwelling wall; Modular construction; NBSIR 73-166.

Operation BREAKTHROUCH; paper honeycomb; structural sandwich; sustained load; accelerated aging; adhesive bond: ductility; flexural shear; housing systems; local buckling: material variability; moisture conditioning; BSSS5I.

Operation BREAKTHROUGH; Performance criteria; Plywoud subflooring; Subflooring; Underlayment; Wood-frame construction; Concentrated-load capacity; Evaluation criteria; Floors; Hardboard; Load capacity; NBSIR 73-116.

Operation BREAKTHROUGH; Performance tests; Precast concrete; Structural design; Building system; Column connection; Concrete traixial strength; Ductility; Neoprene bearing pad; NBSIR 73-148.

Operation Breakthrough; performance test; precast concrete: structural design; building system; column connection; concrete triaxial strength; ductility: neoprene bearing pad; TN811.

Operation BREAKTHROUGH; plywood; subfloors; underlayment; wood; wood joists; concentrated load; deflecrion; floor: hardboard; housing; impact energy; BSS 52.

Operation BREAKTHROUGH; Plywood; Subfloors; Underlayment; Wood; Wood joists; Concentrated loads; Deflection; Floor hardboard; Housing; Impact energy; NBSIR 73-187.

Operation BREAKTHROUGH; Polyurethane foam; Sandwich construction; Wall system; Accelerated aging; Compression; Environmental conditions; Flexure; Housing system; NBSIR 73-105.

Operation BREAKTHROUGH; Polyurethane foam; Toxic gases; Fire endurance; Fire test; Housing systems; Interdwelling wall; Load failure; Modular construction; NBSIR 73-170.

Operation BREAKTHROUGH; Precast concrete; Concrete panels; Connections; Ductibility; Floor diaphragms; Housing systems; Insert connectors; NBSIR 73-126.

Operation BREAKTHROUGH; Precipitation; Temperature; Wind direction; Wind speed; Air contamination; Design conditions; Earthquake risk; Evaluation; Ground temperature; Humidity; Noise level; NBSIR 73-144.

Operation BREAKTHROUGH; Pressurized stairwell; Quantitative experiment; Smoke control; Smoke simulation; Analysis; Basic correlation forumlas; Computer calculations; High-rise building fire; NBSIR 73-277.

Operation BREAKTHROUGH; Racking; Reinforced plastics; Reinforced polyester; Sustained loads; Tensile shear; Adhesive bond; Aging; Composites; Compression; Flexure; Glass fiber; Housing system; Innovations; Laminate; NBSIR 73-188.

Operation BREAKTHROUGH; Reentrant corner; Exterior wall; Fire spread; Fire test; Ignition; NBSIR 73-266.

Operation BREAKTHROUGH; Single-family attached housing; Steel tube column; Fire endurance; Fire test; Housing system; Multifamily housing; NBSIR 73-165.

Operation BREAKTHROUGH; Single-family residences; Small scale; Thermal resistance; Wood floor; Wood joist; Fire endurance; Fire test; Flame through; Full scale; Housing: NBSIR 73-263.

Operation BREAKTHROUGH; Single wall; Fire endurance; Fire test; Housing systems; Interdwelling wall; NBSIR 73-140.

Operation BREAKTHROUGH; Smoke generation; Wall and ceiling; Carpets; Flame spread; Kitchen cabinets; .NBSIR 73-228. 
Operation BREAKTHROUGH; Steel framing; Steel joist floor; Fire test; assembly; Floor-ceiling assembly; Housing systems; Modular construction; NBSIR 73-141.

Operation BREAKTHROUGH; U-value; Building classification; Building thermal mass; Building thermal performance; Building thermal time constant; Housing systems; Industrialized housing; Mass per unit area; NBSIR 75-678.

Optical density; Round robin; Smoke; Smoke density chamber; Statistical analysis; Building materials; Fire tests; Interlaboratory tests; TN708.

Optimal; tornadoes; total cost minimization; benefit-cost analysis; disaster mitigation; earthquakes; economics; efficient; floods; hurricanes; natural disasters; NBSIR 74-473.

Organic coating; Steel reinforcing bars; Chlorides: Concrete; Corrosion; Epoxy coatings; TN768.

Organic coatings; Paint; Pigments; Polymers; Properties: Resins: Selection; Substrates; Surface preparation; Varnish; Water-thinned; Application; Coatings; Coating systems; Corrosion-inhibiting; Federal specifications; Fire-retardant; Lacquer; Latex; Multicolor; BSS7.

Organic coatings; Polyvinyl chloride coatings; Steel reinforcing bars; Bridge decks; Chloride ions; Deicing salts; Epoxy coatings; BSS65.

Outside wall; Ventilation; Wind; Air inlet; Discomfort index; Draft: $T N 710-6$

\section{P}

Paint; Pigments; Polymers; Properties; Resins; Selection; Substrates; Surface preparation; Varnish; Water-thinned; Application; Coatings; Coating systems; Corrosion-inhibiting; Federal specifications; Fire-retardant; Lacquer; Latex; Multicolor; Organic coatings; BSS7.

Paint removal; Abatement; Barrier materials; Building materials; Housing; Lead-based paint; Lead poisoning; NBSIR 75-761.

Paints; poisoning; retail inventory; statistics; survey; lead; lead paint poisoning; NBSIR 73-407.

Paper honeycomb; Roof/ceiling assembly; Structural panel; Fire endurance; Fire test; Flame-through failure, structural panel; Glass-fabric reinforced plastic; Housing system; Operation BREAKTHROUGH; NBSIR 73-167.

Paper honeycomb; Roof/ceiling assembly; Structural sandwich panel; Exterior wall; Fire endurance; Fire test; Housing systems; Operation BREAKTHROUGH; NBSIR 73-135.

Paper honeycomb; Sandwich facings; Sandwich panels; Adhesives; $B S S 43$.

Paper honeycomb; Structural panel; Fire endurance; Fire test; Flame penetration; Floor assembly; Housing systems; Operation BREAKTHROUGH; NBSIR 73-164.

Paper honeycomb; Structural panel; Fire endurance; Fire test; Flame penetration; Glass reinforced plastic; Housing systems; Interdwelling wall; Modular construction; Operation BREAKTHROUGH; NBSIR 73-166.

Paper honeycomb; structural sandwich; sustained load; accelerated aging; adhesive bond; ductility; flexural shear; housing systems; local buckling; material variability; moisture conditioning; Operation BREAKTHROUGH; $B S S 51$.

PB; Polyvinyl chloride; PVC; Residual stress; Thermoplastic piping; ABS; Coefficient of expansion; CPVC; Glass transition temperature; Hardness; Polybutene; NBSIR 74-629.

Performance attributes; Building material; Housing; Leaded paint; Lead hazard elimination methods; Lead paint poisoning; $T N 770$

Performance attributes; performance criteria; physical and engineering properties; test methods; bituminous roof membranes; BSS55.

Performance characteristics for piping; Thermal/structural performance of piping; Thermoplastic piping in plumbing; Fire performance of piping; Functional performance of piping; BSS68.

Performance characteristics for piping; Thermal/structural performance of piping; Thermoplastics in plumbing; Fire performance of piping; Functional performance of piping; NBSIR 74-531.

Performance characteristics; Performance level; Sanitary plumbing fixtures; Scratch resistance; Stain resistance; Surface-impact resistance; Test methods; Abrasion resistance; Chemical resistance; Cigarette-burn resistance; Cleanability and soilability; Concentrated static-load capacity; BSS22.

Performance criteria; Performance evaluation; Performance testing; Reinforced concrete; Standard tests; Structure, testing; Building; Connections; Housing; Neoprene; TN706.

Performance criteria; Performance testing; Building systems; Low-income housing; BSS 25 .

Performance criteria; physical and engineering properties; test methods; bituminous roof membranes; performance attributes; BSS 55 .

Performance criteria; Plywood subflooring; Subflooring; Underlayment; Wood-frame construction; Concentrated-load capacity; Evaluation criteria; Floors; Hardboard; Load capacity; Operation BREAKTHROUGH; NBSIR 73-116.

Performance criteria; Plywood subflooring; Subflooring; Underlayment; Wood-frame construction; Evaluation criteria; Floors; Hardboard; Load capacity; BSS53.

Performance criteria; Roofing temperature effects; Tensile fatigue; Test methods; Bituminous roof membranes; Fatigue testing; Flexural fatigue; TN863.

Performance criteria; Water-proofing materials; Water-repellent materials; Accelerated weathering; Durability of water-proofing materials; Masonry; TN883.

Performance data; Regulatory process; Standard; Construction; Hurricane Agnes; Housing; Mobile homes; Mobile home parks; NBSIR 75-641.

Performance data; Standards; Computer techniques; Enforcement process; Housing; Hurricane Agnes; Mobile home parks; Mobile homes; NBSIR 75-690.

Performance data; Standards; Enforcement process; Field inspection; House trailers; Housing; Hurricane Agnes; Mobile homes; NBSIR 75-688.

Performance evaluation; Performance requirements; User requirements; Buildings; Components; Design procedures; Experience in use; Materials; SP361. Volume I.

Performance evaluation; Performance requirements; Úser requirements; Buildings; Components; Design procedures; Experience in use; Materials; SP36I. Volume 2.

Performance evaluation; Performance testing; Reinforced concrete; Standard tests; Structure, testing; Building; Connections; Housing; Neoprene; Performance criteria; TN706.

Performance, functional; Single-stack drainage; Siphonage, induced; Siphonage, self; Test loads; Hydraulic; Trap-seal reduction detector; Trap-seal retention; Crossflow; Field testing, plumbing; Performance criteria, plumbing; NBSIR 73-161.

Performance guidelines; Protective coatings; Rigid polyurethane; Roofing; Durability; Fire safety; TN778.

Performance level; Sanitary plumbing fixtures; Scratch resistance; Stain resistance; Surface-impact resistance; Test methods; Abrasion resistance; Chemical resistance; Cigarette-burn resistance; Cleanability and soilability; Concentrated static-load capacity; Performance characteristics; BSS22.

Performance of buildings; Standards; Test methods; Urban planning; User needs; Building systems; BSS1.

Performance of plumbing; Single stack plumbing; Criteria for plumbing; Hydraulic test loads; BSS4I. 
Performance of plastics outdoors; Plastics; Weathering of plastics; Manufacturing Chemist's Association (MCS); NBSIR 73-146.

Performance; procurement; specifications; standards; tests; user needs; carpets; floor coverings; government; TN822.

Performance; Properties; Deleading methods; Lead paint poisoning; NBSIR 73-127.

Performance; Properties; Scratch resistance: Smoke generation; Toxic combustion products; Toxicity: Washability; Water vapor permeance; Abrasion; Adhesion; Colorfastness; Covering; Flash point; Flame spread; Impact resistance; Lead paint poisoning; materials; TN808.

Performance requirements; User requirements; Buildings; Components; Design procedures; Experience in use; Materials; Performance evaluation; SP361. Volume 1.

Performance requirements; User requirements; Buildings; Components; Design procedures; Experience in use; Materials: Performance evaluation; SP361. Volume 2.

Performance testing; Branch circuits; Contact resistance; Electrical codes; Electrical connections; Fire safety; Housewiring; NBSIR 75-672.

Performance testing; Building systems; Low-income housing; Performance criteria; BSS 25 .

Performance testing; Contact resistance; Electrical codes; Electrical connections; Fire safety; House wiring; Materials properties; BSS63.

Performance testing; Reduced-size vents; Trap-seal retention; Venting; Venting criteria; Vents, reduced size; DWV; BSS60.

Performance testing; Reinforced concrete; Standard tests; Structure, testing; Building; Connections; Housing; Neoprene; Performance criteria; Performance evaluation; TN706.

Performance tests; Precast concrete; Structural design; Building system; Column connection; Concrete traixial strength; Ductility; Neoprene bearing pad; Operation BREAKTHROUGH; NBSIR 73-148.

Performance test; precast concrete; structural design; building system; column connection; concrete triaxial strength; ductility; neoprene bearing pad; Operation Breakthrough; TN811.

Personal uses; Relationship; Uses; Color; Environment; Experimenting with; Harmony; Hues; Illumination; Light; CIS6.

pH; Porcelain enamel; Relative humidity; Weather resistance; Acid resistance; Color; Gloss; BSS4.

$\mathrm{pH}$; porcelain enamel; relative humidity; weather resistance: acid resistance; color; gloss; $B S S 50$.

Physical and engineering properties; test methods; bituminous roof membranes; performance attributes: performance criteria; $B S S 55$.

Physical properties: Cement: Chemical composition; Concrete: Durability; Material properties: BSS36.

Physical properties; Trace elements; Portland cement; Spectrographic analyses; Cement; Concrete; Material properties; BSS2.

Physical tests: Portland cement; Che mical analyses: BSS 17.

Pigments: Polymers: Properties: Resins: Selection: Substrates: Surface preparation: Varnish: Water-thinned: Application: Coatings: Coating systems: Corrosion-inhibiting: Federal specifications; Fire-retardant; Lacquer; Latex; Multicolor; Orga nic coatings; Paint; BSS7.

Piecewise; Smoothing; Continuous function; Fourier series. J. Res. NBS, 71 C No. 2.

Pin-end; Test method; Wall panels; Walls; Compression; Eccentric loading; Flat-end; Kern; Loading rate; NBSIR 75-779.

Plaster of paris; Setting mechanisms: Colloidal theory: Crystallization theory; Gypsum; Hydration: Induction period: TN755.

Plastic pipe plumbing; PVC; Smoke; ABS; DWV; Fire endurance; Fire spread; Fire test; Gases; $B S S 72$.

Plastic piping; PVC; Smoke; Toxic gases; Vent; Waste; ABS; Drain;
Fire endurance; Fire spread; [ire test; NBSIR 74-444

Plastics; Weathering of plastics; Manufacturing C'hemist's Association (MCS); Performance of plastics outdoors; N ISSIR 73-146, Plumbing system; Vent; Devices; Manıfold; T V253.

Plumbing-vent sizing; reduced-size vents, sinıtisy I)WV systems; secondary ventilation; testıng plumbıng systems: vents for plumbing: hydraulic criterla for plumbing; hydraulic test loads; $B S S 49$.

Plywood subflooring; Subflooring; Underlayment: Concentrated-load capacity; Evaluation criteria; Floors; Hardboard; Load capacity; Operation BREAKTHROUGH: Performance criteria; NBSIR 73-1/6.

Plywood subflooring; subflooring; underlayment: wood-frame construction; evaluation criteria; floors; hardboard; load capacity, performance criteria; BSS53.

Plywood; subfloors: underlayment; wood; wood joists: concen trated load; defiection; floor; hardboard; housing. Impact energy; Operation BREAKTHROUGH: BSSS2

Plywood; Subfloors; Underlayment; Wood; Wood joists; Concentrated loads; Deflection; Floor hardboard; Housing; Impact energy; Operation BREAKTHROUGH; NBS/R 73-187.

Poisoning; retail inventory; statistics; survey; lead; lead paint poisoning: paints; NBSIR 73-407.

Police fleets; vehicle leasing; vehicle management; fleet management; life cycle costing: patrol cars: $N B S / R$ 74-47I

Pollution; Pressure loss; Ventilation; Exchanger dimensions: Frost formation; Heat exchanger: Heating costs; Mechanical systems; TN710-5

Polybutene; PB; Polyvinyl chloride; PVC; Residual stress; Thermoplastic piping; ABS; Coefficient of expansion; CPVC: Glass transition temperature; Hardness; NBSIR 74-629.

Polyester and nylon fabrics; sewn seams: sewn seam strapping: solar heat load; test procedure: adhesives; air-inflatable shelter sections; cloth webs; NBSIR 74-467.

Polymers: Properties: Resins; Selection: Substrates: Surface preparation: Varnish: Water-thinned: Application: Coatings: Coating systems; Corrosion-inhibiting: Federal specifications: Fire-retardant; Lacquer; Latex; Multicolor; Organic coatings; Paint; Pigments; BSS7.

Polyurethane foam; Sandwich construction; Wall system; Accelerated aging; Compression; Environmental conditions; Flexure; Housing system; Operation BREAKTHROUGH; NBSIR 73-105.

Polyurethane foam; Toxic gases; Fire endurance; Fire test; Housing systems; Interdwelling wall; Load failure; Modular construction; Operation BREAKTHROUGH; NBSIR 73-I70.

Polyvinyl chloride coatings; Steel reinforcing bars; Bridge decks; Chloride ions; Deicing salts; Epoxy coatings; Organic coatings; BSS65.

Polyvinylchloride coatings; Steel reinforcing bars; Bridge decks; Corrosion; Creep testing; Epoxy coatings; NBS/R 73-295.

Polyvinyl chloride; PVC; Residual stress; Thermoplastic piping; ABS; Coefficient of expansion; CPVC; Glass transition temperature; Hardness; Polybutene; PB; NBSIR 74-629.

Polyvinyl chloride; Thermal mechanical analysis (TMA); Thermal properties; Thermogravimetric analysis (TGA); Thermoplastic pipe; Chlorinated polyvinyl chloride; Hardness; Internal stress; NBSIR 74-6I0.

Porcelain enamel; Reiative humidity; Weater resistance; Acid resistance; Color; Gloss; $\mathrm{pH}$; $B S S 4$.

Porcelain enamel; relative humidity; weather resistance: acid resistance; color; gloss; $\mathrm{pH}$; BSS50.

Porcelain enamel; spalling: $\mathrm{x}$-ray diffraction: adherence: alu minum; electron microprobe; electron microscope: $B S S 59$

Porcelain enamel; Weather resistance: Acid resistance: Color: Continuity of coating; TN707.

Porcelain enamel: Weather resistance Acid resistance: Color: Gloss; BSS38. 
Porcelain enamel on aluminum: Weather resistance; Color; Gloss; BSS29.

Portable X-ray fluorescence lead calibration standards; Leaded paint detection; Portable $\mathrm{x}$-ray fluorescence lead detector; NBSIR 73-231.

Portable $\mathrm{x}$-ray fluorescence lead detector; Portable $\mathrm{x}$-ray fluorescence lead calibration standards; Leaded paint detection; NBSIR 73-231.

Portland cement: Chemical analyses; Physical tests; BSS 17 .

Portland cement concrete; Shrinkage of concrete; shrinkage of portland cements; Trace elements; Cement composition; Chemical composition of portland cements; Cracking of portland cements; Cracking resistance of cements; Expansion-shrinkage ratios; portland cement; BSSI5.

Portland cement; Portland cement concrete; Shrinkage of concrete; Shrinkage of portland cements; Trace elements; Cement composition; Chemical composition of portland cements; Cracking of portland cements; Cracking resistance of cements; Expansionshrinkage ratios; BSS15.

Portland cement: Shrinkage of portland cements; Trace elements: Chemical composition of portland cements: Cracking of portland cements: Cracking resistance of cements; BSS 15 ,

Portland cement; Spectrographic analyses; Cement; Concrete; Material properties; Physical properties; Trace elements; BSS2.

Portland Cement; Sulfate expansion; Autoclave expansion; Cement; Concrete; Heat of hydration; BSS5.

Potential heat; Structural load; Apartment dwelling; Burnout test; Fire load; Fire performance; Flame penetration; BSS10.

Power factor; Capacitors; Energy conservation; Fluorescent lamp; Fluorescent luminaire; Lighting efficiency; TN886.

Precast concrete; Concrete panels; Connections; Ductibility; Floor diaphragms; Housing systems; Insert connectors; Operation BREAKTHROUGH; NBSIR 73-126.

Precast concrete construction; Progressive collapse; Structural design; Structural joists; Building systems; Housing systems; Large-panel structure; NBSIR 75-715.

Precast concrete: Production capacity; Production management; Production methods; Standardization; United Soviet Socialist Republics; Building economics; Building systems; Construction industry; Housing: SP334.

Precast concrete; structural design; building system; column connection; concrete triaxial strength; ductility; neoprene bearing pad; Operation Breakthrough; performance test; TN811.

Precast concrete; Structural design; Building system; Column connection; Concrete traixial strength; Ductility; Neoprene bearingpad; Operation BREAKTHROUGH; Performance tests; NBSIR 73-148.

Precipitation; Solar radiation; Temperature; Wind direction; Wind speed; Air contamination; Design conditions; Earthquake risk; Evaluation; Ground temperature; Humidity; Noise level; Operation BREAKTHROUGH; NBSIR 73-144.

Precoordination; Standards; Building; Components; BSS32.

Predicted indoor habitability index; Air-conditioning criteria; Building thermal response; Comfort indices; Human comfort; BSS71.

Pressure drop; Temperature; Uniformity; Effectiveness; Forced mixing; Mixing device; BSS27.

Pressure transducers; Socio-economic; Structrual design; Technology implementation; Wind effects; Wind loads; Codes and standards; Disaster mitigation; Information transfer; Low-rise buildings; BSS56.

Pressure fluctuations; Stagnation point; Turbulence; Disk: TN563.

Pressure-loss-depression; Thermal convection; Ventilation; Air infiltration and extraction, airtightness; Discomfort index;
Duct system, collective and individual branch; Flow rates; Noise; TN710-3.

Pressure loss; Ventilation; Exchanger dimensions; Frost formation; Heat exchanger; Heating costs; Mechanical systems; Pollution; TN710-5.

Pressure; Temperature; Composite wall panel; Condensation; Humidity; Moisture; NBSIR 73-220.

Pressure transducers; socio-economic; structural design; technology implementation; wind effects; wind loads; codes and standards; disaster mitigation; information transfer; low-rise buildings; BSS56.

Pressurized stairwell; Quantitative experiment; Smoke control; Smoke simulation; Analysis; Basic correlation forumlas; Computer calculations; High-rise building fire; Operation BREAKTHROUGH; NBSIR 73-277.

Prestressed concrete beams; Tee-beams; Composite concrete construction; BSS 31 .

Prestressed concrete; Relaxation; Shrinkage; Variable prestress; C reep; Loss of prestress; BSSI3.

Probability distribution functions; Reliability; Risk; Statistical analysis; Storms; Structural engineering; Wind loads; Wind speeds; Building codes; Extreme value distributions; Hurricanes; TN868.

Probe conduction errors; Steady periodic heat flow; Earth temperature. J. Res. NBS, $72 C$ No. 4.

Problems of metrication; codes; construction conference; domestic housing, U.S.; foreign metrication; levels of conversion; metrication; NBSIR 73-421.

Procurement; specifications; standards; tests; user needs; carpets; floor coverings; government; performance; TN822.

Production capacity; Production management; Production methods; Standardization; United Soviet Socialist Republics; Building economics; Building systems; Construction industry; Housing; Precast concrete; SP334.

Production management; Production methods; Standardization; United Soviet Socialist Republics; Building economics; Building systems; Construction industry; Housing; Precast concrete; Production capacity; SP334.

Production methods; Standardization; United Soviet Socialist Republics; Building economics; Building systems; Construction industry; Housing; Precast concrete; Production capacity; Production management; SP334.

Professional interaction; cooperative programs; foreign visitors; information exchange; international building technology; international organization memberships; NBSIR 74-432.

Professional interaction; Cooperative programs; Foreign visitors; Information exchange; International building technology; International organization memberships; NBSIR 74-5I4.

Progressive collapse; Abnormal loading; Building; Gas explosion; Load-bearing masonry; Load-bearing walls; Masonry; Masonry research; NBSIR 74-526.

Progressive collapse; Risk; Stability; Standards; Strength; United States; Abnormal loading; Building; Codes; Design criteria; Multistory; NBSIR 73-221.

Progressive collapse; Risk; Statistics; Structure; Building; Explosion; Frequency; Gas; Gas industry; NBSIR 73-208.

Progressive collapse; Specific resistance; Abnormal loading; Alternate path; Annotated bibliography; Bibliography; Building code; Building regulations; Collapse; Failures; BSS67.

Progressive collapse; Standards; Benefit-cost analysis; Building safety; Economics; NBSIR 74-452.

Progressive collapse; Structural design; Structural joists; Building systems; Housing systems; Large-panel structure; Precast concrete construction; NBSIR 75-715.

Properties; Deleading methods; Lead paint poisoning; Performance; NBSIR 73-127.

Properties; Resins; Selection; Substrates; Surface preparation; Varnish; Water-thinned; Application: Coatings: Coating 
systems: Corrosion-inhibiting: Federal specifications: Fire-rctardant; Lacquer; Latex; multicolor; Organic coatings; Paint; Pigments; Polymers; BSS7.

Properties; Scratch resistance: Smoke generation; Toxic combustion products: Toxicity; Washability; Water vapor permeance; Abrasion: Adhesion; Colorfastness; Covering: Materials; Flash point; Flame spread; Impact resistance; Lead paint poisoning; Performance; TN808.

Property measurement test; Standard test methods; Aging test; Building elements and materials; Degradation factors; Durability; NBSIR 75-955.

Protective coatings; Rigid polyurethane; Roofing; Durability; Fire safety: Performance guidelines; TN778.

Psychological; Solar glass; Spaciousness; Sunshine; View; Windowless; Windows; Daylight; Fenestration; BSS70.

Psychrometrics; Saturated and unsaturated moist air; Thermodynamic properties; Computer algorithm; BSS21.

Pull-out loads; Sustained load; Anchors; Concrete slabs; Design loads; Fatigue; Inserts; BSS42.

PVC; Residual stress; Thermoplastic piping; ABS; Coefficient of expansion; CPVC; Glass transition temperature; Hardness; Polybutene; PB; Polyvinyl chloride; NBSIR 74-629.

PVC, Smoke, ABS; DWV; Fire endurance; Fire spread; Fire test; Gases; Plastic pipe plumbing; BSS72.

PVC; Smoke; Toxic gases; Vent; Waste; ABS; Drain; Fire endurance; Fire spread; Fire test; Plastic piping; NBSIR 74-449.

\section{Q}

Quantitative experiment; Smoke control; Smoke simulation; Analysis; Basic correlation forumlas; Computer calculations; High-rise building fire; Operation BREAKTHROUGH; Pressurized stairwell; NBSIR 73-277.

\section{$\mathbf{R}$}

Racking; Reinforced plastics; Reinforced polyester; Sustained loads; Tensile shear; Adhesive bond; Aging; Composites; Compression; Flexure; Glass fiber; Housing system; Innovations; Laminate; Operation BREAKTHROUGH; NBSIR 73.188.

Racking; Stiffness; Strength; Structural tests; Sustained load; Transportation; Vibration; Wood-frame; Deflection; Housing; Laboratory; Module; NBSIR 73-I2I.

Racking: Stiffness; Structural deflections; Vibration: Wind load; Wood frame construction: Building damping; Drift; Dynamics; Earthquake; Frequency: Housing; Lateral resistance: BSS 44 .

Racking strength; seismic loading; shear strength; shear wall; stiffness; analysis; compressive strength; deflection; design; flexural strength; masonry walls; NBSIR 74-520.

Radiation error: Resistance thermometer: Temperature measurement: Thermistor; Thermocouple; Conduction error: BSS26.

Radiation flux measurements; Doors; Barriers; Combustibility; Fire; Smoke; BSS3.

Radiation panel; Carpet; Fire test; Flammability; Flooring; Heat flux Ignition; NBSIR 74-495.

Radiative cooling; Solar heating; Thermal movement; Built-up roofing; Nighttime cooling; TN231.

Radioactive decay; Thermal conductivity; heat conduction; Heat generation; Heat transfer; Neutron absorption. J. Res. NBS, 71 C No. 4.

Random process; Spectral analysis; Vibration; Analysis; experimental; Floor systems; Human response; NBSIR 75-95I.

Reduced-size vents; sanitary DWV systems: secondary ventilation; testing plumbing systems; vents for plumbing; hydraulic criteria for plumbing. hydraulic test loads, plumbing vent s/ ing: $B .5 .540$

Reduced-sizc vents; Tráp-seal retentıon; Venting. Ventung criterıa, Vents, reduced size; DWV; J'erformarice tesung; B.S.So,

Reentrant corner; Exterior wall; Fire spread, Fire test; lgnition; Operation BREAKTHROUGili; N/3.S/R 73-266.

Regulation; Standards; State-of-the-art study; Enforcement; Legislation; Mobiles homes; N/3.S/R 75-681).

Regulations; State; Authority; Bullding; Inergy; Legislation; NBSIR 75-747.

Regulatory process; Standard; Construction; Hurricanc Agnes; Housing; Mobilc homes; Mobilc home parks; Performance data; NBSIR 75-64\%.

Rcinforced concrete masonry walls: Slenderness eflect: Seructural stability: Buckling: (ompressive strength: (oncrete block walls; Flastic slability: F lexural strength: Masonry walls: B.S.533.

Reinforced concrete; Standard tests: Structure, testing: Huld ing; Connections: Housing: Neoprene: Performance criteria: Performance evaluation: Performance testing: TN706.

Reinforced plastics; Reinforced polyester; Sustained loads; Tensile shear; Adhesive bond; Aging; Composites; Compression; Flexure; Glass fiber; Housing system; Innovations; Laminate; Operation BREAKTHROUGH; Racking; NBSIR 73-188.

Reinforced polyester; Sustained loads; Tensile shear; Adhesive bond; Aging; Composites; Compression; Flexure; Glass fiber; Housing system; Innovations; Laminate; Operation BREAKTiIROUGH; Racking; Reinforced plastics; NBSIR 73-188.

Relationship; Uses; Color; Environment; Experimenting with; Harmony; Hues; lllumination; Light; Personal uses; CIS6.

Relative humidity; Structural salidwich panel; Temperature; Testing; Building composite; Buildiñ; material; Conditioning; Equilibration; Gypsum wallboard; Methodology; NBSIR 75-767.

Relative humidity; Weather resistance: Acid resistance; Color; Gloss; pH; Porcelain enams!: BSS4.

Relative humidity; weathe essstance, acid resistance: color: gloss: $\mathrm{pH}$; porcelain enamel; $B \$ S 50$.

Relaxation; Shrinkage; Variaile prestress; Creep; Loss of prestress; Prestressed concrete; $\$ 3 S / 3$.

Reliability; Risk; Statistical analvsis; Storms; Structural engineering; Wind loads; Wind speeds; Building codes; Extreme value distributions; Hurricanes; Probability distribution functions; TN868.

Requirements; Design criteria; Energy conservation; Evaluation criteria; New buildings; NBSIR 74-452.

Residual stress; Thermoplastic piping; ABS; Coefficient of expansion; CPVC; Glass transition temperature; Hardness; Polybutene; PB; Polyvinyl chloride; PVC; NBSIR 74-629.

Resilient flooring; Slipperiness standards; Slip test; Coefficient of friction; Floor slipperiness; Frictional tests; Human perambulation; NBSIR 74-6I3.

Resins; Selection; Substrates; Surface preparation: Varnish; Water-tisinned; A pplication: Coatings; Coating systems; Corrosion-inhibiting: Federal specifications: Fire-retardant: Lacquer; Latex; Muliicolor; Organic coatings; Paint; Pigments; Polymers; Properties; BSS7.

Resistance thermometer: Temperature measurement: Thermistor; Thermocouple; Conduction error: Radiation error: $B S S 26$.

Resistivity: Temperature; Thermal conductivity: Thermal diffusivity: Thermal resistivity; Thermophysical properties: Conductance: Conductivity: Contact conductance: Contact resistance; Electrical conductivity; Electrical resistivity; Heat transfer; Lorenz function; SP302.

Retail inventory; statistics: survey: lead: lead paint poisoning: paints; poisoning; NBSIR 73-4()7.

Retrofitted solar residence; Solar collector; Solar heating and cooling system; Solar-powered absorption refrigeration; TN89?. 
Retrofitting; Storm doors; Storm windows; Tax credit; Vapor barriers; Weatherstripping; Caulks and sealants; Clock thermostats; Energy conservation; Insulation; NBSIR 75-795.

Review; Selenium; Toxic elements in paints; Analytical methods; Antimony; Arsenic; Cadmium; Lead; Mercury; NBSIR 73-25l.

Rigid polyurethane; Roofing: Durability; Fire safety: Performance guidelines; Protective coatings; TN778.

Rigid urethane foam; smoke; dibromotetrafluoroethane; fire tests; flame spread index; heat release rate; ignition temperature; NBSIR 74-456.

Risk; Stability; Standards; Strength; United States; Abnormal loading; Building; Codes; Design criteria; Multistory; Progressive; NBSIR 73-221.

Risk; Statistical analysis; Storms; Structural engineering; Wind loads; Wind speeds; Building codes; Extreme value distributions; Hurricanes; Probability distribution functions; Reliability; TN868.

Risk; Statistics; Structure; Building; Explosion; Frequency; Gas; Gas industry; Progressive collapse; NBSIR 73-208.

Roof/ceiling assembly; Structural panel; Fire endurance; Fire test; Flame-through failure, structural panel; Glass-fabric reinforced plastic; Housing system; Operation BREAKTHROUGH; Paper honeycomb; NBSIR 73-167.

Roof/ceiling assembly; Structural sandwich panel; Exterior wall; Fire endurance; Fire test; Housing systems; Operation BREAKTHROUGH; Paper honeycomb; NBSIR 73-135.

Roofing; Durability; Fire safety; Performance guidelines; Pro. tective coatings; Rigid polyurethane; TN778.

Roofing membranes; Thermally induced forces; Thermai-shock resistance factor; Bituminous built-up roofing; Built-up roofing membranes; BSS\%.

Roofing: Saturation; Absorption; Asphalts; Felts: Moisture: BSS 19 .

Roofing: Shingles; Storm damage; Asphalt shingles; Built-uF roofing: Hail; $B S S 23$

Roofing temperature effects; Tensile Fatigue; Test methods; Bituminous roof membranes; Fatigue testing; Flexural fatigue; Performance criteria; TN863.

Roof projections; Static pressures; Wind effects: Wind tunnel modeling; Architectural features; Buildings; Mullions; Parapets; BSS30, pp. 73-86.

Roofs; standardization; test methods; walls; building construction; complete buildings; floors; $B S S 58$.

Roofs; Structural engineering; Tides; Wind; Buildings; Disaster mitigation; Failure; Hurricanes; Mobile homes; TN569.

Roofs; Structrual engineering; Wind load; Anchorage; Building performance; Disaster mitigation; Glazing; Hailstones; Masonry; Mobile homes; TN558.

Round robin; Smoke; Smoke density chamber; Statistical analysis; Building materials; Fire tests; Interlaboratory tests; Optical density; TN708.

Round robin; Statistical analysis; Test method standard; ASTM E 84; Building materials; Carpets; Fire tests; Flame spread tests; Interlaboratory evaluation; NBSIR 73-I25.

Rules and regulations; state-of-the-art study; building regulation; enforcement; evaluation; inspection; legislation; manufactured building; mobile homes; TN853.

\section{S}

Safety; Architecture; Building; Building codes; Building design; Disaster mitigation; Earthquakes; Engineering; Environmental hazards; Housing; Inspection and testing; TN 885.

Sand wich construction; Wall system; Accelerated aging; Compression; Environmental conditions; Flexure; Housing system; Operation BREAKTHROUGH; Polyurethane foam; NBSIR 73-105.
Sandwich facings; Sandwich panels; Adhesives; Paper hone ycomb; BSS43.

Sandwich panels; Adhesives; Paper honeycomb; Sandwich facings; $B S S 43$.

Sanitary DWV systems; secondary ventilation; testing plumbing systems; vents for plumbing; hydraulic criteria for plumbing; hydraulic test loads; plumbing-vent sizing; reduced-size vents; BSS49.

Sanitary plumbing fixtures; Scratch resistance; Stain resistance; Surface-impact resistance; Test methods; Abrasion resistance; Chemical resistance; Cigarette-burn resistance; Cleanability and soilability; Concentrated static-load capacity; Performance characteristics; Performance level; BSS22.

Saturated and unsaturated moist air; Thermodynamic properties; Computer algorithm: Psychrometrics: BSS21.

Saturation; Absorption; Asphalts: Felts; Moisture; Roofing; BSS 19 .

Saturation coefficient; Absorption: Autogenous healing: Durability factor; Dynamic modulus of elasticity; BSS 35 .

Scratch resistance; Smoke generation; Toxic combustion products; Toxicity; Washability: Water vapor permeance; Abrasion; Adhesion; Colorfastness; Covering; Flash point; Flame spread; Impact resistance; Lead paint poisoning; Materials; Performance; Properties; TN808.

Scratch resistance; Stain resistance; Surface-impact resistance Test methods; Abrasion resistance; Chemical resistance; Cigarette-burn resistance; Cleanability and soilability; Concentrated static-load capacity; Performance characteristics: Performance level; Sanitary plumbing fixtures; BSS22.

Sealant performance; Standardized testing; Test methods; Accelerated laboratory tests; Double-glazed window units; Factory-sealed insulating glass units; Field performance tests, correlation with laboratory tests; $B S S 20$.

Seasonal efficiency; Boiler oversizing; Efficiency versus heating load; Modular boilers; Modular concept; BSS79.

Secondary ventilation; testing plumbing systems; vents for plumbing; hydraulic criteria for plumbing; hydraulic test loads; plumbing-vent sizing; reduced-size vents; sanitary DWV systems; BSS 49.

Seismic loading; shear strength; shear wall; stiffness; analysis; compressive strength; deflection; design; flexural strength; masonry walls; racking strength; NBSIR 74-520.

Seismic; Standards; Structural engineering; Bridge; Building; Codes; Dams; Disaster mitigation; Earthquake damage; Earthquakes; Foundation geology; Highways; Hospital; Housing; Mobile home; BSS40.

Selection; Substrates; Surface preparation; Varnish; Waterthinned; Application; Coatings; Coating systems; Corrosioninhibiting; Federal specifications: Fire-retardant; Lacquer; Latex; Multicolor; Organic coatings; Paint; Pigments Polymers; Properties; Resins; BSS7.

Selenium; Toxic elements in paints; Analytical methods; Antimony; Arsenic; Cadmium; Lead; Mercury; Review; NBSIR 73-25I.

Setting mechanisms; Colloidal theory; Crystallization theory; Gypsum; Hydration; Induction period; Plaster of paris; TN755.

Sewage treatment; user fees; water pollution; cost sharing; efficiency; equity; financing; nonplant treatment; NBSIR 74-479.

Sewn seam strapping; Solar heat load; Test procedure; Adhesives; Air-inflatable shelter sections; Cloth webs; Polyester and nylon fabrics; Sewn seams; NBSIR 74-467.

Sewn seams; sewn seam strapping; solar heat load; test procedure; adhesives; air-inflatable shelter sections; cloth webs; polyester and nylon fabrics; NBSIR 74-467.

Shear resistance; Theory of cement hardening: Time of set; Vane-shear apparatus; Cement; Cement mortar; Cement paste; Early strength; False set; Hardening of cement; Hydration; $B S S 28$.

Shear strength; Shear test; Shear walls; Stress distribution; Stresses; Structural engineering; Brick; Failure; Failure theories; Masonry; NBSIR 75-703. 
Shear strength; shear wall; stiffness; analysis; compressive strength; deflection; design; flexural strength; masonry walls; racking strength; seismic loading; NBSIR 74-520.

Shear test; Shear walls; Stress distribution; Stresses; Structural engineering; Brick; Failure; Failure theories; Masonry; Shear strength; NBSIR 75-703.

Shear wall; stiffness; analysis; compressive strength; deflection; design; flexural strength; masonry walls; racking strength; seismic loading; shear strength; NBSIR 74-520.

Shear walls; Stress distribution; Stresses; Structural engineering; Brick; Failure; Failure theories; Masonry; Shear strength; Shear test; NBSIR 75-703.

Shingles; Storm damage; Asphalt shingles; Built-up roofing; Hail; Roofing; BSS23.

Shingles; Wood fibers; Asphalt; Asplund; Felt; Mineral'surfaced roll roofing; TN477.

Shoreline protection; beach erosion control; cost sharing; economics; efficiency; equity; incentives; NBSIR 73-294.

Short-term tests; weathering factors; accelerated aging; building components and materials; climatological data; durability; environmental factors; long-term tests; TN838.

Shrinkage of concrete; Shrinkage of portland cements; Trace elements; Cement composition; Chemical composition of portland cements; Cracking of portland cements; Cracking resistance of cements; Expansion-shrinkage ratios; Portland cement; Portland cement concrete; BSS15.

Shrinkage of portland cements; Trace elements; Cement composition; Chemical composition of portland cements; Cracking of portland cements; Cracking resistance of cements; expansionshrinkage ratios; Portland cement; Portland cement concrete; Shrinkage of concrete; BSSI5.

Shrinkage: Variable prestress; Creep; Loss of prestress; Prestressed concrete; Relaxation; BSS/3.

Single-family attached housing; Steel tube column; Fire endurance; Fire test; Housing system; Multifamily housing; Operation BREAKTHROUGH: NBSIR 73-165.

Single-family residences; Small scale; Thermal resistance; Wood floor; Wood joist; Fire endurance; Fire test; Flame through; Full scale; Housing; Operation BREAKTHROUGH; NBSIR 73-263.

Single-stack drainage; Siphonage, induced; Siphonage, self; Test loads; Hydraulic; Trap-seal reduction detector; Trap-seal retention; Crossflow; Field testing, plumbing; Performance criteria, plumbing; Performance, functional; NBSIR 63-161.

Single stack plumbing: Criteria for plumbing; Hydraulic test loads; Performance of plumbing; BSS41.

Single wall; Fire endurance; Fire test; Housing systems; Interdwelling wall; Operation BREAKTHROUGH; NBSIR 73-140.

Siphonage, induced; Siphonage, self; Test loads; Hydraulic; Trapseal reduction detector; Trap-seal retention; Crossflow; Field testing, plumbing; Performance criteria, plumbing; Performance functional; Single-stack drainage; NBSIR 73-161.

Siphonage, self; Test loads; Hydraulic; Trap-seal reduction detector; Trap-seal retention; Crossflow; Field testing, plumbing; Performance criteria, plumbing; Performance, functional; Single-stack drainage; Siphonage, induced; NBSIR 73-161.

Slenderness effect; Structural stability; Buckling; Compressive strength; Concrete block walls; Elastic stability; Flexural strength; Masonry walls; Reinforced concrete masonry walls: BSS33.

Slenderness effects; Standards: Structural stability: Walls: Brick; Cavity walls: Composite walls; Compressive strength: Concrete block; Flexural strength: Masonry; Mortar; BSS34.

Slipperiness standards; Slip test; Coefficient of friction; Floor slipperiness; Frictional tests; Human perambulation; Resilient flooring; NBSIR 74-613.

Slip test; Coefficient of friction; Floor slipperiness; Frictional tests; Human perambulation; Resilient flooring; Slipperiness standards; NBSIR 74-613.
Small scale; Thermal resistance; Wood floor; Wood joust, Firc cndurancc; Fire tcst; Flame through; Full scale; Housıng; Opcration BREAKTHROUGif; Single-family residences: NBSIR 73-263.

Smoke; ABS; DWV; Firc endurance; Fire spread; Fire test; Cases, Plastic pipe plumbing; PVC; BSS 572.

Smoke control; Smoke simulation; Analysis; Basic correla'ıon formulas; Computer calculations; High-rise huilding fire; Operation BREAKTHROUGH; Pressurized starrwell; Quant1tative experiment; NBSIR 73-277.

Smoke density chamber; Smoke potential: Test method: Visholi. ty; Building matcrials; Fire; Fire services: Smoke 7 N757

Smoke density chamber: Statistical analysis; Buslding materaals: Fire tests; Interlaboratory tests: Optical density. Ruund robin; Smoke; TN708.

Smoke; dibromotctrafluoroethane; fire tests; flame upread index heat release rate; ignition tcmperature; rigid urethane form. NBSIR 74-456.

Smoke gencration; Toxic combustion products; Toxiculy: Washability; Water vapor permeance; Abrasion; Adhesion. Colorfastncss; Covering; Materials; Flash point; Flame spread; Impact resistance; I, ead paint poisoning: Matcrials: Performance; Properties; Scratch resistance; TN808.

Smoke generation; Wall and ceiling; Carpets; Flame sprcad; Kitchen cabinets; NBSIR 73-228.

Smoke simulation; Analysis; Basic correlation forumlas; Computer calculations; High-rise building fire; Operation BREAKTHROUGH; Pressurized stairwell; Quantitative experiment; Smoke control; NBSIR 73-277.

Smoke potential; Test method; Visibility: Building materials Fire: Fire services; Smoke; Smoke density chamber: $T$ N757.

Smoke; Radiation flux measurements; Doors; Barriers; Combustibility; Fire; $B S S 3$.

Smoke; Smoke density chamber; Smoke potential; Test method Visibility; Building materials; Fire; Fire services: TN757.

Smoke: Smoke density chamber: Statistical analysis: Building materials; Fire tests; Interlaboratory tests; Optical ceristy: Round robin; TN708.

Smoke; Toxic gases: Aircraft materials: Combustion products Fire tests; Interior finish: BSS 18.

Smoke; Toxic gases; Fire retardant; Fire tests; Heat release ignition; Mattress; NBSIR 73-177.

Smoke; Toxic gases; Vent; Waste; ABS; Drain; Fire endurance: Fire spread; Fire test; Plastic piping; PVC; NBSIR 74-449.

Smoothing; Continuous function; Fourier series; Piecewise. J. Res. NBS, $7 / C$ No. 2.

Socio-economic; Structural design; Technology implementation; Wind effects; Wind loads; Codes and Standards; Disaster mitigation; Information transfer; Low-rise buildings; Pressure transducers; BSS56.

Solar collector; Solar energy; Solar radiation; Standard; Standard test; Thermal performance; NBSIR 74-635.

Solar collector; Solar heating and cooling system; Solar-powered absorption refrigeration; Retrofitted solar residence; TN892.

Solar energy; Solar heating and cooling; Economic optimization; HVAC systems; Life-cycle cost analysis; NBSIR 75-7/2.

Solar energy; Solar radiation; Standard; Standard test; Thermal performance; Solar collector; NBSIR 74-635.

Solar energy; Standard; Standard test; Thermal performance; Thermal storage; Thermal test; NBSIR 74-634.

Solar glass; Spaciousness; Sunshine; View; Windowless; Windows; Daylight; Fenestration; Psychological; BSS70.

Solar heating and cooling; Economic optimization; HV AC systems; Life-cycle cost analysis; Solar energy; NBSIR 75-712.

Solar Heating; Thermal movement; Built-up roofing; . Vighttime cooling; Radiative cooling; $T \aleph 231$.

Solar heating and cooling system; Solar-powered absorption refrigeration; Retrofitted solar residence; Solar collector; T1892. 
Solar heat load; test procedure; adhesives; air-inflatable shelter sections; cloth webs; polyester and nylon fabrics; sewn seams; sewn seam strapping; NBSIK 74-467.

Solar-powered absorption refrigeration; Retrofitted solar residence; Solar collector; Solar heating and cooling system; TN892.

Solar radiation; Standard; Standard test; Thermal performance; Solar collector; Solar energy; NBSIR 74-635.

Solar radiation; Temperature; Wind direction; Wind speed; Air contamination; Design conditions; Earthquake risk; Evaluation; Ground temperature; Humidity; Noise level; Operation BREAKTHROUGH; Precipitation; NBSIR 73-144.

Sound insulation: Sound pressure level; Walls; Facade: Noise; TN710-2.

Sound pressure level; Walls; Facade; Noise; Sound insulation; $T N 710-2$

Sound transmission loss; Thermal resistance; Thermal transmittance; Windows; Acoustics; Air infiltration; Air leakage; Architectural acoustics; Building acoustics; Doors; Energy conservation; Heat loss from buildings; Heat transfer; $B S S 77$.

Spaciousness; Sunshine; View; Windowless; Windows; Daylight; Fenestration; Psychological; Solar glass; BSS70.

Spalling; x-ray diffraction; adherence; aluminum; electron microprobex electron microscope; porcelain enamel; BSS 59.

Specifications for underground systems; Corrosion of underground pipes; District heating; Hot and chilled water systems; Insulation of underground pipes; $B S S 66$.

Specifications; standards; tests: liser needs; carpets; floor coverings; government; performance; procurement; TN822.

Specifications: Static; Structural engineering; Subsystems: Vibration; Analysis; Deflection; Design; Dynamic; Experimental; Human sensitivity; Loading functions; $B S S 47$.

Specific Resistance; Abnormal loading; Alternate path; Annotated bibliography; Bibliography; Buiding code; Building regulations; Collapse; Failures; Progressive Collapse; BSS67.

Stabilizer: Weathering; Additive: Asphalt; Durability; Felt: BSS 24

Spectral analysis; Vibration; Analysis; Experimental; Floor systems; Human response; Random process; NBSIR 75-951.

Spectrographic analyses; Cement; Concrete; Material properties; Physical properties; Trace elements; Portland cement; BSS2.

Spectrophotometry; Vision; Bibliography; Color; Color codes; Color measurement; Colorimetry; SP 393.

Square-edged orifice; Temperature measurement; Temperature pattern; Diameter ratio; Mixing effectiveness; BSS12.

Stability; Standards; Strength; United States; Abnormal loading; Building; Codes; Design criteria; Multistory; Progressive collapse; Risk; NBSIR 73-221.

Stagnation point; Turbulence; Disk: Pressure fluctuations; TN563.

Stain resistance; Surface-impact resistance; Test methods; Abrasion resistance; Chemical resistance; Cigarette-burn resistance; Cleanability and soilability; Concentrated staticload capacity; Performance characteristics; Performance level; Sanitary plumbing fixtures; Scratch resistance; BS.S22.

Standard; Construction; Hurricane Agnes; Housing; Mobile homes; Mobile home parks; Performance data; Regulatory process; NBSIR 75-641.

Standardization; test methods; walls: building construction; complete buildings; floors; roofs; BSS 58 .

Standardization; United Soviet Socialist Republics; Building economics: Building systems; Construction industry; Housing: Precast concrete: Production capacity; Production management; Production methods; SP334.

Standardized testing; Test methods; Accelerated laboratory tests; Double-glazed wirdow units; Factory-sealed insulating glass units; Field performance tests, correlation with laboratory tests; Sealant performance; $B S S 20$

Standards; Benefit-cost analysis; Building safety; Economics; Progressive collapse; NBSIR 74-452.
Standards; Building codes; Buildings; Energy conservation; TN789-1.

Standards; Building; Components; Precoordination; BSS32.

Standards; Computer techniques; Enforcement process; Housing; Hurricane Agnes; Mobile home parks; Mobile homes; Performance data; NBSIR 75-690.

Standards; Enforcement process; Field inspection; House trailers; Housing; Hurricane Agnes; Mobile homes; Performance data; NBSIR 75-688.

Standards; State-of-the-art study; Enforcement; Legislation; Mobiles homes; Regulation; NBSIR 75-680.

Standard; Standard test; Thermal performance; Solar collector; Solar energy; Solar radiation; NBSIR 74-635.

Standard; Standard test; Thermal performance; Thermal storage; Thermal test; Solar energy; NBSIR 74-634.

Standards; Strength; United States; Abnormal loading; Building; Codes; Design criteria; Multistory; Progressive collapse; Risk; Stability; NBSIR 73-221.

Standards; Structural engineering; Bridge; Building; Codes; Dams; Disaster mitigation; Earthquake damage; Earthquakes; Foundation geology; Highways; Hospital; Housing; Mobile home; Seismic; BSS40.

Standards; Structural stability; Walls; Brick: Cavity walls; Composite walls; Compressive strength; Concrete block; Flexural strength; Masonry; Mortar; Slenderness effects; BSS34.

Standards; Test methods; Urban planning; User needs; Building systems; Performance of buildings; $B S S I$.

Standards; tests; user needs; carpets; floor coverings; government; performance; procurement; specifications; TN822.

Standards, voluntary index of; Engineering standards, index of; Index of standards, recommended practices, specifications, test methods; Key-word-in-context index of voluntary standards; SP 329, Suppl. 1 .

Standard test methods; Aging test; Building elements and materials; Degradation factors; Durability; Property measurement test; NBSIR 75-955.

Standard test; Thermal performance; Solar collector; Solar energy; Solar radiation; Standard; NBSIR 74-635.

Standard test; Thermal performance; Thermal storage; Thermal test; Solar energy; Standard; NBSIR 74-634.

Standard tests: Structure, testing; Building; Connections; Housing: Neoprene; Performance criteria: Performance evaluation; Performance testing; Reinforced concrete: TN706.

State; Authority; Building; Energy; Legislation; Regulations; NBSIR 75-747.

State-of-the-art study; building regulation; enforcement; evaluation; inspection; legislation; manufactured building; mobile homes; rules and regulations: TN853.

State-of-art study; Building regulation; Evaluation; Inspection; Manufactured building; Mobile homes; Model documents; TN775.

State-of-the-art study; Enforcement; Legislation; Mobiles homes; Regulation; Standards; NBSIR 75-680.

Static; Structural engineering; Subsystems; Vibration; Analysis; Deflection; Design: Dynamic: Experimental; Human sensitivity; Loading functions: Specifications; BSS47.

Statistical analysis; Building materials; Fire tests; Interlaboratory tests; Optical density; Round robin: Smoke: Smoke density chamber: $T N 708$.

Statistical analysis; Storms; Structural engineering; Wind loads; Wind speeds; Building codes; Extreme value distributions; Hurricanes; Probability distribution functions; Reliability; Risk; TN868.

Statistical analysis; Test method standard; ASTM E 84; Building materials; Carpets; Fire tests; Flame spread tests; Interlaboratory evaluation; Round robin; NBSIR 73-125.

Statistics; Structure; Building; Explosion; Frequency; Gas; Gas industry; Progressive collapse; Risk; NBSIR 73-208. 
Statistics; survey; lead; lead paint poisoning; paints; poisoning; retail inventory; NBSIR 73-407.

Steady periodic heat flow; Earth temperature; Probe conduction errors. J. Res. NBS $72 \mathrm{C}$ No. 4.

Steam curing of portland cement mortars; Strength gain of portland cements; Trace elements; Accelerated Curing of cements; Autoclave curing of portland cement mortars; Chemicall composition; Compressive strength of portland cement; Compressive strength of steam-cured cements; Fineness; Heat of hydration; BSS8.

Steel framing; Steel joist floor; Fire test; Floor assembly; Floorceiling assembly; Housing systems; Modular construction; Operation BREAKTHROUGH; NBSIR 73-141.

Steel joist floor; Fire test; Floor assembly; Floor-ceiling assembly; Housing systems; Modular construction; Operation BREAKTHROUGH; Steel framing; NBSIR 73-14I.

Steel plate floors; Burnout tests; Fire endurance; Fire severity; Floor tests; BSSII.

Steel reinforcing bars; Bridge decks; Chloride ions; Deicing salts; Epoxy coatings; Polyvinyl chloride coatings; BSS65.

Steel reinforcing bars; Bridge decks; Corrosion; Creep testing; Epoxy coatings; Polyvinylchloride coatings; NBSIR 73-295.

Steel reinforcing bars: Chlorides; Concrete: Corrosion; Epoxy coatings; Organic coating; TN768.

Steel; Terminal units; Aluminum; Ductwork; Fabric; Fiberglass; Fire tests; High-rise buildings; HVAC systems; NBSIR 73-267.

Steel tube column; Fire endurance; Fire test; Housing system; Multifamily housing; Operation BREAKTHROUGH; Singlefamily attached housing; NBSIR 73-165.

Stiffness; analysis; compressive strength; deflection; design; flexural strength; masonry walls; racking strength; seismic loading; shear strength; shear wall; NBSIR 74-520.

Stiffness; Strength; Structural tests; Sustained load; Transportation; Vibration; Wood-frame; Deflection; Housing; Laboratory; Module; Racking; NBSIR 73-121.

Stiffness: Structural deflections; Vibration; Wind load; Wood frame construction; Building damping; Drift; Dynamics; Earthquake; Frequency; Housing; Lateral resistance; Racking; $\boldsymbol{B} S S 44$.

Stone decay; stone preservation; air pollution; historic structures; laboratory evaluation; natural weathering; NBSIR 74. 444.

Store preservation; air pollution; historic structures; laboratory evaluation; natural weathering; stone decay; NBSIR 74-444.

Storm damage; Asphalt shingles: Built-up roofing; Hail; Roofing: Shingles; $B S S 23$.

Storm doors; Storm windows; Tax credit; Vapor barriers; Weatherstripping; Caulks and sealants; Clock thermostats; Energy conservation; Insulation; Retrofitting; NBSIR 75-795.

Storm windows; Tax credit; Vapor barriers; Weatherstripping; Caulks and sealants; Clock thermostats; Energy conservation; lnsulation; Retrofitting; Storm doors; NBSIR 75-795.

Storms; Structural engineering; Wind loads; Wind speeds; Building codes; Extreme value distributions; Hurricanes; Probability distribution functions; Reliability; Risk; Statistical analysis: TN868.

Strength gain of portland cements; Trace elements; Accelerated curing of cements; Autoclave curing of portland cement mortars; Chemical composition; Compressive strength of portland cement; Compressive strength of steam-cured cements; Fineness; heat of hydration; Steam curing of portland cement mortars; BSS8.

Strength; Structural tests; Sustained load; Transportation; Vibration; Wood-frame; Deflection; Housing; Laboratory; Module; Racking; Stiffness; NBSIR 73-121.

Strength-thickness; Bituminous adhesive; Bituminous built-up membranes; Engineering properties; Laboratory-field comparison; TN473.
Strength; United States; Abnormal loading; Buld ng; Codes, Design criteria; Multistory; Progressive collapse; Risk, Stabilıty; Standards; NBSIR 73-221.

Stress distribution; Stresses; Structural engineernng; Brick, Failure, Failure theories; Masonry; Shear strength; Shear test, Shear walls; NBSIR 75-703.

Stresses; Structural engincering; Brick; Failure; Fallure therorles: Masonry; Shear strength; Shear test; Shear walls, Stress distribution NBSIR 75-703.

Structural connections; Typhoons; Wind loads; Buildings; Code: and standards; Disaster mitigation; Housing, Hurricanes, Low-rise buildings; Natural disaster; N BSIIR 75-790)

Structural deflections: Vibration: Wind load: Wood frame con struction; Building damping: Drift; Dynamics; Farthquake: Frequency; Housing; Lateral resistance; Racking. Stiflncess BSS44.

Structural design; Building system; Column connection; Concrete traixial strength; Ductility; Neoprene bearing pad; Operation BREAKTHROUGH; Performance tests; Precast concrete NBSIR 73-148.

Structural design; building system; column conncction: concrete triaxial strength; ductility; neoprene bearing pad; Operation Breakthrough; performance test; precast concrete; TN811.

Structural design; Structural joists; Building systems; Housing systems; Large-panel structure; Precast concrete construction; Progressive collapse; NBSIR 75-715.

Structural design; Technology Implementation; Wind effects; Wind loads; Codes and Standards; Disaster mitigation; Information transfer; Low-rise buildings; Pressure Transducers; Socioeconomic; BSS56.

Structural design; Turbulence; Wind effects; Wind loads; Aerodynamic forces; Atmospheric boundary layer; Disaster mitigation; $B S S 30$

Structural engineering; Brick; Failure; Failure theories; Masonry; Shear strength; Shear test; Shear walls; Stress distribution; Stresses; NBSIR 75-703.

Structural engineering; Bridge; Building; Codes; Dams; Disaster mitigation; Earthquake damage; Earthquakes; Foundation geology; Highways; Hospital; Housing; Mobile home; Seismic; Standards; BSS40.

Structural engineering: Subsystems; Vibration; Analysis Deflection: Design; Dynamic; Experimental: Human sensitivity: Loading functions; Specifications: Static: BSS 47

Structural engineering; Tides; Wind; Buildings: Failure: Hurricanes; Mobile homes; Roofs; TN569.

Structural engineering; Survey techniques; Buildings; Fire loads; Occupancy live loads; Load surveys; TN858.

Structural engineering; Tides; Wind; Buildings; Disaster mitigation; Failure, Hurricanes; Mobile homes; Roofs; TN569

Structural engineering; Tornadoes; Wind; Buildings; Damage; Disaster mitigation; Dynamic analysis; Earthquakes; Hurricanes; Natural hazards; BSS61.

Structural engineering; Wind effects; Building; Disaster mitıgation; Earthquakes; Hazards; Land use; BSS46.

Structural Engineering, Wind engineering; Wind loads; Accelerations; Buffeting; Building codes; Buildings: Deflections: Dynamic response; Gust factors; BSS74.

Structural engineering; Wind load; Anchorage; Building performance; Disaster mitigation; Glazing; Hailstones; masonry; Mobile homes; Roofs; TN558.

Structural engineering; Wind load; Anchorage: Building performance; Glazing; Hailstones; Masonry: Mobile homes: Roofs: TN558.

Structural engineering; Wind loads; Wind speeds; Building codes: Extreme value distributions; Hurricanes; Probability distribution functions; Reliability; Risk; Statistical analysis; Storms; TN868.

Structural joists; Building systems; Housing systems; Large-panel 
structure; Precast concrete construction; Progressive collapse; Structural design; NBSIR 75-715.

Structural load; Apartment dwelling; Burnout test; Fire load; Fire performance; Flame penetration; Potential heat; BSS 10 .

Structural panel; Fire endurance; Fire test; Flame penetration; Floor assembly; Housing systems; Operation BREAKTHROUGH; Paper honeycomb; NBSIR 73-164.

Structural panel; Fire endurance; Fire test; Flame penetration; Glass reinforced plastic; Housing systems; Interdwelling wall; Modular construction; Operation BREAKTHROUGH; Paper honeycomb; NBSIR 73-166.

Structural panel; Fire endurance; Fire test; Flame-through failure, structural panel; Glass-fabric reinforced plastic; Housing system; Operation BREAKTHROUGH; Paper honeycomb; Roof/ ceiling assembly; NBSIR 73-167.

Structural Response; Wind loads; Buildings; Deflections; Instrumentation; TN873.

Structural sandwich panel; Exterior wall; Fire endurance; Fire test; Housing systems; Operation BREAK THROUGH; Paper honeycomb; Roof/ceiling assembly; NBSIR 73-135.

Structural sandwich panel; Temperature; Testing; Building composite; Building material; Conditioning; Equilibration; Gypsum wallboard; Methodology; Relative humidity; NBSIR 75-767.

Structural sandwich; sustained load; accelerated aging; adhesive bond; ductility; flexural shear; housing systems; local buckling; material variability; moisture conditioning; Operation BREAKTHROUGH; paper honeycomb; BSS5I.

Structural stability; Buckling; Compressive strength; Concrete block walls; Elastic stability; Flexural strength; Masonry walls; Reinforced concrete masonry walls; Slenderness effect; BSS 33 .

Structural stability; Walls; Brick; Cavity walls; Composite walls; Compressive strength; Concrete block; Flexural strength; Masonry; Mortar; Slenderness effects; Standard; BSS34.

Structural tests; Sustained load; Transportation; Vibration; Woodframe; Deflection; Housing; Laboratory; Module; Racking; Stiffness; Strength; NBSIR 73-121.

Structure; Building; Explosion; Frequency; Gas; Gas industry; Progressive collapse; Risk; Statistics; NBSIR 73-208.

Structure, testing; Building; Connections; Housing; Neoprene; Performance criteria; Performance evaluation; Performance testing; Reinforced concrete; Standard tests; TN706.

Structures; Building codes; Buildings; Disaster mitigation; Earthquakes; hazards; natural disasters; TN807.

Structures; Windstorms; Buildings; Construction; Design; Developing countries; Disaster mitigation; Low-cost housing; Natural disasters; BSS48.

Subfloors; underlayment; wood; wood joists; concentrated load; deflection; floor; hardboard; housing; impact energy; Operation BREAKTHROUGH; plywood; BSS 52.

Subflooring; Underlayment; Wood-frame construction; Concentrated-load capacity; Evaluation criteria; Floors; Hardboard; Load capacity; Operation BREAKTHROUGH; Performance criteria; Plywood subflooring; NBSIR 73-116.

Subflooring; underlayment; wood-frame construction; evaluation criteria; floors; hardboard; load capacity, performance criteria; plywood subflooring; $B S S 53$.

Subfloors; Underlayment; Wood; Wood joists; Concentrated loads; Deflection; Floor hardboard; Housing; Impact energy; Operation BREAKTHROUGH; Plywood; NBSIR 73-187.

Substrates: Surface preparation: Varnish: Water-thinned; Application; Coatings: Coating systems; Corrosion-inhibiting; Federal specifications; Fire-retardant: Lacquer: Latex: Multicolor; Organic coatings; Paint; Pigments; Polymers; Properties; Resins; Selection; BSS7.

Subsystems; Vibration; Analysis; Deflection; Design: Dynamic; Experimental; Human sensitivity; Loading functions;
Specifications; Static; Structural engineering; BSS47.

Sulfate expansion; Autoclave expansion; Cement; Concrete; Heat of hydration; Portland cement; BSS5.

Sunshine; View; Windowless; Windows; Daylight; Fenestration; Psychological; Solar glass; Spaciousness; BSS70.

Surface hardness; Compressive strength; Concrete; Flexural strength; Formwork removal; Nondestructive testing; NBSIR 75-729.

Surface-impact resistance; Test methods; Abrasion resistance; Chemical resistance; Cigarette-burn resistance; Cleanability and soilability; Concentrated static-load capacity; Performance characteristics; Performance level; Sanitary plumbing fixtures; Scratch resistance; Stain resistance; $B S S 22$.

Surface preparation; Surface refinishing; Cost analysis; Hazard elimination; Housing; Lead based paint; Materials; NBSIR 73-242.

Surface preparation; Surface refinishing; Water wash paint removal; Cost analysis; Housing; Lead based paint, lead poisoning; NBSIR 74-438.

Surface preparation; Varnish; Water-thinned; Application: Coatings; Coating systems; Corrosion-inhibiting; Federal specifications; Fire-retardant; Lacquer; Latex; Multicolor; Organic coatings; Paint; Pigments; Polymers; Properties; Resins; Selections; Substrates; BSS7.

Surface refinishing; Cost analysis; Hazard elimination; Housing; Lead based paint; Materials; Surface preparation; NBSIR 73-242.

Surface refinishing; Water wash paint removal; Cost analysis; Housing; Lead based paint, lead poisoning; Surface preparation; NBSIR 74-438.

Survey; lead; lead paint poisoning; paints; poisoning; retail inventory; statistics: NBSIR 73-407.

Survey techniques; Buildings; Fire loads; Occupancy live loads; Load surveys; Structural engineering; TN858.

Survey; Water hardness; Corrosion; Corrosion control; Metallic piping; Nondestructive evaluation; NBSIR 75-923.

Sustained load; aecelerated aging; adhesive bond; ductility; flexural shear; housing systems; local buckling; material variability; moisture conditioning; Operation BREAKTHROUGH: paper honeycomb; structural sandwich; BSS5I.

Sustained load; Anchors; Concrete slabs; Design loads; Fatigue; Inserts; Pull-out loads; BSS42.

Sustained loads; Tensile shear; Adhesive bond; Aging; Composites; Compression; Flexure; Glass fiber; Housing system; Innovations; Laminate; Operation BREAKTHROUGH; Racking; Reinforced plastics; Reinforced polyester; NBSIR 73-188.

Sustained load; Transportation; Vibration; Wood-frame; Deflection; Housing; Laboratory; Module; Racking; Stiffness; Strength; Structural tests; NBSIR 73-121.

Switzerland; Building research; Buildings; Cooperation; Housing; International; NBSIR 73-288.

\section{$\mathbf{T}$}

Tax credit; Vapor barriers; Weatherstripping; Caulks and sealants; Clock thermostats; Energy conservation; Insulation; Retrofitting; Storm doors; Storm windows; NBSIR 75-795.

Technology implementation; Wind effects; Wind loads; Codes and standards; Disaster mitigation; Information transfer; Low-rise buildings; Pressure transducers; Socio-economic; Structural design; $B S S 56$.

Tee-beams; Composite concrete construction; Prestressed concrete beams; $B S S 31$ :

Temperature; Composite wall panel; Condensation; Humidity; Moisture; Pressure; NBSIR 73-220.

Temperature measurement; Air-conditioning capacity; Air-mixing devices; Forced air-mixing; Turbulence; Mixer effectiveness; Apparatus design; Air properties. J. Res. NBS, $70 \mathrm{C}$ No. 1 . 
Temperature measurement; Temperature pattern; Diameter ratio; Mixing effectiveness; Square-edged orifice; BSS I 2.

Temperature measurement; Thermistor: Thermocouple: Conduction error: Radiation error: Resistance thermometer: BSS26.

Temperature pattern; Diameter ratio; Mixing effectiveness: Square-edged orifice; Temperature measurement; BSS I2.

Temperature predictions: Thermal analysis; Thermal behavior: Transient heat flows; Building heat transfer; Computer programs; Dynamic thermal performance; Heat flow analysis; Heating and cooling loads; BS.S45.

Temperature predictions; Thermal analysis; Thermostat set-back; Transient heat flows; Air leakage measurement; Building heat transfer; Computer programs; Dynamic thermal performance; Heat flow analysis; Heating and cooling loads; BSS57.

Temperature; Testing; Building composite; Building material; Conditioning; Equilibration; Gypsum wallboard; Methodology; Relative humidity; Structural sandwich panel; NBSIR 75-767.

Temperature: Thermal conductivity: Thermal diffusivity: Thermal resistivity: Thermophysical properies: Conductance: Conductivity; Contact conductance; Contact resistance; Electrical conductivity; Electrical resistivity; Heat transfer; Lorenz function; Resistivity; SP302.

Temperature; Uniformity; Effectiveness; Forced mixing; Mixing device; Pressure drop; BSS27.

Temperature; Wind direction; Wind speed; Air contamination Design conditions; Earthquake risk; Evaluation; Ground temperature; Humidity; Noise level; Operation BREAKTHROUGH; Precipitation; Solar radiation; NBSIR 73-144.

Tensile shear; Adhesive bond; Aging; Composites; Compression; Flexure; Glass fiber; Housing system; Innovations; Laminate; Operation BREAKTHROUGH; Racking; Reinforced plastics; Reinforced polyester; Sustained loads; NBSIR 73-188.

Terminal units; Aluminum; Ductwork; Fabric; Fiberglass; Fire tests; High-rise buildings; HVAC systems; Steel; NBSIR 73-267.

Tensile fatigue; Test methods; Bituminous roof membranes; Fatigue testing; Flexural fatigue; Performance criteria; Roofing temperature effects; TN863.

Testing; Accelerated aging; Aging of buildings; Building components; Climate; Criteria; Deterioration; Durability; Materials; Mechanisms; Nondestructive testing; NBSIR 73-l32.

Testing; Building composite; Building material; Conditioning; Equilibration; Gypsum wallboard; Methodology; Relative humidity; Structural sandwich panel; Temperature; NBSIR 75-767.

Test loads; Hydraulic; Trap-seal reduction detector; Trap-seal retention; Crossflow; Field testing, plumbing; Performance criteria, plumbing; Performance, functional; Single-stack drainage; Siphonage, induced; Siphonage, self; NBSIR 73-161.

Test method standard; ASTM E 84; Building materials; Carpets; Fire tests; Flame spread tests; Interlaboratory evaluation; Round robin; Statistical analysis; NBSIR 73-125.

Test method; Visibility; Building materials; Fire; Fire services; Smoke; Smoke density chamber: Smoke potential: TN757.

Test method; Wall panels; Walls; Compression; Eccentric loading; Flat-end; Kern; Loading rate; Pin-end; NBSIR 75-779.

Test methods; Abrasion resistance; Chemical resistance; Cigarette-burn resistance; Cleanability and soilability; Concentrated static-load capacity; Performance characteristics; Performance level; Sanitary plumbing fixtures; Scratch resistance; Stain resistance; Surface-impact resistance; BSS22.

Test methods; Accelerated laboratory tests: Double-glazed window units; Factory-sealed insulating glass units: Field performance tests, correlation with laboratory tests: Sealant performance: Standardized testing; BSS2O.

Test methods; Bituminous roof membranes; Fatigue testing; Flexural fatigue; Performance criteria; Roofing temperature effects; Tensile fatigue; TN863.
Test methods; bituminous roof membrancs, performance at tributes; performance criteria; physical and engrncering properties: B.SS55.

Test methods: Urban planning; User needs; Buildng systems. Performance of buildings: Standards: BSSSI

Test methods; walls: building construction: complete buildıngs floors; roofs; standardization; BSS58.

Test procedure; adhesives: air-inflatable shelter sections, cluth webs: polyester and nylon fabrics. sewn seams. sеun seam strapping; solar heat load. NBSIR 74-467

Tests; user needs; carpets: floor coverıngs, governunent: performance: procurement; specifications: standards: 11822

Testing plumbing systems: vents for plumbing: hydraulic criterıa for plumbing: hydraulic test loads: plumbing-vent st/ng: reduced-size vents: sanitary DWV systems: secondary ventilation: BSS 49

Theory of cement hardening: Time of set; Vane-shear apparatus: Cement: Cement mortar; Cement paste: Early strength: $t$-alse set: Hardening of cement: Hydration: Shear resistance: BSS 28 .

Thermal analysis: Thermal behavior; Transient heat flows: Building heat transfer: Computer programs: Dynamic thermal performance; Heat flow analysis: Heating and cooling loads: Temperature predictions; BSS 45 .

Thermal analysis; Thermostat setback; Transient heat flows; Air leakage measurement; Building heat transfer; Computer programs; Dynamic thermal performance; Heat flow analysis; Heating and cooling loads; Temperature predictions; BSS57.

Thermal behavior; Transient heat flows; Building heat transter: Computer programs: Dynamic thermal performance: Heat flow analysis: Heating and cooling loads; Temperature predictions: Thermal analysis: BSS45.

Thermal bridges: Thermal insulation: U-values of walls: Floors and panels; Moisture condensation; TN710-7.

Thermal comfort requirement; Curtains, effect of; Environmental conditions; Glazed openings; Human response: TN710-4.

Thermal conductivity, Heat conduction; Heat generation; heat transfer; Nuetron absorption; Radioactive decay. J. Res. NBS, $71 \mathrm{C} \mathrm{No} .4$.

Thermal conductivity: Thermal diffusivity: Thermal resistivity: Thermophysical properties: Conductance: Conductivity: Contact conductance: Contact resistance; Electrical conductivity: Electrical resistivity: Heat transfer; Lorenz function: Resistivity; Temperature; SP302.

Thermal convection; Ventilation; Air infiltration and extraction, airtightness: Discomfort index; Duct system, collective and individual branch; Flow rates; Noise; Pressure-loss-depression; TN710-3.

Thermal diffusivity of earth; Earth temperature; Least squares techniques. J. Res. NBS, 7IC No. 1.

Thermal diffusivity; Thermal resistivity; Thermophysical properties; Conductance: Conductivity: Contact conductance: Contact resistance; Electrical conductivity; Electrical resistivity; Heat transfer; Lorenz function; Resistivity: Temperature; Thermal conductivity; SP302.

Thermal efficiency; benefit-cost analysis; building economics: building envelope; economic analysis: economic efficiency energy conservation: engineering economics: insulation: life cycle costs; marginal analysis; $B S S 64$

Thermal insulation; Flat roofs: Heat transfer: Moisture transfer: BSS37.

Thermal insulation: U-values of walls: Floors and panels: Moisture condensation: Thermal bridges; $T \times 7$ 10-7.

Thermally induced forces; Thermal-shock resistance factor; Bituminous built-up roofing; Built-up roofing membranes; Roofing membranes; BSS9.

Thermal mechanical analysis (TMA); Thermal properties; Thermogravimetric analysis (TGA): Thermoplastic pipe; Chlorinated polyvinyl chloride; Hardness; Internal stress; Polyvinyl chloride; NBSIR 74-610. 
Thermal Movement; Built-up roofing; Nighttime cooling; Radiative cooling; Solar Heating; TN231.

Thermal performance; Thermal storage; Thermal test; Solar energy; Standard, standaru test; iv $\bar{B} \backslash \bar{K} / 4-634$.

Thermal performance; Solar collector; Solar energy; Solar radiation; Standard; Standard test; NBSIR 74-635.

Thermal properties; Thermogravimetric analysis (TGA); Thermoplastic pipe; Chlorinated polyvinyl chloride; Hardness; Internal stress; Polyvinyl chloride; Thermal mechanical analysis (TMA); NBSIR 74-610.

Thermal resistance; Thermal transmittance; Windows; Acoustics; Air infiltration; Air leakage; Architectural acoustics; Building acoustics; Doors; Energy conservation; heat loss from buildings; Heat transfer; Sound transmission Inss: ReS77.

Thermal resistance; Wood floor; Wuvi joist; Fire endurance; Fire test; Flame through; Full scale; Housing; Operation BREAKTHROUGH; Single-family residences; Small scale; NBSIR 73-263.

Thermal resistivity: Thermophysical properties; Conductance; Conductivity; Contact conductance; Contact resistance: Electrical conductivity; Electrical resistivity: Heat transfer: Loreız function; Resistivity; Temperature: Thermal conductivity; Thermal diffusivity; SP302.

Thermal-shock resistance factor; Bituminous built-up roofing; Built-up roofing membranes; Roofing membranes; Thermally induced forces; BSS9.

Thermal storage: Thermal test: Solar emergy; Standard; Standard test; Thermal performance; NBSIR 74-634.

Thermal/structural performance of piping; Thermoplastic piping in in plumbing; Functional performance of piping; Performance characteristis for piping; BSS68.

Thermal/structural performance of piping; Thermoplastics in plumbing; Fire performance of piping; Functional performance of piping; Performance characteristics for piping; NBSIR 74-531.

Thermal test; Solar energy; Standard; Standard test; Thermal performance; Thermal storage; NBSIR 74-634.

Thermal transmittance; Windows; Acoustics; Air infiltration; Air leakage; Architectural acoustics; Building acoustics; Doors; Energy conservation; Heat loss from buildings; Heat transfer; Sound transmission loss; Thermal resistance; BSS77.

Thermistor; Thermocouple; Conduction error; Radiation error; Resistance thermometer; Temperature measurement; BSS26.

Thermocouple: Conduction error; Radiation error; Resistance thermometer; Temperature measurement; Thermistor; BSS26.

Thermodynamic properties: Computer algoritimm; Psychrometrics; Saturated and unsaturated moist air; $B S S 21$.

Thermogravimetric analysis (TGA); Thermoplastic pipe; Chlorinated polyvinyl chloride; Hardness; Internal stress; Polyvinyl chloride; Thermal mechanical analysis (TMA); Thermal properties; NBSIR 74-610.

Thermophysical properties; Conductance; Conductivity; Contact conductance; Contact resistance; Electrical conductivity; Electrical resistivity; Heat transfer; Lorenz function; Resistivity: Temperature: Thermal conductivity; Thermal diffusivity; Thermal resistivity; SP302.

Thermoplastic pipe; Chlorinated polyvinyl chloride; Hardness; Internal stress; Polyvinyl chloride; Thermal mechanical analysis (TMA); Thermal properties; Thermogravimetric analysis (TGA); NBSIR 74-610.

Thermoplastic piping; ABS; Coefficient of expansion; CPVC; Glass transiton temperature; Hardness; Polybutene; PB; Polyvinyl chloride; PVC; Residual stress; NBSIR 74-629.

Thermoplastic piping in plumbing; Fire performance of piping; Functional performance of piping; Performance characteristics for piping; Thermal/structural performance of piping; BSS68.

Thermoplastics in plumbing; Fire performance of piping; Functional performance of piping; Performance characteristics for piping; Thermal/structural performance of piping; NBSIR 74-531.

Thermostat sethack: Transient heat flows; Air leakage measurement; Builuists iteat transfer; Computer programs; Dynamic thermal performance; Heat flow analysis; Heating and cooling loads; Temperature predictions; Thermal analysis; BSS57.

Tides; Wind; Buildings; Disaster mitigation; Failure; Hurricanes; Mobile homes; Roofs; Structural engineering; TN569.

Time of set; Vane-shear apparatus; Cement; Cement mortar; Cement paste; Early strength; False set; Hardening of cement; Hydration; Shear resistance; Theory of cement hardening: $R S S 28$.

Tolerance; Conventions; Dimensional coordination; Industrialized production; Modular coordination; TN710-1.

Tornadoes; total cost minimization; benefit-cost analysis; disaster mitigation; earthquakes; economics; efficient; floods; hurricanes; natural disasters; optimal; NBSIR 74-473.

Tornadoes; Wind; Buildings; Damage; Disaster mitigation; Dynamic analysis; Earthquakes; Hurricanes; Natural Hazards; Structural engineering; BSS6I.

Total cost minimization; benefit-cost analysis; disaster mitigation; earthquakes; economics; efficient; floods; hurricanes; natural disasters; optimal; tornadoes; NBSIR 74-473.

Total energy systems; Utilities for housing; Utility system performance; Air-conditioning; Air pollution; Central utility systems; Data acquisition system; Efficiencies; Electrical power; Energy costs; Fuel utilization; Heat recovery; NBSIR 75-711.

Toxic combustion products; Toxicity; Washability; Water vapor permeance; Abrasion; Adhesion: Colorfastness; Covering; Flash point; Flame spread; Impact resistance; Lead paint poisoning; Materials; Performance; Properties; Scratch resistance; Smoke generation; TN808.

Toxic elements in paints; Analytical methods; Antimony; Arsenic; Cadmium; Lead; Mercury; Review; Selenium; NBSIR 73-251.

Toxic gases: Aircraft materials: Combustion products; Fire tests; Interior finish; Smoke: BSS 18.

Toxic gases; Fire endurance; Fire test; Housing systems; Interdwelling wall; Load failure; Modular construction; Operation BREAKTHROUGH; Polyurethane foam; NBSIR 73-170.

Toxic gases; Fire retardant; Fire test; Heat release ignition; Mattress; Smoke; NBSIR 73-177.

Toxic gases; Vent; Waste; ABS; Drain; Fire endurance; Fire spread; Fire test; Plastic piping; PVC; Smoke; NBSIR 74-449.

Toxicity; Washability; Water vapor permeance; Abrasion; Adhesion; Colorfastness; Covering; Flash point; Flame spread; Impact resistance; Lead paint poisoning; Materials; Performance; Properties; Scratch resistance; Smoke generation; Toxic combustion products; TN808.

Trace elements; Accelerated curing of cements; Autoclave curing of portland cement mortars; Chemical composition; Compressive strength of portland cement; Compressive strength of steamcured cements; Fineness; Heat of hydration; Steam curing of portland cement; Mortar; Strength gain of portland cements; BSS8.

Trace elements; Cement composition; Chemical composition of portland cements; Cracking of portland cements; Cracking resistance of cements; Expansion-shrinkage ratios; Portland cement; Portland cement concrete; Shrinkage of concrete; Shrinkage of portland cements; BSSI5.

Trace elements; Portland cement; Spectrographic analyses; Cement; Concrete; Material properties; Physical properties; BSS2.

Transient- heat flows; Air leakage measurement; Building heat transfer; Computer programs; Dynamic thermal performance; Heat flow analysis; Heating and cooling loads; Temperature predictions; Thermal analysis; Thermostat setback; BSS57.

Transient heat flows; Building heat transfer; Computer programs; Dynamic thermal performance; Heat flow analysis; Heating and 
cooling loads; Temperature predictions; Thermal analysis; Thermal behavior; BSS45.

Transportation; Vibration; Wood-frame; Deflection; Housing; Laboratory; Module; Racking; Stiffness; Strength; Structural tests; Sustained load; NBSIR 73-121.

Trap-seal reduction detector; Trap-seal retention; Crossflow; Field testing, plumbing; Performance criteria, plumbing; Performance, functional; Single-stack drainage; Siphonage, induced; Siphonage, self; Test loads; Hydraulic; NBSIR 73-16I.

Trap-seal retention; Crossflow; Field testing, plumbing; Performance criteria, plumbing; Performance, functional; Sirgle-stack drainage; Siphonage, induced; Siphonage, self; Test loads; Hydraulic; Trap-seal reduction detector; NBSIR 73-161.

Trap-seal retention; Venting; Venting criteria; Vents, reduced size; DWV; Performance testing; Reduced-size vents; BSS60.

Turbulence; Disk; Pressure fluctuations; Stagnation point TN563.

Turbulence, Mixer effectivness; Apparatus design; Air properties; Temperature measurement; Air-conditioning capacity; Air mixing devices, Forced air-mixing. J. Res. NBS, $70 \mathrm{C}$ No. $I$.

Turbulence; Wind effects; Wind loads; Aerodynamic forces; Atmospheric boundary layer; Disaster mitigation; Structural design; BSS30.

Turbulent flow; Buoyant plume; Diffusion flame; Fire; Flame height; Mathematical modeling; NBSIR 73-115.

Typhoons; Wind loads; Buildings; Codes and standards; Disaster mitigation; Housing; Hurricanes; Low-rise buildings; Natural disaster; Structural connections; NBSIR 75-790

\section{U}

Underlayment; Wood-frame construction; Concentrated-load capacity; Evaluation criteria; Floors; Hardboard; Load capacity; Operation BREAKTHROUGH; Performance criteria; Plywood subflooring; Subflooring; NBSIR 73-116.

Underlayment; wood-frame construction; evaluation criteria; floors; hardboard; load capacity; performance criteria; plywood subflooring; subflooring; BSS53.

Underlayment; wood; wood joists; concentrated load; deflection; floor; hardboard; housing; impact energy; Operation BREAKTHROUGH; plywood; subfloors; BSS52.

Underlayment; Wood; Wood joists; Concentrated loads; Deflection Floor hardboard; Housing; Impact energy; Operation BREAKTHROUGH; Plywood; Subfloors; NBSIR 73-187.

Uniformity; Effectiveness; Forced mixing; Mixing device; Pressure drop; Temperature; BSS 27.

United Joviet Socialist Republics; Building economics; Building systems; Construction industry; Housing; Precast concrete; Production capacity; Production management: Production methods; Standardization; SP334.

United States; Abnormal loading; Building; Codes; Design criteria; Multistory; Progressive collapse; Risk; Stability; Standards; Strength; NBSIR 73-22I.

Urban health problems; Childhood diseases; Estimation; Health problems; Lead; Lead paint, lead paint poisoning, Lead poisoning; Mathematical modeling; Models; TN746.

Urban planning; User needs; Building systems: Performance of buildings; Standards; Test methods; BSSI.

Use of computers; Building heat transfer analysis; Energy usage: Environmental engineering; Heating and air conditioning: BSS39.

User fees; Water pollution; Cost sharing; Efficiency; Equity; Financing; Non-plant treatment; Sewage treatment; NBSIR 74-479.

User needs; Building systems; Performance of buildings; Standards; Test methods; Urban planning; BSS1.

User needs; Carpets; Durability; Economics; Field studies; Flooring; Floor coverings; Life-cost; Maintenance; TN783.
User needs; carpets; floor coverings; government; performance: procurement; specifications; standards; tests. TN 822

User requirements: Buildings; ( omponents Desugn procedures: Experience in use; Materials. I'ertormance evaluation, Der formance requirements: . S/"36, I. Volume' I.

User requirements; Buildings; ( omponents. I) eseng procedures. Experience in use; Materials: l'erformance cvaluatton: Performance requirements: SP.361. Volume 2

Uses; Color; Environment; Experimenting with; Harmony; Hues; Illumination; Light; Personal uses; Relationship; CIS\%.

Utilities; Economic incentives; Housing development; Integrated utilities; MIUS; NBSIR 75-72I.

Utilities for housing; Utility system performance; Alr-conditioning; Air pollution; Central utility systems; Data acquisition system; Efficiencies; Electrical power; Energy conservation; Energy costs; Fuel utilization; Heat recovery; Total energy systems; NBSIR 75-7II.

Utility system performance; Air-conditioning; Air pollution; Central utility systems; Data acquisition system; Efficiencies; Electrical power; Energy conservation; Energy costs; Fuel utilization; Heat recovery; Total energy systems; Utilities for housing; NBSIR 75-7II.

U-value; Building classification; Building thermal mass; Building thermal performance; Building thermal time constant; Housing systems; Industrialized housing; Mass per unit area; Operation BREAKTHROUGH; NBSIR 75-678.

U-values of walls; Floors and panels; Moisture condensation; Thermal bridges; Thermal insulation; TN $710-7$

V

Vane-shear apparatus; Cement; Cement mortar: Cement paste: Early strength; False set; Hardening of cement; Hydration; Shear resistance; Theory of cement hardening: Time of set: BSS28.

Vapor barriers; Weatherstripping; Caulks and sealants; Clock thermostats; Energy conservation; Insulation; Retrofitting; Storm doors; Storm windows; Tax credit; NBSIR 75-795.

Variable prestress; Creep: Loss of prestress; Prestressed concrete; Relaxation; Shrinkage; BSS / 3

Varnish; Water-thinned: Application; Coatings: Coating systems; Corrosion-inhibiting: Federal specifications: Fire-retardant; Lacquer: Latex; Multicolor: Organic coatings: Paint; Pigments: Polymers: Properties: Resins: Selection: Substrates; Surface preparation; BSS7.

Vent; Devices; Manifold; Plumbing system; TV253.

Ventilation; Air infiltration and extraction, airtightness; Dıscom fort index; Duct system, collective and individual branch: Flow rates; Noise; Pressure-loss-depression: Thermal convection: TN710-3.

Ventilation; Exchanger dimensions: Frost formation; Heat exchanger; Heating costs: Mechanical svstems: Pollution: Pressure loss: TN710-5

Ventilation; Wind; Air Inlet: Discomfort index: Draft: Outside wall: $T N 710-6$

Venting criteria; Vents, reduced size; DWV; Performance testing; Reduced-size vents; Trap-seal retention; Venting; BSS60.

Venting; Venting criteria; Vents, reduced size; DWV; Performance testing; Reduced-size vents; Trap-seal retention; BSS60.

Vents for plumbing: hydraulic criteria for plumbing: hydraulic test loads; plumbing-vent sizing; reduced-size vents; sanitary DWV systems; secondary ventilation; testing plumbing systems; BSS49.

Vents, reduced size; DWV; Performance testing: Reduced-size vents; Trap-seal retention; Venting; Venting criteria; BSS60.

Vent; Waste; ABS; Drain; Fire endurance; Fire spread; Fire test; Plastic piping; PVC; Smoke; Toxic gases; NBSIR 7\$-449

Vibration; Analysis; Deflection: Design: Dynamıc; Experımental; Human sensitivity; Loading functions: Specifications: 
Static: Structural engineering; Subsystems; BSS47.

Vibration; Analysis; Experimental; Floor systems; Human response; Spectral analysis; NBSIR 75-951.

Vibration; Wind load; Wood frame constructıon; Buıldıng damping: Drift; Dynamics; Earthquake: Frequency; Housing; Lateral resistance; Racking; Stiffness; Structural deflections; BSS44.

Vibration; Wood-frame; Deflection; Housing; Laboratory; Module; Racking; Stiffness; Strength; Structural tests; Sustained load; Transportation; NBSIR 73-121.

View; Windowless; Windows; Daylight; Fenestration; Psychological; Solar glass; Spaciousness; Sunshine; BSS70.

Vision; Bibliography; Color; Color codes; Color measurement; Colorimetry; Spectrophotometry; SP 393.

Visibility; Building materials; Fire; Fire services: Smoke: Smoke density chamber; Smoke potential; Test method: TN757.

\section{W}

Wall and ceiling; Carpets; Flame spread; Kitchen cabinets; Operation BREAKTHROUGH; Smoke generation; NBSIR 73-228.

Wall panels; Walls; Compression; Eccentric loading; Flat-end; Kern; Loading rate; Pin-end; Test method; NBSIR 75-779.

Walls; Brick; Cavity walls; Composite walls; Compressive strength; Concrete block; Flexural strength; Masonry: Mortar; Slenderness effects; Standards; Structural stability BSS34.

Walls; building construction; complete buildings; floors; roofs; standardization; test methods; $B S S 58$.

Walls; Compression; Eccentric loading; Flat-end; Kern; Loading rate; Pin-end; Test method; Wall panels; NBSIR 75-779.

Walls; Facade; Noise; Sound insulation; Sound pressure level; TN710-2

Wall system; Accelerated aging; Compression; Environmental conditionss; Flexure; Housing system; Operation BREAKTHROUGH; Polyurethane foam; Sandwich construction; NBSIR 73-105.

Washability; Water vapor permeanse; Abrasion; Adhesion; Colorfastness; Covering; Flash point; Flame spread; Impact resistance; Lead paint poisoning; Materials; Performance; Properties; Scratch resistance; Smoke generation; Toxic combustion products; Toxicity; TN808.

Waste; ABS; Drain; Fire endurance; Fire spread; Fire test; Plastic PVC; Smoke; Toxic gases; Vent; NBSIR 74-449.

Water hardness; Corrosion; Corrosion control; Metallic piping; Nondestructive evaluation; Survey; NBSIR 75-923.

Water pollution; cost sharing; efficiency; equity; financing; nonplant treatment;sewage treatment; user fees; NBSIR 74-479.

Water-proofing materials; Water-repellent materials; Accelerated weathering; Durability of water-proofing materials; Masonry; Performance criteria; TN883.

Water-repellent materials; Accelerated weathering; Durability of water-proofing materials; Masonry; Performance criteria; Water-proofing materials; TN883.

Water-thinned; Application; Coatings; Coating systems; Corrosion-inhibiting; Federal specifications; Fire-retardant; Lacquer; Latex; Multi-olor; Orgaic coatings; Paint; PIgments; Polymers; Properties; Resins; Selection; Substrates; Surface preparation; Varnish; BSS7.

Water vapor permeance; Abrasion; Adhesion; Colorfastness; Covering; Flash point; Flame spread; Impact resistance; Lead paint poisoning; Materials; Performance; properties; Scratch resistance; Smoke generation; Toxic combustion products; Toxicity; Washability; TN808.

Water wash paint removal; Cost analysis; Housing; Lead based paint, lead poisoning; Surface preparation; Surface refinishing; NBSIR 74-438.
Weather resistance; Acid resistance; Color; Continuity of coating; Porcelain enamel; TN707.

Weather resistance; Acid resistance; Color; Gloss; pH; Porcelain enamel; Relative humidity; BSS4.

Weather resistance; acid resistance; color; gloss; $\mathrm{pH}$; porcelain enamel; relative humidity; $B S S 50$.

Weather resistance; Acid resistance; Color; Gloss: Porcelain enamel; BSS 38 .

Weather resistance; Color; Gloss; Porcelain enamel on aluminum; BSS29.

Weathering; Additive; Asphalt; Durability; Felt; Stabilizer; BSS 24 .

Weathering factors; accelerated aging; building components and materials; climatological data; durability; environmental factors; long-term tests; short-term tests; TN838.

Weathering of plastics; Manufacturing Chemist's Association (MCS); Performance of plastics outdoors; Plastics; NBSIR 73-146.

Weatherstripping; Caulks and sealants; Clock thermostats; Energy conservation; Insulation; Retrofitting; Storm doors; Storm windows; Tax credit; Vapor barriers; NBSIR 75-795.

Wind; Air inlet; Discomfort index: Draft; Outside wall; Ventilation; TN710-6.

Wind; Buildings; Disaster mitigation; Failure Hurricanes; Mobile homes; Roofs; Structural engineering; Tides; TN569.

Wind; Buildings; Damage; Disaster mitigation; Dynamic analysis; Earthquakes; Hurricanes; natural Hazards; Structural engineering; Tornadoes; BSS61.

Wind direction; Wind speed; Air contamination; Design conditions; Earthquake risk; Evaluation; Ground temperature; Humidity; Noise level; Operation BREAKTHROUGH; Precipitation; Solar radiation; Temperature; NBSIR 73-144.

Wind; Disaster mitigation; Buildings; Failure; Hurricanes; Mobile homes; Roofs; Structural engineering; Tides; TN569.

Wind effects; Building; Disaster mitigation; Earthquakes; Hazards; Land use; Structural engineering; BSS46.

Wind effects; Wind loads; Aerodynamic forces; Atmospheric boundary layer; Disaster mitigation; Structural design, Turbulence; $B S S 30$

Wind effects; Wind loads; Codes and standards; Disaster mitigation: Information transfer; Low-rise buildings; Pressure transducers; Socio-economic; Structural design; Technology implementation; BSS56.

Wind engineering; Wind loads; Accelerations; Buffeting; Building codes; Buildings; Deflections; Dynamic response; Gust factors; Structural engineering; $B S S 74$.

Wind load; Anchorage; Building performance; Disaster mitigation; Glazing; Hailstones; Masonry; Mobile homes; Roofs; Structural engineering; TN558.

Wind load; Wood frame construction; Building damping; Drift; Dynamics; Earthquake; Frequency; Housing; Lateral resistance; Racking; Stiffness; Structural deflections; Vibration; $B S S 44$.

Wind loads; Accelerations; Buffeting; Building codes; Buildings; Deflections; Dynamic response; Gust factors; Structural engineering; Wind engineering; $B S S 74$.

Wind loads; Aerodynamic forces; Atmospheric boundary layer; Disaster mitigation; Structural design; Turbulence; Wind effects; $B S S 30$.

Wind loads; Building technology; Cooperation; Fire safety; Hydraulics; NBSIR 74-618.

Wind loads; Building codes and standards; Disaster mitigation; Housing; Hurricanes; Low-rise buildings; natural disaster; Structural connections; Typhoons; NBSIR 75-790.

Wind loads; Buildings; Deflections; Instrumentation; Structural response; Wind loads; TN873.

Wind loads; codes and standards; Disaster mitigation; Information transfer; Low-rise buildings; Pressure transducers; Socio- 
economic; Structural design; Technology implementation, Wind effects; BSS56.

Wind loads; cooperative programs; fire safety; hydraulics; international building technology; NBS/R 74-497.

Wind loads; Wind speeds; Building codes; Extreme value distributions; Hurricanes; Probability distribution functions; Reliability; Risk; Statistical analysis; Storms; Structural engineering; TN868.

Wind loads; Wind tunnel modeling; Buildings; Construction; Data acquisition equipment; Design criteria; Disaster mitigation; Extreme winds; Information transfer; Instrumentation; NBSIR 74-567.

Wind loads; wind tunnels; aerodynamics; boundary layers; buildings; codes and standards; TN 852 .

Windowless; Windows; Daylight; Fenestration; Psychological; Solar glass; Spaciousness; Sunshine; View; BSS70.

Wind speed; Air contamination; Design conditions; Earthquake risk; Evaluation; Ground temperature; Humidity; Noise level; Operation BREAKTHROUGH; Precipitation; Solar radiation; Temperature; Wind direction; NBSIR 73-144.

Wind speeds; Building codes; Extreme value distributions; Hurricanes; Probability distribution functions; Reliability; Risk; Stat ist ical analysis; Storms; Structural engineering; Wind loads; TN868.

Windows; Acoustics; Air infiltration; Air leakage; Architectural acoustics; Building acoustics; Doors; Energy conservation; Heat loss from buildings; Heat transfer; Sound transmission loss; Thermal resistance; Thermal transmittance; BSS77.

Windows; Daylight; Fenestration; Psychological; Solar glass; Spaciousness; Sunshine; View; Windowless; $B S S 70$.

Windstorms; Buildings; Construction; Design; Developing countries; Disaster mitigation; Earthquake; Low-cost housing; Natural disasters; Structures; BSS48.

Wind tunnel; Construction; Design criteria; Disaster mitigation; Extreme winds; Full-scale test buildings; Housing; Instrumentation; NBSIR 74-582.

Wind tunnel modeling; Buildings; Construction; Data acquisition equipment; Disaster mitigation; Design criteria; Extreme winds; Information transfer; Instrumentation; Wind loads; NBSIR 74-567.

Wind tunnels; aerodynamics; boundary layers; buildings; codes and standards; wind loads; TN852.

Wood fibers; Asphalt; Asplund; Felt; Mineral-surfaced roll roofing; Shingles; TN477.

Wood floor; Wood joist; Fire endurance; Fire test; Flame through; Full scale; Housing; Operation BREAKTHROUGH; Singlefamily residences; Small scale; Thermal resistance; NBSIR 73-263.

Wood frame construction: Building damping: Drift; Dynamics: Earthquake: Frequency; Housing; Lateral resistance: Racking: Stiffness: Structural deflections: Vibration; Wind load; BSS44.

Wood-frame construction; Concentrated-load capacity; Evaluation criteria; Floors; Hardboard; Load capacity; Operation BREAKTHROUGH; Performance criteria; Plywood subflooring; Subflooring; Underlayment; NBSIR 73-116.

Wood-frame construction; Evaluation criteria; Floors; Hardboard; Load capacity; Performance criteria; Plywood subflooring; Subflooring, Underlayment; BSS53.

Wood-frame; Deflection; Housing; Laboratory; Module; Racking; Stiffness; Strength; Structural tests; Sustained load; Transportation; Vibration; NBSIR 73-121.

Wood joists; concentrated load; deflection; floor; hardboard; housing; impact energy; Operation BREAKTHROUGH; plywood; subfloors; underlayment; wood; BSS 52.

Wood joists; Concentrated loads; Deflection; Floor hardboard; Housing; Impact energy; Operation BREAKTHROUGH; Plywood; Subfloors; Underlayment; Wood; NBSIR 73-187.
Wood joist; Fire cndurance; I-ire test; Flame through; Full scale; Housing; Opcration BREAKTHROUGH; Single-family residences; Small scale; Thermal resistance; Wood foor; NBSIR 73-263.

Wood; Wood joists; Concentrated load; Deflcction; I-loor; Hardboard; Housing; Impact cnergy; Opcration BREAKTHROUGH; Plywood; Subfloors; Underlayment; BSS52.

Wood; Wood joists; Concentratcd loads; Deflection; Floor hardboard; Housing; Impact cnergy; Operation BREAKTHROUGH; Plywood; Subfloors; Underlayment; NBSIR 73-187.

\section{X}

X-ray diffraction; Adhcrence; Aluminum; Electron microprobe; Electron microscope; Porcelain enamel; Spalling; BSS59.

$\mathrm{X}$-ray patterns of calcium aluminoferrite hydrates; Calcium aluminoferrite hydrates; Calcium sulfate reaction with calcium aluminoferrite hydrates; DTA of calcium aluminoferrite hydrates; BSS6.

None Listed

None Listed 


\section{APPENDIX A. LIST OF FIELD OFFICES OF THE U.S. DEPARTMENT OF COMMERCE}

ALBUQUERQUE, NEW MEXICO 87101

U.S. Courthouse - Room 316

William E. Dwyer, Director

Area Code 505 Tel. 766-2386

FTS 505 766-2386

ANCHORAGE, ALASKA 99501

412 Hill Building

632 Sixth Avenue

Everett W. Buness, Director

Area Code 907 Tel. 265-5597

*ATLANTA, GEORGIA 30309

Suite 523, 1401 Peachtree St., N.E.

David S. Williamson, Regional Dir.

Area Code 404 Tel. 526-6000

District Office FTS 404 526-6000

Regional Office FTS 404 526-6565

BALTIMORE, MARYLAND 21202

415 U.S. Customhouse

Gay and Lombard Streets

Carroll F. Hopkins, Director

Area Code 301 Tel. $962-3560$

FTS 301 962-3560

BIRMINGHAM, ALABAMA 35205

Suite 200-201

908 South 20th Street

Gayle C. Shelton, Jr., Director

Area Code 205 Tel. 325-3327

FTS 205 325-3327

BOSTON, MASSACHUSETTS 02116

I0th Floor, 44I Stuart Street

Richard F. Treadway, Director

Area Code 617 Tel. 223-2312

FTS 617 223-2312

BUFFALO, NEW YORK 14202

1312 Federal Building

111 West Huron Street

Robert F. Magee, Director

Area Code 716 Tel. 842-3208

FTS $716842-3208$

CHARLESTON, WEST VIRGINIA 25301 3000 New Federal Office Building

500 Quarrier Street

J. Raymond DePaulo, Director

Area Code 304 Tel. 343-6181, Ext. 375

FTS 304 343-1375

CHEYENNE, WYOMING 82001

6022 O'Mahoney Federal Center

2120 Capitol A venue

Director, Vacant

Area Code 307 Tel. 778-2220, Ext. 2151

FTS 307 778-2151

-Denotes District Offices also serving as Regional Offices.
*CHICAGO, ILLINOIS 60603

1406 Mid Continental Plaza Building

55 East Monroe Street

Gerald M. Marks

Acting Regional Office Director

Area Code 312 Tel. 353-4450

District Office FTS $312353-4450$

Regional Office FTS 312 353-6957

CINCINNATI, OH1O 45202

8028 Federal Office Building

550 Main Street

Gordon B. Thomas, Director

Area Code 513 Tel. 684-2944

FTS 513 684-2944

CLEVELAND, OH1O 44114

Room 600, 666 Euclid Avenue

Charles B. Stebbins, Director

Area Code 216 Tel. 522-4750

FTS 216 522-4750

COLUMBIA, SOUTH CAROLINA 29204 2611 Forest Drive, Forest Center

Philip A. Ouzts, Director

Area Code 803 Tel. 765-5345

FTS 803 765-5345

*DALLAS, TEXAS 75202

Room 3E7, 1100 Commerce Street

H. Phillip Hubbard

Acting Regional Director

Area Code 214 Tel. 749-1515

District Office FTS 214 749-1515

Regional Office FTS 214749-1513

DENVER, COLORADO 80202

Room 161, New Customhouse

19 th and Stout Streets

John G. McMurtry, Director

Area Code 303 Tel. 837-3246

FTS 303 837-3246

DES MOINES, IOWA 50309

609 Federal Building

210 Walnut Street

Jesse N. Durden, Director

Area Code 515 Tel. 284-4222

FTS 515 284-4222

DETROIT, MICHIGAN 48226

$\mathbf{4 5}$ Federal Building

William L. Welch, Director

Area Code 313 Tel. 226-3650

FTS 313 226-3650

GREENSBORO, NORTH CAROLINA 27402

203 Federal Building

West Market Street, P.O. Box 1950

Joel B. New, Director

Area Code 919 Tel. 275-9I1I, Ext. 345
FTS 919 275-5345

HARTFORI, CONNECTICUT $\$ 6103$ Room 610-B, Federal Oftice Building 450 Main Street

Richard C. Kilbourn, Director

Area Code 203 Tel. 244-3530

FTS 203 244-3530

HONOLULU, HAWAII 96813 286 Alexander Young Building 1015 Bishop Street

John S. Davies, Director

Area Code 808 Tel. 546-8694

HOUSTON, TEXAS 77002

1017 Old Federal Building

201 Fannin Street

Felicito C. Guerrero, Acting Dir.

Area Code 713 Tel. 226-4231

FTS 713 226-4231

INDIANAPOLIS, 1NDIANA 46204 Room 355, Federal Office Building

46 East Ohio Street

Milton R. Sherar

Trade Specialist-in-Charge

Area Code 317 Tel. 269-6214

FTS 317 269-6214

KANSAS C1TY, M1SSOURI 64106

Room 1840, 601 East 12th Street

George H. Payne, Director

Area Code 816 Tel. 374-3142

FTS 816 374-3142

LOS ANGELES, CALIFORNIA 90024

11201 Federal Building

11000 Wilshire Blvd.

Eric C. Silberstein, Director

A rea Code 213 Tel. 824-7591

FTS 213 824-7591

MEMPHIS, TENNESSEE 38103

Room 710, 147 Jefferson Avenue

Bradford H. Rice, Director

Area Code 901 Tel. 534-3213

FTS 901 534-3213

MIAMI, FLORIDA 33130

Room 821, City National Bank Building 25 West Flagler Street

Roger J. LaRoche, Director

Area Code 305 Tel. 350-5267

FTS 305 350-5267

MILWAUKEE, WISCONSIN 53203

Straus Building

238 West Wisconsin Avenue

Russell H, Leitch, Director

Area Code 414 Tel. 224-3473

FTS 414 224-3473 
MINNEAPOLIS, MINNESOTA 55401

306 Federal Building

110 South Fourth Street

Glenn A. Matson, Director

Area Code 612 Tel. 725-2133

FTS 612 725-2133

NEWARK, NEW JERSEY 07102

4th Floor, Gateway Building

Clifford R. Lincoln, Director

Area Code 201 Tel. 645-6214

FTS 201 645-6214

NEW ORLEANS, LOUISIANA 70130

432 International Trade Mart

No. 2 Canal Street

Edwin A. Leland, Jr., Director

Area Code 504 Tel. 589-6546

FTS 504 589-6546

*NEW YORK, NEW YORK 10007 41st Floor, Federal Office Building

26 Federal Plaza, Foley Square

Arthur C. Rutzen

Acting Regional Director

Area Code 212 Tel. 264-0634

District Office FTS 212 264-0603

Regional Office FTS 212 264-0600

*PHILADELPHIA, PENNSYLVANIA 19106

9448 Federal Building

600 Arch Street

Patrick P. McCabe, Regional Dir.

Area Code 215 Tel. 597-2850

District Office FTS 215 597-2850

Regional Office FTS 215 597-2866
PHOENIX, ARIZONA 85004 508 Greater Arizona Savings Bldg. 112 North Central Avenue Donald W. Fry, Director Area Code 602 Tel. 261-3285 FTS 602 261-3285

PITTSBURGH, PENNSYLVANIA 15222 2002 Federal Building

1000 Liberty Avenue

Newton Heston, Jr., Director

Area Code 412 Tel. $644-2850$

FTS 412 644-2850

PORTLAND, OREGON 97205

521 Pittock Block

921 S.W. Washington Street

J. D. Chapman, Director

Area Code 503 Tel. 221-3001

FTS 503 221-3001

RENO, NEVADA 89502

2028 Federal Building

300 Booth Street

Joseph J. Jeremy, Director

Area Code 702 Tel. 784-5203

FTS 702 784-5203

RICHMOND, VIRGINIA 23240

8010 Federal Building

400 North 8th Street

Weldon W. Tuck, Director

Area Code 804 Tel. 782-2246

FTS 804 782-2246

ST. LOUIS, MISSOURI 63105

120 South Central Avenue

Donald R. Loso, Director
Area Code 314 Tel. 622-4243

FTS 314 425-3302-04

SALT LAKE CITY, UTAH 84138

1203 Federal Building

125 South State Street

Sherman P. Lloyd

Trade Specialist-in-Charge

Area Code 801 Tel. 524-5116

FTS 801 524-5116

SAN FRANCISCO, CALIFORNIA 94102

Federal Building, Box 36013

450 Golden Gate Avenue

Philip M. Creighton

Acting Regional Director

Area Code 415 Tel. 556-5860

District Office FTS 415 556-5860

Regional Office FTS 415 556-5868

SAN JUAN, PUERTO RICO 00902

Room 100, Post Office Building

Enrique Vilella, Director

Phone: 723-4640

SAVANNAH, GEORGIA 31402

235 U.S. Courthouse \& Post Office Bldg.

125-29 Bull Street

James W. McIntire, Director

Apea Code 912 Tel. 232-4321, Ext. 204

FTS 912 232-4204

SEATTLE, WASHINGTON 98109

Room 706, Lake Union Bldg.

1700 Westlake A venue North

Judson C. Wonderly, Director

Area Code 206 Tel. 442-5615

FTS 206 442-5615 


\section{APPENDIX B. LIST OF DEPOSITORY LIBRARIES IN THE UNITED STATES}

\section{ALABAMA}

Alexander City: Alexander City State Junior College, Thomas D. Russell Library (1967).

Auburn: Auburn University, Ralph Brown Draughon Library (1907).

Birmingham

Birmingham Public Library (1895).

Birmingham-Southern College Library (1932).

Jefferson State Junior College, James B. Allen Library (1970).

Samford University, Harwell G. Davis Library (1884).

Enterprise: Enterprise State Junior College Library (1967).

Florence: Florence State University, Collier Library (1932).

Gadsden: Gadsden Public Library (1963).

Huntsville: University of Alabama, Huntsville Campus Library (1964).

Jacksonville: Jacksonville State University, Ramona Wood Library (1929).

Maxwell A.F. Base: Air University Library (1963).

Mobile:

Mobile Public Library (1963).

Spring Hill College, Thomas Byrne Memorial Library (1937).

University of South Alabama Library (1968).

Montgomery:

Alabama State Department of Archives and History Library (1884).

Alabama Supreme Court Library (1884).

Auburn University at Montgomery Library (1971).

Normal: Alabama Agricultural and Mechanical College, Drake Memorial Library (1963).

St. Bernard: St. Bernard College Library (1962).

Troy: Troy State University, Lurleen B. Wallace Educational Resources Center (1963).

Tuskegee Institute: Tuskegee Institute, Hollis Burke Frissell Library (1907).

University:

University of Alabama, School of Law Library (1967).

University of Alabama Library (1860)-REGIONAL

\section{ALASKA}

Anchorage:

Anchorage Higher Consortium Library (1961).

Alaska Methodist University Library (1963).

Supreme Court of Alaska Library (1973).

College: University of Alaska, Elmer E. Rasmuson Library (1922).

Juneau: Alaska State Library (1964).

Ketchikan: Ketchikan Community College Library (1970).

\section{ARIZONA}

Coolidge: Central Arizona College, Instructional Materials Center (1973).

Flagstaff: Northern Arizona University Library (1937).

Phoenix:
Department of Library and Archives (unknown)-RE GIONAl.

Phoenix Public Library (1917)

Prescott: Prescott College 1.ibrary (1968).

Tempe: Arizona State University, A. J. Matthews Library (1944).

Thatcher: Eastern Arizona Junior College 1.ibrary (1963).

Tucson:

Tucson Public Library (1970)

University of Arizona Library (1907) - REGIONAI.

Yuma: Yuma City-County Library (1963).

\section{ARKANSAS}

Arkadelphia: Quachita Baptist University, Riley Library (1963). Batesville: Arkansas College Library (1963).

Clarksville: College of the Ozarks Library (1925).

Conway: Hendrix College, O. C. Bailey Library (1903)."

Fayetteville: University of Arkansas Library (1907).

Little Rock:

Arkansas Supreme Court Library (1962).

Little Rock Public Library (1953).

University of Arkansas at Little Rock Library (1973).

Magnolia: Southern State College, J. M. Peace Library (1956).

Monticello: University of Arkansas at Monticello Library (1956).

Pine Bluff: Arkansas Agricultural, Mechanical and Normal College Library (pending)

Russellville: Arkansas Polytechnic College, Tomlinson Library (1925).

Searcy: Harding College, Beaumont Memorial Library (1963).

State College: Arkansas State University, Dean B. Ellis Library (1913).

Walnut Ridge: Southern Baptist College, Felix Goodson Library (1967).

\section{CALIFORNIA}

Anaheim: Anaheim Public Library (1963).

Arcadia: Arcadia Public Library.

Arcata: Humboldt State College Library (1963).

Bakersfield:

California State College, Bakersfield Library (1974).

Kern County Library System (1943).

Berkeley:

University of California, General Library (1907).

University of California, Law Library, Earl Warren Legal Center (1963).

Carson: Carson Regional Library (1973).

Chico: Chico State University Library (1962).

Claremont: Pomona College Documents Collection, Honnold Library (1913).

Compton: Compton Library (1972).

Culver City: Culver City Library (1966).

Davis:

University of California at Davis Library (1953).

University of California at Davis, School of Law Library (1972). 
Dominguez Hills: California State College, Dominguez Hills, Educational Resources Center (1973).

Downey: Downey City Library (1963).

Fresno:

Fresno County Free Library (1920).

Fresno State University Library (1962).

Fullerton: California State College at Fullerton Library (1963).

Garden Grove: Garden Grove Regional Library (1963).

Gardena: Gardena Public Library (1966).

Hayward: California State College at Hayward Library (1963).

Huntington Park: Huntington Park Library, San Antonio Region (1970).

Inglewood: Inglewood Public Library (1963).

Irvine: University of California at Irvine Library (1963).

La Jolla: University of California, San Diego, University Library (1963).

Lakewood: Angelo Iacoboni Public Library (1970).

Lancaster: Lancaster Regional Library (1967).

Long Beach:

California State College at Long Beach Library (1962).

Long Beach Public Library (1933).

Los Angeles:

California State College at Los Angeles, John F. Kennedy Memorial Library (1956).

Los Angeles County Law Library (1963).

Los Angeles Public Library (1891).

Loyola University of Los Angeles Library (1933).

Occidental College, Mary Norton Clapp Library (1941).

Pepperdine University Library (1963).

University of California at Los Angeles Library (1932).

University of California at Los Angeles, Law Library (1958).

University of Southern California Library (1933).

Menlo Park: U.S. Geological Survey Library (1962).

Montebello: Montebello Library (1966).

Monterey: U.S. Naval Postgraduate School Library (1963).

Monterey Park: Bruggemeyer Memorial Library (1964).

Northridge: California State University at Northridge Library (1958).

Norwalk: Los Cerritos Regional Library (1973).

Oakland:

Mills College Library (1966).

Oakland Public Library (1923).

Ontario: Ontario City Library (1974).

Pasadena:

California Institute of Technology, Millikan Memorial Library (1933).

Pasadena Public Library (1963).

Pleasant Hill: Contra Costa County Library (1964).

Redding: Shasta County Library (1956).

Redlands: University of Redlands, Armacost Library (1933).

Redwood City: Redwood City Public Library (1966).

Reseda: West Valley Regional Branch Library (1966).

Richmond: Richmond Public Library (1943).

Riverside:

Riverside Public Library (1947).

University of California at Riverside Library (1963).

Sacramento:

California State Library (1895) - REGIONAL.

Sacramento City-County Library (1880).

Sacramento County Law Library (1963).

Sacramento State College Library (1963).

San Bernardirio: San Bernardino County Free Library (1964).

San Diego:

San Diego County Library (1966).

San Diego Public Library (1895).

San Diego State University, Love Library (1962).

San Diego County Law Library (1973).
San Francisco:

Mechanics' Institute Library (1889).

San Francisco Public Library (1889).

San Francisco State College, Social Science and Business Library (1955)

Supreme Court of California Library (1972).

U.S. Court of Appeals for Ninth Circuit Library (1971).

University of San Francisco, Richard A. Gleeson Library (1963).

San Jose: San Jose State College Library (1962).

San Leandro: San Leandro Community Library Center (1961).

San Luis Obispo: California State Polytechnic University Library (1969).

Santa Ana: Santa Ana Public Library (1959).

Santa Barbara: University of California at Santa Barbara Library (1960).

Santa Clara: University of Santa Clara, Orradre Library (1963).

Santa Cruz: University of California at Santa Cruz Library (1963).

Santa Rosa: Santa Rosa-Sonoma County Public Library (1896).

Stanford: Stanford University Libraries (1895).

Stockton: Public Library of Stockton and San Joaquin County (1884).

Thousand Oaks: California Lutheran Coliege Library (1964).

Torrance: Torrance Civic Center Library (1969).

Turlock: Stanislaus State College Library (1964).

Valencia: Valencia Regional Library (1972).

Van Nuys: Los Angeles Valley College Library (1970).

Visalia: Tulare County Free Library (1967).

Walnut: Mount San Antonio College Library (1966).

West Covina: West Covina Library (1966).

Whittier: Whittier College, Wardman Library (1963).

\section{CANAL ZONE}

Balboa Heights: Canal Zone Library-Museum (1963).

\section{COLORADO}

Alamosa: Adams State College Learning Resources Center (1963).

Boulder: University of Colorado Libraries (1879)-REGIONAL.

Colorado Springs: Colorado College, Charles Leaming Tutt Library (1880).

Denver:

Colorado State Library (unknown).

Denver Public Library (1884) - REGIONAL.

Regis College, Dayton Memorial Library (1915).

University of Denver, Penrose Library (1909).

U.S. Bureau of Reclamation Library (1962).

U.S. Court of Appeals for Tenth Circuit Library (1973).

Fort Collins: Colorado State University Library (1907).

Golden:

Colorado School of Mines, Arthur Lakes Library (1939).

Jefferson County Public Library, Bonfils-Stanton Regional Library (1968).

Greeley: University of Northern Colorado Library (1966).

Gunnison: Western State College, Leslie J. Savage Library (1932).

La Junta: Otero Junior College, Wheeler Library (1963).

Pueblo:

Pueblo Regional Library (1893).

Southern Colorado State College Library (1965).

U.S. Air Force Academy: Academy Library (1956). 


\section{CONNECTICUT}

Bridgeport: Bridgeport Public Library (1884).

Danbury: Western Connecticut State College Library (1967).

Enfield: Enfield Public Library (1967).

Hartford:

Connecticut State Library (unknown) - REGIONAL.

Hartford Public Litrary (1945).

Trinity College Library (1895).

Middletown: Wesleyan University, Olin Library (1906).

Mystic: Marine Historical Association, Inc., Mystic Seaport Library (1964).

New Britain: Central Connecticut State College, Elihu Burritt

New Haven: Library (1973).

Southern Connecticut State College Library (1968).

Yale University, Sterling Memorial Library (1859).

New London:

Connecticut College Library (1926).

U.S. Coast Guard Academy Library (1939).

Pomfret: Pomfret School, du Pont Library (1968).

Stamford: Stamford Public Library (1973).

Storrs: University of Connecticut, Wilbur Cross Library (1907).

Waterbury: Silas Bronson Library (1869).

West Haven: University of New Haven Library (1971).

\section{DELAWARE}

Dover:

Delaware State College, William C. Jason Library (1962).

State Department of Community Affairs and Economic Development, Division of Libraries (1972).

State Law Library in Kent County (unknown).

Georgetown: Delaware Technical and Community College, Southern Branch Library (1968).

Newark: University of Delaware, Morris Library (1907).

Wilmington:

New Castle County Law Library (1974).

Wilmington Institute and New Castle County Library (1861).

\section{DISTRICT OF COLUMBIA}

Washington:

Advisory Commission on Intergovernmental Relations Library.

Department of Agriculture, National Agricultural Library (1895).

Department of Commerce Library (1955).

Department of Health, Education, and Welfare Library (1895).

Department of Housing and Urban Development Library (1969).

Department of the Interior Central Library (1895).

Department of Justice Main Library (1895).

Department of State Library (1895).

Department of State, Office of Legal Advisor, Law Library (1966).

Department of Transportation, National Highway Traffic Safety Administration Library (1968).

District of Columbia Public Library (1943).

District of Columbia Court of Appeals Library (1973).

Federal City College Library (1970).

Federal Deposit Insurance Corporation Library (1972).

General Accounting Office Library.

Georgetown University Library (1969).

Indian Claims Commission Library (1968).
National War College Library (189.5).

Navy Department 1.ibrary (1895).

Office of the Judge Advocate General Library, Department of Navy (1963).

Office of Management and Budget Library, Executive Office of the President (1965).

Office of the Adjutant General, Department of Army Library (1969).

Treasury Department L.ibrary (1895).

U.S. Postal Service Library (1895).

U.S. Civil Service Commission L ibrary (1963).

U.S. Geological Survey Library (1962).

Veterans Administration, Central Office 1.ibrary (1967).

\section{FLORIDA}

Boca Raton: Florida Atlantic University Library ( 1963 ).

Clearwater: Clearwater Public Library (1972).

Coral Gables: University of Miami Library (1939).

Daytona Beach: Volusia County Public Libraries ( I963).

DeLand: Stetson University, duPont-Ball Library (I887).

Fort Lauderdale:

Fort Lauderdale Public Library (1967).

Nova University Library ([967).

Gainesville: University of Florida Libraries (1907)-REJacksonville: GIONAL.

Haydon Burns Library (1914).

Jacksonville University, Swisher Library (1962).

University of North Florida Library (1972).

Lakeland: Lakeland Public Library (1928).

Leesburg: Lake-Sumter Community College Library (1963).

Melbourne: Florida Institute of Technology Library (1963).

Miami:

Florida International University Library (1970).

Miami Public Library (1952).

Opa Locka: Biscayne College Library (1966).

Orlando: Florida Technological University Library (1966).

Palatka: St. Johns River Junior College Library (1963).

Pensacola: University of West Florida, John C. Pace Library (1966).

Port Charlotte: Charlotte County Library System (1973).

St. Petersburg: St. Petersburg Public Library (1965).

Sarasota: Sarasota Public Library (1970).

Tallahassee:

Florida Agricultural and Mechanical University, Coleman Memorial Library (1936).

Florida State Library (1929).

Florida State University, R. M. Strozier Library (1941).

Tampa:

Tampa Public Library (1965).

University of South Florida Library (1962).

University of Tampa, Merle Kelce Library (1953).

Winter Park: Rollins College, Mills Memorial Library (1909).

\section{GEORGIA}

Albany: Albany Public Library (1964).

Americus: Georgia Southwestern College, James Earl Carter Library (1966).

Athens: University of Georgia Libraries (1907).

Atlanta:

Atlanta Public Library (1880).

Atlanta University, Trevor Arnett Library (1962).

Emory University, Robert W. Woodruff Library (1928).

Emory University, School of Law Library (1968).

Georgia Institute of Technology, Price Gilbert Memorial Library (1963). 
Georgia State Library (unknown).

Georgia State University Library (1970).

Augusta: Augusta College Library (1962).

Brunswick: Brunswick Public Library (1965).

Carrollton: West Georgia College, Sanford Library (1962).

Columbus: Simon Schwob Memorial Library, Columbus College.

Dahlonega: North Georgia College Library (1939).

Decatur: Dekalb Community College-South Campus, Learning Resources Center (1973).

Gainesville: Chestatee Regional Library (1968).

Macon: Mercer University, Stetson Memorial Library (1964).

Marietta: Kennesaw Junior College Library (1968).

Milledgeville: Georgia College at Milledgeville, Ina Dillard Russell Library (1950).

Mount Berry: Berry College, Memorial Library (1970).

Savannah: Savannah,Public and Chatham-Effingham Liberty Regional Library (1857).

Statesboro: Georgia Southern College, Rosenwald Library (1939).

Valdosta: Valdosta State College, Richard Holmes Powell Library (1956).

\section{GUAM}

Agana: Nieves M. Flores Memorial Library (3962).

\section{HAWAII}

Hilo: University of Hawaii, Hilo Campus Library (1962).

Honolulu:

Chaminade College of Honolulu Library (1965).

Hawaii Medical Library, Inc. (1968).

Hawaii State Library (1929).

Municipal Reference Library of the City and County of Honolulu (1965).

Supreme Court Law Library (1973).

University of Hawaii Library (1907).

Laie: Church College of Hawaii, Woolley Library (1964).

Lihue: Kauai Public Library (1967).

Pearl City: Leeward Community College Library (1967).

Wailuku: Maui Public Library (1962).

\section{IDAHO}

Boise:

Boise State College Library (1966).

Boise Public Library and Information Center (1929).

Idaho State Law Library (unknown).

Idaho State Library (1971).

Caldwell: College of Idaho, Terteling Library (1930).

Moscow: University of I daho Library (1907) - REGIONAL.

Pocatello: Idaho State University Library (1908).

Rexburg: Ricks College, David O. McKay Library (1946).

Twin Falls: College of Southern Idaho Library (1970).

\section{ILLINOIS}

Bloomington: Illinois Wesleyan University Libraries (1964).

Carbondale: Southern Illinois University, Morris Library (1932).

Carlinville: Blackburn College Library (1954).

Carterville: Shawnee Library System (1971).

Champaign: University of Illinois Law Library, College of Law (1965).
Charleston: Eastern Illinois University, Booth Library (1962)

Chicago:

Field Museum of Natural History Library (1963).

Chicago Public Library (1876).

Chicago State University Library (1954).

John Crerar Library (1909).

Loyola University of Chicago, E. M. Cudahy Memorial Library (1966).

Newberry Library (1890)

Northeastern Illinois University Library (1961).

University of Chicago Law Library (1964).

University of Chicago Library (1897).

University of Illinois, Chicago Circle Campus Library (1957).

Decatur: Decatur Public Library (1954).

De Kalb: Northern Illinois University, Swen Franklin Parson Library (1960).

Edwardsville: Southern Illinois University, Lovejoy Library (1959).

Elsah: Principia College, Marshall Brooks Library (1957).

Evanston: Northwestern University Library (1876).

Freeport: Freeport Public Library (1905).

Galesburg: Galesburg Public Library (1896).

Jacksonville: MacMurray College, Henry Pfeiffer Library (1929).

Kankakee: Olivet Nazarene College, Memorial Library (1946).

Lake Forest: Lake Forest College, Donnelley Library (1962).

Lebanon: McKendree College, Holman Library (1968).

Lisle: Illinois Benedictine College, Theodore F. Lownik Library (1911).

Lockport: Lewis College of Science and Technology Library (1952).

Macomb: Western Illinois University Memorial Library (1962).

Moline: Black Hawk College, Learning Resources Center (1970).

Monmouth: Monmouth College Library (1860).

Normal: Illinois State University, Milner Library (1877).

Oak Park: Oak Park Public Library (1963).

Palos Hills: Moraine Valley Community College Library (1972). Peoria:

Bradley University, Cullom Davis Library (1963).

Peoria Public Library (1883).

River Forest: Rosary College Library (1966).

Rockford: Rockford Public Library (unknown).

Springfield: Illinois State Library (unknown) - REGIONAL.

Urbana: University of Illinois Library (1907).

Wheaton: Wheaton College Library (1964).

Woodstock: Woodstock Public Library (1963).

\section{INDIANA}

Anderson: Anderson College, Charles E. Wilson Library (1959). Bloomington: Indiana University Library (1881).

Crawfordsville: Wabash College, Lilly Library (1906).

Evansville:

Evansville and Vanderburgh County Public Library (1928).

Indiana State University, Evansville Campus Library (1969).

Fort Wayne:

Indiana-Purdue University Regional Campus Library (1965).

Public Library of Fort Wayne and Allen County (1896).

Franklin: Franklin College Library (pending).

Gary:

Gary Public Library (1943).

Indiana University, Northwest Campus Library (1966).

Greencastle: De Pauw University, Roy O. West Library (1879). Hammond: Hammond Public Library (1964). 
Hanover: Hanover College Library (1892).

Huntington: Huntington College Library (1964).

Indianapolis:

Butler University, Irwin Library (1965).

Indiana State Library (unknown)-REGIONAL.

Indiana University, Law Library (1967).

Indianapolis-Marion County Public Library (1967).

Jeffersonville: Indiana University, Southeastern Campus Library (1965).

Kokomo: Indiana University, Kokomo Regional Campus Library (1969).

Lafayette: Purdue University Library (1907).

Muncie:

Ball State University Library (1959).

Muncie Public Library (1906).

Notre Dame: University of Notre Dame, Memorial Library (1883).

Rensselaer: St. Joseph's College Library (1964).

Richmond:

Earlham College, Lilly Library (1964).

Morrison-Reeves Library (1906).

South Bend: Indiana University at South Bend Library (1965).

Terre Haute: Indiana State University, Cunningham Memorial Library (1906).

Valparaiso: Valparaiso University, Moellering Memorial Library (1930).

\section{IOWA}

Ames: Iowa State University of Science and Technology Library (1907).

Cedar Falls: University of Northern Iowa Library (1946).

Council Bluffs:

Free Public Library (1885).

Iowa Western Community College, Hoover Media Library (1972).

Davenport: Davenport Public Library (1973).

Des Moines:

Drake University, Cowles Library (1966).

Drake University Law Library (1972).

Iowa State Traveling Library (unknown).

Public Library of Des Moines (1888).

Dubuque:

Carnegie-Stout Public Library (unknown).

Loras College, Wahlert Memorial Library (1967).

Fayette: Upper lowa College, Hemdeerson-Wilder Library.

Grinnell: Grinnell College, Burling Library (1874).

lowa City:

University of lowa, Law Library (1968).

University of lowa Library (1884) - REGIONAL.

Lamoni: Graceland College, Frederick Madison Smith Library (1927).

Mount Vernon: Cornell College, Russell D. Cole Library (1896).

Orange City: Northwestern College, Ramaker Library (1970).

Sioux City: Sioux City Public Library (1894).

\section{KANSAS}

Atchison: Benedictine College Library (1965).

Baldwin City: Baker University Library (1908).

Colby: Colby Community Junior College Library (1968).

Emporia: Kansas State Teachers College, William Allen White Library (1909).

Hays: Fort Hays Kansas State College, Forsyth Library (1926). Hutchinson: Hutchinson Public Library (1963).
Lawrence:

University of Kansás, Watson Library (1869).

University of Kansas Law Library (1971).

Manhattan: Kansas State University, Farrell Library (1907).

Pittsburg: Kansas State College of Pittsburg, Poner library (1952).

Salina: Kansás Wesleyan University, Memorial Library (1930).

Topeka:

Kansas State Historical Society Library (1877).

Kansas State Library (unknown).

Washburn University of Topeka, Law Library (1971).

Wichita: Wichita State University Library (1901).

\section{KENTUCKY}

Ashland: Ashland Public Library (1946).

Barbourville: Union College, Abigail E. Weeks Memorial Library (1958).

Bowling Green: Western Kentucky University, Cravens Graduate Center and Library (1934).

Covington: Thomas More College Library (1970).

Danville: Centre College, Grace Doherty Library (1884).

Frankfort:

Kentucky Department of Libraries (1967).

Kentucky State University, Blazer Library (1972).

State Law Library (unknown).

Highland Heights: Northern Kentucky State College Library (1973).

Lexington:

University of Kentucky, Law Library (1968).

University of Kentucky, Margaret 1. King Library (1907)-REGIONAL.

Louisville:

Louisville Free Public Library (1904).

University of Louisville, Belknap Campus Library (1925).

Morehead: Morehead State University, Johnson Camden Library (1955).

Murray: Murray State University Library (1924).

Newport: Northern Kentucky State College Library.

Owensboro: Kentucky Wesleyan College Library (1966).

Pikeville: Pikeville College Library (1947).

Richmond: Eastern Kentucky University, John Grant Crabbe Library (1966).

\section{LOUISIANA}

Baton Rouge:

Louisiana State University Law Library (1929).

Louisiana State University Library (1907) - REGIONAL.

Southern University Library (1952).

Eunice: Louisiana State University at Eunice, LeDoux Library (1969).

Hammond: Southeastern Louisiana University, Sims Memorial Library (1966).

Lafayette: University of Southwestern Louisiana Library (1938).

Lake Charles: McNeese State University, Frazar Memorial Library (1941).

Monroe: Northeast Louisiana University, Sandel Library (1963).

Natchitoches: Northwestern State University, Watson Memorial Library (1887).

New Orleans:

Isaac Delgado College, Moss Technical Library (1968).

Law Library of Louisiana (unknown).

Loyola University Library (1942). 
New Orleans Public Library (1883).

Southern University in New Orleans Library (1962).

Tulane University, Howard-Tilton Memorial Library (1942).

University of New Orleans Library (1963).

U.S. Court of Appeals for Fifth Circuit Library (1973).

Pineville: Louisiana College, Richard W. Norton Memorial Library (1969).

Ruston: Louisiana Technical University Library (1896) - REGIONAL.

Shreveport:

Louisiana State University at Shreveport Library (1967).

Shreve Memorial Library (1923).

Thibodaux: Francis T. Nicholls State University, Leonidas Polk Library (1962)

\section{MAINE}

Augusta:

Maine Law and Legislative Reference Library (1973).

Maine State Library (unknown).

Bangor: Bangor Public Library (1884).

Brunswick: Bowdoin College, Hawthorne-Longfellow Library (1884).

Castine: Maine Maritime Academy, Nutting Memorial Library (1969).

Lewiston: Bates College Library (1883).

Orono: University of Maine, Raymond H. Fogler Library (1907) - REGIONAL.

Portland:

Portland Public Library (1884).

University of Maine Law Library (1964).

Springvale: Nasson College Library (1961).

Waterville: Colby College Library (1884).

\section{MARYLAND}

Annapolis:

Maryland State Library (unknown).

U.S. Naval Academy, Nimitz Library (1895).

Baltimore:

Enoch Pratt Free Library (1887)

Johns Hopkins University, Milton S. Eisenhower Library (1882).

Morgan State College, Soper Library (1940).

University of Baltimore, Langsdale Library (1973).

University of Maryland, Baltimore County Library (1971).

University of Maryland, School of Law Library (1969).

Bel Air: Harford Community College Library (1967).

Chestertown: Washington College, Chester M. Miller Library (1891).

College Park: University of Maryland, McKeldin Library (1925) - REGIONAL

Cumberland: Allegany Community College Library.

Frostburg: Frostburg State College Library (1967).

Germantown: U.S. Atomic Energy Commission Headquarters Library (1963).

Patuxent River: U.S. Naval Air Station Library (1968).

Rockville: Montgomery County Department of Public Libraries (1951).

Salisbury: Salisbury State College, Blackwell Library (1965).

Towson: Goucher College, Julia Rogers Library (1966).

Westminster: Western Maryland College Library (1896).

\section{MASSACHUSETTS}

Amherst:

Amherst College Library (1884).

University of Massachusetts, Goodell Library (1907).
Belmont: Belmont Memorial Library (1968).

Boston:

Boston Athenaeum Library (unknown).

Boston Public Library (1859) - REGIONAL.

Curry College Library (1972).

Northeastern University, Robert G. Dodge Library (1962).

State Library of Massachusetts (unknown).

Tufts University Library (1899).

Brookline: Public Library of Brookline (1925).

Cambridge:

Harvard College Library (1860).

Massachusetts Institute of Technology Libraries (1946).

Chestnut Hill: Boston College, Bapst Library (1963).

Chicopee: Our Lady of the Elms College Library (1969).

Lowell: Lowell Technological Institute, Alumni Memorial Library (1952).

Lynn: Lynn Public Library (1953).

Marlborough: Marlborough Public Library (1971).

New Bedford: New Bedford Free Public Library (1858).

North Dartmouth: Southeastern Massachusetts University Library (1965).

North Easton: Stonehill College, Cushing-Martin Library (1962).

Springfield: Springfield City Library (1966).

Waltham: Brandeis University, Goldfarb Library (1965).

Wellesley: Wellesley College Library (1943).

Wenham: Gordon College, Winn Library (1963).

Williamstown: Williams College Library (unknown).

Wilmington: Wilmington Memorial Library (1971).

Worcester:

American Antiquarian Society Library (1814).

University of Massachusetts, Medical Center Library (1972).

Worcester Public Library (1859).

\section{MICHIGAN}

Albion: Albion College, Stockwell Memorial Library (1966).

Allendale: Grand Valley State College Library (1963).

Alma: Alma College, Monteith Library (1963).

Ann Arbor:

Great Lakes Basin Library (1971).

University of Michigan, Harlan Hatcher Library (1884).

Benton Harbor: Benton Harbor Public Library (1907).

Bloomfield Hills: Cranbrook Institute of Science Library (1940).

Dearborn:

Henry Ford Centennial Library (1969).

Henry Ford Community College Library (1957).

Detroit:

Detroit Public Library (1868) - REGIONAL.

Marygrove College Library (1965).

Mercy College of Detroit Library (1965).

University of Detroit Library (1884).

Wayne County Public Library (1957).

Wayne State University Law Library (1971).

Wayne State University, G. Flint Purdy Library (1937).

Dowagiac: Southwestern Michigan College Library (1971).

East Lansing:

Michigan State University, Law Library (1971).

Michigan State University Library (1907).

Escanaba: Michigan State Library, Upper Peninsula Branch (1964).

Farmington: Martin Luther King Learning Resources Center, Oakland Community College (1968).

Flint:

Charles Stewart Mott Library (1959).

Flint Public Library (1967).

Grand Rapids:

Grand Rapids Public Library (1876). 
Calvin College Library (1967).

Houghton: Michigan Technological University Library (1876). Jackson: Jackson Public Library (1965).

Kalamazoo:

Kalamazoo Library System (1907).

Western Michigan University, Dwight B. Waldo Library (1963).

Lansing: Michigan State Library (unknown) - REGIONAL.

Livonia: Schoolcraft College Library (1962).

Marquette: Northern Michigan University, Olson Library (1963).

Monroe: Monroe County Library System (pending).

Mt. Clemens: Macomb County Library (1968).

Mt. Pleasant: Central Michigan University Library (1958).

Muskegon: Hackley Public Library (1894).

Olivet: Olivet College Library.

Petoskey: North Central Michigan College Library (1962).

Port Huron: Saint Clair County Library System (1876).

Rochester: Oakland University, Kresge Library (1964).

Saginaw: Hoyt Public Library (1890).

Traverse City: Northwestern Michigan College, Mark Osterlin Library (1964).

University Center: Delta College Library (1963).

Warren: Warren Public Library, Arthur J. Miller Branch (1973).

Ypsilanti: Eastern Michigan University Library (1965).

\section{MINNESOTA}

Bemidji: Bemidji State College, A. C. Clark Library (1963).

Collegeville: St. John's University, Alcuin Library (1954).

Duluth: Duluth Public Library (1909).

Edina: Hennepin County Library.

Mankato: Mankato State College Memorial Library (1962).

Minneapolis:

Anoka County Library (1971).

Southdale-Hennepin Area Library (1971).

Minneapolis Public Library (1893).

University of Minnesota, Wilson Library (1907)-REGIONAL.

Moorhead: Moorhead State College Library (1956).

Morris: University of Minnesota at Morris Library (1963).

Northfield:

Carleton College Library (1930).

St. Olaf College, Rolvaag Memorial Library (1930).

St. Cloud: St. Cloud State College Library (1962).

St. Paul:

Minnesota Historical Society Library (1867).

Minnesota State Law Library (unknown).

St. Paul Public Library (1914).

University of Minnesota, St. Paul Campus Library (1974).

Saint Peter: Gustavus Adolphus College Library (1941).

Stillwater: Stillwater Public Library (1893).

Willmar: Crow River Regional Library (1958).

Winona: Winona State College, Maxwell Library (1969).

\section{MISSISSIPPI}

Columbus: Mississippi State College for Women, J. C. Fant Memorial Library (1929).

Hattiesburg: University of Southern Mississippi Library (1935). Jackson:

Jackson State College Library (1968).

Millsaps College, Millsaps-Wilson Library (1963).

Mississippi Library Commission (1947).

Mississippi State Law Library (unknown).

Lorman: Alcorn Agricultural and Mechanical College Library (1970).
State College: Mississippi State University, Mitchell Memorial Library (1907).

University:

University of Mississippi L.ibrary (1883).

University of Mississippi, School of Law Library (1967).

\section{MISSOURI}

Cape Girardeau: Southeast Missouri State College, Kent Library (19|6).

Columbia: University of Missouri Library (1862).

Fayette: Central Methodist College Library (1962).

Fulton: Westminster College, Reeves Library ( 1875 ).

Jefferson City:

Lincoln University, 1nman E. Page Library (1944).

Missouri State Library (1963).

Missouri Supreme Court Library (unknown).

Joplin: Missouri Southern State College Library (1966).

Kansas City:

Kansas City Public Library (1881).

Rockhurst College Library (1917).

University of Missouri a: Kansas City, General Library (1938).

Kirksville: Northeast Missouri State Teachers College, Pickler Memorial Library (1966).

Liberty: William Jewell College Library (1900).

Rolla: University of Missouri at Rolla Library (1907).

St. Charles: Lindenwood College, Margaret Leggat Butler Library (1973).

St. Joseph: St. Joseph Public Library (1891).

St. Louis:

St. Louis County Library (1970).

St. Louis Public Library (1866).

St. Louis University, Law Library (1967)

St. Louis University, Pius XII Memorial Library (1866).

University of Missouri at St. Louis, Thomas Jefferson Library (1966).

U.S. Court of Appeals, Eighth Circuit Library (1972).

Washington University, John M. Olin Library (1906).

Springfield:

Drury College, Walker Library (1874).

Southwest Missouri State College Library (1963).

Warrensburg: Central Missouri State College, Ward Edwards Library (1914).

\section{MONTANA}

Billings: Eastern Montana College Library (1924).

Bozeman: Montana State University Library (1907).

Butte: Montana College of Mineral Science and Technology Library (1901).

Helena:

Montana Historical Society Library (unknown).

Montana State Library (1966).

Missoula: University of Montana Library (1909)-REGIONAL.

\section{NEBRASKA}

Blair: Dana College, Dana-LIFE Library (1924).

Crete: Doane College, Whitin Library (1944).

Fremont: Midland Lutheran College Library (1924).

Kearney: Kearney State College, Calvin T. Ryan Library (1962).

Lincoln:

Nebraska Publications Clearinghouse, Nebraska Library Commission (1972). 
Nebraska State Library (unknown).

University of Nebraska, Don L. Love Memorial Library (1907).

Omaha:

Creighton University, Alumni Library (1964).

Omaha Public Library (1880).

University of Nebraska at Omaha, Gene Eppley Library (1939).

Scottsbluff: Scottsbluff Public Library (1925).

Wayne: Wayne State College, U.S. Conn Library (1970).

\section{NEVADA}

Carson City:

Nevada State Library (unknown).

Nevada Supreme Court Library.

Las Vegas:

Clark County Library District (pending).

University of Nevada at Las Vegas, James R. Dickinson Library (1959).

Reno:

Nevada State Historical Society Library (1974).

University of Nevada Library (1907) - REGIONAL

\section{NEW HAMPSHIRE}

Concord:

Franklin Pierce Law Center Library (1973).

New Hampshire State Library (unknown).

Durham: University of New Hampshire Library (1907).

Franconia: Franconia College Library (1972).

Hanover: Dartmouth College, Baker Library (1884).

Henniker: New England College Library (1966).

Manchester:

Manchester City Library (1884).

St. Anselm's College, Geisel Library (1963).

Nashua: Nashua Public Library (1971).

\section{NEW JERSEY}

Bayonne: Bayonne Free Public Library (1909).

Bloomfield: Free Public Library of Bloomfield (1965).

Bridgeton: Cumberland County Library (1966).

Camden: Rutgers University-Camden Library (1966).

Convent Station: College of St. Elizabeth, Mahoney Library (1938).

East Orange: East Orange Public Library (1966).

Elizabeth: Free Public Library of Elizabeth (1895).

Glassboro: Glassboro State College, Savitz Learning Resource Center (1963).

Hackensack: Johnson Free Public Library (1966).

Irvington: Free Public Library of Irvington (1966).

Jersey City:

Free Public Library of Jersey City (1879).

Jersey City State College, Forrest A. Irwin Library (1963).

Madison: Drew University, Rose Memorial Library (1939).

Mahwah: Ramapo College Library (1971).

Mount Holly: Burlington County Library (1966).

New Brunswick:

Free Public Library (1908).

Rutgers University Library (1907).

Newark:

Newark Public Library (1906) - REGIONAL.

Rutgers-The State University, John Cotton Dana Library (1966).

Passaic: Passaic Public Library (1964).

Plainfield: Plainfield Public Library (1971).
Princeton: Princeton University Library (1884).

Rutherford: Fairleigh Dickinson University, Messler Library (1953).

Shrewsbury: Monmouth County Library (1968).

South Orange: Seton Hall University, McLaughlin Library (1947).

Teaneck: Fairleigh Dickinson University Library, Teaneck Campus (1963).

Toms River: Ocean County College Learning Resources Center (1966).

Trenton:

New Jersey State Library, Law and Reference Bureau, Department of Education (unknown).

Trenton Free Public Library (1902).

Union: Newark State College, Nancy Thompson Library (1973).

Upper Montclair: Montclair State College, Harry A. Sprague Library (1967).

Wayne: Wayne Public Library (1972).

West Long Branch: Monmouth College, Guggenheim Memorial Library (1963).

Woodbridge: Free Public Library of Woodbridge (1965).

\section{NEW MEXICO}

Albuquerque:

University of New Mexico, Medical Science Library (1973).

University of New Mexico, School of Law Library (1973).

University of New Mexico, Zimmerman Library (1896) - REGIONAL.

Hobbs: New Mexico Junior College, Pannell Library (1969).

Las Cruces: New Mexico State University Library (1907).

Las Vegas: New Mexico Highlands University, Donnelly Library (1913)

Portales: Eastern New Mexico University Library (1962).

Santa Fe:

New Mexico State Library (1960) - REGIONAL.

Supreme Court Law Library (unknown).

Silver City: Western New Mexico University, Miller Library (1972).

\section{NEW YORK}

Albany:

New York State Library (unknown) - REGIONAL.

State University of New York at Albany Library (1964).

Auburn: Seymour Library (1972).

Bayside: Queensborough Community College Library (1972).

Binghamton: State University of New York at Binghamton Library (1962).

Brockport: State University of New York, Drake Memorial Library (1967).

Bronx:

Herbert H. Lehman College Library (1967).

New York Public Library, Mott Haven Branch (1973).

Bronxville: Sarah Lawrence College Library (1969).

Brooklyn:

Brooklyn College Library (1936).

Brooklyn Law School Library.

Brooklyn Public Library (1908).

Polytechnic Institute of Brooklyn, Spicer Library (1963).

Pratt Institute Library (1891).

State University of New York, Downstate Medical Center Buffalo: Library (1958).

Buffalo and Erie County Public Library (1895). 
State University of New York at Buffalo, Lockwood Memorial Library (1963).

Canton: St. Lawrence University, Owen D. Young Library (1920).

Corning: Corning Community College, Arthur A. Houghton, Jr. Library (1963).

Cortland: State University of New York, College at Cortland, Memorial Library (1964).

Delhi: State University Agricultural and Technical College Library (1970).

Douglaston: Cathedral College Library (1971).

East Islip: East Islip Public Library (1973).

Elmira: Elmira College, Gannett-Tripp Learning Center (1956).

Farmingdale: State University Agricultural and Technical Institute at Farmingdale Library (1917).

Flushing: Queens College, Paul Klapper Library (1939).

Garden City:

Adelphi University, Swirbul Library (1966).

Nassau Library System (1965).

Geneseo: State University College, Milne Library (1967).

Great Neck: U.S. Merchant Marine Academy Library.

Greenvale: C. W. Post College, B. Davis Schwartz Memorial Library (1964).

Hamilton: Colgate University Library (1902).

Hempstead: Hof stra University Library (1964).

Huntington: Huntington Public Library (1966).

Ithaca:

Cornell University Library (1907).

New York State Colleges of Agriculture and Home Economics, Albert R. Mann Library (1943).

Jamaica:

Queens Borough Public Library (1926).

St. John's University Library (1956).

Kings Point: U.S. Military Academy Library (1962).

Mount Vernon: Mount Vernon Public Library (1962).

New Paltz: State University College Library (1965).

New York City:

City University of New York, City College Library (1884).

College of Insurance, Ecker Library (1965).

Columbia University Libraries (1882).

Cooper Union Library (1930).

Fordham University Library (1937).

New York Law Institute Library (1909).

New York Public Library (Astor Branch) (1907).

New York Public Library (Lenox Branch) (1884).

New York University Law Library (1973).

New York University Libraries (1967).

State University of New York, Maritime College Library (1947).

Newburgh: Newburgh Free Library (1909).

Oakdale: Dowling College Library (1965).

Oneonta: State University College, James M. Milne Library (1966).

Oswego: State University College, Penfield Library (1966).

Plattsburgh: State University College, Benjamin F. Feinberg Library (1967).

Potsdam:

Clarkson College of Technology, Hanıet Call Burnap Memorial Library (1938).

State University College, Frederick W. Crumb Memorial Library (1964).

Poughkeepsie: Vassar College Library (1943).

Purchase: State University of New York, College at Purchase Library (1969).

Rochester:

Rochester Public Library (1963).

University of Rochester Library (1880).

St. Bonaventure: St. Bonaventure University, Friedsam
Memorial Library (1938)

Saratoga Springs: Skidmore College Library (1964).

Schenectady: Union College, Schaffer Library (1901).

Southampton: Southamptor College Library (1973).

Staten Island: Wagner College, Horrmann Library (1953).

Stony Brook: State University of New York at Stony Brook Library (1963).

Syracuse: Syracuse University Library (1878).

Troy: Troy Public Library (1869).

Utica: Utica Public Library (1885).

West Point: U.S. Military Academy Library (unknown).

Yonkers:

Yonkers Public Library (1910).

Sarah Lawrence College Library.

\section{NORTH CAROLINA}

Asheville: University of North Carolina at Asheville (1965).

Boiling Springs: Gardner-Webb College, Dover Memorial Library (1974).

Boone: Appalachian State University Library (1963).

Buies Creek: Campbell College, Carrie Rich Memorial Library (1965).

Chapel Hill: University of North Carolina Library (1884) - REGIONAL.

Charlotte:

Public Library of Charlotte and Mecklenburg County (1964).

Queens College, Everett Library (1927).

University of North Carolina at Charlotte, Atkins Library (1964).

Cullowhee: Western Carolina University, Hunter Library (1953).

Davidson: Davidson Col̉lege, Hugh A. \& Jane Grey Memorial Library (1893).

Durham:

Duke University, William R. Perkins Library (1890).

North Carolina Central University, James E. Shepard Memorial Library (1973).

Elon College: Elon College Library (1971).

Fayetteville: Fayetteville State University, Chestnutt Library (1971).

Greensboro:

North Carolina Agricultural and Technical State University, F. D. Bluford Library (1937).

University of North Carolina at Greensboro, Walter Clinton Jackson Library (1963).

Greenville: East Carolina University, J. Y. Joyner Library (1951).

Laurinburg: St. Andrews Presbyterian College, DeTamble Library (1969).

Lexington: Davidson County Public Library System (1971).

Mount Olive: Mount Olive College, Moye Library (1971).

Murfreesboro: Chowan College, Whitaker Library (1963).

Pembroke: Pembroke State University Library (1965).

Raleigh:

North Carolina State Library (unknown).

North Carolina State University, R. H. Hill Library (1923).

North Carolina Supreme Court Library (1972).

Wake County Public Libraries (1969).

Rocky Mount: North Carolina Wesleyan College Library (1969).

Salisbury: Catawba College Library (1925).

Wilmington: University of North Carolina at Wilmington, William M. Randall Library (1965).

Wilson: Atlantic Christian College, Clarence L. Hardy Library (1930). 
Winston-Salem:

Forsyth County Public Library System (1954).

Wake Forest University, Z. Smith Reynolds Library (1902).

\section{NORTH DAKOTA}

Bismarck:

State Historical Society of North Dakota (1907).

North Dakota State Law Library (unknown).

North Dakota State Library Commission Library (1971).

Veterans Memorial Public Library (1968).

Dickinson: Dickinson State College Library (1968).

Fargo:

Fargo Public Library (1964).

North Dakota State University Library (1907)-REGIONAL.

Grand Forks: University of North Dakota, Chester Fritz Library $(1890)$

Minot: Minot State College, Memorial Library (1925).

Valley City: State College Library (1913).

\section{OHIO}

Ada: Ohio Northern University College of Law, J. P. Taggart Library (1965).

Akron:

Akron Public Library (1952).

University of Akron Library (1963).

Alliance: Mount Union College Library (1888).

Ashland: Ashland College Library (1938).

Athens: Ohio University Library (1886).

Batavia: Clermont General and Technical College Library (1973).

Bluffton: Bluffton College, Musselman Library (1951).

Bowling Green: Bowling Green State University Library (1933).

Canton: Malone College, Everett L. Cattell Library (1970).

Chardon: Geauga County Public Library (1971).

Cincinnati:

Public Library of Cincinnati and Hamilton County (1884).

University of Cincinnati Library (1929).

Cleveland:

Case Western Reserve University, Freiberger Library (1913).

Cleveland Heights-University Heights Public Library (1970).

Cleveland Public Library (1886)

Cleveland State University Library (1966).

John Carroll University, Grasselli Library (1963).

Municipal Reference Library (1970).

Columbus:

Capital University Library (1968)

Columbus Public Library (1885).

Ohio State Library (unknown) - REGIONAL.

Ohio State University Library (1907).

Ohio Supreme Court Law Library (1973).

Dayton:

Dayton and Montgomery County Public Library (1909).

University of Dayton, Albert Emanuel Library (1969).

Wright State University Library (1965).

Delaware: Ohio Wesleyan University, L. A. Beeghly Library (1845).

Elyria: E!yria Public Library (1966).

Findlay: Findlay College, Shafer Library (1969).

Gambier: Kenyon College Library (1873).

Granville: Denison University Library (1884).

Hiram: Hiram College, Teachout-Price Memorial Library (1874).
Kent: Kent State University Library (1962).

Marietta: Marietta College, Dawes Memorial Library (1884).

Middletown: Miami University at Middletown, Gardner-Harvey Library (1970).

New Concord: Muskingum College Library (1966).

Oberlin: Oberlin College Library (1858).

Oxford: Miami University, Alumni Library (1909).

Portsmouth: Portsmouth Public Library (unknown).

Rio Grande: Rio Grande College, Jeanette Albiez Davis Library (1966).

Springfield: Warder Public Library (1884).

Steubenville:

College of Steubenville, Starvaggi Memorial Library (1971).

Public Library of Steubenville and Jefferson County (1950).

Tiffin: Heidelberg College, Beeghly Library (1964).

Toledo:

Toledo-Lucas County Public Library (1884).

University of Toledo Library (1963).

Westerville: Otterbein College, Centennial Library (1967).

Wooster: College of Wooster, Andrews Library (1966).

Youngstown:

Public Library of Youngstown and Mahoning County (1923).

Youngstown State University Library (1971).

\section{OKLAHOMA}

Ada: East Central State College, Linscheid Library (1914).

Alva: Northwestern State College Library (1907).

Bartlesville: U.S. Bureau of Mines, Energy Research Center Library (1962).

Bethany: Bethany Nazarene College, R. T. Williams Library (1971).

Durant: Southeastern State College Library (1929).

Edmond: Central State University Library (1934).

Enid: Public Library of Enid and Garfield County (1908).

Langston: Langston University, G. Lamar Harrison Library (1941).

Muskogee: Muskogee Public Library (1971).

Norman: University of Oklahoma Libraries (1893).

Oklahoma City:

Oklahoma City University Library (1963).

Oklahoma County Library System.

Oklahoma Department of Libraries (1893)-REGIONAL. Shawnee: Oklahoma Baptist University Library (1933).

Stillwater: Oklahoma State University Library (1907).

Tahlequah: Northeastern State College, John Vaughan Library (1923).

Tulsa:

Tulsa City-County Library (1963).

University of Tulsa, McFarlin Library (1929).

Weatherford: Southwestern State College Library (1958).

\section{OREGON}

Ashland: Southern Oregon College Library (1953).

Corvallis: Oregon State University Library (1907).

Eugene: University of Oregon Library (1883).

Forest Grove: Pacific University Library (1897).

La Grande: Eastern Oregon College, Walter M. Pierce Library (1954).

McMinnville: Linfield College, Northup Library (1965).

Monmouth: Oregon College of Education Library (1967).

Portland:

Department of the Interior, Bonneville Power Administration Library (1962).

Lewis and Clark College, Aubrey R. Watzek Library (1967). 
Library Association of Portland (1884).

Portland State University Library (1963) - REGIONAL. Salem:

Reed College Library (1912).

Oregon State Library (unknown).

Oregon Supreme Court Library (1974).

Williamette University Library (1969).

\section{PENNSYLVANIA}

Allentown: Muhlenberg College, Haas Library (1939).

Altoona: Altoona Public Library (1969).

Bethlehem: Lehigh University, Linderman Library (1876).

Carlisle: Dickinson College, Boyd Lee Spahr Library (1947).

Cheyney: Cheyney State College, Leslie Pinckney Hill Library (1947).

Collegeville: Ursinus College, Myrin Library (1963).

Doylestown: Bucks County Free Library, Center County Library (1970).

East Stroudsburg: East Stroudsburg State College, Kemp Library (1966).

Erie: Erie Public Library (1897).

Greenville: Thiel College, Langenheim Memorial Library (1963).

Harrisburg: State Library of Pennsylvania (unknown)-REGIONAL.

Haverford: Haverford College Library (1897).

Hazleton: Hazleton Area Public Library (1964).

Indiana: Indiana University of Pennsylvania, Rhodes R. Stabley Library (1962).

Johnstown: Cambria County Glosser Memorial Library (1965).

Lancaster: Franklin and Marshall College, Fackenthal Library (1895).

Lewisburg: Bucknell University, Ellen Clarke Bertrand Library (1963).

Mansfield: Mansfield State College Library (1968).

Meadville: Allegheny College, Reis Library (1907).

Millersville: Millersville State College, Ganser Library (1966).

Monessen: Monessen Public Library (1969).

New Castle: New Castle Free Public Library (1963).

Newtown: Bucks County Community College Library (1968).

Norristown: Montgomery County-Norristown Public Library (1969).

Philadelphia:

Drexel University Library (1963).

Free Library of Philadelphia (1897).

Temple University, Samuel Paley Library (1947).

University of Pennsylvania Library (1886).

U.S. Court of Appeals for Third Circuit Library (1973).

Pittsburgh:

Carnegie Library of Pittsburgh, Allegheny Regional Branch (1924).

Carnegie Library of Pittsburgh (1895).

University of Pittsburgh, Hillman Library (1910).

U.S. Bureau of Mines, Pittsburgh Research Center Library (1962).

Pottsville: Pottsville Free Public Library (1967).

Reading: Reading Public Library (1901).

Scranton: Scranton Public Library (1895).

Shippensburg: Shippensburg State College, Ezra Lehman Memorial Library (1973).

Slippery Rock: Slippery Rock State College, Maltby Library (1965).

Swarthmore: Swarthmore College Library (1923).

University Park: Pennsylvania State University Library (1907).

Villanova: Villanova University, School of Law Library (1964).

Warren: Warren Library Association, Warren Public Library (1885).
Washington: Washington and Jefferson College, Memorial Library (1884).

Waynesburg: Waynesburg College Library (1964).

West Chester: West Chester State College, Francis Harvey Green Library (1967).

Wilkes-Barre: King's College, Corgan Library (1949).

Williamsport: Lycoming College Library (1970).

York: York Junior College l.ibrary ( I 963).

Youngwood: Westmoreland County Community College. Learning Resource Center (1972).

\section{PUERTO RICO}

Mayaguez: University of Puerto Rico, Mayaguez Campus Library (1928).

Ponce: Catholic University of Puerto Rico L ibrary (1966).

Rio Piedras: University of Puerto Rico General Library (1928).

\section{RHODE ISLAND}

Kingston: University of Rhode 1sland Library (1907).

Newport: U.S. Naval War College Library (1963).

Providence:

Brown University Library (unknown).

Providence College, Phillips Memorial Library (1969).

Providence Public Library (1884).

Rhode Island College, James P. Adams Library (1965).

Rhode Island State Library (before 1895).

Warwick: Warwick Public Library (1966).

Westerly: Westerly Public Library (1909).

\section{SOUTH CAROLINA}

Charleston:

Baptist College at Charleston Library (1967).

College of Charleston Library (1869).

The Citadel Memorial Library (1962).

Clemson: Clemson University Library (1893).

Columbia:

Benedict College, Starks Library (1969).

Columbia College, Edens Library (1966).

South Carolina State Library (before 1895).

University of South Carolina, Undergraduate Library (1884).

Conway: University of South Carolina. Coastal Carolina Regional Campus Library (1974).

Due West: Erskine College, McCain Library (1968).

Florence:

Florence County Library (1967).

Francis Marion College, James A. Rogers Library (1970).

Greenville:

Furman University Library (1962).

Greenville County Library (1966).

Greenwood: Lander College Library (1967).

Orangeburg: South Carolina State College, Whittaker Library (1953).

Rock Hill: Winthrop College, Dacus Library (1896).

Spartansburg: Spartansburg County Public Library (1967).

\section{SOUTH DAKOTA}

Aberdeen: Northern State College Library (1963).

Brookings: South Dakota State University, Lincoln Memorial Library (1889). 
Pierre: South Dakota State Library (1973).

Rapid City:

Rapid City Public Library (1963).

South Dakota School of Mines and Technology Library (1963).

Sioux Falls:

Augustana College, Mikkelsen Library and Learning Resources Center (1969).

Sioux Falls Public Library (1903).

Spearfish: Black Hills State College Library (1942).

Vermillion: University of South Dakota, I. D. Weeks Library (1889).

Yankton: Yankton College Library (1904).

\section{TENNESSEE}

Bristol: King College Library (1970).

Chattanooga: Chattanooga Public Library (1907).

Clarksville: Austin Peay State University, Felix G. Woodward Library (1945).

Cleveland: Cleveland State Community College Library (1973).

Columbia: Columbia State Community College, Finney Memorial Library (1973).

Cookeville: Tennessee Technological University, Jere Whitson Memorial Library (1969).

Jackson: Lambuth College, Luther L. Gobbel Library (1967).

Jefferson City: Carson-Newman College Library (1964).

Johnson City: East Tennessee State University, Sherrod Library (1942).

Knoxville:

Public Library of Knoxville and Knox County, Lawson McGhee Library (1973).

University of Tennessee Law Library (1971).

University of Tennessee Library (1907).

Martin: University of Tennessee at Martin Library (1957).

Memphis:

Memphis and Shelby County Public Library and Information Center (1896).

Memphis State University, John W. Brister Library (1966).

Morristown: Morristown College, Carnegie Library (1970).

Murfreesboro: Middle Tennessee State University, Andrew L.

Nashville: Todd Library (1912).

Fisk University Library (1965).

Joint University Libraries (1884).

Public Library of Nashville and Davidson County (1884).

Tennessee State Library and Archives, State Library Division (unknown).

Tennessee State University, Martha M. Brown Memorial Library (1972).

Sewanee: University of the South, Jesse Ball duPont Library (1873).

\section{TEXAS}

Abilene: Hardin-Simmons University Library (1940).

Arlington:

Arlington Public Library (1970).

University of Texas at Arlington Library (1963). Austin:

Texas State Law Library (1972).

Texas State Library (unknown) - REGIONAL.

University of Texas at Austin Library (1884).

University of Texas, Lyndon B. Johnson School of Public Affairs Library (1966).

University of Texas, School of Law Library (1965).

Baytown: Lee College Library (1970).
Beaumont: Lamar University Library (1957).

Brownwood: Howard Payne College, Walker Memorial Library (1964).

Canyon: West Texas State University Library (1928).

College Station: Texas Agricultural and Mechanical University Library (1907).

Commerce: East Texas State University Library (1937).

Corsicana: Navarro Junior College Library (1965).

Dallas:

Bishop College, Zale Library (1966).

Dallas Baptist College Library (1967).

Dallas Public Library (1900).

Southern Methodist University, Fondren Library (1925).

Denton: North Texas State University Library (1948).

Edinburg: Pan American University Library (1959).

El Paso:

El Paso Public Library (1906).

University of Texas at El Paso Library (1966).

Fort Worth:

Fort Worth Public Library (1905).

Texas Christian University, Mary Couts Burnett Library (1916).

Galveston: Rosenberg Library (1909).

Houston:

Houston Public Library (1884).

Rice University, Fondren Library (1967).

University of Houston Library (1957).

Huntsville: Sam Houston State University, Estill Library (1949).

Irving: Irving Municipal Library.

Kingsville: Texas Arts and Industries University Library (1944).

Lake Jackson: Brazosport College Library (1969).

Laredo: Laredo Junior College, Harold R. Yeary Library (1970).

Longview: Nicholson Memorial Public Library (1961).

Lubbock: Texas Tech University Library (1935)-REGIONAL.

Marshall: Wiley College, Cole Library (1962).

Nacogdoches: Stephen F. Austin State University Library (1965).

Plainview: Wayland Baptist College, Van Howeling Memorial Library (1963).

Richardson: University of Texas at Dallas Library (1972).

San Angelo: Angelo State University, Porter Henderson Library (1964).

San Antonio:

San Antonio College Library (1972).

San Antonio Public Library, Business and Science Department (1899).

St. Mary's University Library (1964).

Trinity University Library (1964).

University of Texas at San Antonio Library (1973).

San Marcos: Southwest Texas State University Library (1955).

Seguin: Texas Lutheran College, Blumberg Memorial Library (1970).

Sherman: Austin College, Arthur Hopkins Library (1963).

Texarkana: Texarkana Community College, Palmer Memorial Library (1963).

Victoria: University of Houston, Victoria Center Library (1973).

Waco: Baylor University Library (1905).

Wichita Falls: Midwestern University, Moffett Library (1963).

\section{UTAH}

Cedar City: Southern Utah State College Library (1964).

Ephraim: Snow College, Lucy A. Phillips Library (1963). 
Logan: Utah State University, Merrill Library and Learning Resources Center (1907) - REGIONAL.

Ogden: Weber State College Library (1962).

Provo:

Brigham Young University Library (1908).

Brigham Young University, Law Library (1972).

Salt Lake City:

University of Utah, Law Library (1966).

University of Utah, Eccles Medical Sciences Library (1970).

University of Utah, Marriott Library (1893).

Utah State Library Commission, Documents Library (unknown).

\section{VERMONT}

Burlington: University of Vermont, Bailey Library (1907).

Castleton: Castleton State College, Calvin Coolidge Library (1969).

Christiansted: Christiansted Public Library.

Johnson: Johnson State College, John Dewey Library (1955).

Lyndonville: Lyndon State College, Samuel Reed Hall Library (1969).

Middlebury: Middlebury College, Egbert Starr Library (1884). Montpelier: Vermont Department of Libraries (before 1895).

Northfield: Norwich University Library (1908).

Putney: Windham College, Dorothy Culbertson Marvin Memorial Library (1965).

\section{VIRGIN ISLANDS}

Charlotte Amalie: College of the Virgin Islands, Ralph $\mathbf{M}$. Paiewonsky Library.

St. Croix: Christiansted Public Library (1974).

St. Thomas:

College of the Virgin Islands, Ralph M. Paiewonsky Library (1973).

St. Thomas Public Library (1968).

\section{VIRGINIA}

Blacksburg: Virginia Polytechnic Institute, Newman Library (1907).

Bridgewater: Bridgewater College, Alexander Mack Memorial Library (1902).

Charlottesville:

University of Virginia, Alderman Library (1910)-REGIONAL.

University of Virginia Law Library (1964).

Chesapeake: Chesapeake Public Library System (1970).

Danville: Danville Community College Library (1969).

Emory: Emory and Henry College Library (1884).

Fairfax: George Mason College of the University of Virginia, Fenwick Library (1960)

Fredericksburg: Mary Washington College, E. Lee Trinkle Library (1940).

Hampden-Sydney: Hampden-Sydney College, Eggleston Library (1891).

Harrisonburg: Madison College, Madison Memorial Library (1973).

Hollins College: Hollins College, Fishburn Library (1967).

Lexington:

Virginia Military Institute, Preston Library (1874).

Washington and Lee University, Cyrus Hall McCormick Library (1910).

Martinsville: Patrick Henry Community College Library (1971)
Norfolk:

Armed Forces Staff College Library (1963)

Norfolk Public Library (1895).

Old Dominion University, Hughes Memorial library (1963).

Petersburg: Virginia State College, Johnston Memorial Library (1907).

Quantico:

Federal Bureau of Investigation Academy Library (1970).

Marine Corps Schools, James Carson Breckinridge l_ibrary (1967)

Reston: U.S. Geological Survey Library.

Richmond

State Law Library (1973).

University of Richmond, Boatright Memorial Library (1900).

U.S. Court of Appeals for Fourth Circuit Library (1973).

Virginia Commonwealth University, James Branch Cábell Library (1971).

Virginia State Library (unknown).

Roanoke: Roanoke Public Library (1964)

Salem: Roanoke College Library (1886).

Williamsburg: College of William and Mary, Swem Library (1936).

Wise: Clinch Valley College, John Cook Wyllie Library (1971).

\section{WASHINGTON}

Bellingham: Western Washington State College, Wilson Library (1963).

Cheney: Eastern Washington State College Library (1966).

Ellensburg: Central Washington State College Library (1962).

Everett: Everett Public Library (1914).

Olympia:

Evergeen State College Library (1972)

Washington State Library (unknown) - REGIONAL.

Port Angeles: Port Angeles Public Library (1965).

Pullman: Washington State University Library (1907).

Seattle:

Seattle Public Library (1908).

University of Washington Library (1890).

University of Washington, School of Law Library (1969).

Spokane: Spokane Public Library (1910).

Tacoma:

Tacoma Public Library (1894).

University of Puget Sound, Collins Memorial Library (1938).

Vancouver: Fort Vancouver Regional Library (1962).

Walla Walla: Whitman College, Penrose Memorial Library (1890).

\section{WEST VIRGINIA}

Athens: Concord College Library (1924).

Bluefield: Bluefield State College Library (1972).

Charleston:

Kanawha County Public Library (1952).

West Virginia Department of Archives and History Library (unknown).

Elkins: Davis and Elkins College Library (1913).

Fairmont: Fairmont State College Library (1884).

Glenville: Glenville State College, Robert F. Kidd Library (1966).

Huntington: Marshall University Library (1925).

Institute: West Virginia State College Library (1907).

Morgantown: West Virginia University Library (1907)-REGIONAL. 
Salem: Salem College Library (1921).

Shepherdstown: Shepherd College Library (1971).

Weirton: Mary H. Weir Public Library (1963).

\section{WISCONSIN}

Appleton: Lawrence University, Samuel Appleton Library (1869).

Beloit: Beloit College Libraries (1888).

Eau Claire: University of Wisconsin-Eau Claire, William D. Mclntyre Library (1951).

Fond du Lac: Fond du Lac Public Library (1966).

Green Bay: University of Wisconsin at Green Bay Library (1968).

La Crosse:

La Crosse Public Library (1883).

University of Wisconsin-La Crosse, Murphy Library (1965).

Madison:

Department of Public Instruction, Division for Library Services, Reference and Loan Library (1965).

Madison Public Library (1965).

State Historical Society Library (1870) - REGIONAL.

University of Wisconsin, Memorial Library (1939).

Wisconsin State Library (unknown).

Milwaukee:

Alverno College Library (1971).

Milwaukee County Law Library (1934).

Milwaukee Public Library (1961) - REGIONAL.
Mount Mary College Library (1964).

Oklahoma Neighborhood Library (1965).

University of Wisconsin-Milwaukee Library (1960).

Oshkosh: University of Wisconsin-Oshkosh, Forrest R. Polk Library (1956).

Platteville: University of Wisconsin-Platteville, Karrmann Library (1964).

Racine: Racine Public Library (1898).

River Falls: University of Wisconsin-River Falls, Chalmer Davee Library (1962).

Stevens Point: University of Wisconsin-Stevens Point, Learning Resources Center (1951).

Superior:

Superior Public Library (1908).

University of Wisconsin-Superior, Jim Dan Hill Library (1935).

Waukesha: Waukesha Public Library (1966).

Wausau: Wausau Public Library (1971).

Whitewater: University of Wisconsin-Whitewater, Harold Andersen Library (1963).

\section{WYOMING}

Casper: Natrona County Public Library (1929).

Cheyenne: Wyoming State Library (unknown).

Laramie: University of Wyoming, Coe Library (1907).

Powell: Northwest Community College Library (1967).

Riverton: Central Wyoming College Library (1969).

Rock Springs: Western Wyoming College Library (1969).

Sheridan: Sheridan College, Mary Brown Kooi Library (1963). 
The National Bureau of Standards, Center for Building Technology (CBT) publications are available from the Government Printing Office (GPO) or the National Technical Information Service (NTIS). The following table lists the CBT publication numbers, the SD Catalog No. (if available from GPO) or the Order No. (if available from NTIS), and the most recent price of each document.
Those documents designated with an * in the Order No. column are available from NTIS; when ordering use the NBS publication number. Note the Journal of Research reports are only available from the individual NBS authors. Page $i$ i provides complete instructions on how to obtain publications.

\section{BUILDING SCIENCE SERIES}

\begin{tabular}{|c|c|c|c|c|c|c|c|c|c|}
\hline \multirow[b]{2}{*}{$\begin{array}{l}\text { Publication } \\
\text { Number }\end{array}$} & \multicolumn{2}{|c|}{$\begin{array}{l}\text { Government Printing } \\
\text { Office }\end{array}$} & \multicolumn{2}{|c|}{$\begin{array}{l}\text { National Technical } \\
\text { Information Service }\end{array}$} & \multirow[b]{2}{*}{$\begin{array}{c}\text { Publication } \\
\text { Number }\end{array}$} & \multicolumn{2}{|c|}{$\begin{array}{l}\text { Government Printing } \\
\text { Office }\end{array}$} & \multicolumn{2}{|c|}{$\begin{array}{l}\text { National Technical } \\
\text { Information Service }\end{array}$} \\
\hline & SD Catalog No. & Price & Order No. & Price & & SD Catalog No. & Price & Order No. & Price \\
\hline 0 & & & COM 71-00046 & 5.50 & 40 & $\mathrm{Cl} 3.29 / 2: 40$ & 3.95 & & \\
\hline 1 & & & PB 189713 & 5.50 & 41 & & & COM 72-50533 & 4.00 \\
\hline 2 & & & COM 72-10542 & 4.00 & 42 & & & COM 72-50675 & 4.00 \\
\hline 3 & & & $*$ & 3.50 & 43 & & & COM 75-10173 & 3.50 \\
\hline 4 & & & * & 3.50 & 44 & $\mathrm{Cl} 3.29 / 2: 44$ & .65 & & \\
\hline 5 & & & * & 4.00 & 45 & & & COM 73-50725 & 5.50 \\
\hline 6 & & & * & 3.25 & 46 & & & COM 73-50188 & 12.50 \\
\hline 7 & $\mathrm{C} 13.29 / 2: 7$ & 6.50 & & & 47 & & & COM 73-50975 & 5.50 \\
\hline 8 & & & COM 73-10487 & 5.50 & 48 & C13.29/2:48 & 4.85 & & \\
\hline 9 & & & PB 193907 & 3.50 & 49 & $\mathrm{Cl} 3.29 / 2: 49$ & .95 & & \\
\hline 10 & & & * & 3.50 & 50 & $\mathrm{Cl} 3.29 / 2: 50$ & .55 & & \\
\hline 11 & & & * & 3.50 & 51 & C13.29/2:51 & .90 & & \\
\hline 12 & & & * & 3.50 & 52 & & & COM 74-50537 & 4.00 \\
\hline 13 & & & * & 3.50 & 53 & $\mathrm{Cl} 3.29 / 2: 53$ & .85 & & \\
\hline 14 & & & * & 3.50 & 54 & $\mathrm{Cl} 3.29 / 2: 54$ & 1.25 & & \\
\hline 15 & & & * & 4.75 & 55 & & & COM 74-57188 & 3.50 \\
\hline 16 & & & * & 4.00 & 56 & $\mathrm{Cl} 3.29 / 2: 56$ & 2.35 & & \\
\hline 17 & & & $*$ & 4.00 & 57 & C13.29/2:57 & 1.20 & & \\
\hline 18 & & & PB 193736 & 4.00 & 58 & $\mathrm{C} 13.29 / 2: 58$ & 2.00 & & \\
\hline 19 & & & * & 3.50 & 59 & C13.29/2:59 & 1.30 & & \\
\hline 20 & & & PB 189639 & 4.75 & 60 & C13.29:2/60 & 1.05 & & \\
\hline 21 & & & PB 189459 & 4.25 & 61 & C13.29:2/61 & 11.10 & & \\
\hline 22 & & & PB 189456 & 4.50 & 62 & in preparation & & & \\
\hline 23 & & & * & 3.50 & 63 & $\mathrm{C} 13.29: 2 / 63$ & .70 & & \\
\hline 24 & & & $*$ & 3.50 & 64 & $\mathrm{C} 13.29: 2 / 64$ & 1.35 & & \\
\hline 25 & & & PB $188-789$ & 6.00 & 65 & C13.29/2:65 & 1.00 & & \\
\hline 26 & & & * & 3.25 & 66 & $\mathrm{Cl} 3.29: 2 / 66$ & 2.10 & & \\
\hline 27 & & & PB̀ 191-304 & 4.00 & 67 & $\mathrm{Cl} 3.29: 2 / 67$ & 1.20 & & \\
\hline 28 & & & PB 193924 & 3.00 & 68 & C13.29:2/68 & 1.25 & & \\
\hline 29 & & & PB 190603 & 3.25 & 69 & in preparation & & & \\
\hline 30 & & & COM 71-00141 & 6.75 & 70 & $\mathrm{Cl} 3.29 / 2: 70$ & 1.55 & & \\
\hline 31 & & & PB 193601 & 3.50 & 71 & $\mathrm{C} 13.29 / 2: 71$ & 2.25 & & \\
\hline 32 & & & COM 71-50078 & 6.00 & 72 & C13.29/2:72 & 1.80 & & \\
\hline 33 & & & COM 71-00159 & 3.75 & 73 & in preparation & & & \\
\hline 34 & & & COM 75-10286 & 4.75 & 74 & $\mathrm{Cl} 3.29: 2 / 74$ & 1.55 & & \\
\hline 35 & & & COM 71-50591 & 6.00 & 75 & in preparation & & & \\
\hline 36 & $\mathrm{C} 13.29 / 2: 36$ & 1.55 & & & 76 & in preparation & & & \\
\hline 37 & $\mathrm{Cl} 3.29 / 2: 37$ & 1.25 & & & 77 & $\mathrm{Cl} 3.29 / 2: 77$ & 2.35 & & \\
\hline 38 & C. $13.29 / 2: 38$ & .40 & & & 78 & $\mathrm{C} 13.29 / 2: 78$ & 1.25 & & \\
\hline 39 & $\mathrm{C} 13.29 / 2: 39$ & 10.80 & & & 79 & $\mathrm{Cl} 3.29 / 2: 79$ & 1.15 & & \\
\hline
\end{tabular}


TECHNICAL NOTES

\begin{tabular}{|c|c|c|c|c|c|c|c|c|c|}
\hline \multirow[b]{2}{*}{$\begin{array}{l}\text { Publication } \\
\text { Number }\end{array}$} & \multicolumn{2}{|c|}{$\begin{array}{c}\text { Government Printing } \\
\text { Office }\end{array}$} & \multicolumn{2}{|c|}{$\begin{array}{l}\text { National Technical } \\
\text { Information Service }\end{array}$} & \multirow[b]{2}{*}{$\begin{array}{c}\text { Publication } \\
\text { Number }\end{array}$} & \multicolumn{2}{|c|}{$\begin{array}{c}\text { Government Printing } \\
\text { Office }\end{array}$} & \multicolumn{2}{|c|}{$\begin{array}{l}\text { National Technical } \\
\text { Information Service }\end{array}$} \\
\hline & SD Catalog No. & Price & SD Catalog No. & Price & & SD Catalog No. & Price & SD Catalog No. & Price \\
\hline $\begin{array}{l}231 \\
253 \\
473 \\
477 \\
558 \\
563 \\
569 \\
706 \\
707 \\
708 \\
710-1 \\
710-2 \\
710-3 \\
710-4 \\
710-5 \\
710-6 \\
710-7 \\
746 \\
755 \\
757 \\
759 \\
768 \\
770\end{array}$ & $\begin{array}{l}\text { C13.46:710-3 } \\
\text { C13.46:710-5 } \\
\text { C13.46:710-6 } \\
\text { C13.46:710-7 } \\
\text { C13.46:755 } \\
\text { C13.46:757 } \\
\text { C13.46:759 } \\
\text { C13.46:770 }\end{array}$ & $\begin{array}{r}.85 \\
\\
.95 \\
1.00 \\
1.30 \\
\\
.70 \\
.45 \\
.65 \\
\\
1.40\end{array}$ & $\begin{array}{c}\text { COM } 72-10587 \\
\text { PB } 184176 \\
* \\
\text { COM } 71-50072 \\
\text { COM } 71-50341 \\
\text { COM } 74-10436 \\
\text { COM } 72-50892 \\
\text { COM } 72-50054 \\
\text { COM } 72-50062 \\
\text { COM } 72-50276 \\
\text { COM } 72-50346 \\
\text { COM } 72-50521\end{array}$ & $\begin{array}{l}4.00 \\
3.50 \\
3.50 \\
4.00 \\
4.00 \\
4.00 \\
4.00 \\
3.50 \\
3.50 \\
5.00 \\
3.25 \\
3.75 \\
4.25\end{array}$ & $\begin{array}{l}775 \\
778 \\
783 \\
789 \\
789-1 \\
794 \\
807 \\
808 \\
811 \\
818 \\
822 \\
838 \\
852 \\
853 \\
858 \\
863 \\
868 \\
873 \\
883 \\
885 \\
886 \\
892\end{array}$ & $\begin{array}{l}\text { C13.46:852 } \\
\text { C13.46:853 } \\
\text { C13.46:858 } \\
\text { C13.46:863 } \\
\text { C13.46:868 } \\
\text { C13.46:873 } \\
\text { C13.46:883 } \\
\text { C13.46:885 } \\
\text { C13.46:886 } \\
\text { C13.46:892 }\end{array}$ & $\begin{array}{r}.85 \\
.85 \\
3.75 \\
1.15 \\
1.50 \\
.75 \\
1.45 \\
1.45 \\
.65 \\
1.70\end{array}$ & $\begin{array}{l}\text { COM 73-50927 } \\
\text { COM 73-50971 } \\
\text { COM 74-50085 } \\
\text { COM 74-50340 } \\
\text { COM 74-50841 }\end{array}$ & $\begin{array}{l}6.00 \\
6.75 \\
7.50\end{array}$ \\
\hline
\end{tabular}

SPECIAL PUBLICATIONS

\begin{tabular}{|c|c|c|c|c|c|c|c|}
\hline $\begin{array}{l}302 \\
329, \text { Supp.1 } \\
334 \\
361 \text {,Vol. } 1\end{array}$ & $\begin{array}{c}* \\
\text { COM } 73-50679 \\
\text { COM } 74-11482 \\
\text { COM } 72-10309\end{array}$ & $\begin{array}{r}21.25 \\
12.00 \\
5.00 \\
21.52\end{array}$ & $\begin{array}{l}361 \text {, Vol. } 2 \\
393 \\
429\end{array}$ & C13.10:429 & 1.95 & $\begin{array}{l}\text { COM } 72-50850 \\
\text { COM } 74-50350\end{array}$ & $\begin{array}{l}6.75 \\
4.50\end{array}$ \\
\hline
\end{tabular}

HANDBOOKS

\begin{tabular}{|l|l|l|l|l||l|l|l|l|l|}
\hline 115 & $\mathrm{C} 13.11: 115$ & 2.90 & & & & - & - & - & - \\
\hline
\end{tabular}

NBS INTERAGENCY REPORTS

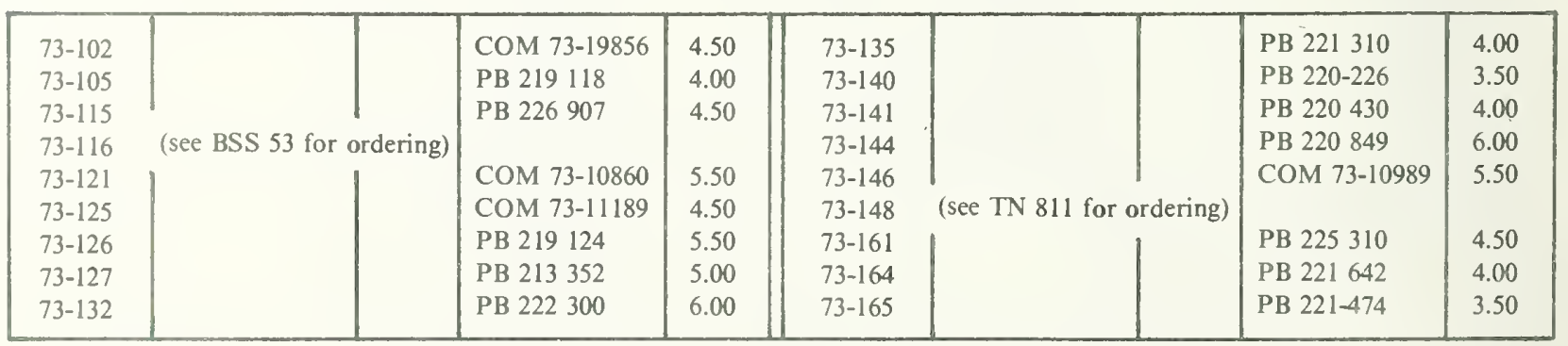


NBS INTERAGENCY REPORTS (cont)

\begin{tabular}{|c|c|c|c|c|c|c|c|c|c|}
\hline \multirow[b]{2}{*}{$\begin{array}{c}\text { Publication } \\
\text { Number }\end{array}$} & \multicolumn{2}{|c|}{$\begin{array}{c}\text { Government Printing } \\
\text { Office }\end{array}$} & \multicolumn{2}{|c|}{$\begin{array}{l}\text { National Technical } \\
\text { Information Service }\end{array}$} & \multirow[b]{2}{*}{$\begin{array}{c}\text { Publication } \\
\text { Number }\end{array}$} & \multicolumn{2}{|c|}{$\begin{array}{c}\text { Government Printing } \\
\text { Office }\end{array}$} & \multicolumn{2}{|c|}{$\begin{array}{l}\text { National Technical } \\
\text { Information Service }\end{array}$} \\
\hline & SD Catalog No. & Price & Order No. & Price & & SD Catalog No. & Price & Order No. & Price \\
\hline $73-166$ & & & PB 222297 & 3.50 & $74-495$ & \multirow{37}{*}{ (see BSS 68 for } & & COM 74-11575 & 5.00 \\
\hline $73-167$ & & & PB 222298 & 3.50 & $74-497$ & & & COM 74-11269 & 3.50 \\
\hline $73-168$ & & & PB 221184 & 4.00 & $74-514$ & & & COM 75-10102 & 4.50 \\
\hline $73-169$ & & & PB 221185 & 3.50 & $74-520$ & & & COM 74- 11480 & 6.00 \\
\hline $73-170$ & & & PB 221193 & 4.00 & $74-526$ & & & COM 75-10087 & 4.50 \\
\hline $73-173$ & & & COM 73-10844 & 4.00 & $74-531$ & & rdering) & & \\
\hline $73-177$ & & & COM 75-10336 & 4.00 & $74-542$ & & & COM 75-10081 & 4.00 \\
\hline $73-187$ & & & PB 221188 & 4.50 & $74-567$ & & & COM 74-|1631 & 9.25 \\
\hline $73-188$ & & & PB $221 \quad 183$ & 5.00 & $74-574$ & & & PB 246-1 84 & 11.00 \\
\hline $73-190$ & & & PB 221189 & 3.50 & $74-582$ & & & COM 74-11645 & 4.00 \\
\hline $73-191$ & & & PB 221-695 & 3.50 & $74-610$ & & & COM 75-10072 & 4.00 \\
\hline $73-192$ & & & PB 222231 & 3.50 & $74-613$ & & & COM 75-10059 & 4.00 \\
\hline $73-208$ & & & COM 74-10127 & 4.00 & $74-618$ & & & COM 75-11014 & 3.50 \\
\hline $73-220$ & & & PB 222-437 & 3.50 & $74-629$ & & & COM 75-11281 & 4.00 \\
\hline $73-221$ & & & PB 220-849 & 5.00 & $74-634$ & & & COM 74-10685 & 4.00 \\
\hline $73-228$ & & & PB 222425 & 3.50 & $74-635$ & & & COM 75-10276 & 4.50 \\
\hline $73-231$ & & & PB 224-645 & 4.00 & $75-641$ & & & COM 75-11209 & 5.00 \\
\hline $73-242$ & & & PB 224-654 & 4.00 & $75-672$ & & & COM 75-10338 & 4.00 \\
\hline $73-251$ & & & PB 224-688 & 4.00 & $75-678$ & & & PB 248-687 & 4.50 \\
\hline $73-263$ & & & PB 225-284 & 4.50 & $75-680$ & & & COM 75-10423 & 5.50 \\
\hline $73-266$ & & & PB 225-286 & 4.00 & $75-688$ & & & COM 75-11222 & 5.50 \\
\hline $73-267$ & & & COM 73-11955 & 4.50 & $75-690$ & & & COM 75-11207 & 5.00 \\
\hline $73-277$ & & & PB $225-278$ & 4.50 & $75-703$ & & & COM 75-11278 & 4.00 \\
\hline $73-288$ & & & COM 73-11861 & 4.50 & $75-711$ & & & COM 75-10689 & 4.50 \\
\hline $73-294$ & & & COM 74-10541 & 4.50 & $75-712$ & & & COM 75-11070 & 4.00 \\
\hline $73-295$ & & & COM 74-10471 & 3.50 & $75-715$ & & & COM 75-11208 & 3.25 \\
\hline $73-407$ & & & COM 74-1 1078 & 5.00 & $75-721$ & & & PB 266-864 & 4.00 \\
\hline $73-421$ & & & COM 74-11224 & 4.00 & $75-729$ & & & PB $246-858$ & 4.00 \\
\hline $74-432$ & & & COM 74-10751 & 4.50 & $75-747$ & & & COM 75-11131 & 4.00 \\
\hline $74-438$ & & & COM 74-10980. & 4.00 & $75-761$ & & & COM 73-11377 & 5.50 \\
\hline $74-444$ & & & COM 74-10548 & 4.00 & $75-767$ & & & PB 246-879 & 4.00 \\
\hline $74-449$ & & & COM 75-10049 & 4.00 & $75-779$ & & & PB $249-935$ & 5.50 \\
\hline $74-452$ & & & PB 204-586 & 5.50 & $75-790$ & & & PB $250-848$ & 10.50 \\
\hline $74-456$ & & & COM 74-11793 & 3.50 & $75-795$ & & & PB 246-866 & 4.50 \\
\hline $74-467$ & & & COM 74-11754 & 4.50 & $75-923$ & & & PB $250-767$ & 3.50 \\
\hline $74-473$ & & & COM 74-11719 & 4.50 & $75-951$ & & & PB 249-094 & 4.00 \\
\hline $74-479$ & & & COM 74-11769 & 6.00 & $75-955$ & & & PB 248-685 & 6.75 \\
\hline
\end{tabular}

NBS REPORTS

\begin{tabular}{|c|c|c|c|c|c|c|}
\hline \begin{tabular}{|c|}
9668 \\
9849 \\
9850 \\
9851 \\
10200 (Fiv \\
Vol. I \\
Vol. II \\
Vol. III \\
Vol. IV \\
Vol. V \\
10213 (fou \\
Vol. I \\
Vol. II \\
Vol. III \\
Vol. IV
\end{tabular} & $\begin{array}{l}\text { e volumes) } \\
\text { (Volumes may be pur- } \\
\text { chased individually) } \\
\text { (Volumes may be pur- } \\
\text { chased individually) }\end{array}$ & $\begin{array}{l}\text { PB } 176-959 \\
\text { PB } 184-458 \\
\text { PB } 184-876 \\
\text { PB } 184-459 \\
\text { PB } 212-055 \\
\text { PB } 212-056 \\
\text { PB } 212-057 \\
\text { PB 212-058 } \\
\text { PB 212-538 } \\
\text { PB 214-460 } \\
\text { PB 214-461 } \\
\text { PB 214-462 } \\
\text { PB 215-463 }\end{array}$ & $\begin{array}{r}6.75 \\
10.50 \\
7.50 \\
10.50 \\
50.75\end{array}$ & $\begin{array}{l}10214 \\
10215 \\
10216 \\
10248 \\
10314 \\
10317 \\
10319 \\
10407 \\
10408 \\
10409 \\
10410 \\
10411 \\
10412 \\
10413 \\
10414\end{array}$ & $\begin{array}{l}\text { PB } 212-059 \\
\text { PB 212-060 } \\
\text { PB 212-061 } \\
\text { PB 211-854 } \\
\text { PB 211-847 } \\
\text { PB 212-297 } \\
\text { PB 212-062 } \\
\text { PB 214-781 } \\
\text { PB 214-784 } \\
\text { PB 213-240 } \\
\text { PB 216-501 } \\
\text { PB 212-785 } \\
\text { PB 213-053 } \\
\text { PB 213-143 } \\
\text { PB 214-336 }\end{array}$ & $\begin{array}{l}4.50 \\
3.50 \\
3.50 \\
4.00 \\
3.50 \\
4.00 \\
4.00 \\
3.50 \\
3.50 \\
4.00 \\
3.50 \\
4.00 \\
4.00 \\
4.50 \\
4.00\end{array}$ \\
\hline
\end{tabular}


NBS REPORTS (cont)

\begin{tabular}{|c|c|c|c|c|c|c|c|c|c|}
\hline \multirow[b]{2}{*}{$\begin{array}{l}\text { Publication } \\
\text { Number }\end{array}$} & \multicolumn{2}{|c|}{$\begin{array}{c}\text { Government Printing } \\
\text { Office }\end{array}$} & \multicolumn{2}{|c|}{$\begin{array}{l}\text { National Technical } \\
\text { Information Service }\end{array}$} & \multirow[b]{2}{*}{$\begin{array}{l}\text { Publication } \\
\text { Number }\end{array}$} & \multicolumn{2}{|c|}{$\begin{array}{c}\text { Government Printing } \\
\text { Office }\end{array}$} & \multicolumn{2}{|c|}{$\begin{array}{l}\text { National Technical } \\
\text { Information Service }\end{array}$} \\
\hline & SD Catalog No. & Price & Order No. & Price & & SD Catalog No. & Price & Order No. & Price \\
\hline $\begin{array}{l}10415 \\
10416 \\
10417 \\
10418 \\
10499 \\
10632 \\
10649 \\
10651\end{array}$ & & & $\begin{array}{l}\text { PB } 217-362 \\
\text { PB } 217-363 \\
\text { PB } 217-364 \\
\text { PB } 217-365 \\
\text { PB } 212-617 \\
\text { PB } 213-014 \\
\text { PB } 213-351 \\
\text { PB } 213-354\end{array}$ & $\begin{array}{l}3.50 \\
3.50 \\
3.50 \\
3.50 \\
3.50 \\
4.00 \\
3.50 \\
3.50\end{array}$ & $\begin{array}{l}10654 \\
10658 \\
10667 \\
10676 \\
10917 \\
10961 \\
10972\end{array}$ & & & $\begin{array}{l}\text { PB 213-666 } \\
\text { PB 213-535 } \\
\text { PB 213-353 } \\
\text { PB 213-662 } \\
\text { COM 73-11285 } \\
\text { PB 218-975 }\end{array}$ & $\begin{array}{l}4.00 \\
4.00 \\
3.50 \\
4.00 \\
4.50 \\
4.50 \\
8.00\end{array}$ \\
\hline
\end{tabular}

\section{CONSUMER INFORMATION SERIES}

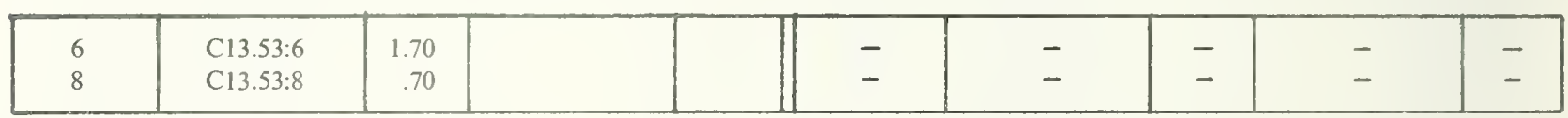


Clip this page and mail to:

Nins

National Technical Information Service, Springfield, Virginia 22161

U.S. DEPARTMENT OF COMMERCE
FOR DDC USERS ONLY

DDC USER CODE

CONTRACT NUMBER

(Last 6 characters only)

\section{ITEMS REQUESTED}

Send me the reports I have selected on this order form. I have placed numbers in appropriate blanks to indicate the quantity and form.

PURCHASER:

Name

Address

City, State, ZIP

Attention:

SHIP TO: (Enter if different from address above)

Name

Organization

Address

City, State, ZIP

\section{(703) $321-8543 \quad$ TELEX 89-9405}

Please allow 3-5 weeks for delivery on your order.
Charge my NTIS deposit account no.

$\square$ Purchase order no

$\square$ Check enclosed for $\$$

$\square$ Charge to my American Express Card account number. Card expiration date:
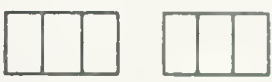

\section{Signature}

Wherever a foreign sales price is NOT specified in the listings, all foreign buyers must add the following charges to each order.

$\$ 2.50$ for each document

$\$ 1.50$ for each microfiche

Please order by number or your order may be delayed.

\begin{tabular}{|c|c|c|c|c|c|c|c|c|c|}
\hline \multirow{2}{*}{\multicolumn{2}{|c|}{$\begin{array}{l}\text { Item } \\
\text { Number }\end{array}$}} & \multirow[b]{2}{*}{$\begin{array}{l}\text { Routing* } \\
\text { Code }\end{array}$} & \multicolumn{3}{|c|}{ Quantity } & \multirow{2}{*}{\multicolumn{2}{|c|}{$\begin{array}{l}\text { Unit } \\
\text { Price** }\end{array}$}} & & \multirow[b]{2}{*}{$\begin{array}{l}\text { Total } \\
\text { Price** }\end{array}$} \\
\hline & & & $\begin{array}{l}\text { Paper } \\
\text { Copy }\end{array}$ & & $\begin{array}{l}\text { Micro- } \\
\text { fiche }\end{array}$ & & & & \\
\hline \multicolumn{10}{|c|}{ PS } \\
\hline \multicolumn{10}{|c|}{ /PS } \\
\hline \multicolumn{10}{|c|}{ /PS } \\
\hline \multicolumn{10}{|c|}{ PS } \\
\hline \multicolumn{10}{|c|}{ Pu } \\
\hline \multicolumn{10}{|c|}{ /PS } \\
\hline \multicolumn{10}{|c|}{ PS } \\
\hline \multicolumn{10}{|c|}{ PS } \\
\hline \multicolumn{10}{|c|}{ PS } \\
\hline \multicolumn{10}{|c|}{ /PS } \\
\hline \multicolumn{10}{|c|}{ /PS } \\
\hline $\begin{array}{l}\text { Routing Code NTIS } \\
\text { organization. If you } \\
\text { box marked Routin }\end{array}$ & $\begin{array}{l}\text { s can label } \\
\text { u want this } \\
\text { ig Code. }\end{array}$ & $\begin{array}{l}\text { ach document for routing } \\
\text { service put your routing }\end{array}$ & $\begin{array}{l}\text { ithin your } \\
\text { de In the }\end{array}$ & $* * A I$ & Prices Subject to & Change & $\begin{array}{l}\text { Enter } \\
\text { Grand } \\
\text { Total }\end{array}$ & $\$$ & \\
\hline
\end{tabular}

INFORMATION REQUESTED

$\square$ Send me an application for an NTIS deposit account. NTIS-PR-33

Send me your current general catalog, NTIS-PR-154

Send me an application for Special Credit Account for state/local governments and universities, NTIS-PR-220.

Name

Address

City, State, Zip 


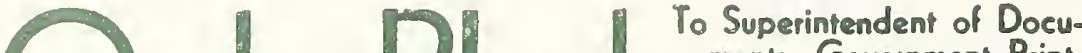 ments Government Print. ing Office, Washington, D.C. 20402}

Name

Strest addrexs

Ciry

Zip Cods

mon ues or aurt. or poce.

Enclored

To be mailed

later

Subseription

Rolund

Coupon Refund

Postage

Srote

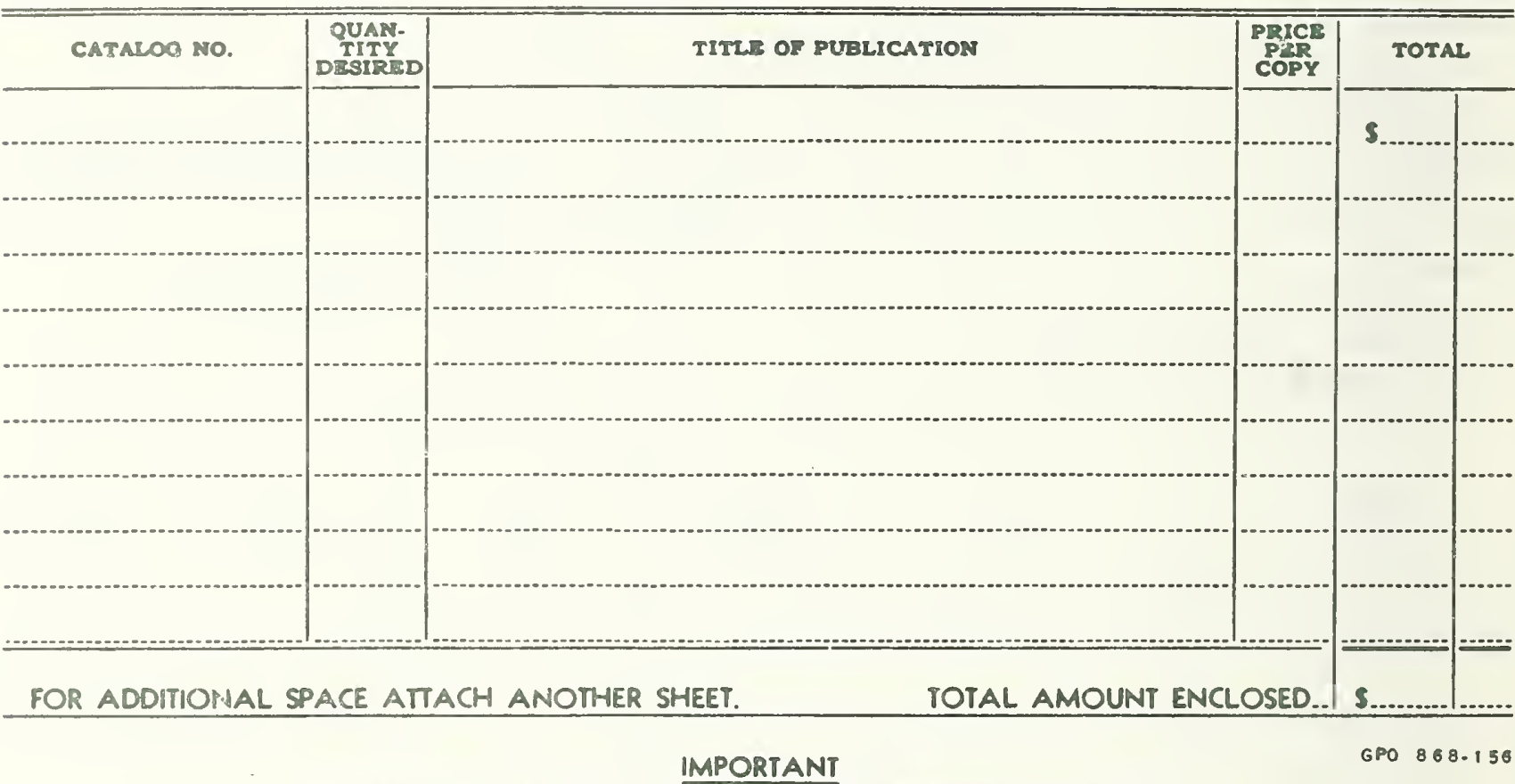

Please include your ZIP CODE when filling out the mailing label below.

U.S. GOVERNMENT PRINTING OFFICE PUBLIC DOCUMENTS DEPARTMENT WASHINGTON, D.C. 20402

OFFICIAL BUSINESS
POSTAGE AND FEES PAD U.S. GOVERNMENT PRINTING OF rICE

SPECIAL FOURTH-CLASS RATE BOOK

Name

Street address

Ciry and State 


The Center's four-bedroom test townhouse on the NBS campus is being used to compare the performance of a solar heating and cooling system with a conventional system.

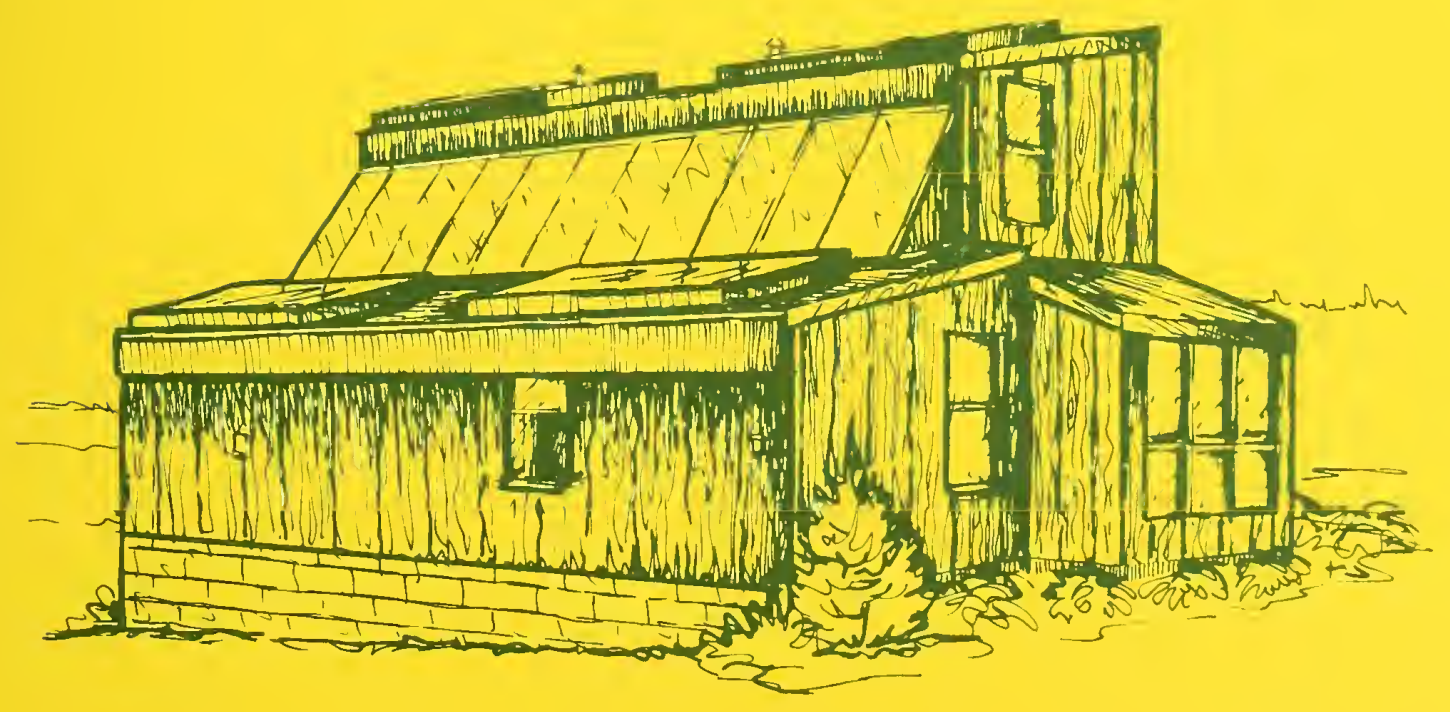




\section{Center for Building Technology Institute for Applied Technology}

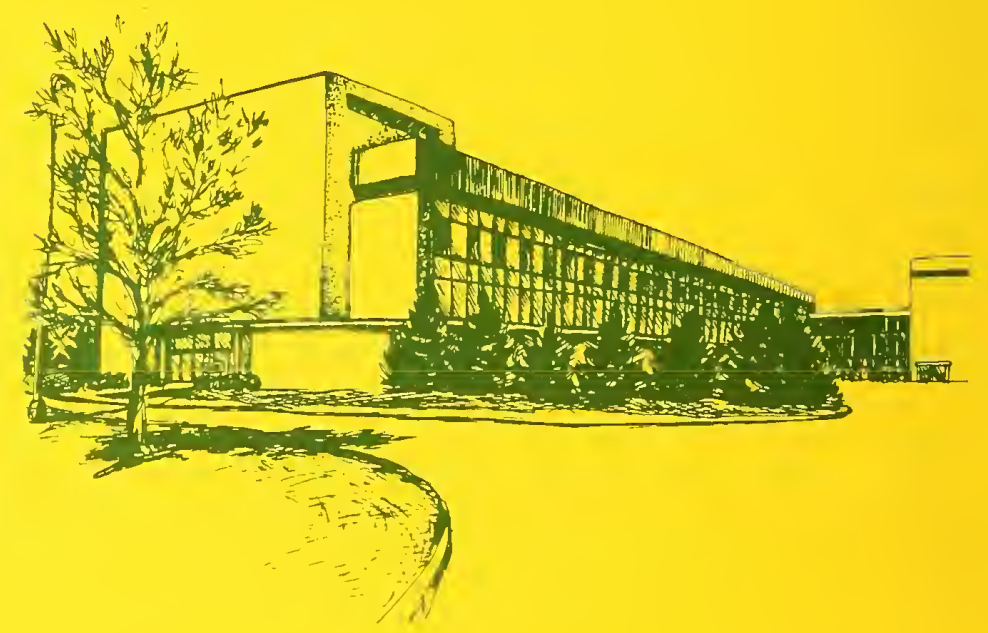

U.S. DEPARTMENT OF COMMERCE

Elliot L. Richardson, Secretary

Edward O. Vetter, Under Secretary

Betsy Ancker-Johnson, Ph.D., Assistant

Secretary for Science and Technology

National Bureau of Standards

Ernest Ambler, Acting Director

Nat. Bur. Stand. (U.S.), Spec. Publ. 457, 109 pages

(November, 1976)

For sale by the Superintendent of Documents

U.S. Government Printing Office, Washington, D.C. 20402

Price $\$ 1.80 \quad$ Stock No. 003-003-01685-3

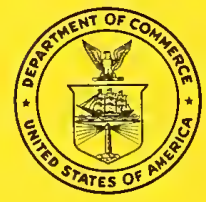

